\title{
Characterizing the Environmental Availability of Trace Metals in Savannah River Site Soils
}

by

S. M. Serkiz

Westinghouse Savannah River Company

Savannah River Site

Aiken, South Carolina 29808

DOE Contract No. DE-AC09-96SR18500

This paper was prepared in connection with work done under the above contract number with the U.S.

Department of Energy. By acceptance of this paper, the publisher and/or recipient acknowledges the U.S. Government's right to retain a nonexclusive, royalty-free license in and to any copyright covering this paper, along with the right to reproduce and to authorize others to reproduce all or part of the copyrighted paper. 


\section{DISCLAIMER}

This report was prepared as an account of work sponsored by an agency of the United States Government. Neither the United States Government nor any agency thereof, nor any of their employees, makes any warranty, express or implied, or assumes any legal liability or responsibility for the accuracy, completeness, or usefulness of any information, apparatus, product, or process disclosed, or represents that its use would not infringe privately owned rights. Reference herein to any specific commercial product, process, or service by trade name, trademark, manufacturer, or otherwise does not necessarily constitute or imply its endorsement, recommendation, or favoring by the United States Government or any agency thereof. The views and opinions of authors expressed herein do not necessarily state or reflect those of the United States Government or any agency thereof.

This report has been reproduced directly from the best available copy.

Available to DOE and DOE contractors from the Office of Scientific and Technical Information, P.O. Box 62, Oak Ridge, TN 37831; prices available from (615) 576-8401.

Available to the public from the National Technical Information Service, U.S. Department of Commerce; 5285 Port Royal Road, Springfield, VA 22161. 
WSRC-TR-98-00359

Rev. 0

Keywords: Background and Contaminated Soils, Heavy

Metal/Radionuclide

Speciation/Availability, CMP Pits, F-Area Seepage Basins

Retention: Permanent

\section{Characterizing the Environmental Availability of Trace Metals} in Savannah River Site Soils $(U)$

September 30, 1998

S. M. Serkiz, 773 A

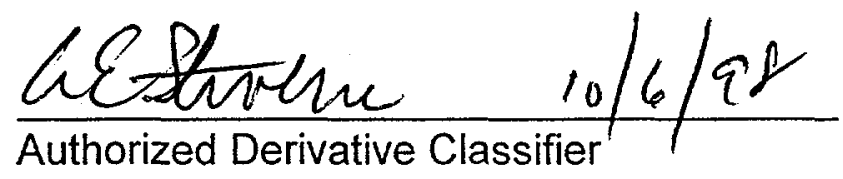

Savannah River Technology Center

Westinghouse Savannah River Company

Aiken, SC 29808 
Author

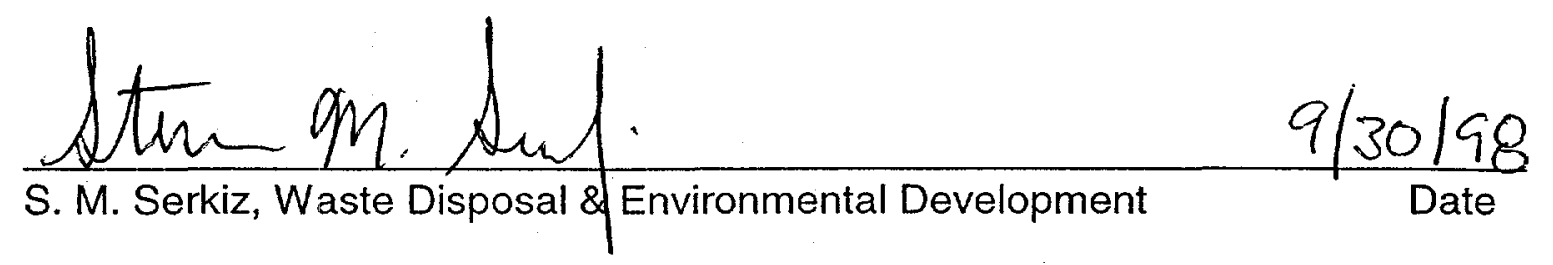

Design Check

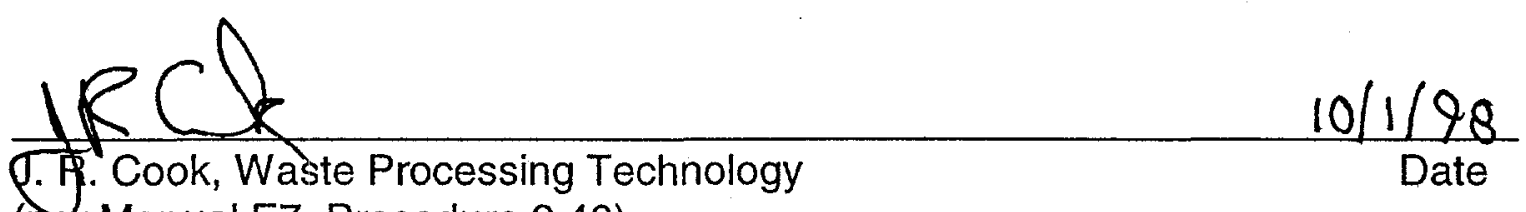
(per Manual E7, Procedure 2.40)

Approvals/Review
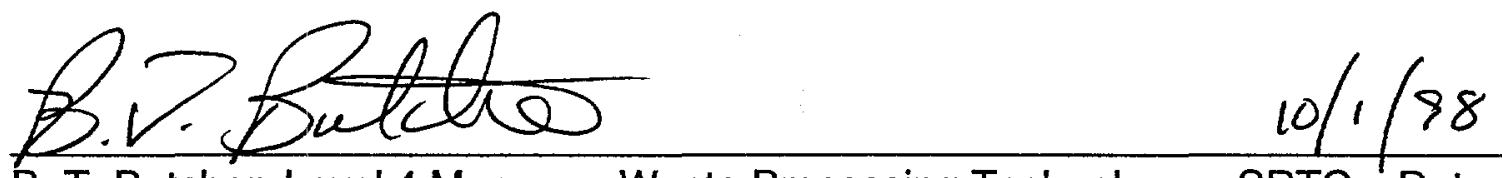

B. T. Butcher, Level 4 Manager, Waste Processing Technology - SRTC Date

E. G. Tops, Manager, Hate and Transport Analysis - SGS

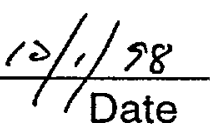

WSRC-TR-98-00359 Rev. 0

Page 2 of 23 


\subsection{Summary}

Matt Findley of the Environmental Systems Engineering Department of Clemson University has finished his Master's thesis under the direction of Steven Serkiz and with the assistance of Bill Boyce and Laura Tovo of the Analytical Development Section of STRC. His research on trace metal and radionuclide leaching/availability of Savannah River Site Soils is summarized below and a copy of his M. S. thesis is included as Attachment 1.

The release of metals and nuclides from soils into surrounding vadose-zone moisture or groundwater is a prerequisite for many exposure pathways (e.g., groundwater transport and bioaccumulation) relevant to risk assessment and remediation decisions at waste sites. Furthermore, the development of the "monitored natural attenuation" approach as a waste site management strategy requires an accurate description of the long-term release and availability of heavy metals/nuclides.

The "environmental availability" of soil bound metals has been defined by Ammonette et al. (1994) as "the ability of a soil to maintain an aqueous concentration of [a metal] in the soil solution." The chemical form (i.e., solidphase speciation) of soil-bound metals, combined with the conditions of the surrounding aqueous geochemical conditions (with respect to parameters such as $\mathrm{pH}$, redox potential, and ionic strength) determine the environmental availability of metals/nuclides in subsurface systems. Stated more simply, only a fraction of the total metal/radionuclide inventory is generally available for transport from soils to groundwater under credible environmental conditions.

In this study, we have employed a selective sequential leaching technique to examine both the chemical form of soil-bound metals/nuclides and the effect of increasingly aggressive leaching conditions on metals/nuclide release. The experimental conditions and the targeted solid phase for each extraction step is summarized in Table 1. This selective leaching procedure was employed on background and two waste-site (Chemical Metal and Pesticide Pits (CMP Pits) and F-Area Seepage Basins) soils.

Ion Coupled Plasma - Mass Spectroscopy (ICP-MS) was used to measure the concentration of 23 elements, listed in Table 2, in leachates from the sequential extraction procedure. Metal/nuclide availability was examined with respect to (1) soil physical properties (e.g., soil texture); (2) soil chemical properties (cation exchange capacity, $\mathrm{pH}$, carbon content, and major ion chemistry); and (3) soil history (waste site and background). 
Table 1. Description of sequential extraction procedure steps.

\begin{tabular}{|c|c|c|c|c|}
\hline Fraction & Reagent & Description & Extraction Conditions & Targeted Phase \\
\hline $\begin{array}{c}1 \\
\text { "DDl" }\end{array}$ & Distilled deionized water & & $\begin{array}{l}\text { Tumble for } 16 \text { hours } \\
\text { at room temperature }\end{array}$ & $\begin{array}{l}\text { easily soluble salts and ions already } \\
\text { present in the soil solution }\end{array}$ \\
\hline $\begin{array}{c}2 \\
\text { "Salt" }\end{array}$ & $0.5 \mathrm{M}$ calcium nitrate & neutral salt & $\begin{array}{l}\text { Tumble for } 16 \text { hours } \\
\text { at room temperature }\end{array}$ & $\begin{array}{l}\text { Easily exchangeable } \\
\text { ions on soil surfaces }\end{array}$ \\
\hline $\begin{array}{c}3 \\
\text { "Ac" }\end{array}$ & $\begin{array}{l}0.44 \mathrm{M} \text { acetic acid \& } \\
0.1 \mathrm{M} \text { calcium nitrate }\end{array}$ & $\begin{array}{c}\text { weak acid } \\
\text { w/ neutral } \\
\text { salt }\end{array}$ & $\begin{array}{l}\text { Tumble for } 8 \text { hours } \\
\text { at room temperature }\end{array}$ & $\begin{array}{c}\text { carbonate minerals, acid exchangeable } \\
\text { metals on the soil surfaces }\end{array}$ \\
\hline $\begin{array}{c}4 \\
\text { "HAHCl" }\end{array}$ & $\begin{array}{c}0.01 \mathrm{M} \text { hydroxylamine- } \\
\text { hydrochloride \& } \\
0.1 \mathrm{M} \text { nitric acid }\end{array}$ & $\begin{array}{l}\text { weak } \\
\text { reducing } \\
\text { agent }\end{array}$ & $\begin{array}{l}\text { Tumble for } 0.5 \text { hours } \\
\text { at room temperature }\end{array}$ & Manganese oxides \\
\hline $\begin{array}{c}5 \\
\text { "PP" }\end{array}$ & $0.1 \mathrm{M}$ sodium pyrophosphate & $\begin{array}{c}\text { Complexing } \\
\text { agent }\end{array}$ & $\begin{array}{l}\text { Tumble } 24 \text { hours } \\
\text { at room temperature }\end{array}$ & Organic matter \\
\hline $\begin{array}{c}6 \\
\text { "AOD" }\end{array}$ & $\begin{array}{c}0.175 \mathrm{M} \text { ammonium oxalate \& } \\
0.1 \mathrm{M} \text { oxalic acid }\end{array}$ & $\begin{array}{l}\text { Buffered } \\
\text { mild } \\
\text { reducing } \\
\text { agent } \\
\end{array}$ & $\begin{array}{l}\text { Tumble } 4 \text { hours } \\
\text { in darkness } \\
\text { at room temperature }\end{array}$ & Amorphous iron oxides \\
\hline $\begin{array}{c}7 \\
\text { "DC" }\end{array}$ & $\begin{array}{c}0.15 \mathrm{M} \text { sodium citrate, } \\
0.05 \mathrm{M} \text { citric acid, \& } \\
25 \mathrm{~g} / \mathrm{L} \text { sodium dithionate }\end{array}$ & $\begin{array}{l}\text { Buffered } \\
\text { strong } \\
\text { reducing } \\
\text { agent }\end{array}$ & $\begin{array}{l}\text { Shake for } 0.5 \text { hours } \\
\text { in water bath at } 50^{\circ} \mathrm{C}\end{array}$ & Crystalline iron oxides \\
\hline $\begin{array}{c}8 \\
H F "\end{array}$ & $\begin{array}{l}48 \% \text { hydrofluoric acid \& } \\
\text { aqua regia }\end{array}$ & $\begin{array}{l}\text { Strong } \\
\text { corrosive }\end{array}$ & Microwave digestion & all remaining solids \\
\hline $\begin{array}{c}0 \\
\text { "TD" }\end{array}$ & $\begin{array}{c}48 \% \text { hydrofluoric acid \& } \\
\text { aqua regia }\end{array}$ & $\begin{array}{l}\text { Strong } \\
\text { corrosive }\end{array}$ & Microwave digestion & Total digestion of untreated soil \\
\hline
\end{tabular}

Note: Adapted from Miller et al. (1986) 
Table 2. Analytes determined by ICP-MS.

\begin{tabular}{|c|c|c|}
\hline $\begin{array}{l}\text { Common Soil } \\
\text { Elements: }\end{array}$ & $\begin{array}{l}\text { Iron } \\
\text { Aluminum }\end{array}$ & $\begin{array}{l}\text { Manganese } \\
\text { Titanium }\end{array}$ \\
\hline $\begin{array}{l}\text { RCRA Metals: } \\
\text { (40 CFR 261.24) }\end{array}$ & $\begin{array}{l}\text { Arsenic } \\
\text { Barium } \\
\text { Cadmium } \\
\text { Chromium }\end{array}$ & $\begin{array}{l}\text { Lead } \\
\text { Selenium } \\
\text { Silver }\end{array}$ \\
\hline Other Trace Elements: & $\begin{array}{l}\text { Cesium } \\
\text { Cerium } \\
\text { Cobalt } \\
\text { Copper } \\
\text { Nickel } \\
\text { Rubidium }\end{array}$ & $\begin{array}{l}\text { Strontium } \\
\text { Thorium } \\
\text { Uranium } \\
\text { Yttrium } \\
\text { Zinc } \\
\text { Zirconium }\end{array}$ \\
\hline
\end{tabular}

For the purposes of this study a conservative definition of "environmentally available fraction" was the sum of the metals Inuclides released in the first six extraction steps (through the amorphous iron hydroxide target phase). For background soils, most trace metals were not released from the soil until the final two extraction steps, indicating that the environmentally available fraction of trace metals in background soils is much smaller than the total concentration (see Table 3). A portion of the total barium, lead, and cerium was released from the soil during the extraction steps that targeted surface bound species, indicating that these trace metals are more environmentally available than other metals. Soil samples with higher clay contents tended to have higher concentrations of environmentally available trace metals. Additionally, environmentally available uranium from the background soils was highly correlated with aluminum released during the first six extraction steps.

This study has shown that sequential extraction techniques can be used to elucidate the environmental availability of metals and radionuclides in SRS soils. More specifically, the results of this study indicate:

- The majority of the total metal pool in background soils is unavailable for significant environmental release;

- Waste site soils exhibit distinct availability profiles compared with unimpacted (i.e., background) soils and, therefore, sequential extraction techniques may provide a method of identifying soils impacted by waste disposal activities;

- Environmental availability of many metals and nuclides is highly correlated to soil texture (particle size distribution) and the presence of extractable iron and aluminum. 


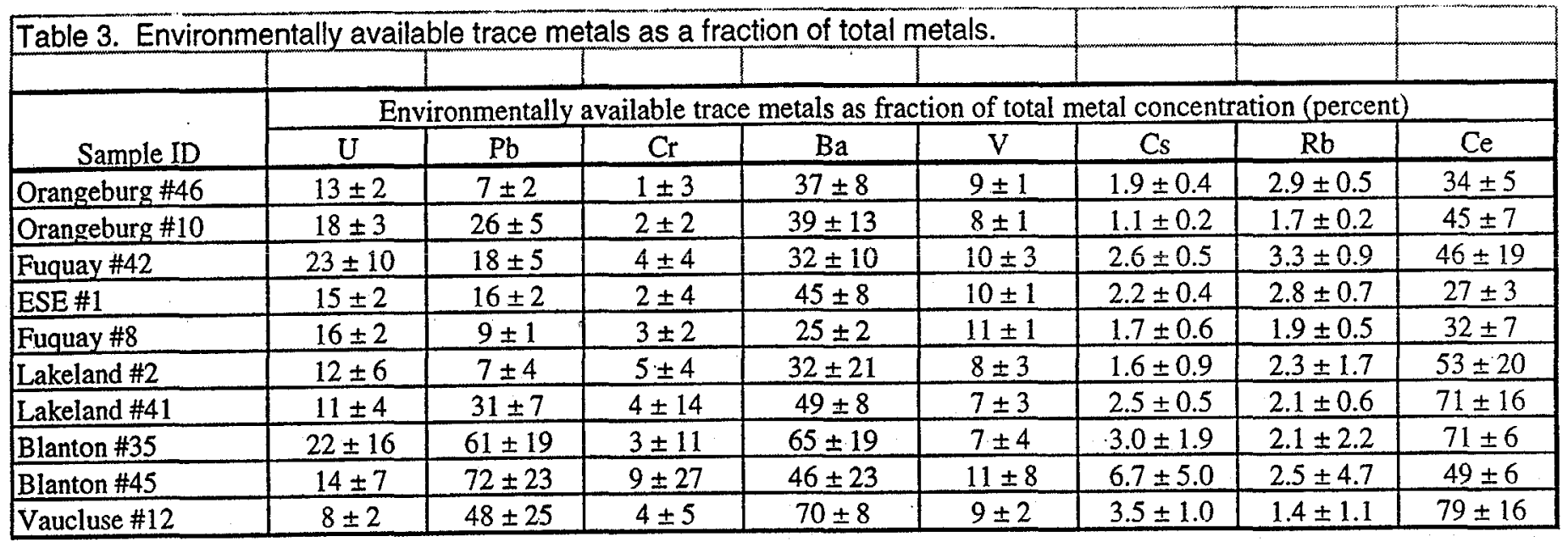


Because sequential extractions are resource intensive, work should be initiated to eliminate extraction steps to improve the utility of the sequential extraction procedure in estimating the environmental availability of trace metals and contaminants from SRS soils. Additional work to index trace element availability to the major ion chemistry of the soil (particularly reactive iron and aluminum) is recommended.

Currently, soil metal concentrations at waste site soils undergoing characterization in the Environmental Restoration program at SRS are determined by analysis of extracts obtained using EPA Method 3050B. This method uses heated $\left(90-95^{\circ} \mathrm{C}\right)$ strong mineral acids in the presence of hydrogen peroxide to extract metals from soils. Metal concentrations obtain under these very aggressive extraction conditions are then used as available metal input concentrations for risk analyses. A cross correlation between sequential extraction procedures and the EPA $3050 \mathrm{~B}$ technique would provide an estimate of the degree of conservatism in the current approach and would provide a basis for more realistic utilization of existing soil data.

Finally, additional studies in the following areas would be beneficial:

1. Evaluation of soils collected from other waste of with differing disposal histories;

2. analysis of metal availability in hydric soils; and

3. analysis of soils (both waste site and background) for metals not evaluated in this study (e.g., Be, Sb, and Th);

4. cross correlation of bioavailability studies with sequential extraction results.

\subsection{Experimental}

\subsection{Organization}

This section describes the sample collection, sequential extraction procedures (including extract analysis), and soil property procedures used in this study.

\subsection{Sample Collection}

For this study, three sets of soil samples collected from the SRS were examined. The first set consisted of ten soil samples collected from relatively undisturbed upland locations at SRS (i.e., background soils). The second and third sets were from two waste sites at SRS; the Chemical, Metals, and Pesticide Pits (CMP Pits) and the F-Area Seepage Basins.

Background soil samples were collected on June 16, 1996, using a stainless steel hand auger. All but one of the background soil samples were taken from locations described in Looney et al. (1990). The approximate locations of these background soil sampling sites and the depth that the samples were collected 
are presented in Figure 1 and Table 4. The first letter of sample identification code represents soil series and the number represents the soil number used in Looney et al. (1990). For example, soil-sample O46 is the Orangeburg soil taken from the location that was described for background soil sample (BSS) number 46 in Looney et al. (1990). Two soil samples each were collected from the Orangeburg, Blanton, Lakeland, and Fuquay soils series. Only one soil sample from the Vaucluse series was collected.

One of the background soil samples does not correspond to any of the samples collected by Looney et al. (1990) and is identified as "ESE\#1." This sample was collected from an area near the intersection of Forest Service roads 2-1 and E-2. To locate this sample site, proceed east from the intersection 1.2 to 1.3 miles, take a right on an unmarked gravel road that dead ends at an area with several concrete pads. ESE\#1 was sampled from a location approximately 0.3 miles down that road, near a drainage cut, on the right. The sample was taken from a wooded area 20 feet from the road.

Soil samples were collected from eight locations in the CMP pit area between May 8, 1996 and May 10, 1996 as part of a separate project (WSRC, 1996). Materials from several depths were collected; however, only the intervals between zero and one foot and between five and six feet were analyzed in this study. Four samples, identified as $2 A, 2 E, 3 A$, and $5 A$, were selected from the collected samples and included as part of this study. Figure 2 is a map showing the sample locations and other relevant features at the CMP Pits.

Johnson (1995) collected soil samples from the subsurface downgradient of the $\mathrm{F}$ - and $\mathrm{H}$ - Area Seepage Basins. This project examines the uranium sequential extraction results from five samples collected from under the F-Area Seepage Basin. These samples had the highest concentrations of uranium in the surrounding porewater and provided the best examples of acid impacted soils. In contrast to the background and CMP Pit soil samples, which are all nearsurface soils, these samples were retrieved from the saturated zone of a groundwater aquifer immediately downgradient of the F-Area Seepage Basin. 


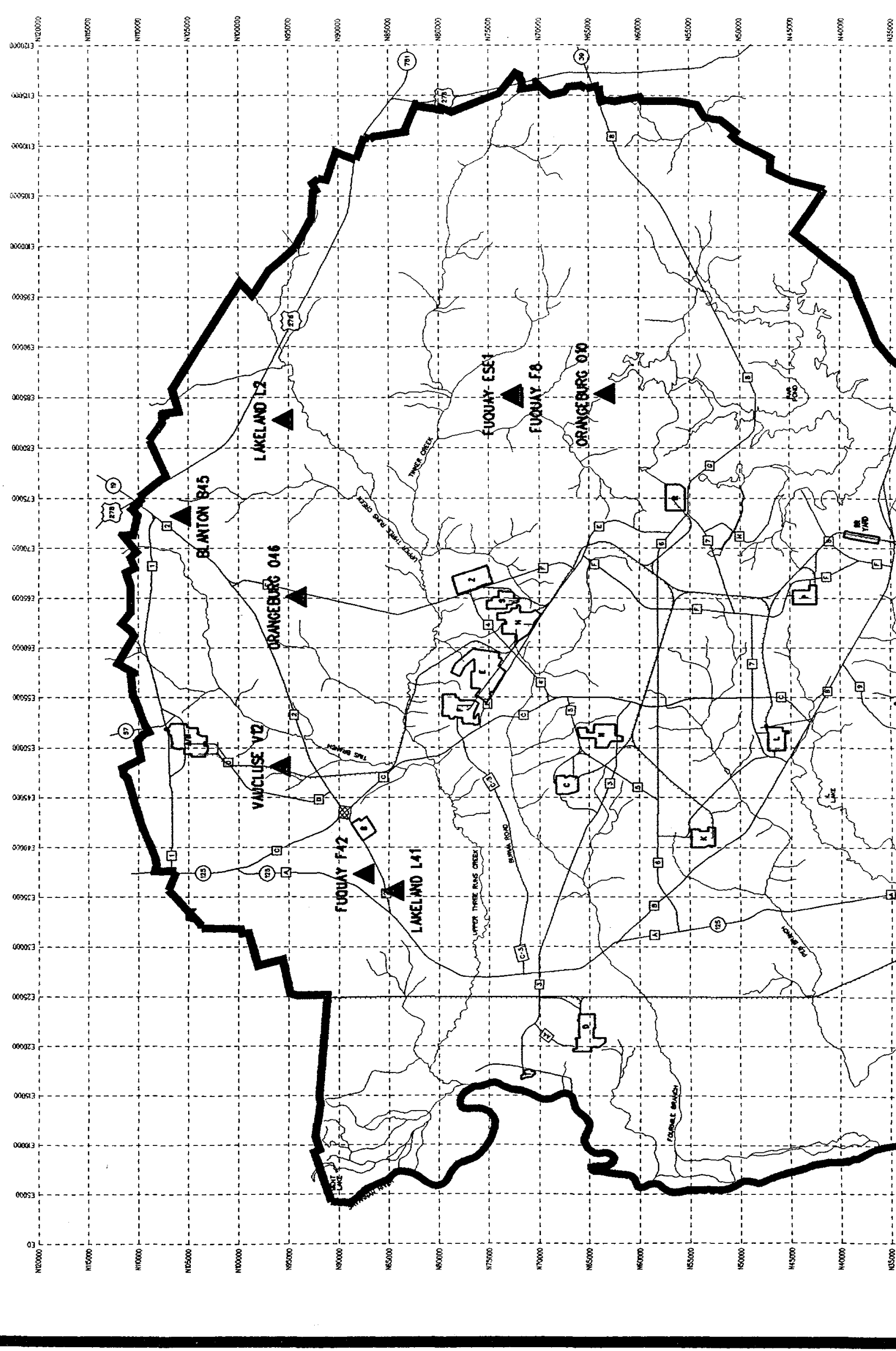




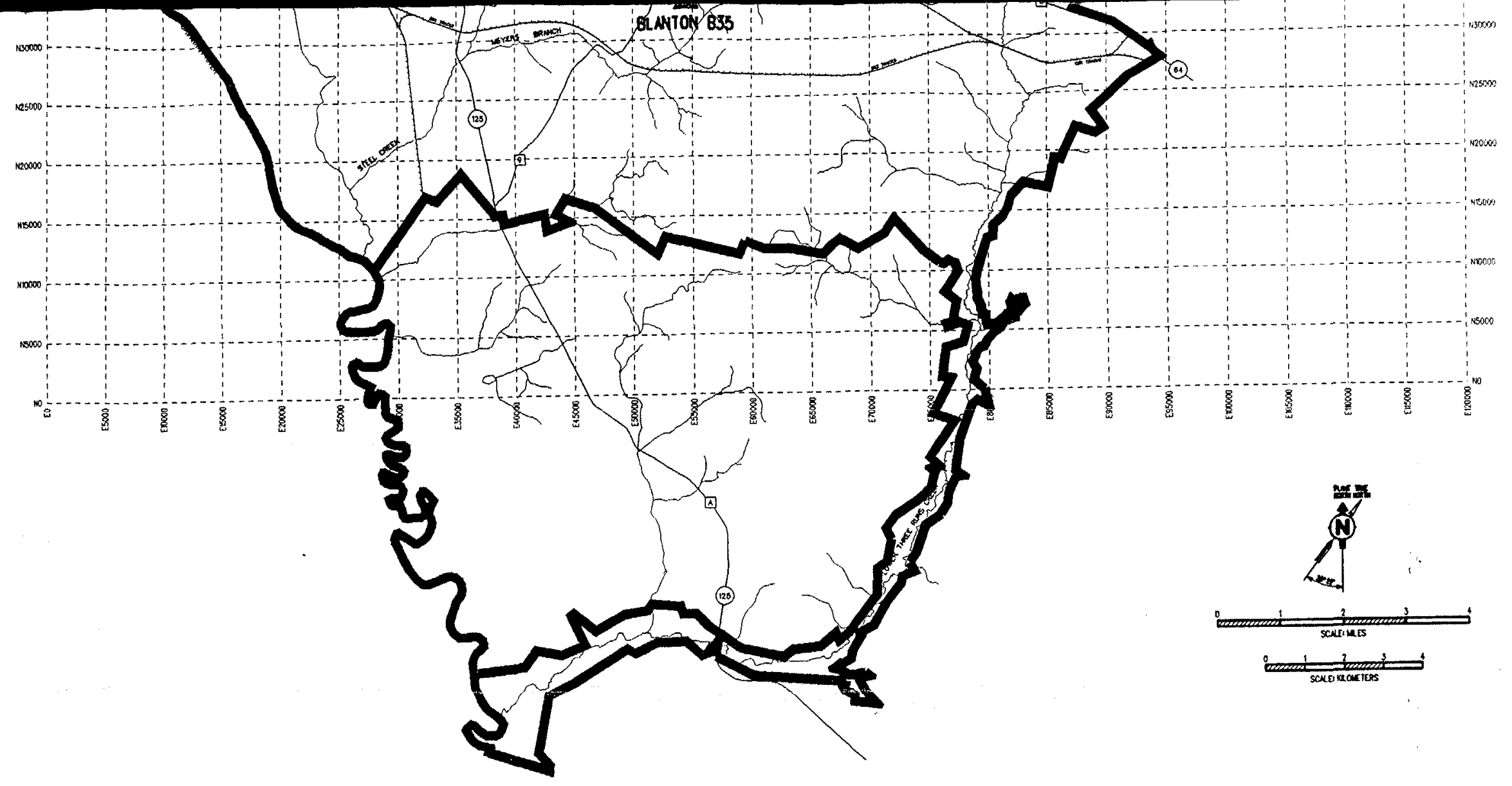

FIGURE 1. BACKGROUND SOLL SAMPLE LOCATIONS - SAVANNAH RIVER SITE, SOUTH CAROLINA

\begin{tabular}{|c|c|c|c|c|}
\hline \multirow[b]{2}{*}{ Series } & \multirow[b]{2}{*}{ Soir Somple 10 } & \multicolumn{2}{|c|}{ Approximate Sample Coorónates } & \multirow[b]{2}{*}{ Sompling Depth } \\
\hline & & Sep North & SRP East & \\
\hline \multirow{2}{*}{ Bianton } & 835 & 33,348 & 54,468 & $10-20^{\prime \prime}$ \\
\hline & 845 & 105,482 & 73,220 & $12-24^{\prime \prime}$ \\
\hline \multirow{2}{*}{ Orongeburg } & 010 & 63,148 & 85,332 & $20-30^{\prime \prime}$ \\
\hline & 046 & 93,938 & 65,113 & $22 \cdot 32^{\prime \prime}$ \\
\hline \multirow{2}{*}{ Lokelond } & $\mathrm{L} 2$ & 95,318 & 82.743 & $20-30 "$ \\
\hline & L41 & 84,253 & 35,616 & $14-24^{\prime \prime}$ \\
\hline \multirow[t]{2}{*}{ Fuquoy } & $F 8$ & 72,281 & 84,950 & 45-55" \\
\hline & $F 42$ & 87,219 & 37,347 & $48-60^{\prime \prime}$ \\
\hline Voucluse & $\mathrm{V} / 2$ & 95,572 & 48,098 & $26-36^{\prime \prime}$ \\
\hline Funuoy & ESEI & 72,466 & 85,233 & $24 \cdot 34 "$ \\
\hline
\end{tabular}


Table 4. Location of background soil samples.

\begin{tabular}{|c|c|c|c|c|}
\hline \multirow[b]{2}{*}{ Series } & \multirow{2}{*}{$\begin{array}{l}\text { Soil } \\
\text { Sample } \\
\text { ID }\end{array}$} & \multicolumn{2}{|c|}{$\begin{array}{l}\text { Approximate Sample } \\
\text { Coordinates }\end{array}$} & \multirow{2}{*}{$\begin{array}{l}\text { Sampling } \\
\text { Depth }\end{array}$} \\
\hline & & SRP N & SRP E & \\
\hline \multirow{2}{*}{ Blanton } & B35 & 33,348 & 54,468 & $10-20 "$ \\
\hline & $\overline{B 45}$ & 105,482 & 73,220 & $12-24^{\prime \prime}$ \\
\hline \multirow{2}{*}{ Orangeburg } & 010 & 63,148 & 85,332 & $20-30^{\prime \prime}$ \\
\hline & 046 & 93,938 & 65,113 & $22-32^{\prime \prime}$ \\
\hline \multirow{2}{*}{ Lakeland } & L2 & 95,318 & 82,743 & $20-30^{\prime \prime}$ \\
\hline & L41 & 84,253 & 35,616 & $14-24^{\prime \prime}$ \\
\hline \multirow{2}{*}{ Fuquay } & F8 & 72,281 & 84,950 & $45-55^{\prime \prime}$ \\
\hline & $\longdiv { F 4 2 }$ & 87,219 & 37,347 & $48-60^{\prime \prime}$ \\
\hline Vaucluse & V12 & 95,572 & 48,098 & 26-36" \\
\hline Fuquay & ESE1 & 72,466 & 85,233 & 24-34" \\
\hline
\end{tabular}


Figure 2- CMP Pits Sample Locations

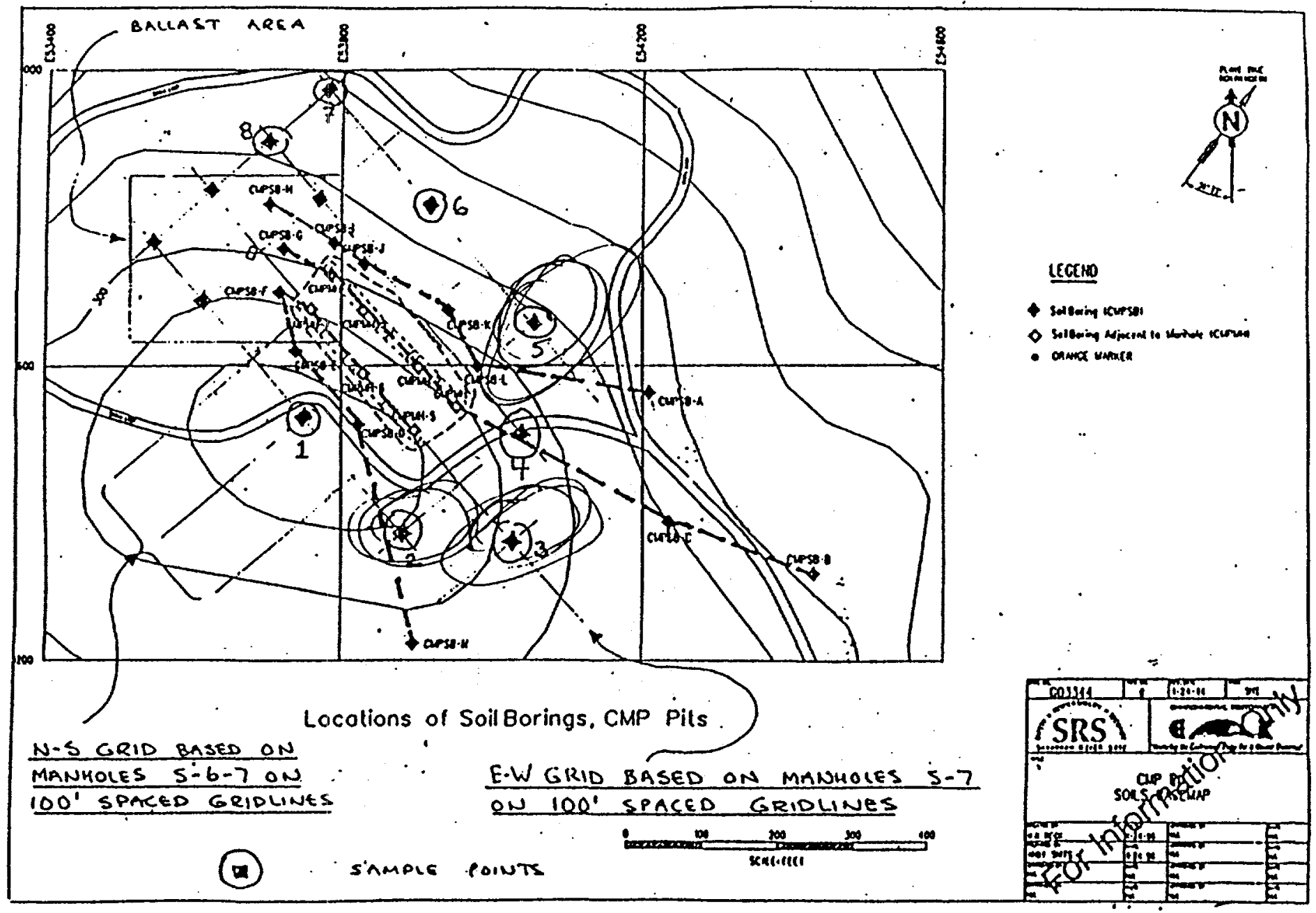




\subsection{Sequential Extraction Procedure}

Techniques that selectively remove mineral phases from soils and sediments were not originally employed for the purpose of examining trace metals. Rather, they were used to characterize the bulk chemistry of these solids and as pretreatments to remove free iron oxides, carbonates, or organic matter phases to simplify the interpretation of $x$-ray diffraction patterns and thermal analysis curves. These techniques were also employed to quantify the amount of specific mineral phases (e.g., gypsum, carbonates, free iron oxides, or only the noncrystalline (amorphous) iron oxides) present in a whole soil or sediment.

Five general types of reagents are used either individually or in combination to selectively dissolve specific soil phases: neutral salts, complexing agents, reducing agents, oxidizing agents, and acids. Several different combinations of the selective dissolution techniques have been assembled into sequential extraction schemes. An advantage of sequential extraction techniques for estimation of trace metal availability over a single-step extraction procedures is that no single step is capable of selectively removing metals from all of the different phases at once without attacking residual phases (Tessier et al. (1979)).

Much has been written about the accuracy of sequential extraction procedures (Martin et al., 1987, Nirel and Morel, 1990, Tessier and Campbell, 1991). In addition to concerns about efficiency and selectivity of individual extraction steps, an additional consideration is reabsorption of trace metals. If trace metals are released from the targeted soil fraction during an extraction step and subsequently reabsorb onto remaining soil surfaces then the results of a sequential extraction procedure do not accurately reflect the distribution of metals in that soil.

In spite of the limitations inherent with sequential extraction schemes, they remain one of the few techniques for determining trace metal speciation in soils and sediments. Applications have included: characterization of the availability of metals from contaminated soils and sediments, modeling sorption/desorption reactions, evaluating treatment technologies, and geochemical prospecting.

The sequential extraction procedure used in this project was based on one developed by Miller et al. (1986), and divides soil bound metals into eight fractions. The reagents and conditions used in each of the extraction steps are summarized in Table 1.

During the course of this project a series of informal shorthand codes (see column 1 of Table 1) were used to identify the different extraction steps. This convention for identifying the different extraction steps is retained throughout this report and in the remainder of the project documentation (database tables, lab notebook entries, and sample IDs).

Ion Coupled Plasma - Mass Spectroscopy (ICP-MS) was used to measure the concentration of 23 elements, listed in Table 1, in the samples generated from the sequential extraction procedure. The methods used to analyze the samples were adapted from EPA Method 6020 (US EPA, 1994) and users manuals 
supplied with the instrument (Fisons, 1992). Extraction method blanks were included as a part of each analysis. All standards and samples were prepared with an internal standard of 100 part-per-billion beryllium, gadolinium, indium, and thallium.

\subsection{Soil Property Measurements}

In an attempt to account for similarities and differences in trace metal availability between soil samples, soil property measurements were also conducted as a part of this study. These included soil pH, texture, color, cation exchange capacity (CEC), and carbon content. Soil pH measurements were based on EPA method 9045 (US EPA, 1986). Soil texture or particle size measurements were based on the pipette method described in Gee and Bauder (1986). Soil color was described at field moisture conditions using the Munsell color notation (Munsell Color Co., 1975). The $\mathrm{Ba}^{+2}$ exchange method designed for use on acid soils and described by Rhoades (1982) was used to estimate CEC. The carbon contents of the background soils were measured using a commercially available carbon analyzer (TOC-5000, Shimadzu Corporation).

\subsection{Results}

An eight step sequential extraction technique was used to characterize the environmental availability of trace metals from background and waste site soil samples collected from the SRS. Based on the review of the ICP-MS results, data for nine trace metals $(\mathrm{U}, \mathrm{Pb}, \mathrm{Cr}, \mathrm{Ba}, \mathrm{V}, \mathrm{Cr}, \mathrm{Cs}, \mathrm{Ce}$, and $\mathrm{Rb})$ were used to evaluate differences among trace metal availability for SRS background soils. Consistent results were not observed for other trace metals of interest such as arsenic, selenium, thorium, zinc, nickel, and copper.

\subsection{Total Metal Concentration}

One of the major differences between the background soils is soil texture. Because other factors, such as $\mathrm{pH}$ and organic matter content, are similar for all the soils, these confounding factors are minimized. Data from these soils illustrates the affect of soil texture (i.e., clay, silt, sand distribution) on the total concentrations and environmental availability of trace metals in SRS soils. The clay contents of the ten background soils ranged between 1 percent (Vaucluse $\# 12$ ) and 25 percent (Orangeburg \#46). The ranges of trace element concentrations measured in the background soils and the correlation coefficients with clay content are summarized in Table 5. As shown, total concentrations of vanadium, cerium, chromium, lead, cesium, and uranium $\left(R^{2}>0.73\right)$ are correlated with clay content of the background soils. 
Table 5. Ranges of total trace and minor metal concentrations in background soils.

\begin{tabular}{|l|c|c|}
\hline Element & $\begin{array}{c}\text { Rangê of } \\
\text { Concentrations } \\
(\mathrm{mg} / \mathrm{kg})\end{array}$ & $\begin{array}{c}\text { Correlation with } \\
\text { Clay Content } \\
\left(\mathrm{R}^{2}\right)\end{array}$ \\
\hline Zirconium & $30-120$ & 0.13 \\
\hline Manganese & $30-80$ & 0.17 \\
\hline Barium & $10-60$ & 0.22 \\
\hline Vanadium & $10-50$ & 0.90 \\
\hline Cerium & $2-40$ & 0.75 \\
\hline Chromium & $10-30$ & 0.73 \\
\hline Rubidium & $10-40$ & 0.59 \\
\hline Strontium & $3-15$ & 0.55 \\
\hline Lead & $3-15$ & 0.84 \\
\hline Cesium & $0.5-5$ & 0.83 \\
\hline Cobalt & $1-5$ & 0.17 \\
\hline Uranium & $0.5-2$ & 0.82 \\
\hline Silver & $<0.5$ & N/A \\
\hline Cadmium & $<1$ & N/A \\
\hline Arsenic & $<10$ & N/A \\
\hline Selenium & $<10$ & N/A \\
\hline
\end{tabular}

\subsection{Environmentally Available Metals}

Soil texture also seems to influence the environmental availability of at least some trace elements in the background soils. In this study, the environmentally available (i.e., labile) fraction is defined as in Johnson (1995) as the sum of the metal released in the first six extraction steps. This divides labile and residual metals between the amorphous (AOD) and crystalline (DC) iron oxide AOD and DC extraction steps. Metals released from the soil during the first six extraction steps operationally represent the environmentally available pool of trace metals, while the metals release during the final two extraction steps (DC and HF) represent the residual fraction. Concentrations of trace metal released from the first six extraction steps for nine of the elements of interest and the comparisons between available metals and clay content of the soil are summarized in Table 6.

The uncertainty surrounding each sum was quantified using standard error propagation techniques (Knoll, 1989) by calculating a standard deviation associated with each extraction step and, based on these standard deviations, the error from adding across extraction steps. 
Table 6 Environmentally available fraction of trace metals released from background soils and correlation with soil clay contents.

\begin{tabular}{|c|c|c|c|c|c|c|c|c|c|}
\hline & & & & & & & & & \\
\hline \multirow[b]{2}{*}{ Sample ID } & \multirow[b]{2}{*}{ Percent Clay } & \multicolumn{8}{|c|}{ Sum of metals released across first six extraction steps $(\mathrm{mg} / \mathrm{kg})$} \\
\hline & & $\mathrm{U}$ & $\mathrm{Pb}$ & $\mathrm{Cr}$ & $\mathrm{Ba}$ & $\mathrm{V}$ & $\mathrm{Cs}$ & $\mathrm{Rb}$ & $\mathrm{Ce}$ \\
\hline Orangeburg \#46 & $24.0 \%$ & $0.20 \pm 0.03$ & $0.81 \pm 0.35$ & $0.30 \pm 0.86$ & $9.99 \pm 0.83$ & $3.32 \pm 0.48$ & $0.05 \pm 0.01$ & $0.50 \pm 0.04$ & $3.32 \pm 0.48$ \\
\hline Orangeburg \#10 & $16.0 \%$ & $0.39 \pm 0.02$ & $5.19 \pm 0.16$ & $0.56 \pm 0.72$ & $11.43 \pm 1.09$ & $4.91 \pm 0.26$ & $0.05 \pm 0.01$ & $0.45 \pm 0.04$ & $4.91 \pm 0.26$ \\
\hline Fuquay \#42 & $17.7 \%$ & $0.26 \pm 0.03$ & $1.74 \pm 0.14$ & $0.78 \pm 0.50$ & $8.67 \pm 0.20$ & $2.84 \pm 0.26$ & $0.07 \pm 0.00$ & $0.49 \pm 0.07$ & $2.84 \pm 0.26$ \\
\hline ESE\#1 & $13.1 \%$ & $0.20 \pm 0.02$ & $1.70 \pm 0.14$ & $0.52 \pm 0.71$ & $15.40 \pm 0.46$ & $4.27 \pm 0.23$ & $0.05 \pm 0.01$ & $0.38 \pm 0.05$ & $4.27 \pm 0.23$ \\
\hline Fuquay \#8 & $12.5 \%$ & $0.28 \pm 0.02$ & $1.36 \pm 0.07$ & $0.99 \pm 0.94$ & $5.27 \pm 1.53$ & $4.82 \pm 0.29$ & $0.06 \pm 0.01$ & $0.31 \pm 0.09$ & $4.82 \pm 0.29$ \\
\hline Lakeland \#2 & $6.0 \%$ & $0.13 \pm 0.01$ & $0.47 \pm 0.76$ & $0.85 \pm 0.22$ & $8.75 \pm 0.08$ & $1.67 \pm 0.09$ & $0.03 \pm 0.00$ & $0.30 \pm 0.03$ & $1.67 \pm 0.09$ \\
\hline Lakeland \#41 & $3.6 \%$ & $0.06 \pm 0.03$ & $0.86 \pm 0.11$ & $0.21 \pm 0.57$ & $4.06 \pm 0.26$ & $0.67 \pm 0.21$ & $0.03 \pm 0.00$ & $0.17 \pm 0.01$ & $0.67 \pm 0.21$ \\
\hline Blanton \#35 & $2.3 \%$ & $0.06 \pm 0.01$ & $1.74 \pm 0.26$ & $0.17 \pm 0.88$ & $2.67 \pm 0.07$ & $0.56 \pm 0.27$ & $0.03 \pm 0.00$ & $0.16 \pm 0.05$ & $0.56 \pm 0.27$ \\
\hline Blanton \#45 & $1.6 \%$ & $0.03 \pm 0.03$ & $3.38 \pm 0.12$ & $0.29 \pm 0.62$ & $1.87 \pm 0.47$ & $0.42 \pm 0.22$ & $0.02 \pm 0.01$ & $0.13 \pm 0.16$ & $0.42 \pm 0.22$ \\
\hline Vaucluse $\# 12$ & $1.3 \%$ & $0.04 \pm 0.01$ & $1.66 \pm 0.09$ & $0.19 \pm 0.84$ & $2.55 \pm 0.27$ & $0.55 \pm 0.27$ & $0.02 \pm 0.00$ & $0.13 \pm 0.02$ & $0.55 \pm 0.27$ \\
\hline \multicolumn{2}{|c|}{ Correlation Coefficient $\left(\mathrm{r}^{2}\right)$} & 0.86 & 0.07 & 0.41 & 0.52 & 0.75 & 0.89 & 0.93 & 0.75 \\
\hline
\end{tabular}

Correlation Coefficient $\left(\mathrm{r}^{2}\right.$

0.86

0.41

0.52

0.75 
The information in this table suggests that soil texture influences the environmental availability of the uranium, vanadium, cesium, rubidium, and cerium present in background soils. Except for cerium, most of these metals are released from the soil during the $\mathrm{HAHCl}, \mathrm{PP}$, and $\mathrm{AOD}$ steps of the sequential extraction procedure. The DDI, Salt, and Ac extraction steps that are intended to remove metals from the surface of soil solids had little capacity to extract these naturally occurring trace metals.

Soil texture does not account for the differences in the environmental availability of lead, barium, and chromium among background soils. Chromium was below detection limits in all of the early extraction steps except PP. Lead and barium are released from soils during the salt extraction step and the amount of the metals released during this step is not completely explained by soil texture.

The clay-sized component of soil solids plays an important role in the trace metal content of soils because reactive minerals such as kaolinites, sesquioxides, and humic substances are concentrated in this fraction. Smaller particles also have higher specific surface areas to react with aqueous species than larger sized particles.

To investigate the relationship between environmentally available components of soil trace metals and HFO reactive surfaces (e.g., iron coatings), environmentally available trace metals were plotted against iron released during the $\mathrm{HAHCl}, \mathrm{PP}$, and $A O D$ extraction steps. Relatively large standard deviation values limit the analysis of the chromium and cesium data (most of the values were below detection limits). Rubidium, lead, barium and cerium are not strongly correlated with iron removed during the three extraction steps, with correlation coefficients $\left(R^{2}\right)$ not exceeding 0.4 (presented as Table 7). The remaining two elements, uranium and vanadium, are weakly correlated with iron $\left(R^{2}=0.66\right.$ for vanadium and $R^{2}=0.53$ for uranium).

Table 7. Correlation of environmentally available trace metals with soil extract phases.

\begin{tabular}{|l|c|c|c|}
\hline \multirow{2}{*}{$\begin{array}{c}\text { Trace } \\
\text { Metal1-6 }\end{array}$} & \multicolumn{3}{|c|}{ Correlation Coefficient $\left(\mathrm{r}^{2}\right)$} \\
\cline { 2 - 4 } & Fe4-6 & Fe\&A l4-6 $^{2}$ & All-6 \\
\hline Barium & 0.29 & 0.43 & 0.50 \\
\hline Cerium & 0.38 & 0.60 & 0.65 \\
\hline Lead & 0.07 & 0.12 & 0.14 \\
\hline Uranium & 0.53 & 0.83 & 0.92 \\
\hline Vanadium & 0.66 & 0.83 & 0.77 \\
\hline Chromium & 0.33 & 0.39 & 0.36 \\
\hline Rubidium & 0.19 & 0.45 & 0.67 \\
\hline Cesium & 0.15 & 0.40 & 0.61 \\
\hline
\end{tabular}

Because iron and aluminum are readily substituted for each other in their respective oxides, a similar comparison was made between environmentally available trace metals and iron and aluminum removed from the soil during the $\mathrm{HAHCl}, \mathrm{PP}$, and AOD extraction steps. On a molar basis, iron represents 
between 30 and 40 percent of the total of the iron and aluminum released from the background soils during these three extraction steps.

Because, on a molar-basis; more aluminum than iron is removed during the first six extraction steps, environmentally available trace metals were compared to aluminum released during the first six extraction steps. Aluminum released during these extraction steps was concentrated into three of the extraction steps, $A c, P P$, and $A O D$. These three steps comprise, on average, 90 percent of aluminum removed during the first six steps from the background soils, with all values falling between 80 and 95 percent. The correlation coefficients describing the relationship between environmentally available trace metals and aluminum extracted through the AOD extraction step are also presented in Table 7.

Environmentally available uranium and aluminum are highly correlated with each other $\left(R^{2}=0.92\right)$ and the relationship is graphed as Figure 3 . The sequential extraction profiles of the two elements are similar in that both have components that are associated with the Ac extraction step. The strong correlation between these two metals suggests that environmentally available uranium is controlled by aluminum oxides present in the background soils.

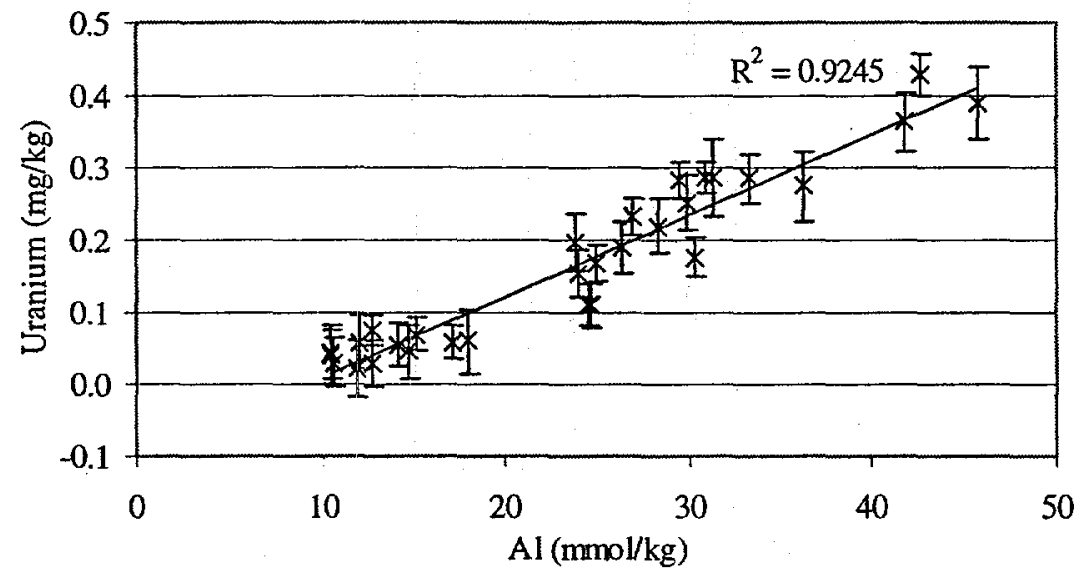

Figure 3. Environmentally available uranium from SRS background soils plotted against aluminum extracted during the first six sequential extraction steps.

\subsection{Summary of Availability of Trace Metals in Background Soils}

Sequential extraction results of the different trace metals from background soils can be roughly grouped into four categories:

1. total metal is present in the soils at very low concentrations (silver, cadmium, and cobalt);

2. significant quantities of trace metals released during the first three extraction steps (lead, barium, and cerium);

3. metal remains in the soil until the final two extraction steps (DC and HF) but is present in both fractions (chromium and vanadium); and 
4. majority of the metal is released from the soil only during the final (HF) extraction step (rubidium, cesium, and, to some extent, uranium).

Figure 4 shows characteristic extraction profiles for lead, barium, cerium, chromium, vanadium, rubidium, cesium, and uranium. The results in this figure are from the sequential extraction of Orangeburg \#10 except for the barium results, which are from Orangeburg \#46.

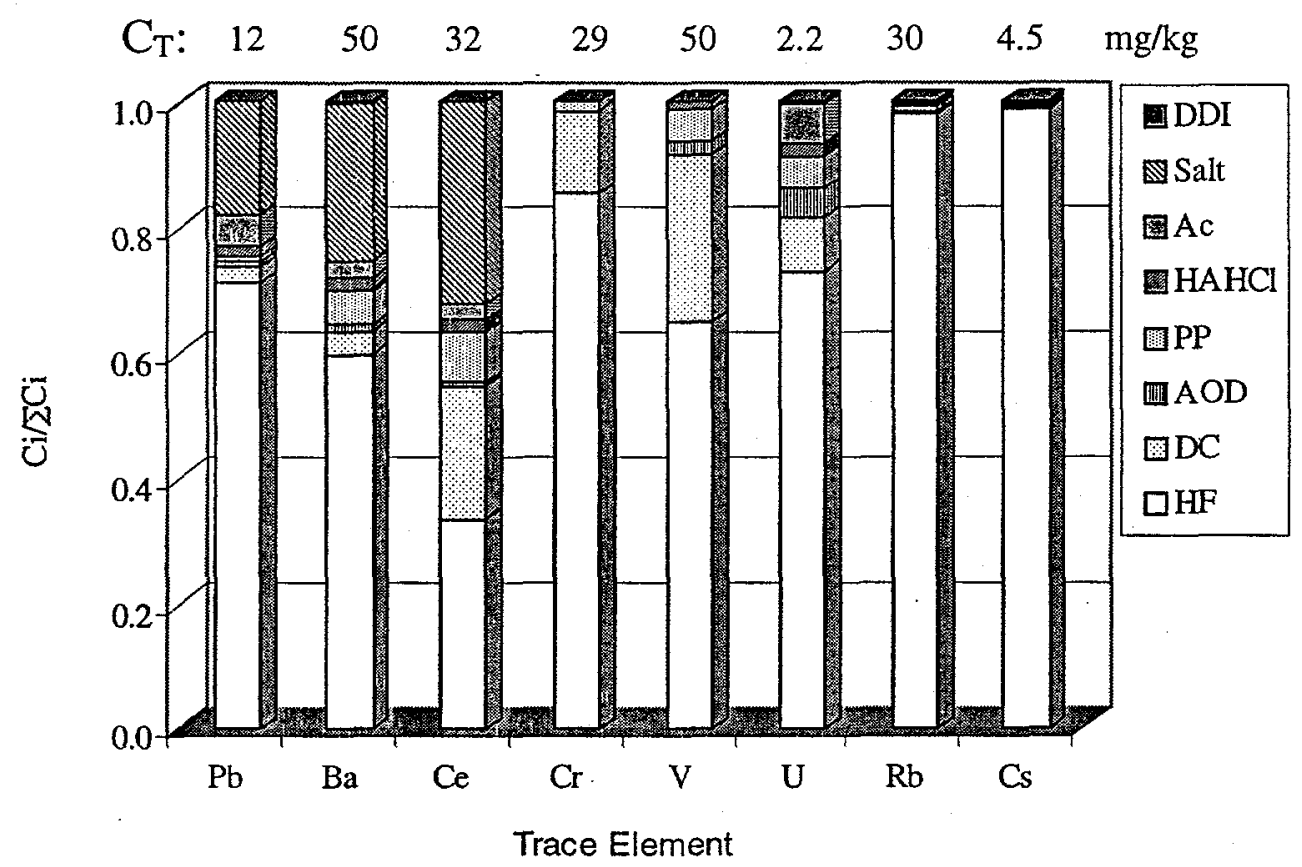

Figure 4. Sequential extraction of profiles of different trace elements from SRS background soils. The barium results are from Orangeburg \#46, while the other results are from Orangeburg \#10.

\subsection{Waste Site Soils}

Figures 5 and 6 contrast the sequential extraction profiles of uranium from the background soils (including CMP Pits soils where there is no indication of uranium disposal) and the soil samples from the F-Area Seepage Basin. The sequential extraction technique shows differences in the environmental availability of uranium from the F-Area Seepage Basin soils when compared to the background soils. A greater fraction of the soil uranium in the waste site soils is released during early extraction steps when compared to the background soils. Because total uranium concentrations were also higher in the waste site soils when compared to the background soils, differences between these two sets appear to be as a result of waste disposal activities. 


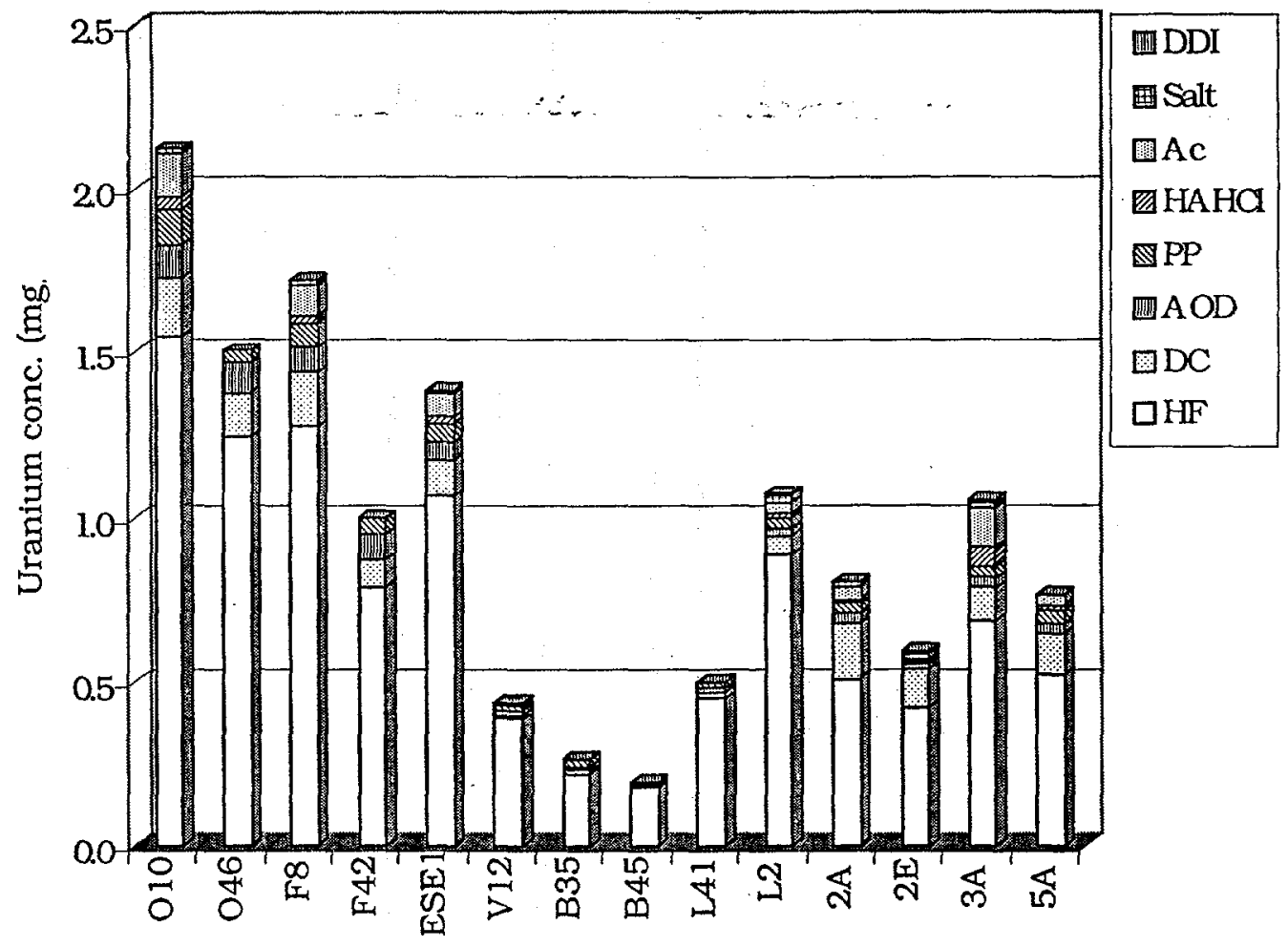

Figure 5. Sequential extraction of uranium from background/CMP Pit soils.

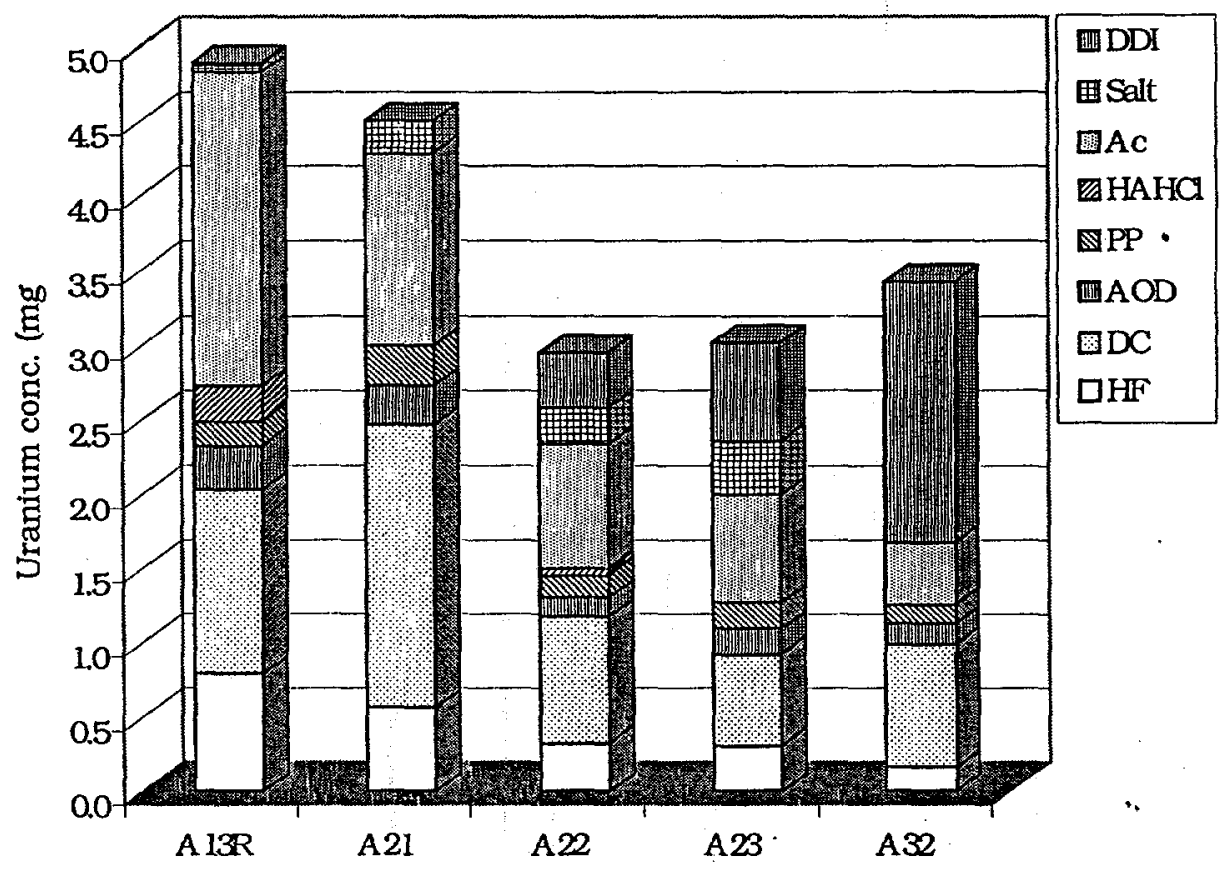

Figure 6. Sequential extraction of uranium from F-Area Seepage Basin soil samples. 


\subsection{Conclusions and Recommendations}

Characterization of the environmental availability of metals/radionuclides is an important concept for cost-effective remediation decisions, more accurate risk calculations, and strengthening intrinsic remediation approaches.

This study has shown that sequential extraction techniques can be used to elucidate the environmental availability of metals and radionuclides in SRS soils. More specifically, the results of this study indicate:

- The majority of the total metal pool in background soils is unavailable for significant environmental release;

- Waste site soils exhibit distinct availability profiles compared with unimpacted (i.e., background) soils and, therefore, sequential extraction techniques may provide a method of identifying soils impacted by waste disposal activities;

- Environmental availability of many metals and nuclides is highly correlated to soil texture (particle size distribution) and the presence of extractable iron and aluminum.

Because sequential extractions are resource intensive, work should be initiated to eliminate extraction steps to improve the utility of the sequential extraction procedure in estimating the environmental availability of trace metals and contaminants from SRS soils. Additional work to index trace element availability to the major ion chemistry of the soil (particularly reactive iron and aluminum) is recommended.

Currently, soil metal concentrations at waste site soils undergoing characterization in the Environmental Restoration program at SRS are determined by analysis of extracts obtained using EPA Method 3050B. This method uses heated $\left(90-95^{\circ} \mathrm{C}\right)$ strong mineral acids in the presence of hydrogen peroxide to extract metals from soils. Metal concentrations obtain under these very aggressive extraction conditions are then used as available metal input concentrations for risk analyses. A cross correlation between sequential extraction procedures and the EPA $3050 \mathrm{~B}$ technique would provide an estimate of the degree of conservatism in the current approach and would provide a basis for more realistic utilization of existing soil data.

Finally, additional studies in the following areas would be beneficial:

5. Evaluation of soils collected from other waste of with differing disposal histories;

6. analysis of metal availability in hydric soils; and

7. analysis of soils (both waste site and background) for metals not evaluated in this study (e.g., Be, Sb, and Th);

8. cross correlation of bioavailability studies with sequential extraction results. 


\subsection{References}

Ammonette, J. E., G. R. Holdren, K. M. Krupa, C. W. Lindenmeier. Assessing the Environmental Availability of Uranium in Soils and Sediments. U.S. Nuclear Regulatory Commission report NUREG/CR-6232. 1994.

Fisons. PlasmaQuad System Manual. Fisons Instruments, Inc. 1992.

Gee, G. W., J. W. Bauder. in Methods of Soil Analysis: Part 1 - Physical and Mineralogical Methods, $2^{\text {nd }}$ Edition. A.L. Page; R.H. Miller; D.R. Keeney, eds. American Society of Agronomy, Madison. pp. 383-409. 1986.

Johnson, W. Sorption Models of Uranium, Cesium, and Cadmium on Upper Atlantic Coastal Plain Soils. Ph.D. Dissertation. Georgia Institute of Technology. 1995.

Knoll, G. F. Radiation Detection and Measurement, $2^{\text {nd }}$ ed. John Wiley and Sons, New York. 1989.

Looney, B. B., C. A. Eddy, M. Ramdeen, J. Pickett, V. Rogers, M. T. Scott, P. A. Shirley. Geochemical and Physical Properties of Soils and Shallow Sediments at the Savannah River Site (U). WSRC (Westinghouse Savannah River Company). WSRC-RP-90-1031. August 1990.

Martin, J. M., P. Nirel, A. J. Thomas. Sequential Extraction Techniques: Promises and Problems. Marine Chemistry. Vol. 22 pp. 313-341. 1987.

Miller, W., D. Martens, L. Zelazny. Effect of Sequence in Extraction of Trace Metals from Soils. Journal of the Soil Science Society of America. 50:598601.1986.

Munsell Color Company. Munsell Soil Color Charts. Munsell Color Co., Baltimore. 1975.

Nirel, P. M. V., F. M. M. Morel, Technical Note: Pitfalls of Sequential Extractions. Water Research. Vol. 24, No. 8, pp. 1055-1056. 1990.

Rhoades, J. D. in Methods of Soil Analysis: Part 2 - Chemical and Microbiological Properties, $2^{\text {nd }}$ Edition. A.L. Page; R.H. Miller; D.R. Keeney, eds. American Society of Agronomy, Madison. p 149. 1982.

Tessier, A., P. G. C. Campbell, M. Bisson. Sequential Extraction Procedure for the Speciation of Trace Metals. Analytical Chemistry. Vol. 51, No. 7. June 1979.

Tessier, A., P. G. C. Campbell. Comment on "Piffalls of Sequential Extractions". Water Research. Vol. 25, no. 1, pp. 115-117. 1991. 
U.S. Environmental Protection Agency, Office of Solid Waste and Emergency Response. Method 9045; Soil pH. in Test Methods for Evaluating Solid Waste, Volume IC: Laboratory Manual; Physical/Chemical Methods, $3^{\text {rd }}$ Edition. SW-846. November 1986.

U.S. Environmental Protection Agency, Office of Solid Waste and Emergency Response. Method 6020; Inductively Coupled Mass Spectrometry. in Test Methods for Evaluating Solid Waste, Volume IC: Laboratory Manual; Physical/Chemical Methods, $3^{\text {rd }}$ Edition. SW-846. September 1994.

WSRC. CMP Pits - Arsenic in Soil Remediation Study (U). WSRC-RP-96-301, Rev. 0. 1996. 
6.0 Attachment 1-Matthew Findley Thesis Clemson University 1998 
CHARACTERIZING THE ENVIRONMENTAL AVAILABILITY OF TRACE METALS IN SOLLS AT THE SAVANNAH RIVER SITE

\begin{tabular}{c} 
A Thesis \\
Presented to \\
the Graduate School of \\
Clemson University \\
\hline
\end{tabular}

\author{
In Partial Fulfillment \\ of the Requirements for the Degree \\ Master of Science
}

Environmental Engineering and Science

by

Matthew Findley

May 1998 
May 1, 1998

To the Graduate School:

This thesis entitled "Characterizing the Environmental Availability of Trace Metals in Soils at the Savannah River Site" and written by Matthew Findley is presented to the Graduate School of Clemson University. I recommend that it be accepted in partial fulfillment of the requirements for the degree of Master of Science with a major in Environmental Engineering and Science.
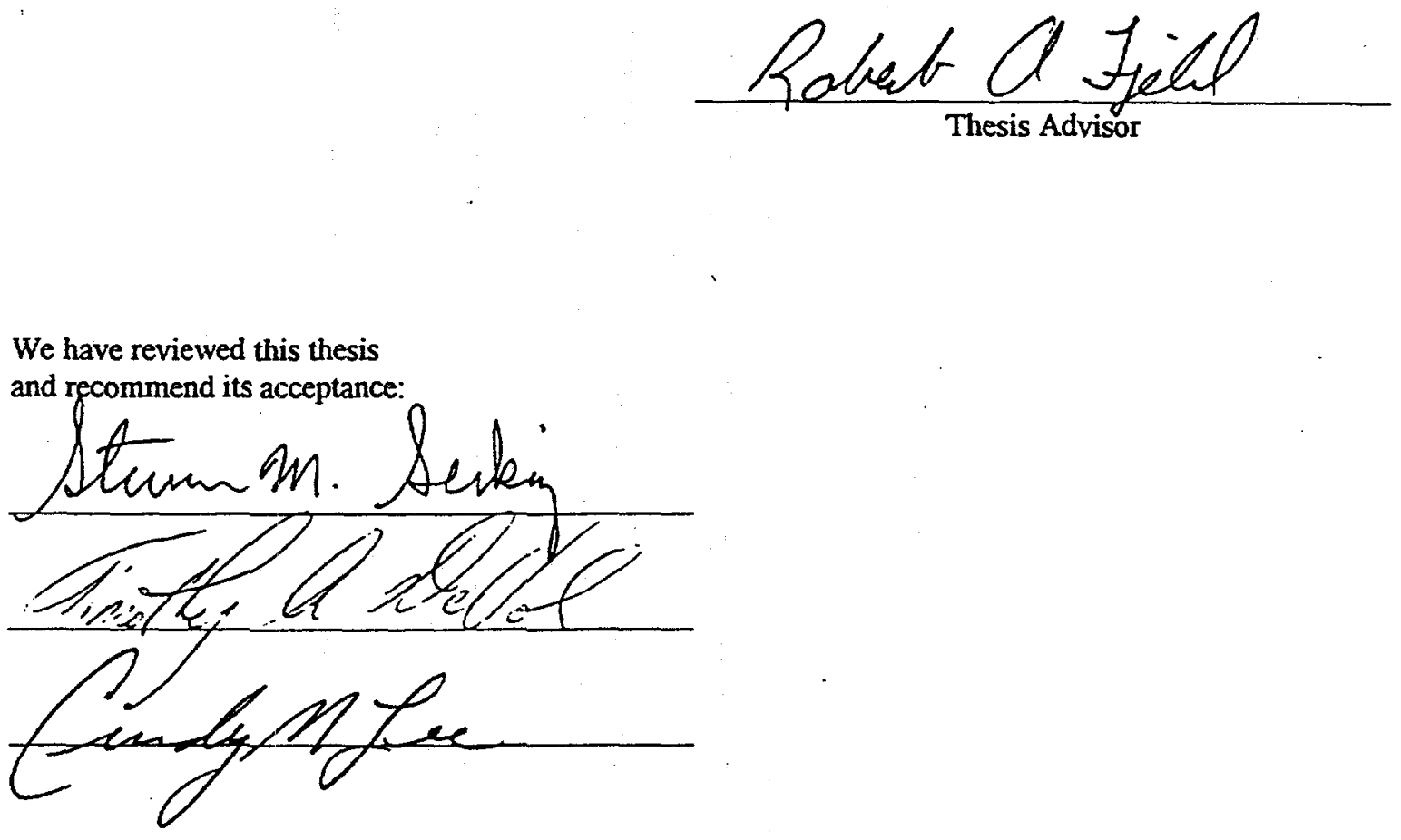

Accepted for the Graduate School:






\begin{abstract}
An eight step sequential extraction technique was used to characterize the environmental availability of trace metals from background and waste site soil samples collected from the U.S. Department of Energy's Savannah River Site (SRS). The amounts released during the first six extraction steps were combined to represent the environmentally available portion of soil bound metals. The trace metal concentrations were determined using an inductively coupled plasma mass spectrometer (ICP-MS). Sequential extraction profiles of eight trace metals $(\mathrm{Ba}, \mathrm{Ce}, \mathrm{Cr}, \mathrm{Cs}, \mathrm{Rb}, \mathrm{Pb}, \mathrm{V}$, and $\mathrm{U}$ ) from 10 background soil samples were compared and differences were noted based on differences in soil texture and type of trace metal. In general, most trace metals were not released from the soil until the final extraction steps, indicating that the environmentally available fraction of trace metals in background soils is smaller than the total concentration. A portion of the total barium, lead, and cerium were released from the soil during the extraction steps that targeted surface bound species, indicating that these trace metals are more environmentally available than other metals. Soil samples with higher clay contents tended to have higher concentrations of environmentally available trace metals. Additionally, environmentally available uranium from the background soils was highly correlated with aluminum that was removed during the first six extraction steps. Environmentally available uranium from the F-Area Seepage Basin and rubidium, cesium, and cerium from the Chemical Metal and Pesticide Pits (CMP Pits) was significantly higher than the background soils. This suggests that a sequential extraction technique can be used to distinguish between natural and anthropogenic sources of trace metals.
\end{abstract}




\section{ACKNOWLEDGEMENTS}

As cliché as it may sound, this project demonstrated to me, above all else, the maxim that no man is

an isiand. There were times during this project where I felt more like a lone wolf or biker than a member of a pack; however such feelings were nothing more than delusions. It can be said without any equivocation that most of the work described in this report simply would not have taken place without the generosity and assistance of a small army of individuals. It is tempting to simply say: "You know who you are and you know what you've done, Thank you." However, such a blanket statement, while eliminating the risk of leaving any one out, would not do justice to the individuals whose assistance was especially notable.

I would like to acknowledge all the people that assisted me in the labs, especially Howard Uhal, Francis Wake, Jim Myers, Raed El-Farhan, and Jim Roane. I would also like to acknowledge the assistance of the Analytical Development Section at the Savannah River Technology Center, particularly Laura Tovo, Joe Clymire, and Paul Cloessner. Any benefit that they may have obtained from allowing a graduate student access to their instruments is intangible at best. I, for one, hope they continue to make their resources available to students. It was an exceptional opportunity. I can't even begin to pay back the debt of gratitude I owe to Bill Boyce for teaching me how to run an ICP-MS and for all of his patient support.

A special word of thanks needs to be extended to my research advisor, Dr. Steven Serkiz, and his family for their exceptional generosity, and my academic advisor, Dr. Robert Fjeld. As with most advisors, they provided assistance in several ways. However, I think I am most grateful for their patience and for allowing me to approach this project on my own terms.

Finally, the assistance of two organizations, South Carolina Universities Research and Education Foundation (SCUREF) and Oak Ridge Institute for Science and Education (ORISE) needs be acknowledged for providing my meal ticket throughout the course of this project.

Of course there are several other people that deserve acknowledgements, but it's not like I was just awarded an academy award or anything. Enjoy the thesis. 


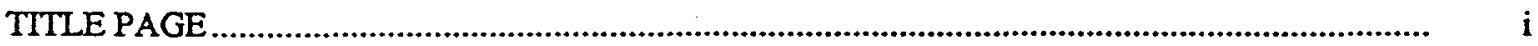

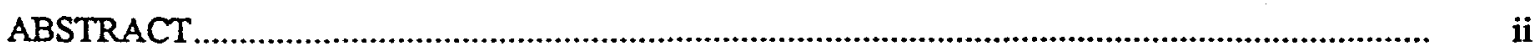

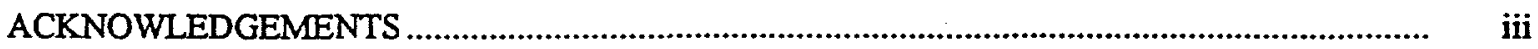

LIST OF TABLES

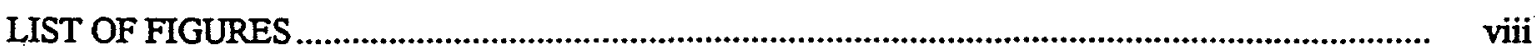

CHAPTER

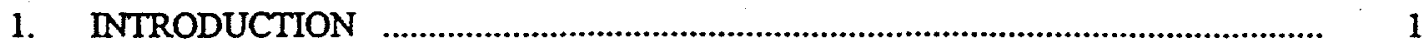

2. BACKGROUND AND LITERATURE REVIEW ................................................ 5

Soil Minerals and SRS Soils ........................................................................... 5

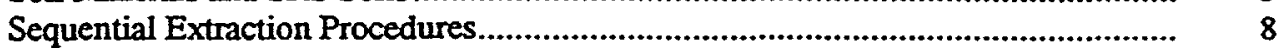

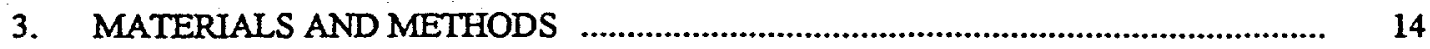

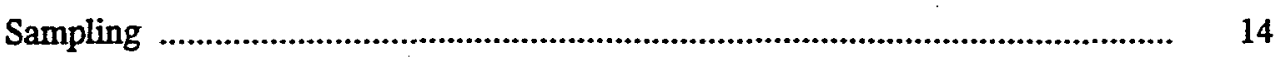

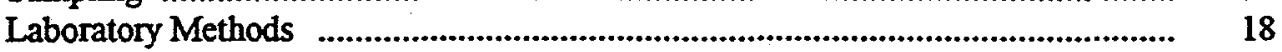

Instrumental Analysis of Soil Extracts ......................................................... 22

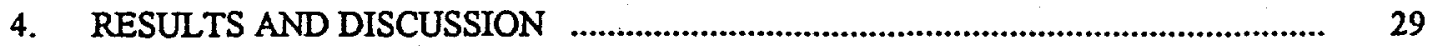

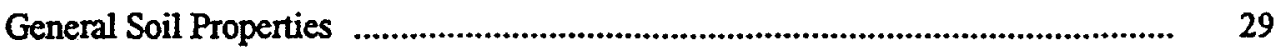

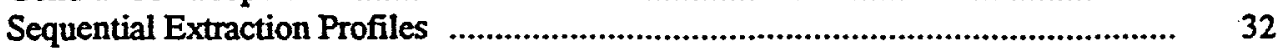

Discussion of Results

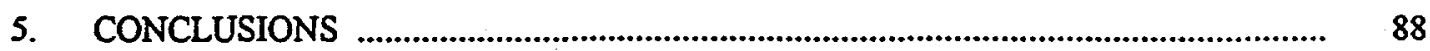

6. ENGINEERING AND SCIENTIFIC SIGNIFICANCE ......................................... 90

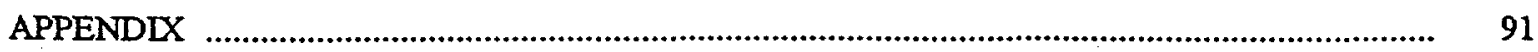

REFERENCES 


\section{LIST OF TABLES}

Table

2.1 Taxonomic names of backgound soils used for this project and extent of the soils at SRS

3.1 Location of background soil samples

3.2 Description of sequential extraction procedure steps

3.3 Analytes determined by ICP-MS

3.4 Typical ICP-MS operating conditions

3.5 Dilution factors used for analyzing samples

4.1 General properties of soil samples

4.2 Estimates of HFO binding site concentrations in SRS background soils

4.3 Estimates of binding site concentrations of gibbsite surface coatings

4.4 Comparison between measured and predicted soil aluminum

4.5 Sequential extraction of aluminum from the F-Area Seepage Basin soils

4.6 Sequential extraction of uranium from F-area seepage basin soils

4.7 Cadmium and silver detection limits

4.8 Arsenic and selenium detection limits

4.9 Concentration of lanthanides in $\mathrm{HAHCl}$ extracts from CMP Pit sample 3A

4.10 Ranges of total trace metal concentrations measured in background soils

4.11 Environmentally available fraction of trace metals released from background soils and correlation with soil clay contents

4.12 Environmentally available trace metals as a fraction of total metals

4.13 Correlation of environmentally available trace metals with different soil components

4.14 Comparison of trace metals released from CMP Pit soil sample 3A compared to average background concentrations 
List of Tables (Continued)

Table

Page

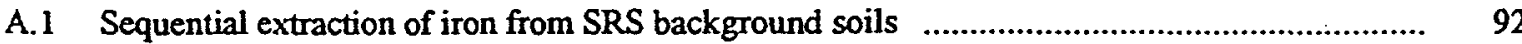

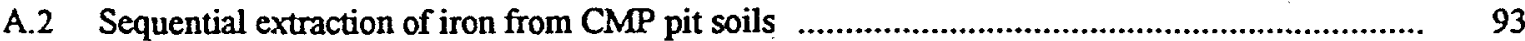

A.3 Sequential extraction of aluminum from SRS background soils



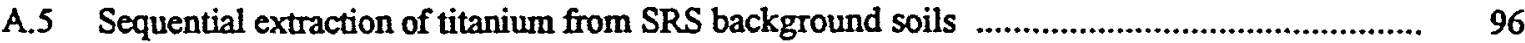

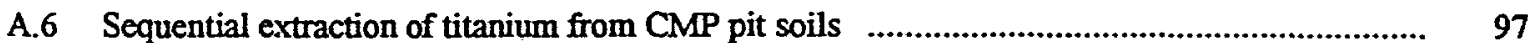

A.7 Sequential extraction of manganese from SRS backgroud soils

A.8 Sequential extraction of manganese from CMP pit soils

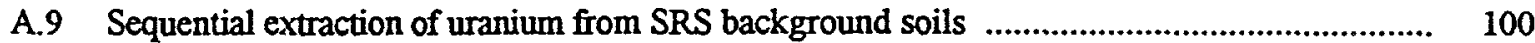

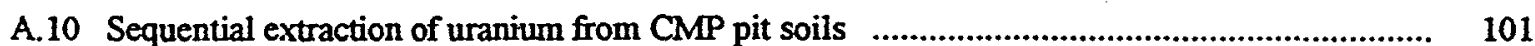

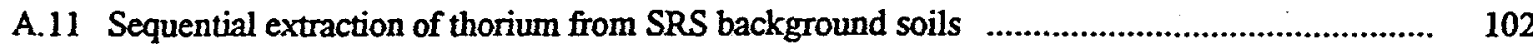

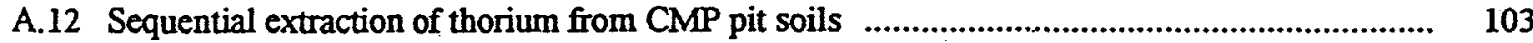

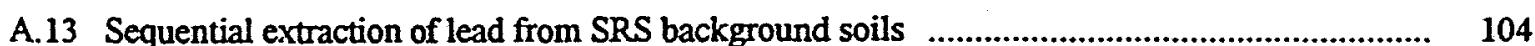

A.14 Sequential extraction of lead from CMP pit soils ................................................................

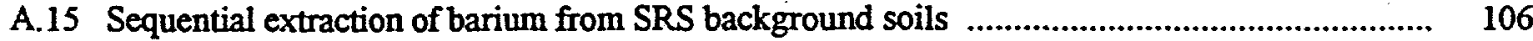

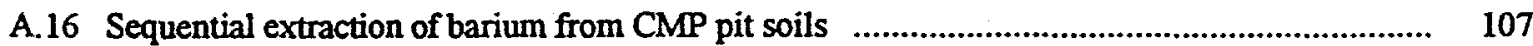

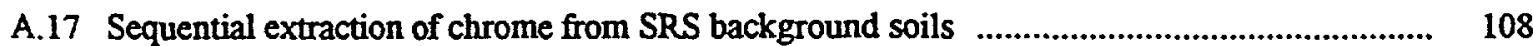

A.18 Sequential extraction of chrome from CMP pit soils ............................................................. 109

A.19 Sequential extraction of vanadium from SRS background soils

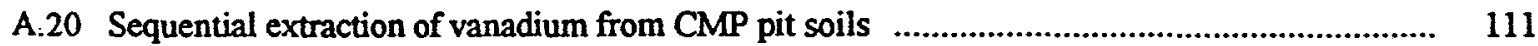



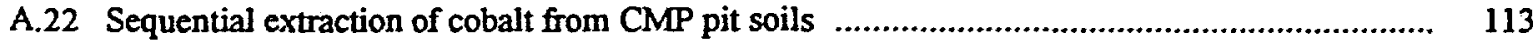

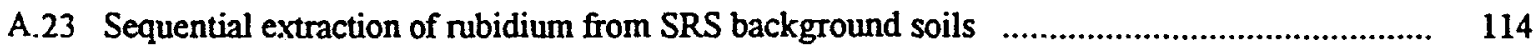

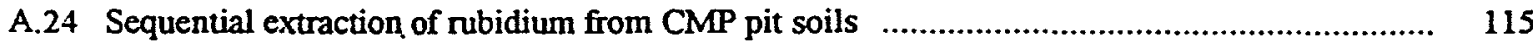

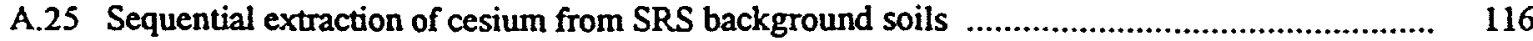




List of Tables (Continued)

Table

Page

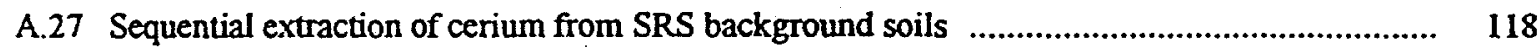

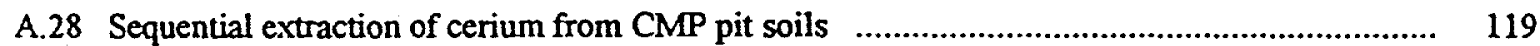

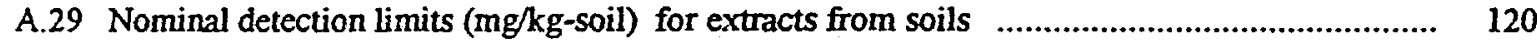

A.30 Average amount of metal extracted from SRS background soils during sequential extraction procedure 


\section{LIST OF FIGURES}

Figure

3.1 Background soil sample locations, Savannah River Site, South Carolina

3.2 Map of the Chemical, Metal, and Pesticide (CMP) Pits

3.3 Schematic of an inductively coupled-mass spectrometer (ICP-MS)

3.4 Mass spectra for uranium calibration standards between zero and one part-per-billion

4.1 Correlation of total soil iron and aluminum with the clay contents of background and CMP Pit soils

4.2 Sequential extraction of iron from background and CMP pit soils

4.3 Sequential extraction profiles of aluminum from background and

CMP pit soil samples

4.4 Relationship between iron and aluminum removed from background soils during DC extraction step

4.5 Sequential extraction profile of aluminum from soil sample A13R from the F-Area Seepage Basin

4.6 Sequential extraction profiles of titanium from background and

CMP Pit soil samples

4.7 Sequential extraction profiles of manganese from background and CMP Pit soil samples

4.8 Sequential extraction profiles of uranium from background and CMP Pit soil samples

4.9 Sequential extraction of uranium from F-Area Seepage Basin soil samples

4.10 ICP-MS calibration curve of thorium-232

4.11 Sequential extraction profiles of lead from background and CMP pit soils

4.12 Sequential extraction profiles of barium from background and CMP Pit soil samples

4.13 Salt extractable barium vs. cation exchange capacity of the background soils 
List of Figures (Continued)

Figure

4.14 Sequential extraction profiles of chromium from background and CMP Pit soil samples

4.15 Selenium signal drift during an ICP-MS nun

4.16 Sequential extraction profiles for vanadium from SRS background and CMP Pit soil samples

4.17 ICP-MS calibration curves of nickel and silver

4.18 Sequential extraction profiles of rubidium from background and CMP pit soil samples

4.19 Sequential extraction profiles of cesium from background and CMP pit soil samples

4.20 Sequential extraction profiles of cerium from background and CMP pit soil samples

4.21 Detail of a mass spectrum from an $\mathrm{HAHCl}$ extract of CMP Pit soil samples $3 \mathrm{~A}$

4.22 Environmentally available uranium from SRS background soils plotted against aluminum extracted during the first six sequential extraction steps

4.23 Sequential extraction profiles of different trace elements from SRS background soils 


\section{CHAPTER 1}

\section{INTRODUCTION}

Assessing and minimizing the environmental impact of soils contaminated with metals and radionuclides is an important contemporary problem in environmental science and engineering. Soils contamination can occur from various causes including acid mine drainage, atmospheric deposition from automobiles, power plants and smelters, and land application of sewage sludge and other solid wastes. At U.S. Department of Energy (DOE) facilities, and in particular at the Savannah River Site (SRS), many contaminated soils are the result of either the discharge of liquid wastes to open pits or shallow land burial of solid wastes. Common contaminants of concern at DOE sites include metals regulated under the Resource Conservation and Recovery Act (RCRA) such as lead and chromium; fission products such as cesium, strontium, and technetium; and actinides such as uranium, neptunium, plutonium, and americium (US DOE, 1997).

Soils, by their nature, are heterogeneous materials that contain a broad array of elements and reactive mineral components. While they are composed primarily of oxygen, silicon, aluminum, and iron, which can account for over 90 percent of the mass of the solid fraction, soils also contain many other trace elements, such as lead, copper, zinc and uranium. These trace elements occur naturally at much lower concentrations, typically less than $100 \mathrm{mg} / \mathrm{kg}$ (Sposito, 1989). Soils contain a wide range of solids and reactive surfaces, and trace metals can bind to soil solids in a variety of chemical forms determined by the aqueous speciation of the metal ion, the type of the solid involved in the reaction, and the type of interaction between the metal and solid. Factors such as $\mathrm{pH}, \mathrm{pE}$, and the presence of ligands all influence the speciation of a metal in solution. Soil solids such as organic matter, iron oxides, clays, and primary minerals can all play important but different roles in determining how trace metals are bound. Also, metals behave differently from each other in soil systems depending on parameters such as valance, ionic radii, electronegativity, and "hardness" or "softness" of the metal (Stumm and Morgan, 1996). There are several different sorption mechanisms between soils and metals. As examples, metals may be present in the diffuse layer of aqueous cations and anions that surround charged clay particles, complexed with functional 
groups that are present on the surfaces of soil solids (particulariy organic matter), or incorporated within the crystal structure of soil minerals. Cadmium, for example, can be present in several different forms within the solid fraction of a soil. In carbonaceous soils, it is common to find it isomorphically substituted for calcium or magnesium atoms in carbonate minerals (Stumm and Morgan, 1996). Alternatively, a portion of the cadmium pool may be specifically adsorbed onto the surface of iron oxide crystals or complexed with organic ligands that are functional groups in soil organic matter.

The distribution of a soil bound metal among different phases is referred to as the solid phase speciation of the metal in the soil. Different chemical forms of soil bound metals have different chemical behaviors, particularly with respect to their release from solid phases into the aqueous phase. Metal ions that are sorbed on the surfaces of soil minerals have a greater tendency to be solublized and released into the soil solution than metals that have been incorporated within the crystal matrix of a soil mineral. Even among sorbed metals, there are different degrees of availability. Solvated metal ions that are present in the diffuse ion layer move into the bulk soil solution with greater ease than metal ions that have formed complexes with functional groups present on mineral surfaces. Soil minerals containing trace metals in their mineral matrix also have different degrees of stability. For example, carbonate minerals generally are more labile than oxides.

The release of metals from soil solids into the surrounding aqueous medium is a prerequisite for many of the pathways of exposure (groundwater transport, and bioaccumulation in plant and animal tissues) that are relevant to risk assessment and remediation decisions at waste sites with metals contamination. "The ability of a soil to maintain an aqueous concentration of [a metal] in the soil solution" has been defined as the "environmental availability" of soil bound metals (Ammonette et al., 1994) and is an important consideration when predicting the fate of metal contaminants in subsurface systems. It is an operationally defined concept and can have different meanings depending on the time scales and conditions that are being considered. For example, at time scales where soil formation processes are relevant, even the trace elements that are incorporated in the primary and secondary minerals of a soil are considered environmentally available. Also, the portion of metals that are available to plants may be different from the availability of metals in a soil subject to periodic flooding. In other words, processes that liberate metals from soils in the rhizosphere are different from liberating processes in submerged soils, and the concept of 
environmental availability must be examined differently in each case. The solid-phase speciation of soil bound metals, combined with the conditions of the surrounding aqueous environment (with respect to parameters such as $\mathrm{pH}$, redox potential, and ionic strength) determine the environmental availability of trace metals and metal contaminants in soil systems.

One method for obtaining information on solid-phase speciation and environmental availability is through sequential extraction techniques. These procedures have been developed to divide the total mass of soil bound metal among different leachable fractions. This is accomplished by contacting the soil with different reagents in a sequence designed to extract metals from different phases of a soil. The amount of metal released from the soil during each extraction step is determined by measuring the concentration of the metal in each extractant. The distribution of a metal between the various steps of the sequential extraction procedure is defined as the extraction profile of the metal. Initial sequential extraction reagents, such as deionized water and neutral salt solutions, are generally non-specific and are intended to remove the soluble salts and readily exchangeable ions from the soil. These steps are followed by reagents that are capable of dissolving specific soil solids and releasing trace metals that are associated with them. Targeted fractions include organic matter, manganese oxides, and amorphous and crystalline iron oxides. The final extraction steps are generally stronger, less specific, and capable of dissolving the most resistant mineral fractions. The reagents in the sequential extraction procedure used in this study were adopted from selective dissolution techniques that were originally used to characterize the mineralogy (i.e. major ion chemistry) of soils (Martin et al., 1987).

Sequential extraction techniques, while useful, fall short of the goal of describing the solid phase speciation of soil bound trace metals. Problems with reabsorption of trace metals onto remaining or newly exposed reactive surfaces, incomplete dissolution of targeted mineral phases, and side reactions that dissolve other minerals limit the information provided by these techniques. Nonetheless, sequential extraction procedures can provide a general indication of the association between trace metals and the operationally defined extractions (Martin et al., 1987). They also provide a way of quantifying the environmental availability of metals in soils. Metals released during the early extraction steps are considered more environmentally available than the metals that remain bound up in the soil until the final extraction steps. Because sequential extraction reagents preferentially dissolve specific mineral 
components within a soil, the technique also provides information on the amount of reactive metals in the soil.

The research described in this thesis has two main objectives. The first objective is to use a sequential extraction technique to characterize the environmental availability of trace metals from undisturbed soils at SRS and identify differences in availability that are due to differences in soil morphology, soil chemistry, and the metal of interest. The chemical and mineral properties of a soil are expected to influence sequential extraction profiles of trace metals. For example, the $\mathrm{pH}$ of a soil solution is an important parameter in determining the tendency of metals to be released from soil. Other factors being equal, metals tend to be more mobile in low $\mathrm{pH}$ soils than in high $\mathrm{pH}$ soils. Also, soil texture is relevant to the behavior of metals in soils because most of the reactive surfaces and minerals that are found in soil are in the clay fraction, and sandy soils have very little capacity to sorb metals. This baseline of information on background soils, once established, can be compared to waste site soils to evaluate if soil metals are due to natural or anthropogenic activities.

The other objective of this project is to compare the environmental availability of metals from areas of known contamination with the environmental availability of metals from background soils. A sequential extraction procedure, the technique chosen in this study to quantify environmental availability of metals and radionuclides, has the potential to be used to distinguish between anthropogenic and natural sources of metals. Soil samples collected from two SRS waste sites, the F-Area Seepage Basins and the Chemical, Metal and Pesticide (CMP) Pits, are examined. The waste sites are examples of two different types of waste dispcsal activities that occurred at DOE sites. The F-Area Seepage Basins were used to dispose of acidic wastewater, while the CMP Pits represent shallow land burial of solid wastes. 


\section{CHAPTER 2}

\section{BACKGROUND AND LITERATURE REVIEW}

This chapter contains information on the types of minerals typically found in SRS soils, a description of the soil series and waste sites that are examined in this project, and a background literature review on sequential extraction techniques, their applications, and their limitations.

\section{Soil Minerals and SRS Soils}

Soil minerals can be conceptually divided into two groups. Primary minerals are derived from rock forming processes that occur deep below the earth's surface and include quartzes, feldspars, micas, and other rock forming minerals. Many primary minerals are thermodynamically unstable when in surface environments, and chemical weathering reactions transform them to more stable secondary minerals. These secondary minerals include oxides and hydroxides of iron, aluminum, and manganese (generically referred to as sesquioxides), carbonate minerals, and clay minerals such as kaolinite and montmorillonite (Schulze, 1989). In the upland (well drained) soils found at the Savannah River Site, weather resistant quartz makes up the bulk of the soils, while kaolinite (a clay mineral made of silica and aluminum) dominates the clay sized materials (Looney et al., 1990). Quartz and kaolinite, although comprising the bulk of soil material, play secondary roles in absorbing trace metals relative to the iron, aluminum, and manganese oxides and organic matter in soil. They act as "matrix vehicles" and provide surfaces for the more reactive materials to coat (Martin et al., 1987). Because of the parent materials and weathering environment of the soils, carbonate minerals and 2:1 clays are not significant components of SRS soils. Organic matter is confined to, at most, the top twelve inches of soils in this area and usually does not extend past six inches (USDA, 1990).

Metal oxide/hydroxides, kaolinite, and soil organic matter possess variable surface charge depending on, among other things, the $\mathrm{pH}$ of the surrounding soil solution. Consequently, one of the factors controlling the capacity of soils to absorb trace metals is soil pH (Sposito, 1989). The acidic soils found throughout SRS and the rest of the Atlantic coastal plain have a lower capacity to sorb trace metals than 
alkaline soils and soils that contain large amounts of 2:1 clays possessing permanent (independent of $\mathrm{pH}$ ) charge.

The weathering environment is characterized by a temperate climate with relatively high amounts of precipitation and a soil moisture regime where soils remain moist year round yet only experience brief periods of complete saturation. Soil parent material is derived from the shallow marine sediments of an ancient ocean that receded during the Cretaceous age (65 million years ago). The Atlantic coastal plain was a boundary region between the ocean and the continent, and the geology of the SRS is a complex mixture of ancient sand dunes, estuaries, and beaches. Parent materials were formed from different depositional environments (low energy sites, such as estuaries, produced materials with higher amounts of clay), and this leads to textural variations in soils at the SRS (Stich, 1994).

\section{Background Soils}

The five types of background soils examined in this study are distinguished from each other based on their taxonomic names. Soil taxonomy is a systematic way of classifying soils based on their different properties and provides a concise way for specialists in this field to describe soils. The most detailed classification of a soil is at the series level, and five different series are examined in this project: Blanton, Fuquay; Lakeland, Vaucluse, and Orangeburg (soil series are customarily named after nearby communities). Complete taxonomic names for each of these series are presented in Table 2.1. These five soils, in turn, are representative of five general categories of upland soils found at SRS (Looney et al., . 1990). The descriptions of the soil series presented below are summarized from the SRS Soil Survey (USDA, 1990).

Table 2.1. Taxonomic names of background soils used for this project and extent of the soils at SRS.

\begin{tabular}{|l|l|c|}
\hline Series Name & Taxonomic Name & $\begin{array}{c}\text { Coverage at SRS } \\
\text { (\% of total area) }\end{array}$ \\
\hline Blanton & Loamy, siliceous, thermic Grossarenic Paleudults & $21 \%$ \\
\hline Fuquay & Loamy, siliceous, thermic Plinthic Paleudults & $11.3 \%$ \\
\hline Lakeland & Thermic, coated Typic Quartzipsamments & $4.3 \%$ \\
\hline Orangeburg & Fine-loamy, siliceous, thermic Typic Paleudults & $3.4 \%$ \\
\hline Vaucluse & Fine-loamy, siliceous, thermic Typic Hapludults & $6.9 \%$ \\
\hline
\end{tabular}


The Blanton soil is the most common soil series at SRS, covering around 20 percent of the site. It is characterized by a thick eluvial horizon (E horizon), beginning around 10-20 centimeters below the surface and extends into the subsurface for more than a meter. Eluvation is the removal of soil material in suspension (or in solution) from a layer or layers of a soil (SSSA, 1997). This horizon has been extensively leached and the remaining material is weather resistant sand with only slight amounts of clay. The horizon is also characterized by having a low cation exchange capacity and an acidic $\mathrm{pH}$.

The Fuquay series is also a common soil at SRS, covering around 10 percent of the site. Like the Blanton soil, it has an eluvial horizon just below the surface (although not as thick). The feature that distinguishes this soil from the others, however, is the amount of plinthite nodules present in the subsurface (B) horizons. Greater than 5 percent of the mass of material from these horizons consists of these nodules. Plinthite is sesquioxide-rich cemented aggregate that hardens irreversibly when dried.

The Lakeland series covers approximately 4 percent of the site and is characterized by its almost complete lack of horizon development. These soils are characterized by a horizon of unweathered sands that is present just below the soil surface (around 8 centimeters) and extends over two meters into the subsurface. Although the soils are as old as other soils found on the site, the parent material consists almost entirely of quartz sand and, consequently, they have resisted soil forming processes.

The Vaucluse series covers approximately 7 percent of the site. In contrast with the Blanton soils, which have a mature eluvial horizon, the Vaucluse soils have only the simplest set of horizons, and lack an E horizon of depleted colloidal material. Subsurface horizons also have a characteristic thin, dense, and brittle layer that is rich in clay.

The Orangeburg series covers 3.5 percent of the site. These soils generally have a finer texture than the other soils, do not possess an eluvial horizon, and the subsurface horizons have a stronger reddish hue.

\section{CMP Pits and the F-Area Seepage Basins}

The CMP Pits are a series of unlined pits, 10 to 15 feet deep, that were used during the 1970 s to dispose of non-radioactive chemical, metal, and pesticide wastes. A slope just adjacent to the pits, referred to as the ballast area, also received waste during that time, including fluorescent light ballasts (possibly containing PCBs) and other debris. In the early eighties, organic compounds such as chlorinated solvents were detected in the groundwater beneath the pits and, beginning in 1984 , the pits were excavated, 
backfilled with clean soil, and capped. Cleanup efforts revealed that the surface soil, vadose zone, and underlying groundwater aquifers were extensively contaminated with solvents and pesticides.

Because the remediation efforts were not carried out under any formal regulatory program and the extent of contamination in the areas surrounding the CMP Pits was not thoroughly investigated, additional investigations were conducted between 1994 and 1995 (WSRC, 1996a). Sampling efforts were directed at characterizing the extent of contamination at the waste site and revealed that solvents and pesticides still contaminated the surface soils, vadose zone, and groundwater at the site. The results were consistent with previous sampling efforts; however, a few surface soil locations had metals concentrations that were slightly higher than the background soils. Based on the data from this sampling effort, a risk assessment of the site identified metals, such as arsenic, in surface soils as a potential risk driver (WSRC, 1996a).

The F- and H-Area Seepage Basins are a series of unlined basins that were used to dispose of process waste water and storm water runoff from SRS separations facilities between 1955 and 1988. Wastewater percolated into the underlying aquifers or evaporated. As a result of these disposal activities, the soil and groundwater undemeath the sites contain elevated levels of metals, radionuclides, and other contaminants. Discharges to the seepage basins had widely varying $\mathrm{pH}$ values (between 2 and 12), but most discharges were acidic with high concentrations of nitric acid. The wastewater also contained uranium-238, cesium137, stable cadmium, and tritium. The acidic wastewater has also promoted the dissolution of aquifer materials and resulted in increased aluminum and silica concentrations in the groundwater (Johnson, 1995). This plume of contaminants is moving through the aquifer towards a local stream.

\section{Sequential Extraction Procedures}

Techniques that selectively remove mineral phases from soils and sediments were not originally employed for the express purpose of examining trace metals but for characterizing the bulk chemistry of these solids. Pretreatment of samples to remove free iron oxides, carbonates, or organic matter simplifies the interpretation of $x$-ray diffraction patterns and thermal analysis curves from the remaining minerals. These techniques were also employed to quantify the amount the mineral that was targeted for dissolution. Jackson et al. (1986), Kunze and Dixon (1986), and Gee and Bauder (1986) present several of the most common techniques. These have been used to quantify soluble salts such as gypsum, carbonates, free iron oxides, or only the non-crystalline.(amorphous) iron oxides. 
Selective dissolution techniques were first employed for trace element analysis by geochemists that were interested in the origin of trace metals found in marine sediments. They wanted to be able to resolve the fraction of trace metals that originated from marine environments (authigenic) from the trace metals that came from the continents. The authigenic materials of practical importance were carbonates and ferromanganese nodules (Chester and Hughes, 1976).

Five general types of reagents are used either individually or in combination to selectively attack different phases of a soil: neutral salts, complexing agents, reducing agents, oxidizing agents, and acids. Kersten and Forstner (1990) provide a thorough evaluation of the different reagents employed in selective dissolution techniques.

Neutral salts such as magnesium chloride and ammonium acetate, sometimes used in combination with acetic acid, are employed to selectively remove metals that are sorbed onto soil surfaces. Swamping concentrations of salts are used to exchange with metals that have higher affinities for soil surfaces.

The chealating agent sodium pyrophosphate is commonly used to remove the metals associated with organic matter (McKeague, 1967). Pyrophosphate effectively competes for metals coordinated with low molecular weight soil organic matter (Hayes and Himes, 1986). One limitation of the reagent is that it may also attack and dissolve oxide minerals (Shuman, 1982). Chelating agents are also used in selective dissolution analysis techniques to increase the metal solubility. Citric acid is used in the dithionate/citrate/bicarbonate (DCB) extraction of free iron oxides to increase the solubility of iron (Mehra and Jackson, 1960).

Oxidizing agents such as hydrogen peroxide and sodium perchlorate are sometimes incorporated into sequential extraction procedures to remove organic matter and sulfides from soils and sediments. Reducing agents are used to dissolve iron and manganese oxide minerals. Manganese and iron in minerals from oxic soils are in oxidized forms $\left(\mathrm{Mn}^{+4}\right.$ and $\left.\mathrm{Fe}^{+3}\right)$. The reduced forms $\left(\mathrm{Mn}^{+2}\right.$ and $\left.\mathrm{Fe}^{+2}\right)$ of these metals are more soluble, and reducing agents such as hydroxylamine hydrochloride and sodium dithionate promote the dissolution of the oxidized minerals. Because heterogeneous redox reactions have complicated kinetics and reaction pathways, researchers have been able to "fine tune" reductive dissolution techniques to selectively dissolve only manganese oxides (Chao, 1972) or only amorphous iron oxides (Chao and Zhou, 1983). 
Aggressive mineral acids such as hydrofluoric and perchloric acid are rarely used in selective dissolution techniques because they are nonspecific and attack unwanted mineral phases. However, they are used to digest residual material. Acids are also used to adjust the $\mathrm{pH}$ of selective dissolution reagents. The $\mathrm{pH}$ of a solution controls factors such as solubility, oxidation or reduction potential, and the kinetics of reactions. Extractants can also be buffered with weak acids to minimize $\mathrm{pH}$ changes during extractions.

The ability to selectively resolve manganese and amorphous oxides from crystalline oxides illustrates an important point concerning selective dissolution techniques. The composition of the extraction reagent is only one of many factors that influence the selectivity and efficiency from these techniques. Other factors include solid to extractant ratio, sample preparation steps (freezing or oven drying), contact time, degree of agitation, temperature, and surface area of the soil (LaGrega et al., 1994, Rapin et al., 1986). The technique (Chao and Thou, 1983) that is used to selectively remove amorphous iron oxides specifies that the reaction take place in the dark because ultraviolet light catalyzes the reduction of ferric iron and promotes crystalline iron oxide dissolution. Mehra and Jackson (1960) found that simply the order in which the reagents were mixed (sodium dithionate is added as a solid powder) influenced the results. Because of these confounding factors, results from extraction techniques are operationally defined.

Evaluating an extraction technique involves testing it with respect to two main criteria. The technique should be efficient (it should remove all of the targeted phase) and it should be selective (should not attack any other unwanted phases). Subjecting standard reference materials and pure mineral phases to dissolution steps aid in evaluating extraction procedures. Extracts are analyzed for the presence of unwanted metals such as iron released during the manganese oxide dissolution step or silica released during any step not targeting clay minerals (Malo, 1977). These metals will always be present in extracts to some extent because of impurities in mineral phases (particularly from natural samples), and interpretation of the results often requires making judgements about the origin of unwanted metals. Total metal concentrations are helpful in interpreting results. Lahann (1976) subjected reference standards for clay minerals montmorillonite, kaolinite, and illite to ten selective dissolution extraction reagents. In addition to measuring extracted silicon and aluminum concentrations, he also examined the $x$-ray diffraction patterns of the minerals to identify non-specific reagents. Using this approach he concluded that kaolinite was 
resistant to dissolution under most extraction conditions. The 2:1 clay minerals were more susceptible, however, particularly with respect to hydrogen peroxide and mineral acids.

Several different combinations of the selective dissolution techniques have been assembled into sequential extraction schemes. Martin et al. (1987) and Kersten and Fröstner (1989) identified and reviewed several of them. Tessier et al. (1979) noted that one of the advantages of using a sequential extraction technique to estimate an environmentally available fraction of trace elements versus single-step extraction procedures is that no single step is capable of selectively removing metals from all of the different phases at once without attacking residual phases.

Much has been written about the accuracy of sequential extraction procedures (Martin et al., 1987, Nirel and Morel, 1990, Tessier and Campbell, 1991). Other considerations, in addition to concerns about efficiency and selectivity of individual extraction steps, must be addressed when evaluating sequential extraction procedures. The order of sequential extraction steps, particularly the organic matter and oxide steps, have received attention (Miller et al., 1986). Another consideration that has received attention is reabsorption of trace metals. If trace metals are released from the targeted soil fraction during an extraction step and subsequently reabsorb onto remaining soil surfaces then the results of a sequential extraction procedure do not accurately reflect the distribution of metals in that soil.

Reabsorption of trace elements has been tested by measuring recovery of doped metals from different synthetic phases in model sediments (Kheboian and Bauer, 1987). Xiao-Quan and Bin (1993) evaluated reabsorption by preparing a model soil from reference materials (hematite, montmorillonite, carbonate, pyrolusite, and other minerals). Both papers concluded that reabsorption introduced inaccuracies into sequential extraction procedures. However, Belzile et al. (1989) subjected natural sediments to a sequential extraction procedure and tested reabsoption by spiking each extraction reagent with a small amount of trace metals. Using this standard addition approach they concluded that reabsorption was not a factor.

In spite of the limitations inherent with sequential extraction schemes, they remain one of the few - techniques available for speciating trace metals in soils and sediments, and have found several applications. These include characterizing the availability of metals from contaminated soils and sediments, modeling sorption/desorption reactions, evaluating treatment technologies, and identifying anomalous concentrations of trace elements. 
Gibson and Farmer (1986) applied a six-step sequential extraction technique to urban soils and used the results to estimate environmental availability of cadmium, zinc, copper, and lead under several different environmental conditions. The first two extractions, targeting exchangeable and carbonate bound fractions, were combined to estimate the fraction of metals available for transport. These fractions, combined with the organically bound fraction, were used to estimate plant available fraction. They also suggest that the portion of metals that may be leached upon ingestion can be estimated by a combination of the exchangeable, carbonate (acetic acid), and easily reducible fractions. Clevenger (1990) used the Tessier et al. (1979) five-step extraction procedure to conclude that trace metals (lead, cadmium, copper, and zinc) in tailings from Missouri lead and zinc mines were in a residual environmentally unavailable form.

Oughton et al. (1992) used a six-step sequential extraction technique to estimate the mobility of cesium-137 and strontium-90 from Chernobyl fallout on soils in Norway, Byelonussia, and in the immediate vicinity of the accident. Results from the technique were used to develop a "mobility factor" for predicting transfers from soils to plants.

Tessier et al. (1985) applied a six-step sequential extraction scheme to lake sediments near a metals smelter. The amount of trace metals $(\mathrm{Cd}, \mathrm{Cu}, \mathrm{Ni}, \mathrm{Pb}$, and $\mathrm{Zn}$ ) released during the iron oxide dissolution step was combined with the iron released during the step and used to estimate the concentration of metals associated with iron oxides. This information was combined with measurements of porewater $\mathrm{pH}$ and metal concentrations to estimate the apparent equilibrium constant, $\mathrm{K}_{\mathrm{A}}$, for absorption reactions in a surface complexation model. The researchers concluded that there was good agreement (within orders of magnitude) between field evaluated equilibrium constants and those measured in controlled laboratory experiments.

Contaminated soil from an area at Idaho National Engineering Laboratories that received cooling water discharges was subjected to a six-step sequential extraction procedure to evaluate the appropriateness of a soil washing remediation strategy (Gombert, 1993). Greater than 80 percent of Cesium-137, the primary risk driver at the site, remained in the soil until the final extraction step; suggesting that soil washing would not be an appropriate cleanup technology at this site. 
Finally, Chao (1984) explored the use sequential extraction techniques for geochemical prospecting.

He noted that:

"one of the major objectives of geochemical exploration is to detect in geological sample media anomalous concentrations of elements that constitute an expression of mineralization."

and argued that sequential extraction procedures aid in detecting anomalies. In some sense, the objective of prospectors is no different than that of investigators characterizing waste sites: to identify anomalous concentrations of metals from an area with naturally occurring background levels. 
CHAPTER 3

\section{MATERIALS AND METHODS}

The materials and methods that were used to complete this project are described in this chapter. Presented in the first section is information on how the soil samples were collected. The laboratory techniques that were used to characterize the soils are presented in the second section. The last section contains information on how an inductively coupled plasma mass spectrometer (ICP-MS) was used to analyze extracts from the sequential extraction procedure.

\section{Sampling}

For this study, three sets of soil samples from SRS were examined. The first set consisted of ten soil samples collected from relatively undisturbed locations at SRS. The second and third sets were from two waste sites at SRS; the Chemical, Metals, and Pesticide Pits (CMP Pits) and the F-Area Seepage Basins.

Background soil samples were collected on June 16, 1996, using a stainless steel hand auger. Between sampling events, the hand auger was cleaned by a gross wash with a detergent solution and brush to remove all visible solid material, a gross rinse with deionized water, a rinse with dilute nitric acid, and a final rinse with deionized water. Samples were stored at room temperature in labeled 2-liter plastic containers. All but one of the background soil samples were taken from locations described in Looney et al. (1990). The approximate locations of these background soil sampling sites and the depth that the samples were collected are presented in Figure 3.1 and Table 3.1. The first letter of sample identification code represents soil series and the number represents the soil number used in Looney et al. (1990). For example, soil sample $\mathrm{O} 46$ is the Orangeburg soil taken from the location that was described for background soil sample (BSS) number 46 in Looney et al. (1990). Two soil samples each were collected from the Orangeburg, Blanton, Lakeland, and Fuquay soils series. Only one soil sample from the Vaucluse series was collected. 


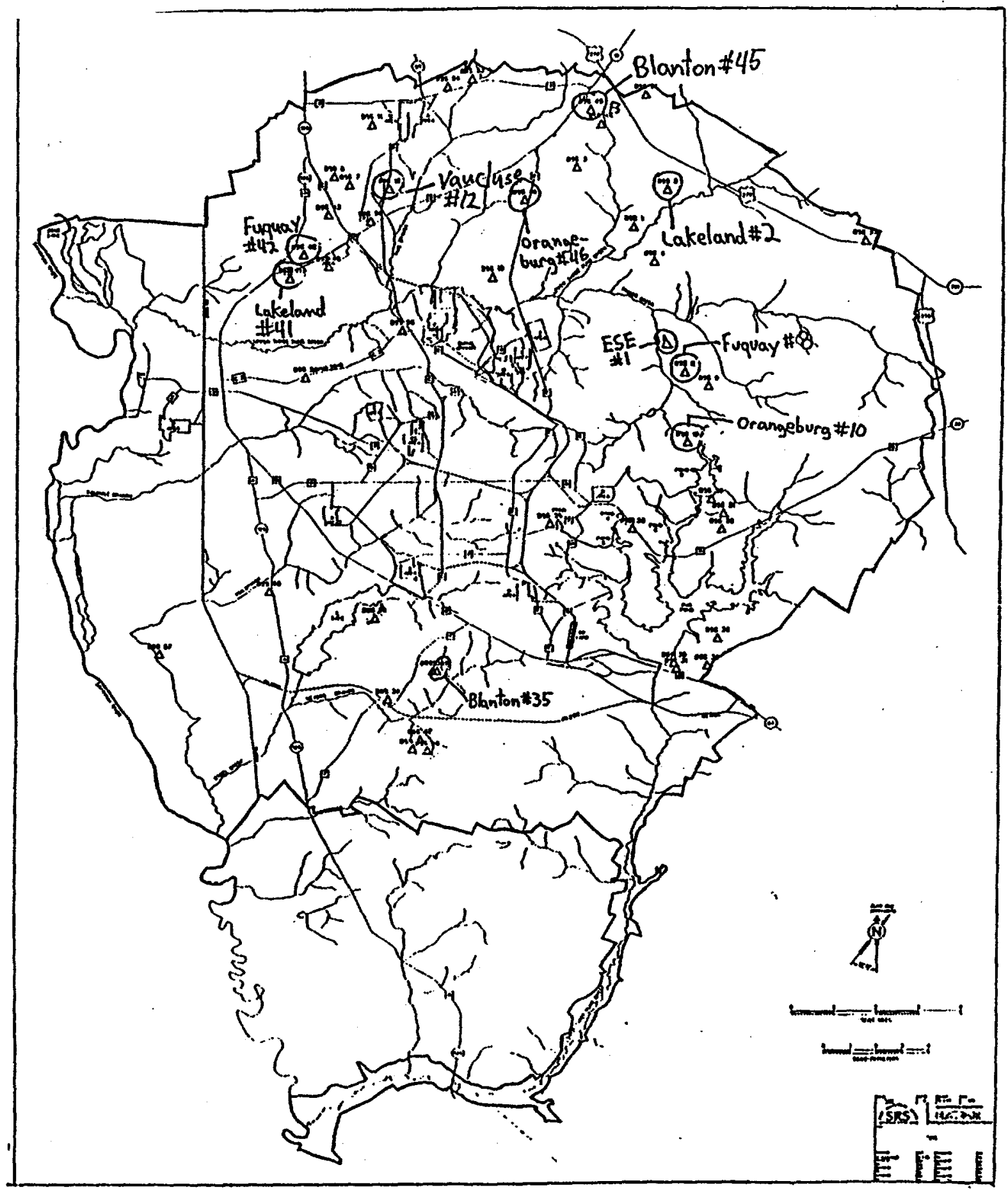

Figure 3.1. Background soll sample locations, Savanuah River Stie, South Carolina. 
Table 3.1. Location of background soil samples.

\begin{tabular}{|c|c|c|c|c|}
\hline \multirow[b]{2}{*}{ Series } & \multirow{2}{*}{$\begin{array}{c}\text { Soil Sample } \\
\text { ID }\end{array}$} & \multicolumn{2}{|c|}{ Approximate Sample Coordinates } & \multirow{2}{*}{$\begin{array}{l}\text { Sampling } \\
\text { Depth }\end{array}$} \\
\hline & & SRP N & SRP E & \\
\hline \multirow{2}{*}{ Blanton } & $\overline{B 35}$ & 33,348 & 54,468 & $10-20^{\prime \prime}$ \\
\hline & $\mathrm{B} 45$ & 105,482 & 73,220 & $12-24^{\prime \prime}$ \\
\hline \multirow{2}{*}{ Orangeburg } & 010 & 63,148 & 85,332 & $20-30^{\prime \prime}$ \\
\hline & $\overline{\mathrm{O} 46}$ & 93,938 & 65,113 & $22-32^{\prime \prime}$ \\
\hline \multirow{2}{*}{ Lakeland } & L2 & 95,318 & 82,743 & $20-30^{\prime \prime}$ \\
\hline & L41 & 84,253 & 35,616 & $14-24^{n}$ \\
\hline \multirow{2}{*}{ Fuquay } & $\overline{F 8}$ & 72,281 & 84,950 & $45-55^{n}$ \\
\hline & $\overline{F 42}$ & 87,219 & 37,347 & $48-60^{\prime \prime}$ \\
\hline Vaucluse & V12 & 95,572 & 48,098 & $26-36^{\prime \prime}$ \\
\hline Fuquay & ESE1 & 72,466 & 85,233 & $24-34^{\prime \prime}$ \\
\hline
\end{tabular}

One of the background soil samples does not correspond to any of the samples collected by Looney et al. (1990). For lack of a better name, this soil was called "ESE\#1" during the sampling effort. The ID was carried throughout the project and is retained in this report. This sample was collected from an area near the intersection of Forest Service roads 2-1 and E-2. To locate this sample site, proceed east from the intersection 1.2 to 1.3 miles, take a right on an unmarked gravel road that dead ends at an area with several concrete pads. ESE\#1 was sampled from a location approximately 0.3 miles down that road, near a drainage cut, on the right. The sample was taken from a wooded area 20 feet from the road.

Surface soil samples were collected from eight locations in the CMP pit area between May 8, 1996 and May 10, 1996 as part of a separate project (WSRC, 1996b). Materials from several depths were collected; however, only the intervals between zero and one foot and between five and six feet (the two depths nearest to the surface) were analyzed in this study. Four samples, identified as $2 \mathrm{~A}, 2 \mathrm{E}, 3 \mathrm{~A}$, and $5 \mathrm{~A}$, were selected from the collected samples and included as part of this study. Figure 3.2 is a map showing the sample locations and other relevant features at the CMP Pits.

Johnson (1995) collected several soil samples from the aquifers beneath the F- and H- Area Seepage Basins. This project examines the uranium sequential extraction results from five samples collected from under the F-Area Seepage Basin. These samples had the highest concentrations of uranium in the surrounding porewater and provided the best examples of acid impacted, uranium contaminated soils. In contrast to the background and CMP pit soil samples, which are all surface soils, these samples were 


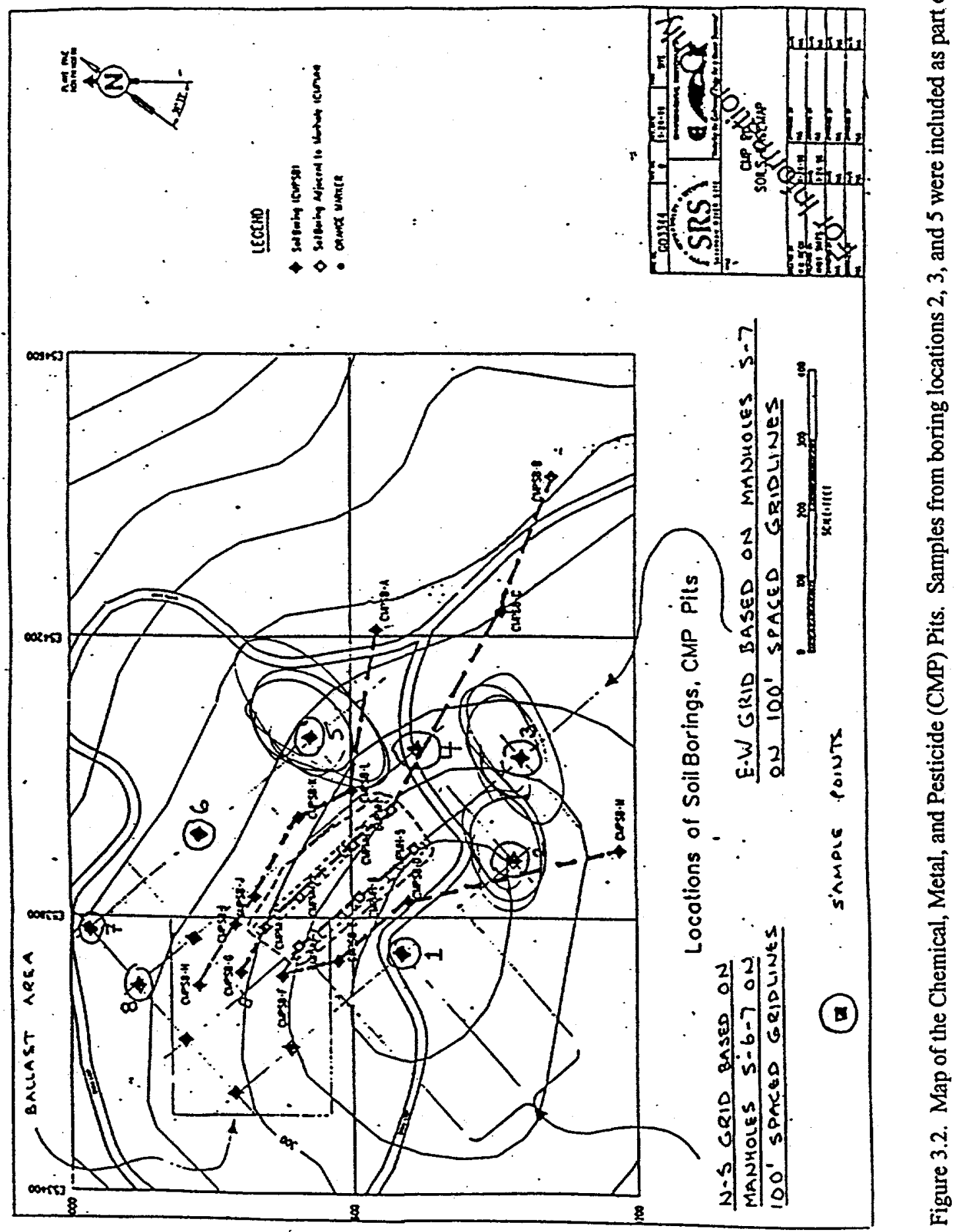


retrieved from the saturated zone of a groundwater aquifer just beneath the F-Area Seepage Basin. The results for only two metals are examined for this study, uranium and aluminum. More details concerning the collection of these samples are found in Johnson (1995).

\section{Laboratory Methods}

\section{Sequential Extraction Procedure}

The sequential extraction procedure used in this project was based on one developed by Miller et al. (1986), and divides soil bound metals into eight fractions. A detailed outline of the procedure is found in Johnson (1995). Because of its operationally defined nature and the desire to have results that are comparable with the Johnson (1995) data set, the procedure was adopted with as few changes as possible. The technique is summarized as follows.

The procedure began by adding a known amount of soil (nominally $750-\mathrm{mg}$ ) and the first extraction reagent (DDI water) to a tared 50-ml polypropylene centrifuge tube. Four tubes were required for each soil sample, three replicates and one blank. The amount of reagent that was added to a tube is measured gravimetrically. After tumbling the tubes for the prescribed contact time, the tubes were centrifuged (30 -minutes at 10,000 RPM) to separate the soil from the extractant. The extractant was then transferred from the tubes to a polystyrene syringe, filtered through a disposable $0.45-\mu \mathrm{m}$ nylon syringe filter into a polyethylene sample bottle, acidified, and stored for future analysis. The soil in the centrifuge tube was then washed with about $20-\mathrm{ml}$ of wash solution (DDI water after the first extraction step and $0.0125 \mathrm{M}$ calcium nitrate solution after all other steps) to minimize carry over from entrained extractant and minimize any readsorption that may have taken place. The wash solution was removed and discarded by centrifuging the tubes and discarding the supernatant. At this point, 30-ml of the next extraction reagent is added to the tubes. This procedure was continued through step seven. The reagents and conditions involved in each of the extraction steps are summarized in Table 3.2. During the course of this project a series of informal shorthand codes, also in Table 3.2, were used to identify the different extraction steps. This convention for identifying the different extraction steps is retained throughout this report so that it is consistent with other documentation of the project (database tables, lab notebook entries, and sample IDs). 
Table 3.2. Description of sequential extraction procedure steps.

\begin{tabular}{|c|c|c|c|c|}
\hline Fraction & Reagent & Description & Extraction Conditions & Targeted Phase \\
\hline $\begin{array}{c}1 \\
\text { "DDI" }\end{array}$ & Distilled deionized water & & $\begin{array}{l}\text { Tumble for } 16 \text { hours } \\
\text { at room temperature }\end{array}$ & $\begin{array}{l}\text { easily soluble salts and ions already present in } \\
\text { the soil solution }\end{array}$ \\
\hline $\begin{array}{c}2 \\
2 \\
\text { "Salt" }\end{array}$ & $0.5 \mathrm{M}$ calcium nitrate & neutral salt & $\begin{array}{l}\text { Tumble for } 16 \text { hours } \\
\text { at room temperature }\end{array}$ & $\begin{array}{l}\text { Easily exchangeable } \\
\text { ions on soil surfaces }\end{array}$ \\
\hline "Ac" & $\begin{array}{l}0.44 \mathrm{M} \text { acetic acid } \& \\
0.1 \mathrm{M} \text { calcium nitrate }\end{array}$ & $\begin{array}{c}\text { weak acid w/ } \\
\text { nentral salt }\end{array}$ & $\begin{array}{l}\text { Tumble for } 8 \text { hours } \\
\text { at room temperature }\end{array}$ & $\begin{array}{c}\text { carbonate minerals, acid exchangeable metals } \\
\text { on the soil surfaces }\end{array}$ \\
\hline $\begin{array}{c}4 \\
\text { "HAHCl" }\end{array}$ & $\begin{array}{c}0.01 \mathrm{M} \text { hydroxylamine-hydrochloride } \\
\& \\
0.1 \mathrm{M} \text { nitric acid }\end{array}$ & $\begin{array}{l}\text { weak } \\
\text { reducing } \\
\text { agent }\end{array}$ & $\begin{array}{l}\text { Tumble for } 0.5 \text { hours } \\
\text { at room temperature }\end{array}$ & Manganese oxides \\
\hline $\begin{array}{l}5 \\
\text { "PP" }\end{array}$ & $0.1 \mathrm{M}$ sodium pyrophosphate & $\begin{array}{c}\text { complexing } \\
\text { agent }\end{array}$ & $\begin{array}{l}\text { Tumble } 24 \text { hours } \\
\text { at room temperature }\end{array}$ & Organic matter \\
\hline "AOD" & $\begin{array}{l}0.175 \mathrm{M} \text { ammonium oxalate \& } \\
0.1 \mathrm{M} \text { oxalic acid }\end{array}$ & $\begin{array}{l}\text { buffered mild } \\
\text { reducing } \\
\text { agent }\end{array}$ & $\begin{array}{l}\text { Tumble } 4 \text { hours } \\
\text { in darkness } \\
\text { at room temperature }\end{array}$ & Amorphous iron oxides \\
\hline " $\mathrm{7}$ " & $\begin{array}{c}0.15 \mathrm{M} \text { sodium citrate, } \\
0.05 \mathrm{M} \text { citric acid, \& } \\
25 \mathrm{~g} / \mathrm{L} \text { sodium dithionate }\end{array}$ & $\begin{array}{l}\text { buffered } \\
\text { strong } \\
\text { reducing } \\
\text { agent }\end{array}$ & $\begin{array}{l}\text { Shake for } 0.5 \text { hours } \\
\text { in water bath at } 50^{\circ} \mathrm{C}\end{array}$ & Crystalline iron oxides \\
\hline $\begin{array}{l}8 \\
\text { "HF" }\end{array}$ & $\begin{array}{l}48 \% \text { hydrofluoric acid \& } \\
\text { aqua regia }\end{array}$ & $\begin{array}{l}\text { Strong } \\
\text { corrosive }\end{array}$ & Microwave digestion & all remaining solids \\
\hline "TD" & $\begin{array}{l}48 \% \text { hydrofluoric acid \& } \\
\text { aqua regia }\end{array}$ & $\begin{array}{l}\text { Strong } \\
\text { corrosive }\end{array}$ & Microwave digestion & Total digestion of untreated soil \\
\hline
\end{tabular}

Note: Adapted from Miller et al. (1986) 
After the dithionate extraction step (the dissolution of oxides using dithionate and citric acid), the remaining solids were oven dried. A 200 -mg portion of the residual soil material was digested using 1-ml of aqua regia (a mixture of one part concentrated nitric acid and three parts concentrated hydrochloric acid) and 10-ml of concentrated hydrofluoric acid. Digestions were performed using a commercially available microwave digestion system (MDS-2000, CEM Corporation). The sample and acids were combined in a $100-\mathrm{ml}$ Teflon ${ }^{\oplus}$ reaction vessel, sealed, and heated in the microwave oven for 20 minutes at 200 psia and $150^{\circ} \mathrm{C}$. After the reaction vessels cooled and reached atmospheric pressure, the contents were filtered through a disposable $0.45-\mu \mathrm{m}$ nylon syringe filter, diluted up to $50-\mathrm{ml}$ in a volumetric flask, and transferred to a polyethylene sample bottle. Total elemental concentrations (total digestions) of metals in the soils were determined by subjecting untreated soil samples to the same procedure that was used to digest residual soil fractions.

The technique used to digest residual materials and untreated soil samples represents a divergence from the Johnson (1995) work. In that project, soils and residual material were digested using a Parr bomb in a convection oven instead of a microwave digestion system. The amounts of sample materials and digestion reagents were identical for both methods and digestion was essentially complete for both methods, so it is assumed that both methods produce the same results.

All solutions were prepared from at least ACS reagent grade chemicals except for the reagents used in the dithionate extraction step. The sodium dithionate employed for this step was described as a "purified grade". The mineral acids used in the procedure (nitric, hydrochloric, and hydrofluoric acids) were all suitable for trace metals work. Extraction reagents were prepared with deionized distilled (DDI) water that was obtained from the water deionizer located at L.G. Rich Labs in Clemson.

Because this project focused on the trace metal contents of SRS soils, measures were taken to reduce the likelihood of contamination. Volumetric flasks, centrifuge tubes, syringes, and any other glassware were soaked overnight in $0.1 \mathrm{~N}$ nitric acid and triple rinsed with DDI water before they were used. Clean labware was stored in plastic bags. 


\section{Additional Measurements of Soil Properties}

In an effort to identify similarities and differences between the soil samples, general soil property measurements were also made. These include soil pH, texture, color, cation exchange capacity, and carbon content

\section{$\underline{\text { Soil pH}}$}

Soil pH measurements were based on EPA method 9045 (US EPA, 1986). This method involved using a $\mathrm{pH}$ meter to measure the $\mathrm{pH}$ of a 1:1 suspension of soil and DDI water that had been thoroughly mixed and allowed to stand for about one hour.

\section{Soil Texture}

Soil texture measurements were based on the pipette method described in Gee and Bauder (1986). A known quantity of soil was tumbled overnight in a dispersant of hexametaphosphate (HMP). The silt and clay fractions were separated from the sand fraction by passing the suspension through a 53- $\mu \mathrm{m}$ sieve. The remaining sand fraction was dried overnight $\left(105^{\circ} \mathrm{C}\right)$ and weighed, while the suspension of silt $(2-53 \mu \mathrm{m})$ and clay particles $(<2 \mu \mathrm{m})$ was transferred to a 1-L graduated cylinder. The silt and clay fractions of the soil were estimated by measuring the decrease in solids content over time of the suspension sampled $10 \mathrm{~cm}$ below the water surface. Stoke's law was used to estimate the amount of silt and clay based on the different settling velocities of different sized particles.

As with most soil tests, soil texture measurements are operationally defined. Soil particles are sometimes cemented together by iron oxide or organic matter to form aggregates. The degree to which the cementing agents are destroyed and the soil is broken down into primary particles affects particle size distribution measurements. Gee and Bauder (1996) describe pretreatment steps that can be used to remove any cementing material; however, this project measures soil texture without any pretreatment of the soil samples.

\section{$\underline{\text { Soil Color }}$}

Soil color was described at field moisture conditions using the Munsell color notation (Munsell Color Co., 1975). Soils are matched with paint chips of standard colors and evaluated with respect to three 
variables: hue, value, and chroma. For example, a soil with a Munsell notation of 10YR 6/4 has a hue of $10 \mathrm{YR}$, a value of 6 , and a chroma of 4 .

\section{Cation Exchange Capacity}

The method described by Rhoades (1982) for measurement in acid soils was used to estimate CEC of the soils. The method involves: (1) saturating the soil with $\mathrm{Ba}^{+2}$ cations, (2) equilibrating the soil with a solution containing 0.1 meq of $\mathrm{Mg}^{+2}$, and (3) removing the supernatant and measuring the amount of magnesium that is removed from solution and absorbed onto the soil. The $\mathrm{Mg}^{+2}$ concentration in the supernatant solutions is measured using a flame atomic absorption spectrophotometer.

\section{Total Carbon Content}

The carbon contents of the background soils were measured using a commercially available carbon analyzer (TOC-5000, Shimadzu Corporation) with a solids sampling module. A known amount of soil (approximately $1500-\mathrm{mg}$ ) was placed into a ceramic sampling boat and loaded into a $900^{\circ} \mathrm{C}$ furnace in the presence of a stream of high purity oxygen. The $\mathrm{CO}_{2}$ evolved from the soil during oxidation is carried through a flow cell and measured by the amount infra-red light absorbed by the molecules. The integrated area underneath the absorption peak is linearly related to the amount of carbon in the sample. The instrument was calibrated by loading sample boats with known amounts of carbon (in the form of fructose) (Shimadzu Corporation, 1993).

\section{Instrumental Analysis of Soil Extracts}

Trace metal contents of extracts generated from the sequential extraction procedure were determined with a commercially available inductively coupled plasma-mass spectrometer (ICP-MS) (VG PlasmaQuad PQ2S, Fisons Corp.). The basic principals of an ICP-MS can be described by dividing the system into two parts; signal generation and signal detection. Figure 3.3 is a diagram showing components of the ICP-MS. 


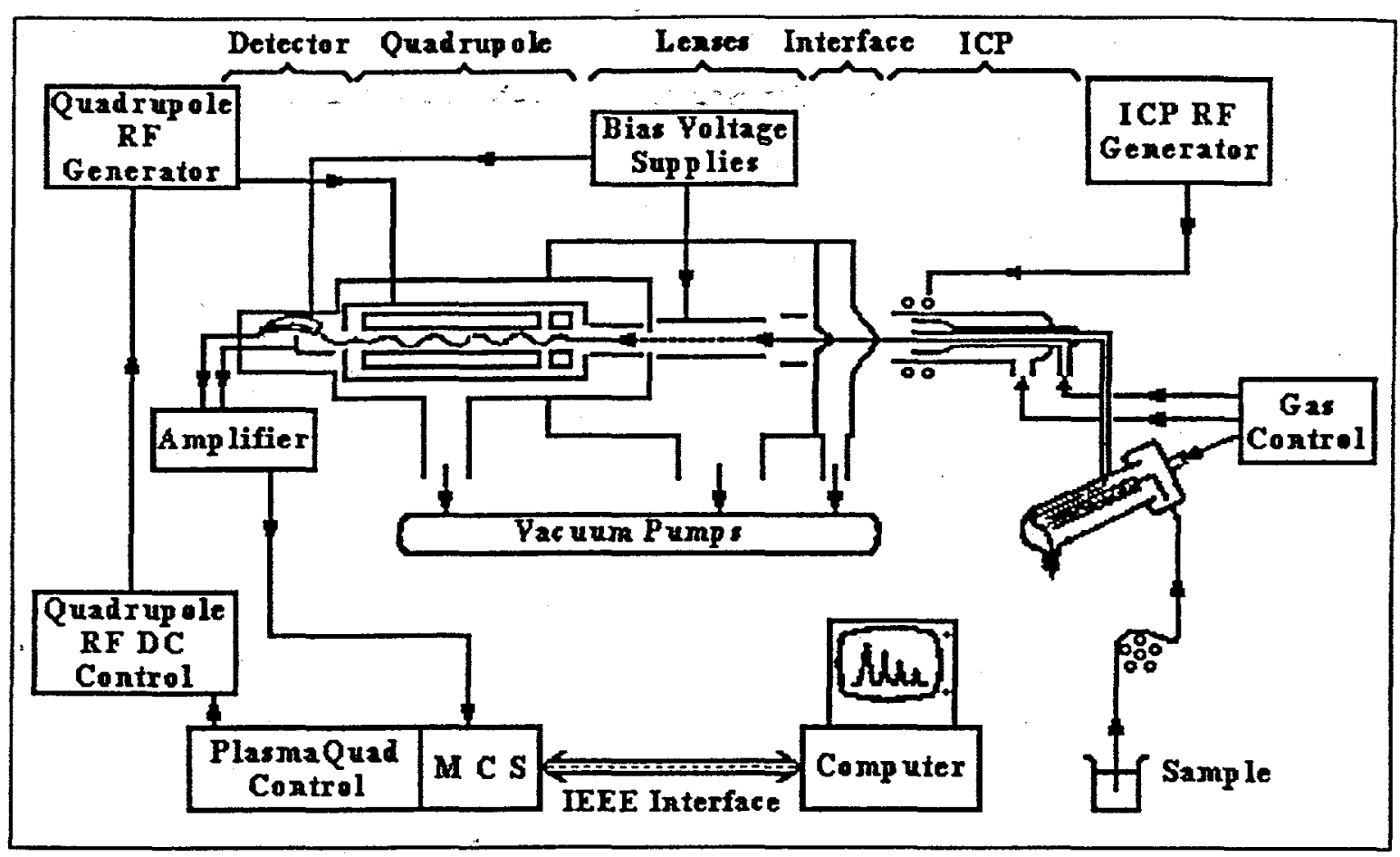

Figure 3.3. Schematic of an inductively coupled plasma-mass spectrometer (ICP-MS). Used with permission from VG Elemental (1988).

The signal generation part of the ICP-MS begins when the aqueous sample is pumped to a Meinhardt nebulizer and aspirated into a fine aerosol. A stream of argon gas carries the smallest aerosol drops through a double-pass Scott spray chamber and into an inductively coupled argon plasma torch. The plasma source consists of ionized argon atoms and free electrons with temperatures that may exceed 8,000 K (Johnson, 1995). As the aerosol is introduced into the torch, the sample is quickly desolvated, atomized, and, finally, atoms are stripped of one or more electrons and turned into ions. The metal ions generated by the plasma torch serve as the signal for the instrument.

The plasma (which operates at atmospheric pressure) is sampled and ions are introduced into a vacuum chamber containing a quadrupole mass spectrometer. As the ions move from the plasma into the vacuum chamber they gain kinetic energy and are projected through focussing, lenses to create an ion beam. The quadrupole filters the ion beam based on the mass charge ratio ( $m / z$ value) of the ions. At any one time only cations with a certain $\mathrm{m} / \mathrm{z}$ are permitted to reach the detector.

Computer control of the quadrupole and the signal processing electronics allows the instrument to quickly sweep through $\mathrm{m} / \mathrm{z}$ values between 5 and 250 and count the number of ions that reach the detector 
at each $m / z$ value. The ICP-MS creates a mass spectnum of the sample showing the mass/charge ratio along the $x$-axis and the number of counts or count rate of ions on the $y$-axis. Because most ions are singly charged, the $\mathrm{x}$-axis of a mass spectrum can also be presented in units of atomic mass units (amu). Elements appear on the spectra as a series of peaks for each of the isotopes that are in that element. Figure 4.20, presented later in this text, illustrates what a mass spectnum looks like.

ICP-MS is not an interference free technique. The potential interferences and features of a mass spectrum that must be considered include:

- isobaric interferences - isotopes of different elements that have the same nominal mass and combine to form a single peak

- polyatomic ions - the relative amounts of ions such as $\mathrm{ArCl}^{+}, \mathrm{NO}^{+}, \mathrm{SO}_{2}^{+}$, and $\mathrm{CO}_{2}^{+}$depend, in part on the composition of the sample.

- xenon and krypton impurities in the argon gas supply

- doubly charged ions - elements with low ionization potentials, such as barium, can form doubly charged ions.

- metal oxide and hydroxide ions the relative amounts of ions such as $\mathrm{NaO}^{+}$and $\mathrm{CaOH}^{+}$ depend on the sample matrix.

Interferences can be minimized by examining the spectra of method blanks and selecting isotope peaks for an element that are not coincident with any interference peaks. Quantitative analysis is possible with an ICP-MS because the count rate measured at an isotope peak is directly proportional to the concentration of that isotope in the sample or standard. To compensate for subtle drifts in instrument sensitively, samples and standards are spiked with internal standards of known concentrations and the instrument response is normalized to the intensity of the internal standard signal. Because the instrument detects individual analyte ions as they collide with the detector, it is capable of multi-element analysis of aqueous samples at concentrations less than one part-per-billion. Figure 3.4 presents the mass spectrums of five calibration standards between zero and one part per billion uranium and illustrates the sensitivity of this instrument to trace amounts of metals. 




Figure 3.4. Mass spectra for uranium calibration standards between zero and one part-per-billion.

For this project, an ICP-MS was used to measure the concentration of 23 elements, listed in Table 3.3, in the samples generated from the sequential extraction procedure. The methods used to analyze the samples were adapted from EPA Method 6020 (US EPA, 1994) and users manuals supplied with the instrument (Fisons, 1992). Typical operating conditions for the instrument are presented in Table 3.4. The ICP-MS does not tolerate samples with high concentrations of dissolved solids and it was necessary to dilute many of the samples before they could be analyzed. The dilution factors that were used to analyze the different extractants are presented in Table 3.5. Extraction method blanks were diluted by the same amount as the samples. All standards and samples were prepared with an intemal standard of 100 part-perbillion beryllium, gadolinium, indium, and thallium. 
Table 3.3. Analytes determined by ICP-MS.

\begin{tabular}{|l|ll|}
\hline Common Soil Elements: & $\begin{array}{l}\text { Iron } \\
\text { Aluminum }\end{array}$ & $\begin{array}{l}\text { Manganese } \\
\text { Titanium }\end{array}$ \\
\hline RCRA Metals: & Arsenic & Lead \\
(40 CFR 261.24) & Barium & Selenium \\
& Cadmium & Silver \\
& Chromium & \\
\hline Other Trace Elements: & Cesium & Strontium \\
& Cerium & Thorium \\
& Cobalt & Uranium \\
& Copper & Yttrium \\
& Nickel & Zinc \\
& Rubidium & Zirconium \\
\hline
\end{tabular}

Table 3.4. Typical ICP-MS operating conditions.

\begin{tabular}{|l|l|}
\hline RF Power to the Plasma & 1350 Watts \\
\hline Gas Flow Rates & $10 \mathrm{~L} / \mathrm{min}$ \\
Coolant & $0.8 \mathrm{~L} / \mathrm{min}$ \\
Auxiliary & $0.8 \mathrm{~L} / \mathrm{min}$ \\
Nebulizer & $0.5 \mathrm{ml} / \mathrm{min}$ \\
\hline Uptake Rate & Meinhardt "K" nebulizer \\
\hline Nebulizer & $60 \mathrm{sec}$ \\
\hline Acquisition time & 19 \\
\hline Channels/amu & 10.24 ms \\
\hline Dwell time per channel & 3 \\
\hline Replicates per sample & $10 \mathrm{ppb}$ solution of Indium \\
\hline Instrument Sensitivity & sroduces a $150,000 \mathrm{cps}$ \\
& signal at mass 115 \\
\hline
\end{tabular}

Table 3.5. Dilution factors used for analyzing samples.

\begin{tabular}{|c|c|}
\hline Extraction Step & Dilution Factor \\
\hline DDI & 1.02 \\
\hline Salt & 50 \\
\hline Ac & 10 \\
\hline HAHCl & 1.02 \\
\hline PP & 10 \\
\hline AOD & 10 \\
\hline DC & 50 \\
\hline HF and TD & 15 \\
\hline
\end{tabular}


Calibration standards were prepared from commercially available $1000 \mu \mathrm{g} / \mathrm{ml}$ single-element standards (High Purity Standards). The instrument was calibrated using a five-point calibration curve, with calibration points equally spaced between the calibration blank the highest calibration standard. The concentration of the highest standard depended on the element and type of extract that was analyzed. Calibration ranges were determined by selecting a small subset of samples and estimating the highest concentrations that were likely to be encountered. There were a few instances where the concentration of an analyte in a sample exceeded that of the highest calibration standard. However, in all of these cases the signal was within the linear range of the instrument.

After the instrument was calibrated, 10-15 samples were analyzed, followed by a check standard and blank to check the calibration. The instrument was rinsed with 1 percent nitric acid for $60 \mathrm{sec}$ (or until the Indium-115 signal returned to baseline) between each standard and sample. Samples were analyzed in a random sequence to control for bias due to instrument drift over time. Results were calculated by subtracting the average analyte concentration measured in the method blanks from the average concentration measured in the sample. Blank subtraction was necessary for two reasons. The first reason is that it corrected for interferences due to impurities and isobaric interferences from the extraction reagents. For example, the calcium nitrate used in the second and third extraction step contained measurable amounts of strontium as impurities. Also, the carbon present in the acetic acid and oxalic acid in the third and sixth extraction steps created a isobaric interference with chromium signal $\left({ }^{52} \mathrm{Cr}\right.$ and ${ }^{40} \mathrm{Ar}^{12} \mathrm{C}^{+}$have the same nominal mass). Subtracting the signal measured in the method blank corrects for these sorts of biases. The second reason for blank subtraction is that the manufacturer of the instrument recognized that the instrument response is based on counting statistics and attempted to take this into consideration by weighting each calibration point based on the number of counts observed. High standards had a greater influence on the slope and intercept of the calibration curve than the low standards and blanks. Consequently, baselines were often not accurate. Subtracting the effective concentration of the method blank (sometimes a negative number) corrected instances where the baseline signal was inaccurate. The standard deviation of a result was estimated by propagating the standard deviations of the method blanks and the sample. 
An inductively coupled plasma-emission spectrometer (Thermo-Jarrell-Ash POEMS/IRIS ICP Spectrometer) was used to measure the concentrations of aluminum, iron, and titanium in the HF, TD, DC, $\mathrm{AOD}, \mathrm{PP}$, and $\mathrm{HAHCl}$ extraction steps. This instrument was used for measuring the concentration of these elements because their signals from the ICP-MS often exceeded the linear range of the instrument at dilutions that were necessary for trace element measurement (dead time in the counting electronics limits the linear range of the ICP-MS). Although two or three emission lines each were monitored for iron and aluminum, the $309.2 \mathrm{~nm}$ line for aluminum and the $259.9 \mathrm{~nm}$ line for iron exhibited the least amount of drift and resulted in lower variation in method blank responses. Results are derived from these emission lines. The three titanium emission lines that were monitored (323.4 nm, $334.9 \mathrm{~nm}$, and $337.2 \mathrm{~nm}$ ) displayed the same amount of drift and variability, so the sample results are the average of the three values. After 10-15 samples were analyzed, standards were run to check for instrument drift. Four replicate measurements were made for each sample and the intensities of emissions were integrated over ten seconds for each replicate.

Detection limits for the instruments were estimated by using a method described by Kirchmer (1988) based on the variability of the method blank responses. Minimum detection limits (MDLs), for this project are defined as $4.65 \times \mathrm{s}_{\mathrm{B}}$, where $\mathrm{s}_{\mathrm{B}}$ is the standard deviation of responses observed in the method blanks. This approach assumes: (1) that the standard deviation of method blank responses and the standard deviation of responses from samples that have analyte concentrations that are near the detection limit are equal (i.e. $\sigma_{\mathrm{B}}=\sigma_{\mathrm{S}}$ ), and (2) that method blank and sample responses follow a normal distribution. Because the results are calculated by blank subtraction, the results that would be observed from a sample without any analyte will be normally distributed around a mean value of $0 \mathrm{ppb}$ with a standard deviation of:

$$
\sigma_{R}=\sqrt{\sigma_{B}^{2}+\sigma_{S}^{2}}=\sqrt{2} \times \sigma_{B} \approx 1.41 \times \sigma_{B}
$$

Setting the minimum detection limit to 4.65 method blank standard deviations reduces the chances of a type II error (a false negative - concluding that the analyte is not present in the sample, when it is) to $5 \%$ ( 1 in 20). At this level, the probability of committing a type I error (a false positive - concluding that the analyte is present in the sample, when it is not) is less than 2 in one million. 
CHAPTER 4

\section{RESULTS AND DISCUSSION}

Presented in this chapter are the results of the laboratory work done for this study and a discussion of the results with respect to the two objectives of this project. The first section contains a description of the general soil properties of the soil samples and highlights differences among the background soils. This is followed by a section that contains the results of the sequential extraction procedure for each of the different elements. The final section contains a discussion of differences that were observed between the elements, differences between background and waste site soils, and modifications to the sequential extraction procedure.

\section{General Soil Properties}

Presented in Table 4.1 are the measured $\mathrm{pH}$, total carbon, soil color, soil texture, cation exchange capacity (CEC) and total iron and aluminum concentrations for the background and waste site soil samples. The data for the background soils are the result of laboratory work done for this study, while the general properties of the waste site soil samples have been described elsewhere (Johnson, 1995 and WSRC, 1996c.).

All of the soils examined for this study were acidic, consistent with soils found throughout the Atlantic coastal plain. The pHs of the background soils were similar, with all the measurements falling between 5.1 and 5.6. The four CMP pit soil samples had $\mathrm{pH}$ measurements between 4.5 and 5.4. The samples collected from beneath the F-Area Seepage Basin had $\mathrm{pH}$ values that were consistent with soil/groundwater systems that were used for the disposal of acidic wastewater, with $\mathrm{pH}$ values between 3.1 and 3.6.

All of the soil samples examined in this project contained total carbon contents below 0.5 percent, consistent with subsurface (greater than one foot in depth) horizons found on the site. All the background soil samples, except Orangeburg \#10, were below the detection limit $(<0.1$ percent) of the method used to analyze them. 
Table 4.1. General properties of soil samples.

\begin{tabular}{|c|c|c|c|c|c|c|c|c|}
\hline \multirow[b]{2}{*}{$\begin{array}{l}\text { Background Soil } \\
\text { Samples }\end{array}$} & \multirow[b]{2}{*}{$\mathrm{pH}$} & \multirow{2}{*}{$\begin{array}{c}\text { Total } \\
\text { Carbon } \\
\text { (percent) }\end{array}$} & \multirow[b]{2}{*}{$\begin{array}{l}\text { Soil } \\
\text { Color }\end{array}$} & \multicolumn{2}{|c|}{ Texture } & \multirow[b]{2}{*}{$\begin{array}{c}\text { CEC } \\
\text { (meg/100g-soil) }\end{array}$} & \multirow{2}{*}{$\begin{array}{l}\text { Total } \\
\text { Aluminum } \\
\text { (mg/kg) }\end{array}$} & \multirow[b]{2}{*}{$\begin{array}{l}\text { Total Iron } \\
(\mathrm{mg} / \mathrm{kg})\end{array}$} \\
\hline & & & & $\begin{array}{c}\text { Sand/Silt/Clay } \\
\text { (Percent) }\end{array}$ & USDA Classification & & & \\
\hline Orangeburg \#10 & 5.39 & 0.10 & $10 \mathrm{YR} 6 / 8$ & $68 / 8 / 24$ & Sandy Clay Loam & $2.1 \pm 0.05$ & $47,123 \pm 368$ & $14,663 \pm 296$ \\
\hline Orangeburg \#46 & 5.60 & $<0.1$ & 2.5 YR 4/8 & $76 / 8 / 16$ & Sandy Loam & $1.7 \pm 0.11$ & $28,193 \pm 1,966$ & $9,045 \pm 1,093$ \\
\hline Fuquay \#8 & 5.39 & $<0.1$ & 7.5 YR $6 / 8$ & $80 / 8 / 13$ & Sandy Loam & $1.1 \pm 0.42$ & $27,705 \pm 629$ & $10,802 \pm 825$ \\
\hline Fuquay \#42 & 5.29 & $<0.1$ & $7.5 \mathrm{YR} 7 / 0$ & $76 / 7 / 18$ & Sandy Loam & $2.0 \pm 0.05$ & $30,655 \pm 594$ & $6,270 \pm 804$ \\
\hline ESE \#1 & 5.28 & $<0.1$ & 7.5 YR $6 / 8$ & $81 / 6 / 13$ & Sandy Loam & $1.1 \pm 0.10$ & $25,269 \pm 842$ & $9,170 \pm 537$ \\
\hline Vaucluse \#12 & 5.18 & $<0.1$ & 7.5 YR $8 / 4$ & $96 / 3 / 1$ & Sand & $0.3 \pm 0.10$ & $3,401 \pm 344$ & $2,043 \pm 223$ \\
\hline Blanton \#35 & 5.13 & $<0.1$ & $10 \mathrm{YR} 7 / 6$ & $92 / 6 / 2$ & Sand & $0.5 \pm 0.31$ & $5,156 \pm 216$ & $2,484 \pm 268$ \\
\hline Blanton \#45 & 5.21 & $<0.1$ & $10 \mathrm{YR} 7 / 6$ & $92 / 6 / 2$ & Sand & $0.4 \pm 0.20$ & $5,065 \pm 54$ & $1,805 \pm 210$ \\
\hline Lakeland \#41 & 5.11 & $<0.1$ & 7.5 YR $5 / 6$ & $90 / 6 / 4$ & Sand & $0.4 \pm 0.43$ & $7,364 \pm 176$ & $2,631 \pm 161$ \\
\hline Lakeland \#2 & 5.06 & $<0.1$ & $7.5 \mathrm{YR} 6 / 6$ & $88 / 6 / 6$ & Loamy Sand & $0.5 \pm 0.21$ & $11,575 \pm 1,816$ & $4,171 \pm 705$ \\
\hline \multicolumn{9}{|l|}{$\begin{array}{l}\text { Lakeland \#2 } \\
\text { CMP Pit Samples } \\
\end{array}$} \\
\hline $2 A$ & 4.95 & 0.10 & N/A & $61 / 10 / 29$ & Sandy Clay Loam & 2.7 & $70,265 \pm 3,205$ & $19,727 \pm 1,501$ \\
\hline $2 \mathrm{E}$ & 5.01 & 0.01 & N/A & $67 / 7 / 26$ & Sandy Clay Loam & 2.4 & $60,292 \pm 2,865$ & $10,871 \pm 695$ \\
\hline $3 \mathrm{~A}$ & 5.38 & 0.37 & N/A & $76 / 9 / 14$ & Sandy Loam & 4.1 & $40,079 \pm 295$ & $11,716 \pm 553$ \\
\hline $5 \mathrm{~A}$ & 4.49 & 0.29 & N/A & $81 / 7 / 12$ & Loamy Sand & 2.4 & $29,915 \pm 1,589$ & $10,976 \pm 1,223$ \\
\hline \multicolumn{9}{|l|}{$\begin{array}{l}\text { FA } \\
\text { F- Area Seepage } \\
\text { Basin Samples }\end{array}$} \\
\hline $\mathrm{A} 13 \mathrm{R}$ & 3.63 & 0.05 & N/A & $94 / 3 / 3$ & Sand & $0.37 \pm 0.02$ & $10,294 \pm 1,042$ & $23,666 \pm 1,276$ \\
\hline A22 & 3.30 & N/A & N/A & $96 / 3 / 1$ & Sand & $0.14 \pm 0.02$ & $11,723 \pm 548$ & $22,096 \pm 543$ \\
\hline A23 & 3.15 & 0.08 & N/A & $95 / 0 / 5$ & Sand & $0.14 \pm 0.02$ & $12,364 \pm 485$ & $14,052 \pm 390$ \\
\hline A31 & 3.39 & 0.09 & $\mathrm{~N} / \mathrm{A}$ & $96 / 0 / 4$ & Sand & $0.79 \pm 0.02$ & $53,558 \pm 2,425$ & $38,956 \pm 2,204$ \\
\hline $\mathrm{A} 32$ & 3.14 & 0.10 & N/A & $90 / 8 / 3$ & Sand & $<0.1$ & $11,450 \pm 1,138$ & $17,125 \pm 1,058$ \\
\hline
\end{tabular}

Note: Except for soil texture measurements, CMP Pit data are from WSRC (1997c). F-Area Seepage Basin data are from Johnson (1995) 
The soil samples show consistent differences in texture, $\mathrm{CEC}$, and total iron and aluminum concentrations. Sand sized particles make up the bulk (by wieght) of all the samples. However, five of the soil samples, (the Orangeburg and Fuquay soils, and ESE\#1) contain higher proportions of clay than the other five background samples (the Lakeland, Vaucluse, and Blanton samples). These textural differences can also be seen when looking at the USDA texture classification of the samples. The five soils with higher clay contents are sandy loams or sandy clay loams, while the other five soils are sands or loamy sands. The samples collected from the F-Area Seepage Basin are predominately sand.

As expected, the differences between the soil samples with respect to clay content can be extended to the CEC of the soils. The loamy background soil samples have CECs between 1 and 2 meq/100g-soil and the CMP pit samples have values that are between 2 and 4 meq/100g-soil. These values are slightly higher than the CEC measured in the sandy background soils. The F-Area samples have CECs below 1 meg/ $100 \mathrm{~g}$-soil - consistent with the low clay content of these materials. All of the CEC values are within the range expected from sandy/loamy mineral soils that have kaolinite as the dominant clay mineral (Brady, 1974). Kaolinite has a characteristically low cation exchange capacity, between 3 and 7 meq/100g-clay (Langmuir, 1997).

The relationship between clay content of the soils and total iron and aluminum is demonstrated in Figure 4.1. The soil samples with high clay contents tended to have higher total concentrations of iron and aluminum $\left(R^{2}=0.98\right.$ for aluminum and $R^{2}=0.83$ for iron).



Figure 4.1. Correlation of total soil iron and aluminum with the clay contents of background and CMP Pit soils. 
The Munsell notation for describing soil color does not adequately convey the color of the soils to people who do not work with the notation on a regular basis. In general, all the samples had a similar color except for Orangeburg \#46, which exhibited a stronger reddish hue. Fuquay \#8, Fuquay \#42 and ESE\#1 had nodules and aggregates that were slightly darker and redder than the bulk soil.

\section{Sequential Extraction Profiles}

Individual sequential extraction results are presented as tables in Appendix A. These tables contain the amount of metal released during each of the extraction steps, the cumulative amount released across all extraction steps (labeled as "Sum"), and the results of the total digestions that were performed independently of the sequential extraction procedure. Percent recovery was calculated as the ratio of the sum across all extraction steps and the total digestion results. In the text, results are represented graphically by taking average values of the three replicates of a soil sample. The results are presented graphically two different ways. One approach to presenting the information involves displaying the results as a stacked bar graph, with the average amount of metal released during each extraction step represented by a different block on a column. This type of presentation of the results is concise and simplifies comparisons between different soils or metals. The drawback to this approach is that it masks the variability associated with each extraction step. An alternative approach is to present the results of a single extraction profile on one graph, with each extraction step as a separate column. With this approach, error bars with the standard deviations associated with each value can be added to the graph. This conveys some sense of the uncertainty behind each value. Both styles of graphically presenting the data are used throughout the text depending on the purpose of the figure.

Another way of presenting sequential extraction information is to normalize the amount of a trace metal released during each extraction step to the total trace metal content of the soil sample. The amount of metal removed during exaction step is presented as a fraction or percentage of total rather than in concentration units (such as $\mathrm{mg} / \mathrm{kg}$ ). Figure 4-23, found later in the text, is an example of this way of presenting sequential extraction results.

Johnson (1995) identified several problems when he used the sequential extraction technique on the F- and H-Area Seepage Basin soils. These problems included contamination from impurities in the extraction reagents, ICP-MS interferences, and problems with not being able to settle colloidal particles. 
All of these problems apply to the sequential extraction of the soils during this study. Other problems, which were not mentioned in Johnson (1995), are also worth noting.

The extracts generated from the pyrophosphate and dithionate steps of the sequential extraction procedure were not stable over time. After approximately two weeks, a precipitate formed in all of the pyrophosphate and dithionate sample bottles from soils (precipitate was not observed in the method blanks). Adding small amounts of concentrated nitric acid did not redissolve the precipitates. The nature of the precipitates from the pyrophosphate step is not known, but they may be phosphate salts. The pyrophosphate ligand used to extract metals during the pyrophosphate extraction step is metastable in solution and undergoes a slow hydrolysis reaction (Lindsay, 1979):

$$
\mathrm{H}_{2} \mathrm{P}_{2} \mathrm{O}_{7}^{-2}+\mathrm{H}_{2} \mathrm{O} \rightarrow 2 \mathrm{H}_{2} \mathrm{PO}_{4}^{-}
$$

The concentration of pyrophosphate in the extraction reagent was $0.1 \mathrm{M}$, so the total concentration of phosphate ions could be as high as $0.2 \mathrm{M}$. It is possible that, as the pyrophosphate ions hydrolyzed, the solution became oversaturated with respect to phosphate salts. The precipitates from the dithionate extraction step are likely to be elemental sulfur or pyrite (FeS). Mehra and Jackson (1960) note that the precipitation of these materials is promoted at $\mathrm{pH}$ values below 6 (a situation that occurs when the extracts are acidified with $0.1 \mathrm{ml}$ of concentrated nitric acid). Such problems can be avoided by reducing the holding time between sample generation and sample analysis.

The other problem was that calcium from the rinse solution is incompatible with the oxalic acid used during the AOD extraction step. Calcium oxalate is a relatively insoluble salt and a precipitate formed instantly when the AOD reagent mixed with the calcium nitrate rinse solution that is entrained in the soils from the previous extraction step.

Unstable extractants and incompatibilities between extraction reagents can cause a problem because of coprecipitation of trace metals along with the bulk reactants. This represents a potential removal pathway of trace metals from the system and can lead to underestimates of the amount of trace metals removed during the extraction steps.

\section{Major Soil Components}

Presented in this section are the results of the sequential extraction procedure for the major elements present in the soils: iron, aluminum, titanium, and manganese. Results from the background and CMP Pit 
soil samples are presented for all of the major soil components. Only the aluminum results are presented from the F-Area Seepage Basin samples.

Iron

The results of the sequential extraction procedure for iron from the background and CMP pit soil samples are presented in the appendix as Tables A.1 and A.2 and are summarized in Figure 4.2. As shown, the bulk of the iron was released during the final two extraction steps (DC and HF) with detectable amounts present in the $\mathrm{HAHCl}, \mathrm{PP}$, and $\mathrm{AOD}$ extraction steps. Iron was not detected in the DDI, Ac, and Salt extraction steps from the background soil samples. The amount of iron recovered from all extraction steps fell between 71 and 110 percent of the iron measured during the total digestion, with an average recovery of 90 percent. This suggests that iron was conserved during the sequential extraction procedure.

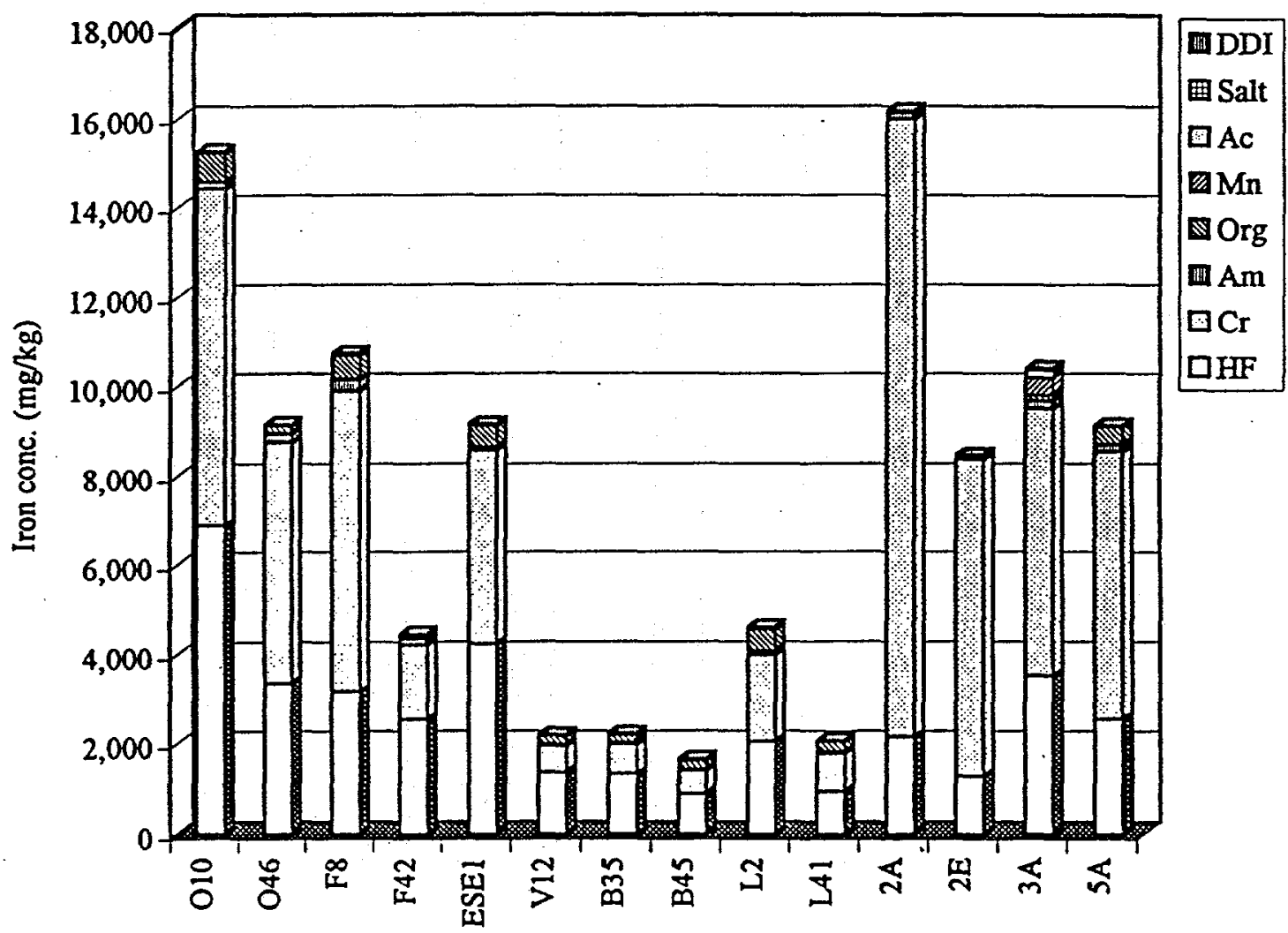

Figure 4.2. Sequential extraction of iron from background and CMP pit soils. 
The DC extraction step targets crystalline iron oxides such as geothite and hematite that are present in the soil. Consequently, the iron released during this step is likely derived from these minerals. It is not known if the iron released during the last extraction step (the HF step - digestion of residual materials using HF and aqua regia) originates from clay minerals or from iron oxides that were not completely dissolved during the previous extraction steps. In most cases the soil had a bleached white color following the dithionate/citrate extraction step (DC), indicating that most of the iron oxide layer was removed. However, Johnson (1995) identified incomplete dissolution of iron oxides during the DC extraction step as a limitation of the sequential extraction procedure.

The iron released during the hydroxlyamine hydrochloride (HAHCl) extraction step generally represented less than 1 percent of the total iron measured across all steps. This suggests that the HAHCl extraction step does not remove much of the free iron oxides present in the soil. The origin of the iron released during this step is not known. It may have originated from iron coprecipiated with the targeted mineral phase $\left(\mathrm{MnO}_{2}\right)$, unintended dissolution of iron oxide/hydroxide minerals, or both.

The amount of iron released during the $\mathrm{PP}$ and AOD steps was higher than the $\mathrm{HAHCl}$ step and lower than the DC step. The amount of iron released during the PP extraction step generally made up 1 to 10 percent of iron measured across all extraction steps, while iron removed during the AOD step falls below 5 percent. Eight of the background soils had higher amounts of iron released during the PP than the AOD step. Given that all of the soil examined in this study contained negligible amounts of organic matter, it is unlikely that the iron released from the soil during the PP extraction step originated from iron-organic matter associations. The source of the iron released during the PP extraction step is not known. However, if iron removed during this step originated from crystalline or amorphous iron oxides, then the extraction procedure, in its current form, is not able to selectively dissolve the different iron minerals in soils.

In an attempt to determine the controlling mineral phases in SRS soils, a rough calculation was performed to estimate the number of reactive hydrous ferric oxide (HFO) (another term for amorphous iron oxides) binding sites in the background soils. The upper bounds of the HFO binding sites was estimated by making a calculation based on the clay contents of the soils. For these calculations, it was assumed that the clay fraction of the soil is composed entirely of kaolinite and that a monolayer of HFO coats the entire clay 
fraction. Specific surface areas and other constants were taken from Dzombak and Morel (1990) and Sposito (1989) and are presented as follows:

$S_{\mathrm{A}, \text { bool }}=$ specific surface area for kaolinite $=18 \mathrm{~m}^{2} / \mathrm{g}$ (Sposito, 1989)

$S_{\mathrm{A}, \mathrm{HFO}}=$ specific surface area for $\mathrm{HFO}=600 \mathrm{~m}^{2} / \mathrm{g}$ (Dzombak and Morel, 1990)

$\mathrm{FW}_{\mathrm{HFO}}=$ formula weight of $\mathrm{HFO}=89 \mathrm{~g}-\mathrm{HFO} / \mathrm{mol}-\mathrm{Fe}$ (Dzombak and Morel, 1990)

$\mathrm{N}_{\mathrm{S} 2}=\mathrm{HFO}$ site density $=0.2 \mathrm{~mol}-\mathrm{sites} / \mathrm{mol}-\mathrm{Fe}$ (Dzombak and Morel, 1990).

HFO binding site density was estimated using the equation:

$$
N_{\text {HFO }}=\frac{C F \times S A_{\text {kaol }} \times N_{s 2} \times 10^{6}}{S A_{\text {HFO }} \times F W_{H F O}}
$$

where:

$\mathrm{CF}=$ soil clay fraction $(\mathrm{g}$-clay/g-soil),

$\mathrm{N}_{\mathrm{FFO}}=$ binding site concentration in soil (mmol/kg-soil).

HFO binding site estimates were also made using results from the sequential extraction procedure.

The amount of amorphous iron oxide present in the soils can be estimated by combining iron released during the $\mathrm{HAHCl}, \mathrm{PP}$, and $\mathrm{AOD}$ extraction steps. This assumption is represented by the equation:

$$
\sum_{i=4(\mathrm{HAHCl})}^{6(\mathrm{AOD})} \mathrm{C}_{\mathrm{i}, \mathrm{Fe}}=\mathrm{C}_{\mathrm{Fe}, \mathrm{HFO}}
$$

where:

$\mathrm{C}_{\mathrm{Fo}}=$ iron removed during extraction step $i$,

$\mathrm{C}_{\mathrm{HFO}, \mathrm{Fe}}=$ iron present as hydrous ferric oxide.

Results were calculated by the equation:

$$
N_{H F O}=\frac{\sum_{i=H A H C l}^{A O D} C_{i, F e} \times N_{s 2}}{M W}
$$

where:

$\mathrm{MW}=$ molar weight of iron $=55.84 \mathrm{~g} / \mathrm{mol}$.

The two different approaches to estimating HFO binding site concentrations are compared in Table 4.2 for all of the background soil samples. As shown, the calculations that estimate binding site 
concentrations based on the sequential extraction results do not exceed the upper bounds set by the calculations based on clay-content of the soils. The two approaches yield similar results for the Blanton, Lakeland and Vaucluse soil samples in particular. This information suggests that, provided the assumptions are valid, the sequential extraction results may provide an estimate of the amount of HFO present in soils.

Table 4.2. Estimates of HFO binding site concentrations in SRS background soils.

\begin{tabular}{|c|c|c|c|c|c|c|c|c|}
\hline \multirow[b]{2}{*}{$\begin{array}{l}\text { Background } \\
\text { Soil Sample ID }\end{array}$} & \multirow[b]{2}{*}{$\begin{array}{c}\text { Clay } \\
\text { Content }\end{array}$} & \multicolumn{4}{|c|}{ Extraction Step (mg/kg) } & \multicolumn{2}{|c|}{ mmoles of HFO sites $/ \mathrm{kg}$ soil } & \multirow{2}{*}{$\begin{array}{l}\text { Percent S.E. } \\
\text { of Clay } \\
\text { Estimate }\end{array}$} \\
\hline & & $\mathrm{HAHCl}$ & PP & AOD & Sum & $\begin{array}{l}\text { Estimated By } \\
\text { S.E. Results }\end{array}$ & $\begin{array}{l}\text { Estimated by clay } \\
\text { content of soil }\end{array}$ & \\
\hline $\begin{array}{c}\text { Orangeburg } \\
\# 10\end{array}$ & $24.0 \%$ & $\begin{array}{c}11 \\
7 \\
6\end{array}$ & \begin{tabular}{l|}
605 \\
593 \\
733
\end{tabular} & $\begin{array}{l}176 \\
172 \\
152\end{array}$ & $\begin{array}{l}792 \\
772 \\
891 \\
\end{array}$ & $\begin{array}{l}2.836 \\
2.766 \\
3.192 \\
\end{array}$ & 16.18 & $18 \%$ \\
\hline $\begin{array}{l}\text { Orangeburg } \\
\quad \# 46\end{array}$ & $16.0 \%$ & $\begin{array}{l}10 \\
11 \\
13 \\
\end{array}$ & $\begin{array}{l}163 \\
159 \\
195 \\
\end{array}$ & $\begin{array}{l}244 \\
189 \\
188 \\
\end{array}$ & $\begin{array}{l}417 \\
359 \\
396 \\
\end{array}$ & $\begin{array}{l}1.495 \\
1.285 \\
1.418 \\
\end{array}$ & 10.77 & $13 \%$ \\
\hline $\begin{array}{l}\text { Fuquay } \\
\# 8\end{array}$ & $12.5 \%$ & $\begin{array}{l}10 \\
10 \\
10\end{array}$ & \begin{tabular}{|l|}
568 \\
555 \\
489 \\
\end{tabular} & $\begin{array}{l}251 \\
270 \\
236\end{array}$ & $\begin{array}{l}829 \\
835 \\
735\end{array}$ & $\begin{array}{l}2.968 \\
2.992 \\
2.633\end{array}$ & 8.40 & $34 \%$ \\
\hline $\begin{array}{l}\text { Fuquay } \\
\# 42\end{array}$ & $17.7 \%$ & $\begin{array}{l}6 \\
6 \\
9\end{array}$ & $\begin{array}{l}62 \\
63 \\
42 \\
\end{array}$ & $\begin{array}{l}159 \\
158 \\
160\end{array}$ & $\begin{array}{l}227 \\
227 \\
211\end{array}$ & $\begin{array}{l}0.811 \\
0.814 \\
0.755\end{array}$ & 11.93 & $7 \%$ \\
\hline $\begin{array}{c}\text { ESE } \\
\# 1\end{array}$ & $13.1 \%$ & $\begin{array}{c}6 \\
6 \\
10 \\
\end{array}$ & $\begin{array}{l}420 \\
573 \\
440 \\
\end{array}$ & $\begin{array}{l}89 \\
81 \\
87 \\
\end{array}$ & $\begin{array}{l}515 \\
660 \\
537 \\
\end{array}$ & $\begin{array}{l}1.846 \\
2.364 \\
1.923 \\
\end{array}$ & 8.86 & $23 \%$ \\
\hline $\begin{array}{c}\text { Vaucluse } \\
\# 12\end{array}$ & $1.3 \%$ & $\begin{array}{l}6 \\
9 \\
5\end{array}$ & $\begin{array}{l}202 \\
195 \\
212\end{array}$ & $\begin{array}{l}36 \\
36 \\
38\end{array}$ & $\begin{array}{l}244 \\
240 \\
255\end{array}$ & $\begin{array}{l}0.872 \\
0.860 \\
0.914\end{array}$ & 0.875 & $101 \%$ \\
\hline $\begin{array}{c}\text { Blanton } \\
\text { \#35 }\end{array}$ & $2.3 \%$ & $\begin{array}{c}9 \\
11 \\
8\end{array}$ & \begin{tabular}{l|}
165 \\
181 \\
200
\end{tabular} & $\begin{array}{l}27 \\
28 \\
27\end{array}$ & $\begin{array}{l}201 \\
220 \\
235\end{array}$ & $\begin{array}{l}0.719 \\
0.788 \\
0.843\end{array}$ & 1.583 & $49 \%$ \\
\hline $\begin{array}{l}\text { Blanton } \\
\# 45\end{array}$ & $1.6 \%$ & $\begin{array}{c}11 \\
9 \\
8\end{array}$ & \begin{tabular}{|l|}
197 \\
167 \\
196 \\
\end{tabular} & $\begin{array}{l}27 \\
24 \\
24\end{array}$ & $\begin{array}{l}235 \\
200 \\
228\end{array}$ & $\begin{array}{l}0.842 \\
0.715 \\
0.815\end{array}$ & 1.060 & $75 \%$ \\
\hline $\begin{array}{l}\text { Lakeland } \\
\quad \# 41\end{array}$ & $3.6 \%$ & $\begin{array}{l}11 \\
10 \\
13\end{array}$ & \begin{tabular}{|l|}
197 \\
279 \\
228 \\
\end{tabular} & $\begin{array}{l}39 \\
36 \\
37\end{array}$ & $\begin{array}{l}247 \\
325 \\
278\end{array}$ & $\begin{array}{l}0.884 \\
1.164 \\
0.995\end{array}$ & 2.420 & $42 \%$ \\
\hline $\begin{array}{l}\text { Lakeland } \\
\quad \# 2\end{array}$ & $6.6 \%$ & $\begin{array}{l}15 \\
16 \\
18\end{array}$ & $\begin{array}{l}482 \\
442 \\
495\end{array}$ & $\begin{array}{c}92 \\
94 \\
101\end{array}$ & $\begin{array}{l}589 \\
552 \\
614\end{array}$ & $\begin{array}{l}2.109 \\
1.978 \\
2.197\end{array}$ & 4.45 & $47 \%$ \\
\hline
\end{tabular}


The sequential extraction profiles of iron from the CMP Pits soil samples exhibited the same general trends as the background soil samples, with the bulk of the soil being released during the final two extraction steps. Two of the waste site samples, however, exhibited subtle differences in their sequential extraction profiles that distinguished them from the background soils and the other two CMP pit samples. The sequential extraction of sample $3 \mathrm{~A}$ had iron appear in the DDI, Ac and $\mathrm{HAHCl}$ extraction steps. Iron was absent or present at much smaller amounts in these steps for the other soils.

\section{Aluminum}

The results of the sequential extraction procedure for aluminum from the background and CMP pit soil samples are presented as Tables A.3 and A.4 and summarized in Figure 4.3. As shown, the bulk of the aluminum (around 95 percent) was not released until the final extraction step. However, in contrast to the extraction profiles of iron; aluminum was present in detectable amounts in all the other extraction steps for nearly all soils. For example, aluminum appeared in significant quantities in the Ac extraction step. Differences are likely a result of the greater solubility of $\mathrm{Al}^{+3}$ compared to $\mathrm{Fe}^{+3}$ at most $\mathrm{pH}$ values and especially the low $\mathrm{pH}$ of the acetic acid extracts. $\mathrm{Al}^{+3}$ is also a commonly occurring exchangeable ion in acid soils, and the aluminum released during the early sequential extraction steps may have been ions sorbed onto soil surfaces. Aluminum recoveries, which ranged between 50 and 116 percent with an average value of 85 percent, were generally lower than those for iron. Consequently, aluminum may be lost from the procedure during the rinse steps.

The clay content and iron oxide contents of the background soils influence the sequential extraction profiles of aluminum from the background soils. As with total aluminum concentrations, the amount of aluminum released from a soil during the HF, DC, AOD, and PP steps follows the clay content of the different soils. The aluminum released from these steps also seems to be correlated with iron removal.

Figure 4.4 is a graph showing the relationship between the aluminum removal and iron removal during the DC extraction step and suggests that approximately 0.4 moles of aluminum are removed for every mole of iron. $\mathrm{Al}^{+3}$ has a similar ionic radius as $\mathrm{Fe}^{+3}$ and it is not uncommon for these metals to substitute for one another in their respective oxide minerals (Schwertmann and Taylor, 1982). 

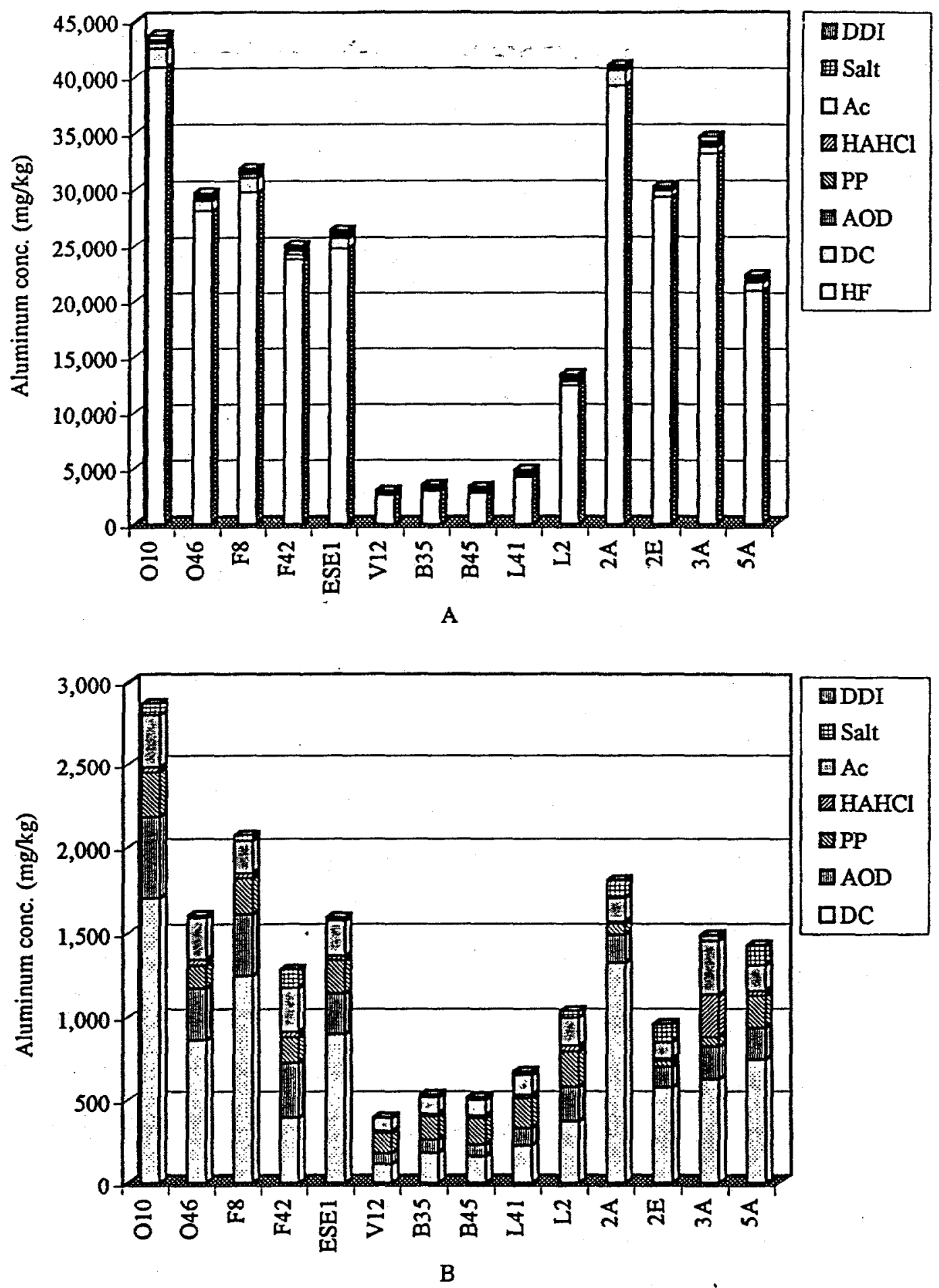

Figure 4.3. Sequential extraction profiles of aluminum from background and CMP pit soil samples. Figure A presents the amount of aluminum released during the entire extraction procedure (steps DDI through $\mathrm{HF}$ ). Figure $B$ is a detail focussing on the first seven steps (steps DDI through DC). 


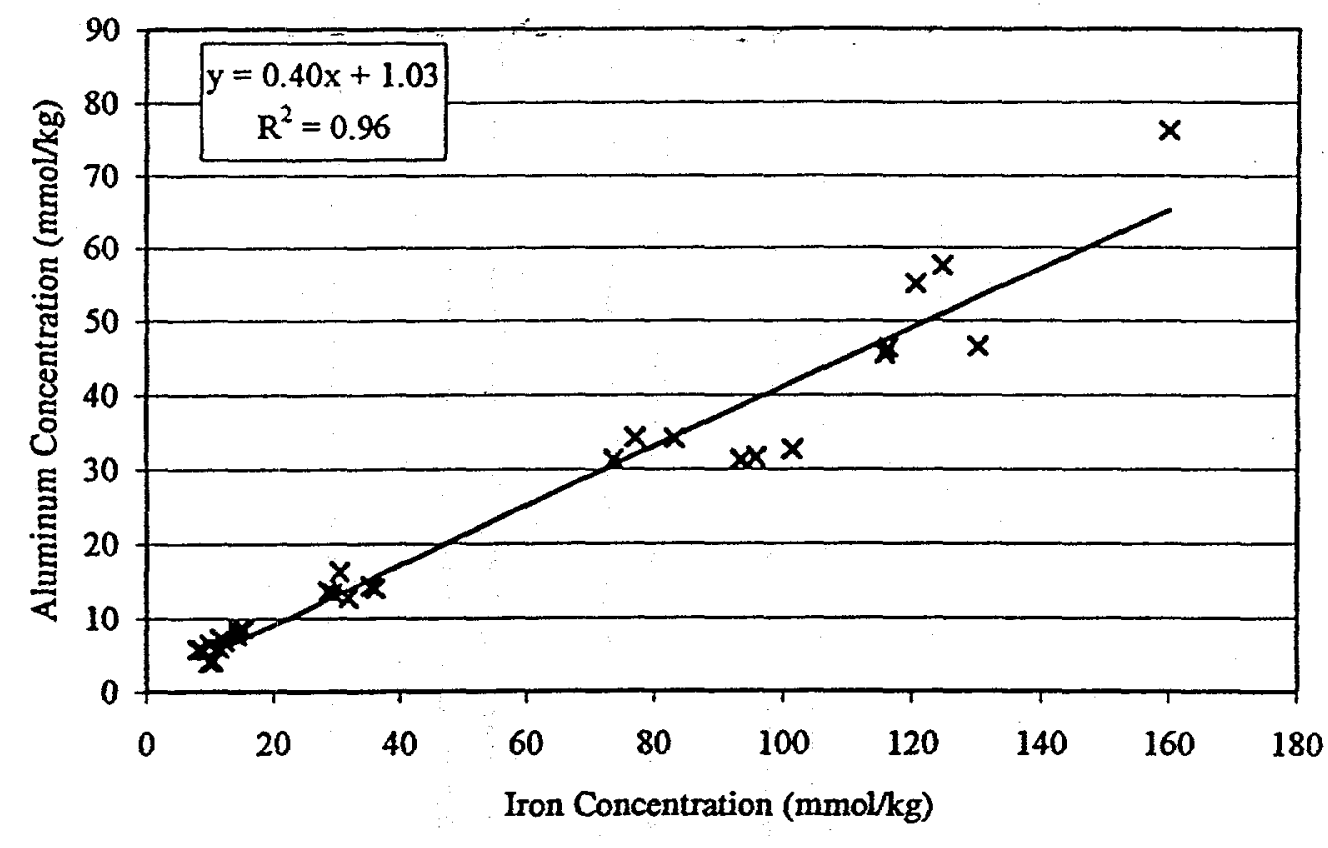

Figure 4.4. Relationship between iron and aluminum removed from background soils during DC extraction step.

The same approach that was used to estimate the HFO binding site concentration was adopted to estimate the concentration of binding sites from gibbsite surface coatings. The calculations assume that aluminum released during the initial six extraction steps represents aluminum from gibbsite surface coatings. The specific surface area of gibbsite is based on surface area measurements of synthetic gibbsite (Johnson, 1995) and assumed to be $175 \mathrm{~m}^{2} / \mathrm{g}-\mathrm{Al}$. The binding site concentration is derived from a literature value of $5 \mathrm{sites} / \mathrm{nm}^{2}$ (Johnson, 1995). Using the specific surface area and a formula weight for gibbsite $\left(\mathrm{AlO}_{3} \mathrm{H}_{3}\right)$ of $78 \mathrm{~g} / \mathrm{mol}$, gibbsite binding site density was calculated as $0.114 \mathrm{~mol}-\mathrm{sites} / \mathrm{mol}-\mathrm{Al}$. The results of the calculations based on extracted aluminum and the calculations based on soil clay content are presented as Table 4.3. The results are similar to the HFO binding site estimates in that the calculations based on the sequential extraction results do not exceed the upper bounds set by the calculations based on the clay content of the soils. 
Table 4.3. Estimates of binding site concentrations of gibbsite surface coatings in SRS background soils.

\begin{tabular}{|c|c|c|c|c|c|}
\hline \multirow[b]{2}{*}{$\begin{array}{c}\text { Background } \\
\text { Soil Sample ID }\end{array}$} & \multirow[b]{2}{*}{ Clay Content } & \multirow[b]{2}{*}{$\begin{array}{l}\text { Sum 1-6 } \\
(\mathrm{mg} / \mathrm{kg})\end{array}$} & \multicolumn{2}{|c|}{ mmoles of Gibbsite sites $/ \mathrm{kg}$ soil } & \multirow{2}{*}{$\begin{array}{c}\text { Percent S.E. } \\
\text { of Clay } \\
\text { Estimate }\end{array}$} \\
\hline & & & $\begin{array}{l}\text { Estimated By } \\
\text { S.E. Results }\end{array}$ & $\begin{array}{l}\text { Estimated by clay } \\
\text { content of soil }\end{array}$ & \\
\hline $\begin{array}{c}\text { Orangeburg } \\
\# 10\end{array}$ & $24.0 \%$ & $\begin{array}{l}1,236 \\
1,129 \\
1,152\end{array}$ & $\begin{array}{l}5.2 \\
4.7 \\
4.8\end{array}$ & 35.9 & $14 \%$ \\
\hline $\begin{array}{l}\text { Orangeburg } \\
\qquad \# 46\end{array}$ & $16.0 \%$ & $\begin{array}{l}819 \\
641 \\
764 \\
\end{array}$ & $\begin{array}{l}3.4 \\
2.7 \\
3.2 \\
\end{array}$ & 23.9 & $13 \%$ \\
\hline $\begin{array}{c}\text { Fuquay } \\
\text { \#8 }\end{array}$ & $12.5 \%$ & $\begin{array}{l}834 \\
846 \\
794\end{array}$ & $\begin{array}{l}3.5 \\
3.6 \\
3.3\end{array}$ & 18.7 & $19 \%$ \\
\hline $\begin{array}{l}\text { Fuquay } \\
\# 42\end{array}$ & $17.7 \%$ & $\begin{array}{l}980 \\
897 \\
806 \\
\end{array}$ & $\begin{array}{l}4.1 \\
3.8 \\
3.4 \\
\end{array}$ & 26.5 & $14 \%$ \\
\hline $\begin{array}{c}\text { ESE } \\
\# 1\end{array}$ & $13.1 \%$ & $\begin{array}{l}710 \\
726 \\
646\end{array}$ & $\begin{array}{l}3.0 \\
3.1 \\
2.7\end{array}$ & 19.7 & $15 \%$ \\
\hline $\begin{array}{c}\text { Vaucluse } \\
\# 12\end{array}$ & $1.3 \%$ & $\begin{array}{l}282 \\
284 \\
287\end{array}$ & $\begin{array}{l}1.2 \\
1.2 \\
1.2\end{array}$ & 1.9 & $62 \%$ \\
\hline $\begin{array}{c}\text { Blanton } \\
\# 35\end{array}$ & $2.3 \%$ & $\begin{array}{l}326 \\
346 \\
382\end{array}$ & $\begin{array}{l}1.4 \\
1.5 \\
1.6\end{array}$ & 3.5 & $42 \%$ \\
\hline $\begin{array}{c}\text { Blanton } \\
\# 45\end{array}$ & $1.6 \%$ & $\begin{array}{l}398 \\
320 \\
344 \\
\end{array}$ & $\begin{array}{l}1.7 \\
1.3 \\
1.4 \\
\end{array}$ & 2.4 & $63 \%$ \\
\hline $\begin{array}{l}\text { Lakeland } \\
\quad \# 41\end{array}$ & $3.6 \%$ & $\begin{array}{l}408 \\
485 \\
461 \\
\end{array}$ & $\begin{array}{l}1.7 \\
2.0 \\
1.9 \\
\end{array}$ & 5.4 & $35 \%$ \\
\hline $\begin{array}{l}\text { Lakeland } \\
\qquad \# 2\end{array}$ & $6.6 \%$ & $\begin{array}{l}666 \\
675 \\
661 \\
\end{array}$ & $\begin{array}{l}2.8 \\
2.8 \\
2.8\end{array}$ & 9.9 & $28 \%$ \\
\hline
\end{tabular}

Because the amount of aluminum released during the HF digestion step is influenced by soil texture, it is likely that most of the aluminum released during this step originates from clay minerals such as kaolinite. The amount of aluminum associated with clay minerals can be estimated by assuming that the clay fraction of the background soils is completely made up of kaolinite having the chemical formula $\mathrm{Si}_{4} \mathrm{Al}_{4} \mathrm{O}_{10}\left(\mathrm{OH}_{8} \bullet 4 \mathrm{H}_{2} \mathrm{O}\right.$. The results from these calculations are presented in Table 4.4 and are compared with the average amount of aluminum removed during the HF and TD extractions. The ratio of predicted aluminum concentrations and measured concentrations averages 95 percent for the HF data and $119 \%$ for 
the TD data This is consistent with the bulk of soil aluminum being present as kaolinite minerals. X-ray diffraction data of surface soils from SRS confirms this (Looney et al., 1990).

Table 4.4. Comparison between measured and predicted soil aluminum.

\begin{tabular}{|c|c|c|c|c|c|c|}
\hline \multirow{2}{*}{$\begin{array}{c}\text { Background } \\
\text { Soil Sample ID }\end{array}$} & \multirow{2}{*}{$\begin{array}{c}\text { Clay } \\
\text { Content }\end{array}$} & \multicolumn{3}{|c|}{ Aluminum Concentration (mg/kg) } & \multicolumn{2}{|c|}{$\begin{array}{c}\text { Mass Balance } \\
\text { (measured/predicted) }\end{array}$} \\
\hline & & Predicted & $\mathrm{HF}$ & $\mathrm{TD}$ & HF & TD \\
\hline $\begin{array}{c}\text { Orangeburg } \\
\# 10\end{array}$ & $24.0 \%$ & 43,194 & $40,829 \pm 15 \%$ & $47,124 \pm 1 \%$ & $95 \%$ & $109 \%$ \\
\hline $\begin{array}{c}\text { Orangeburg } \\
\# 46\end{array}$ & $16.0 \%$ & 28,752 & $28,052 \pm 13 \%$ & $28,194 \pm 9 \%$ & $98 \%$ & $98 \%$ \\
\hline $\begin{array}{c}\text { Fuquay } \\
\text { \#8 }\end{array}$ & $12.5 \%$ & 11,876 & $29,729 \pm 9 \%$ & $27,705 \pm 3 \%$ & $133 \%$ & $124 \%$ \\
\hline $\begin{array}{l}\text { Fuquay } \\
\# 42\end{array}$ & $17.7 \%$ & 6,463 & $23,735 \pm 25 \%$ & $30,655 \pm 2 \%$ & $74 \%$ & $96 \%$ \\
\hline $\begin{array}{c}\text { ESE } \\
\# 1\end{array}$ & $13.1 \%$ & 31,860 & $24,753 \pm 10 \%$ & $25,269 \pm 4 \%$ & $105 \%$ & $107 \%$ \\
\hline $\begin{array}{c}\text { Vaucluse } \\
\# 12\end{array}$ & $1.3 \%$ & 2,336 & $2,608 \pm 18 \%$ & $3,401 \pm 12 \%$ & $112 \%$ & $146 \%$ \\
\hline $\begin{array}{c}\text { Blanton } \\
\# 35 \\
\end{array}$ & $2.3 \%$ & 23,646 & $2,960 \pm 39 \%$ & $5,157 \pm 5 \%$ & $70 \%$ & $122 \%$ \\
\hline $\begin{array}{l}\text { Blanton } \\
\# 45\end{array}$ & $1.6 \%$ & 2,829 & $2,788 \pm 36 \%$ & $5,065 \pm 1 \%$ & $99 \%$ & $179 \%$ \\
\hline $\begin{array}{l}\text { Lakeland } \\
\# 41\end{array}$ & $3.6 \%$ & 4,226 & $4,153 \pm 20 \%$ & $7,365 \pm 3 \%$ & $64 \%$ & $114 \%$ \\
\hline $\begin{array}{l}\text { Lakeland } \\
\quad \# 2\end{array}$ & $6.6 \%$ & 22,422 & $12,336 \pm 44 \%$ & $11,575 \pm 19 \%$ & $104 \%$ & $97 \%$ \\
\hline
\end{tabular}

The CMP pit soil samples showed the same general distribution of aluminum as the background soils, with the bulk being retained until the last step and the remainder spread out across all of the other extraction steps. The only difference of note between any of the CMP pit samples and the background soils (once textural differences have been considered) is that aluminum was noticeably absent from the Salt extraction step of sample 3A. The percent recovery of aluminum from the CMP Pit soil samples is generally lower than the background soils. One of the flaws in the experimental design of this project was that extracts from the background soils were analyzed during a different set of ICP-MS sessions than the CMP pit soil samples, rather than randomizing the entire sample set. It is possible that the differences in the mass balance among the two sets of soil samples are a result in discrepancies among the ICP-MS sessions. 
The sequential extraction profiles of aluminum from the F-Area Seepage Basin soil samples are presented in Table 4.5. The extraction profile for one sample, A13R, is presented as Figure 4.5 and shows that aluminum is distributed across nearly all extraction steps (except the Salt step). A notable feature of the profile is the amount of aluminum released during the Ac step. At $2,400 \mathrm{mg} / \mathrm{kg}$, the amount of aluminum released from the sample during this step exceeds any of the other soil samples. The F-Area Seepage Basin soils have been extensively leached with acidic wastewater, and this has transformed soil aluminum into a more environmentally available form (Johnson, 1995). The groundwater from the aquifer contains aluminum at concentrations upward of $230 \mathrm{ppm}$. To emphasize the amount of aluminum this represents, typical background concentrations of aluminum in groundwater have been established at only around $50 \mathrm{ppb}$ (Johnson, 1995). The wastewater leached from the F-Area Seepage Basin acts not only as a direct source of contamination, but it also serves as an indirect source by mobilizing metals initially present in the soil.

Table 4.5. Sequential extraction of aluminum from the F-Area Seepage Basin Soils.

\begin{tabular}{|c|r|r|r|r|r|r|r|r|r|r|}
\hline Sample & \multicolumn{8}{|c|}{ Aluminum Removed During Extraction Step (mg/kg) } & Average \\
\cline { 2 - 11 } ID & \multicolumn{1}{|c|}{ DDI } & Salt & \multicolumn{1}{|c|}{ Ac } & HAHCl & PP & AOD & DC & \multicolumn{1}{c|}{ HF } & \multicolumn{1}{c|}{ TD } & Total \\
\hline & 4 & $<40$ & 2,470 & 386 & 394 & 1,670 & 8,062 & 5,783 & 13,606 & \\
A13R & 3 & $<40$ & 2,400 & 392 & 410 & 1,910 & 5,610 & 7,746 & 7,915 & 10,294 \\
& 3 & & 2.260 & 387 & 341 & 1,930 & 6,620 & 8,396 & 9,362 & \\
\hline & 68 & 705 & 817 & 99 & 215 & 282 & & 5,190 & 12,269 & \\
A22 & 51 & 485 & 776 & 96 & missing & 192 & missing & 4,080 & 6,200 & 11,723 \\
& 64 & 517 & 799 & 96 & 177 & 275 & & 5,402 & 16,700 & \\
\hline & 39 & 430 & 817 & & 273 & 543 & & 4,941 & 14,232 & \\
A23 & missing & 687 & 831 & missing & 368 & 544 & missing & 3,747 & 11,352 & 12,364 \\
& 25 & 774 & 907 & & 313 & 540 & & 5,792 & 11,509 & \\
\hline & & 907 & 1784 & & 586 & 787 & & 23,800 & 67,185 & \\
A31 & missing & 594 & 15.5 & missing & 475 & 476 & missing & 16,990 & 50,476 & 53,558 \\
& & 630 & 1810 & & 474 & 20 & & 14,943 & 43,012 & \\
\hline & 99 & 212 & 661 & & missing & 717 & & 6,016 & 12,655 & \\
A32 & 200 & 202 & $<10$ & missing & 191 & 675 & missing & 26,934 & 8,172 & 11,450 \\
& 289 & 322 & $<10$ & & 229 & 772 & & 31,104 & 13,523 & \\
\hline
\end{tabular}




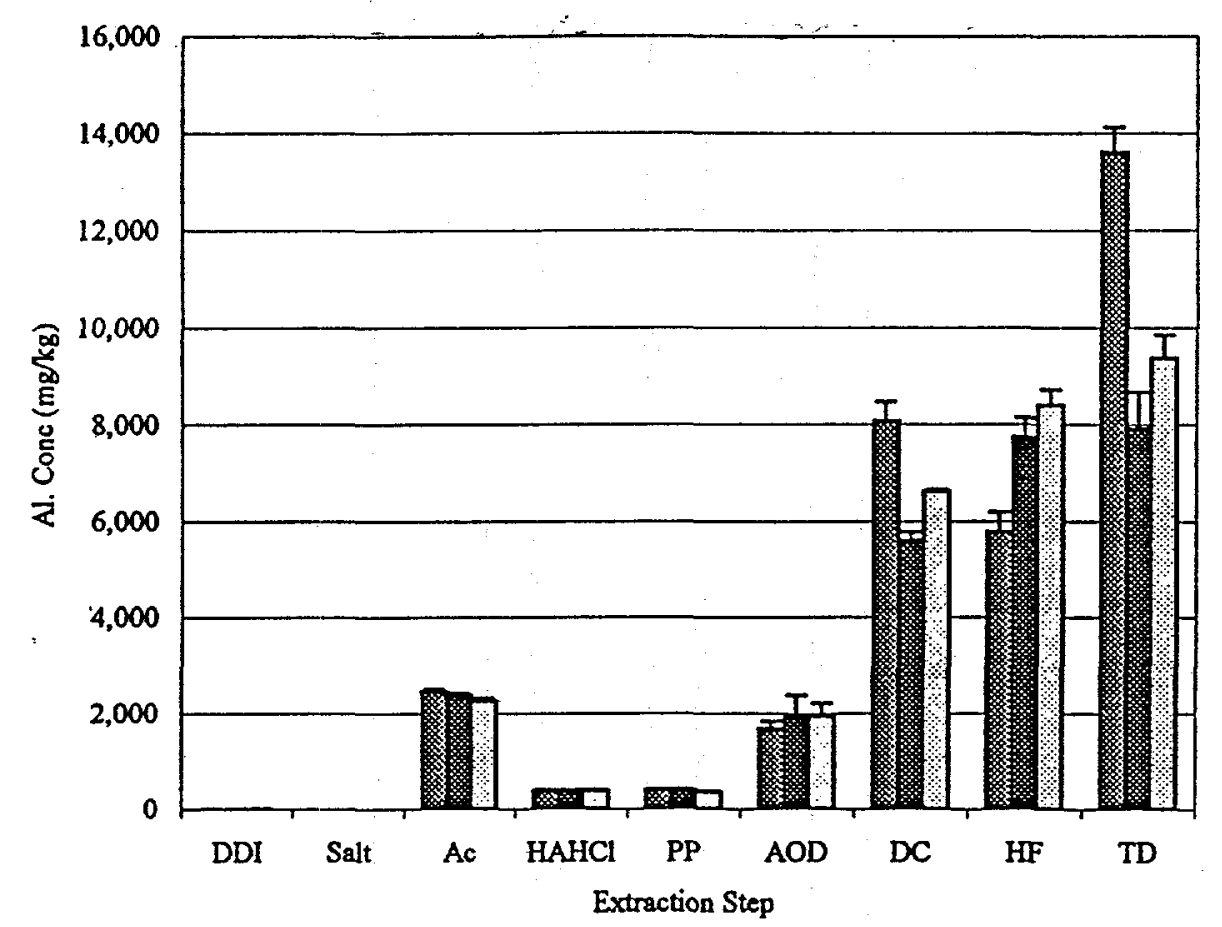

Figure 4.3. Sequential extraction profile of aluminum from soil sample A13R from the F-Area Seepage Basin.

\section{Titanium}

The results of the sequential extraction profiles for titanium from the background and CMP pit soils are presented in the appendix as Tables A.5 and A.6 and are summarized in Figure 4.6. As shown, the bulk of the titanium in the background soils was not released until the final extraction step. Trace amounts were released at detectable levels during the earlier steps. The extraction profiles are consistent with titanium being present in soils in the form of refractory titanium dioxide minerals. Total titanium concentrations are not related to soil texture $\left(r^{2}=0.47\right)$.

The percent recovered ranged between 53 and 116 percent with an average of 85 percent. Because soil titanium was not observed until the final extraction step, it would be difficult to attribute low recoveries to the removal of material during the wash steps. Another explanation for poor mass balances may be the method used to digest the soil. Only $200-\mathrm{mg}$ of solid material is loaded into the digestion vessels. The precision of the technique was limited by, among other things, the natural heterogeneity of soil materials. Increasing the amount of solid loaded into the digestion vessel, or incorporating a milling step to 
homogenize the soil, may have increased the precision of the results. Another explanation for poor mass balances in the procedure is that, by the final extraction step, the coarse sand fraction was separated from the fine clay- and silt-sized fractions. Although each size fraction was still present in the centrifuge tubes they were no longer mixed together like the original soil. It was difficult to take an unbiased $200-\mathrm{mg}$ sample of residual material that reflected the particle size distribution of the original soil. Some $200-\mathrm{mg}$ samples may have been enriched in fine sized particles, while other samples may have been enriched in coarse size particles. Because most of the titanium and other elements were bound in the soil until the HF extraction, the precision of this step limited the precision of the mass balance of the entire sequential extraction procedure.

A detail of the extraction profiles of titanium, showing only the first seven steps, is also presented in Figure 4.6. The titanium extraction profiles of one sample, $3 \mathrm{~A}$, is different from the other waste site soils and from the background soils. In this sample, titanium was present in several of the early extraction steps such as the extraction with $\mathrm{DDI}$ water. 



Figure 4.6. Sequential extraction profiles of titanium from background and CMP pit soil samples. Figure A presents the amount of titanium released during the entire extraction procedure (steps DDI through HF). Figure $B$ is a detail showing the first seven steps (steps DDI through DC). 


\section{Manganese}

The results of the sequential extraction of manganese from the background and CMP pit soil samples are presented graphically in Figure 4.7 for the background and CMP Pits and as Table A.7 and A.8 in the appendix. The precision associated with the manganese results was low, particularly with respect to the HF digestions where relative standard deviations of the results were as high as 75 percent (as seen with Blanton \#45). As a result, recoveries ranged between 54 and 283 percent.

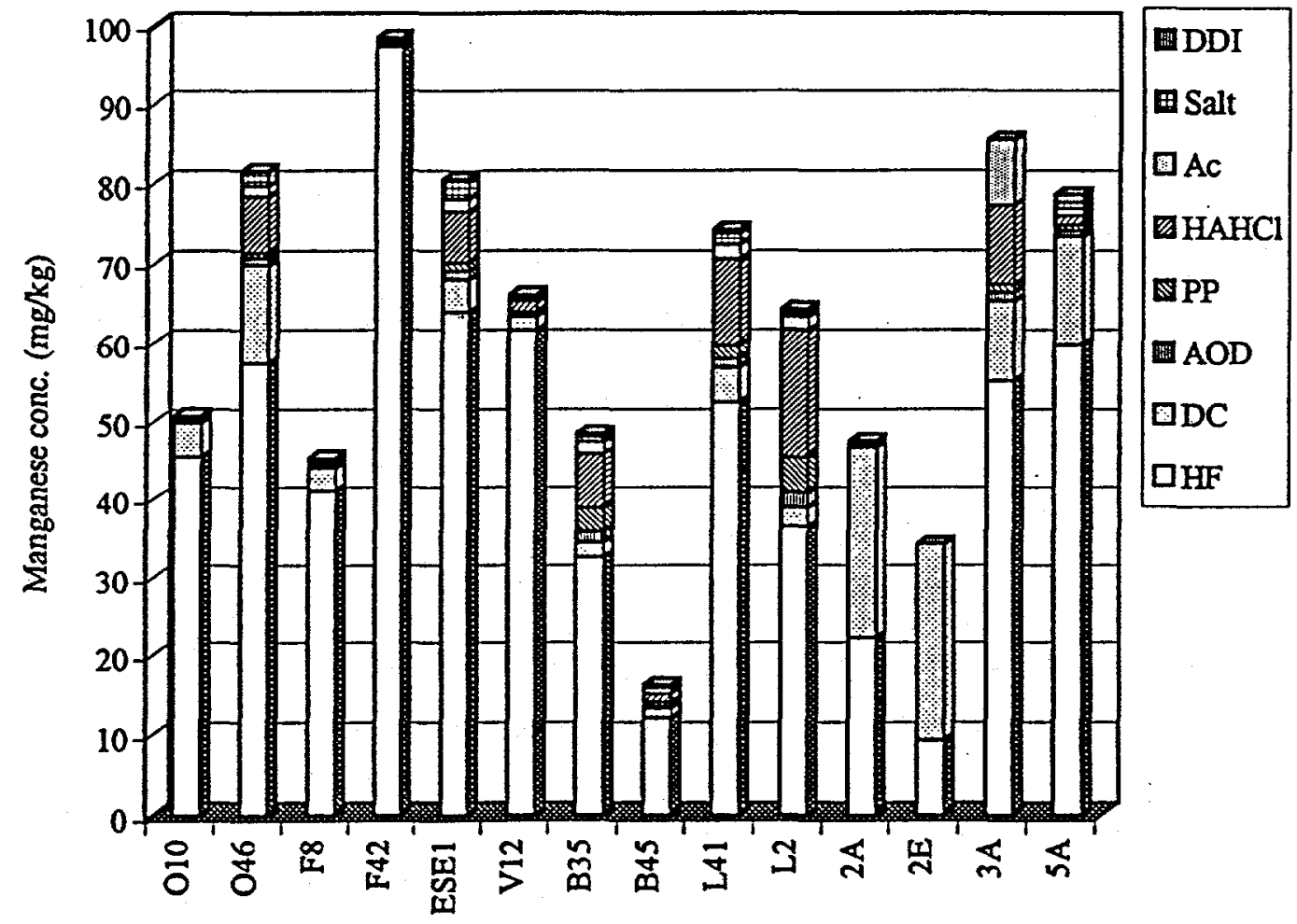

Figure 4.7. Sequential extraction profiles of manganese from background and CMP Pit soil samples.

On a mass basis, manganese is not a major component of any of the soil samples examined in this project. The maximum total manganese concentration was measured at approximately $100 \mathrm{mg} / \mathrm{kg}$; in contrast to titanium at $1,000 \mathrm{mg} / \mathrm{kg}$ and iron and aluminum at $10,000 \mathrm{mg} / \mathrm{kg}$. Most of the manganese is retained in the soil until the final extraction step. However, five of the background soils, Orangeburg \#46, ESE \#1, Blanton \#35, Lakeland \#2, and Lakeland \#41, have significant amounts of manganese released 
during the $\mathrm{HAHCl}$ extraction step (as demonstrated in Figure 4.7). This suggests that these soils contain discrete manganese oxide phases. The amount manganese released during the $\mathrm{HAHCl}$ step from these soils falls between 10 and 20 percent of total manganese. The poor precision in the values results in large uncertainties surrounding these ratios. Clay content does not seem to influence the total concentrations of manganese as was seen with iron and aluminum $\left(\mathrm{R}^{2}=0.17\right)$. Of the soils with notable amounts of HAHCl extractable manganese, Orangeburg \#46 and ESE \#1 fall into the group of background soils with relatively higher amounts of clay, while Blanton \#35, Lakeland \#2, and Lakeland \#41 contain lower amounts. These five soils also have higher amounts of manganese present in the Ac, PP, and AOD extraction steps relative to the other soils.

Manganese from the CMP Pit soil samples exhibited sequential extraction profiles that were similar to the background soils. Manganese from samples $2 \mathrm{~A}, 2 \mathrm{E}$, and $5 \mathrm{~A}$ was generally not released until the final two extraction steps (DC and HF). The Ac and $\mathrm{HAHCl}$ extracts from soil sample $3 \mathrm{~A}$ contained significant amounts of manganese and approximately 10 percent of total manganese was released during each of these steps.

\section{Naturally Occurring Radionuclides and RCRA Metals}

Presented in this section are the results of the sequential extractions for two naturally occurring radionuclides (Uranium-238 and Thorium-232), and the RCRA metals that were present in the soil samples. The results for barium, chromium, and lead are addressed individually. Silver, cadmium, selenium, and arsenic were rarely detected in the extracts and these results will be presented and discussed within one section.

\section{$\underline{\text { Uranium-238 }}$}

The results of the sequential extraction procedure for uranium-238 from the background and the CMP pit soils are presented in the appendix as Tables A.9 and A.10 and are summarized in Figure 4.8. As shown, the bulk of soil uranium is retained in the soil up until the final digestion of residual material. The percent recovery of uranium-238 from the background and CMP pit soils falls between 34 and 116 percent, with an average recovery of 78 percent. The most inaccurate recoveries were found in the group of soils with lower total uranium concentrations. 


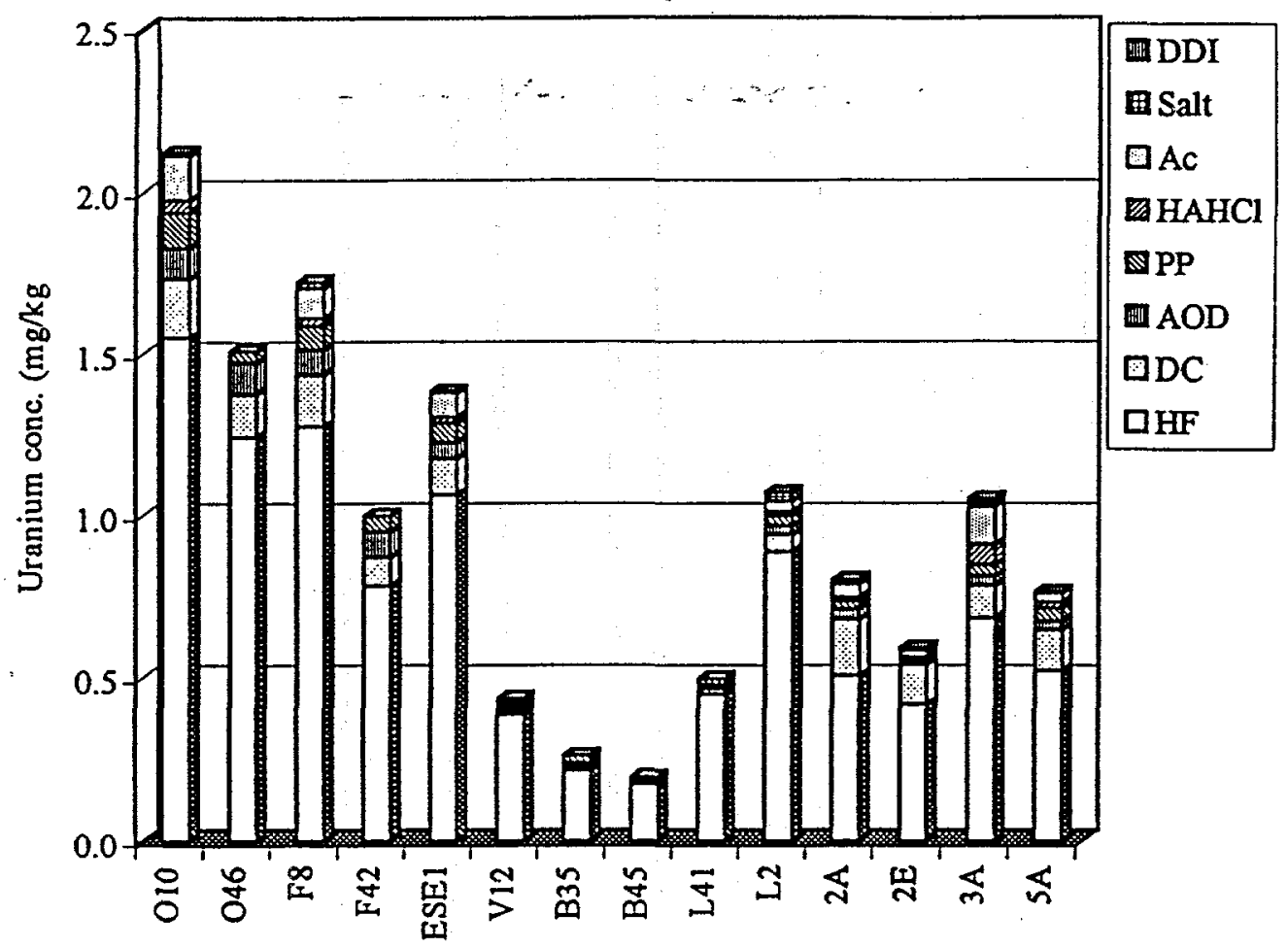

Figure 4.8. Sequential extraction profiles of uranium from background and CMP Pit soil samples.

The total uranium concentrations and the amount of uranium released during the extraction steps is influenced by the clay content of the soil $\left(\mathrm{R}^{2}=0.82\right)$. Soils with higher amounts of clay tended to have higher total amounts of U-238 (just above $1.0 \mathrm{mg} / \mathrm{kg}$ ) than those soils with lower amounts of clay (with concentrations around $0.5 \mathrm{mg} / \mathrm{kg}$ ). This trend is also apparent within the extraction steps. The uranium concentrations in extracts from the five soils with lower clay contents (B35, B45, L41, L2, and V12) are consistently at or below detection limits, while the soils with higher clay contents have detectable amounts of uranium distributed across the $\mathrm{Ac}, \mathrm{HAHCl}, \mathrm{PP}, \mathrm{AOD}$; and DC extraction steps. The uranium released during the Ac step suggests that a fraction of naturally occurring soil uranium is leachable under acidic conditions.

The results for the sequential extraction of uranium from the F-Area Seepage Basin soils are presented in Table 4.6 and Figure 4.9. This figure shows that the samples from the waste site have more uranium released during early extraction steps (particularly the Ac step) than the background soils. 
Table 4.6. Sequential extraction of uranium from F-Area Seepage Basin Soils.

\begin{tabular}{|c|c|c|c|c|c|c|c|c|c|c|c|}
\hline $\begin{array}{c}\text { Sample } \\
\text { ID }\end{array}$ & \multicolumn{7}{|c|}{ Uranium-238 Removed During Extraction Step (mg/kg) } & Percent \\
\cline { 2 - 13 } & DDI & Salt & Ac & HAHCl & PP & AOD & DC & HF & Sum & TD & Recovery \\
\hline A13R & 0.004 & 0.05 & 2.10 & 0.24 & 0.16 & 0.30 & 1.2 & 0.80 & 4.9 & 7.6 & $65 \%$ \\
\hline A22 & 0.367 & 0.24 & 0.83 & 0.05 & 0.16 & 0.13 & 0.8 & 0.33 & 3.0 & 3.3 & $91 \%$ \\
\hline A23 & 0.656 & 0.37 & 0.72 & missing & 0.18 & 0.17 & 0.6 & 0.32 & 3.0 & 5.6 & $54 \%$ \\
\hline A31 & missing & 0.48 & 2.93 & missing & 0.28 & 0.06 & 0.2 & 1.53 & 5.5 & 7.9 & $70 \%$ \\
\hline A32 & 1.740 & 0.053 & 0.42 & missing & 0.13 & 0.14 & 0.8 & 0.17 & 3.4 & 4.1 & $84 \%$ \\
\hline
\end{tabular}

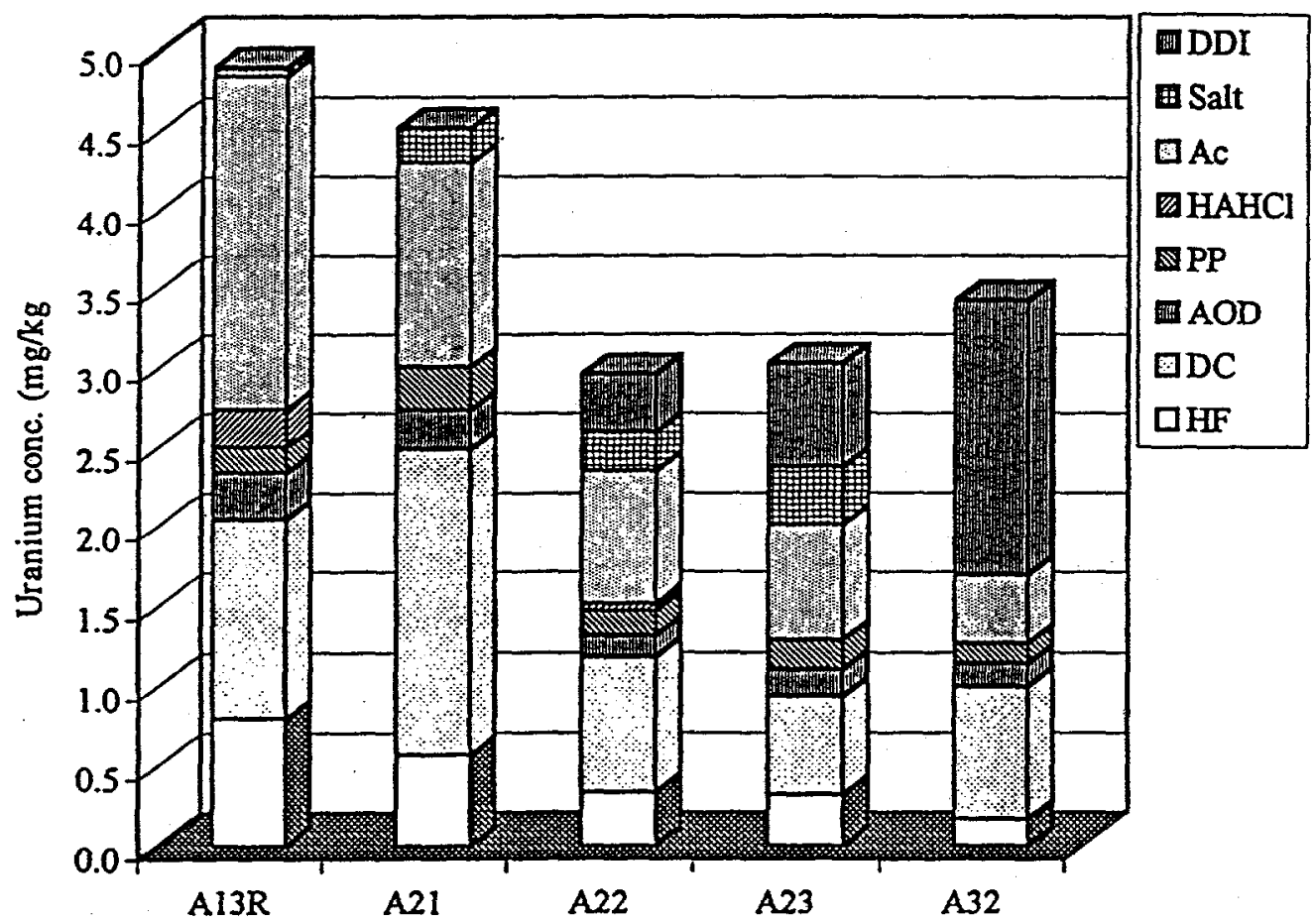

Figure 4.9. Sequential extraction of uranium from F-Area Seepage Basin soil samples. 
Thorium-232

It was difficult to obtain reliable results for Thorium-232 in most of the extracts. Concentrations in the diluted samples rarely exceeded 1 part per billion and thorium calibration curves for the instrument tended to be poor. A reoccurring feature in the calibration curves is presented in Figure 4.10. As shown, the response of the ICP-MS to calibration standards between 0 and 1 part per billion looks more like an exponential growth curve than a straight line. This same non-linear response was also seen for zirconium, another sparingly soluble element. Although Figure 4.10 does not show the response of the three replicates taken for each standard, concentrations increase between the first and third replicates. A reverse trend is noticed for method blanks and samples analyzed immediately after the highest calibration standard. This suggests that the amount of time needed for the instrument to reach a steady state is much longer for thorium and zirconium than other elements (like the indium internal standard that was used to confirm appropriate rinse and uptake times). . Thorium and zirconium may be sorbing onto instrument components such as the nebulizer, spray chamber, torch, or tubing and causing "memory" effects. Another problem with thorium measurements was that the check standards that were analyzed at the end of a run did not always agree with the initial calibration standards. While the response of the calibration blank did not drif, thorium measurements in the standards were below initial measurements.

Results of the sequential extraction procedure for thorium are presented in the appendix as tables A.11 and A.12. Because of difficulties with instrument calibration and disparities between calibration standards and check standards, results for the PP, DC, HF, and TD extraction steps should not be used as a quantitative measurement of thorium concentrations but rather a qualitative indication of the presence or absence of thorium. The instrument response was more reliable for the DDI, Salt, Ac, $\mathrm{HAHCl}$, and AOD extraction steps. Thorium was not detected in any of the background soils during the first two steps of the sequential extraction procedure. The Ac extraction step removed detectable amounts of thorium from those soils with relatively high clay contents, but not the low-clay background soils. This suggests that the amount of thorium released from soil was influenced by soil texture. Although the other results are not quantitatively reliable, they do suggest that thorium is released from the soil during the later stages of the sequential extraction procedure. Thorium was not detected in many of the total digestions of background soils and this causes large errors in the thorium mass balances. 
Th 232

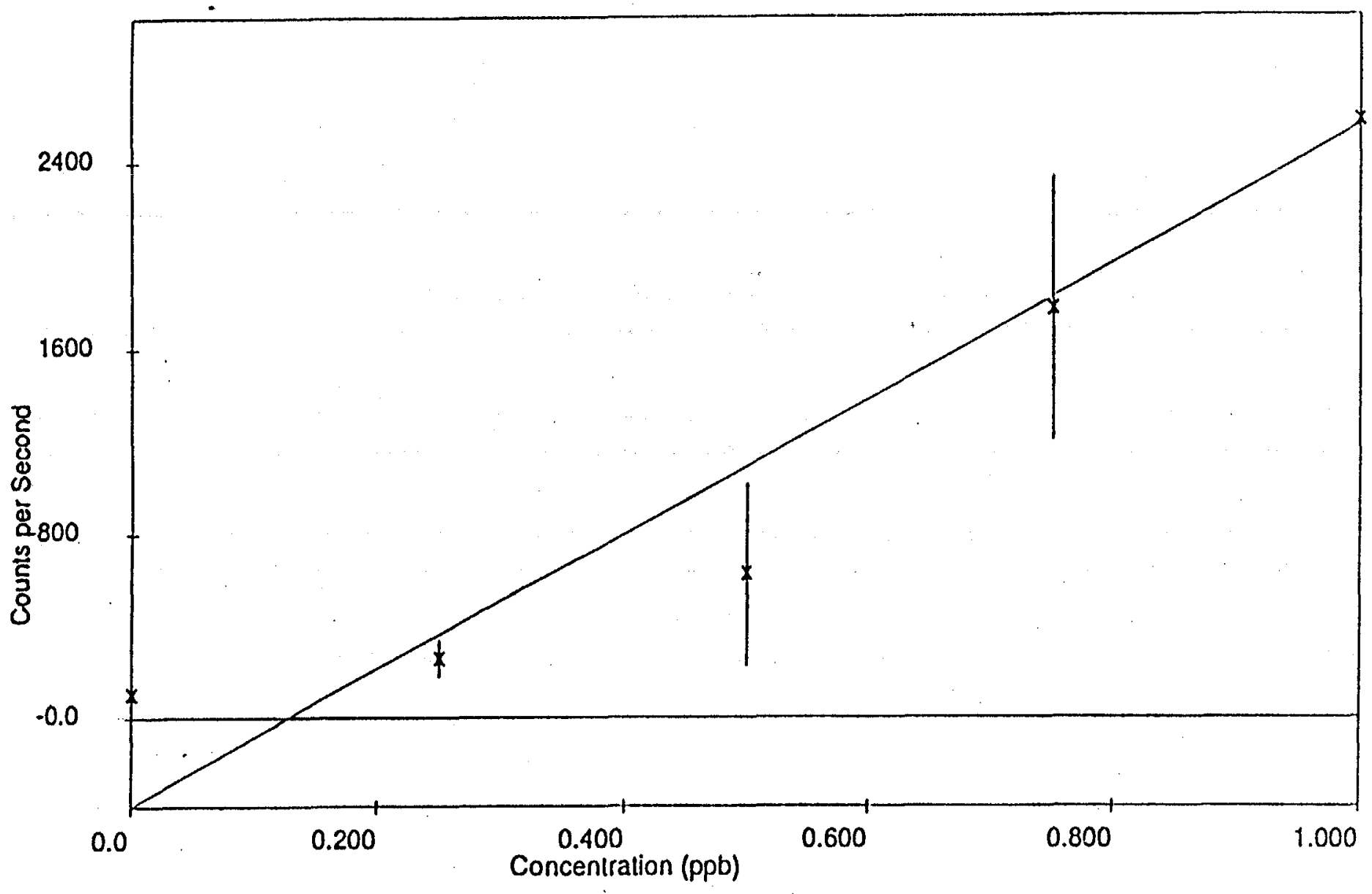

Figure 4.10. ICP-MS calibration curve of thorium-232. 
Detectable amounts of thorium were released from one of the CMP pit soil samples, $3 \mathrm{~A}$, during first extraction step (DDI water). Each of the CMP pit soil samples released detectable amounts of thorium during the Ac extraction step.

Lead

The results of the sequential extractions for lead are in the appendix as Tables A.13 and A.14 and summarized graphically as Figure 4.11. One of the noticeable features of the data is the disparity between results within soil samples from the HF extraction steps. Orangeburg \#10, Fuquay \#42; Blanton \#45, Lakeland \#41 and Lakeland \#2 have relative standard deviations between replicates that are as high as $121 \%$ percent.

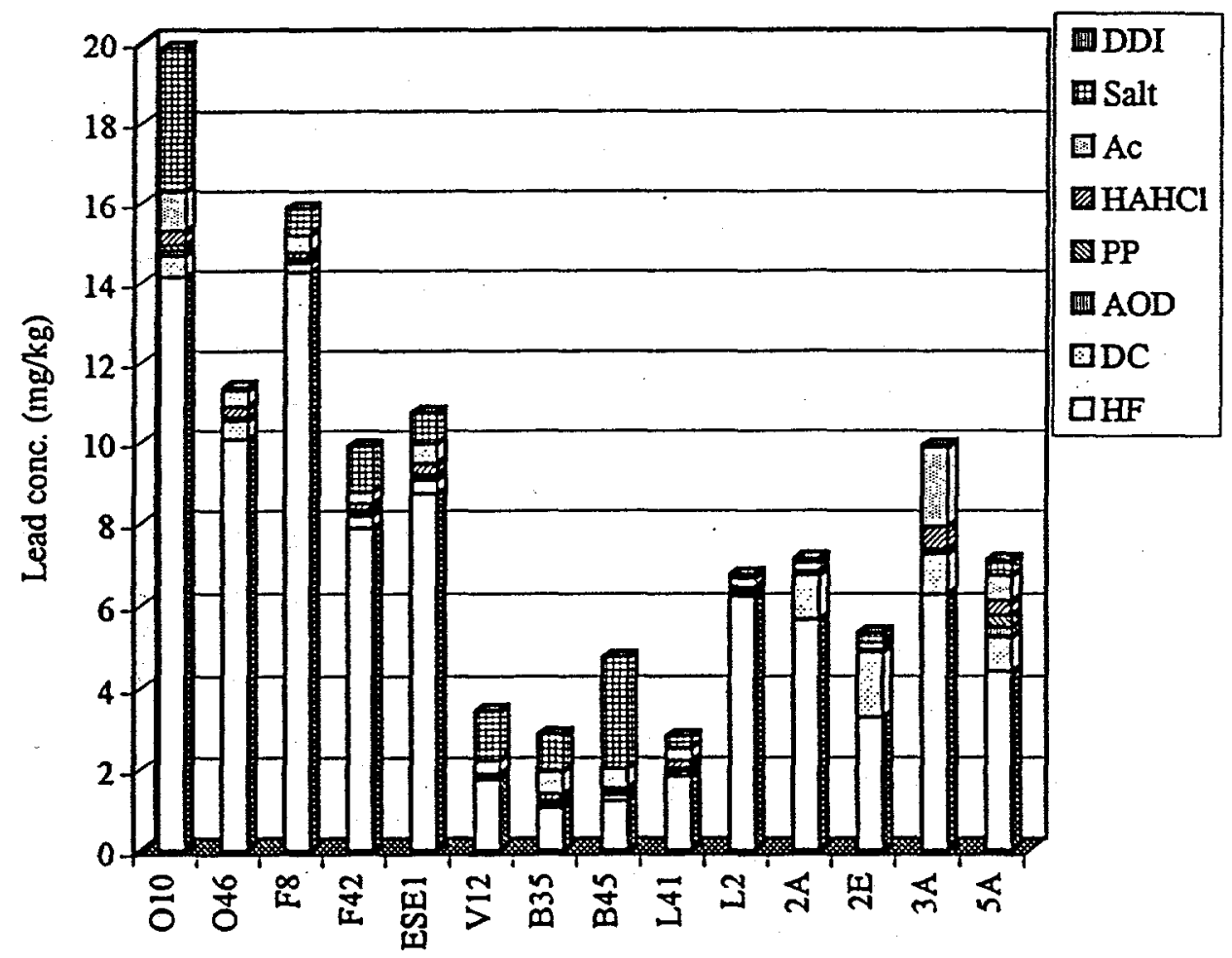

Figure 4.11. Sequential extraction profiles of lead from background and CMP pit soils. 
The data also suggest that soil texture does not completely predict amount of lead released from the soil, particularly with respect to the initial extraction steps, Salt and Ac. This is exemplified by the results for the two Orangeburg soil samples. These soils contain similar clay contents yet, Orangeburg \#10 has around 3 to $4 \mathrm{mg} / \mathrm{kg}$ removed during the salt extraction, and Orangeburg \#46 releases less than $0.75 \mathrm{mg} / \mathrm{kg}$. The two Blanton soils, a pair of soils with lower clay contents, show the same type of differences. Even with the differences seen during the early extraction steps, the amount of lead released from the soil during the AOD and DC steps appears to be described by soil texture. During these steps, the only samples that contained detectable amounts of lead were the soils with relatively higher clay contents. Total lead results from the background soils were also positively correlated with clay content $\left(R^{2}=0.84\right)$.

One possible explanation for the lead released from the Salt step of Orangeburg \#10 and Blanton \#45 is that these soils have received inputs of lead from the atmosphere. Most sampling locations were 20-30 feet off of service roads at the site. Blanton \#45 was located near the main gatehouse providing access to the site, an area of high traffic. Soils and sediments near roads often have slightly elevated concentrations of lead from when this element was used as a gasoline additive (Gibson and Farmer, 1986).

Lead from the CMP pit soils is generally not released until the final extraction step, however sample $3 \mathrm{~A}$ and $5 \mathrm{~A}$ have slightly higher amounts of lead released during the first four extraction steps.

\section{$\underline{\text { Barium }}$}

The results of the sequential extractions for barium from the background and the CMP pit soils are presented in the appendix as Tables A.15 and A.16 and are summarized in Figure 4.12. While barium is extracted in detectable amounts during each step for nearly every soil sample (except CMP pit sample 2E), the bulk of the barium is concentrated in three extraction steps (Sait, PP, and HF). Except for Orangeburg \#10, the mass balance of the sequential extraction procedure for barium from the background and CMP pit soils falls between 17 and 62 percent with an average recovery of 45 percent. 


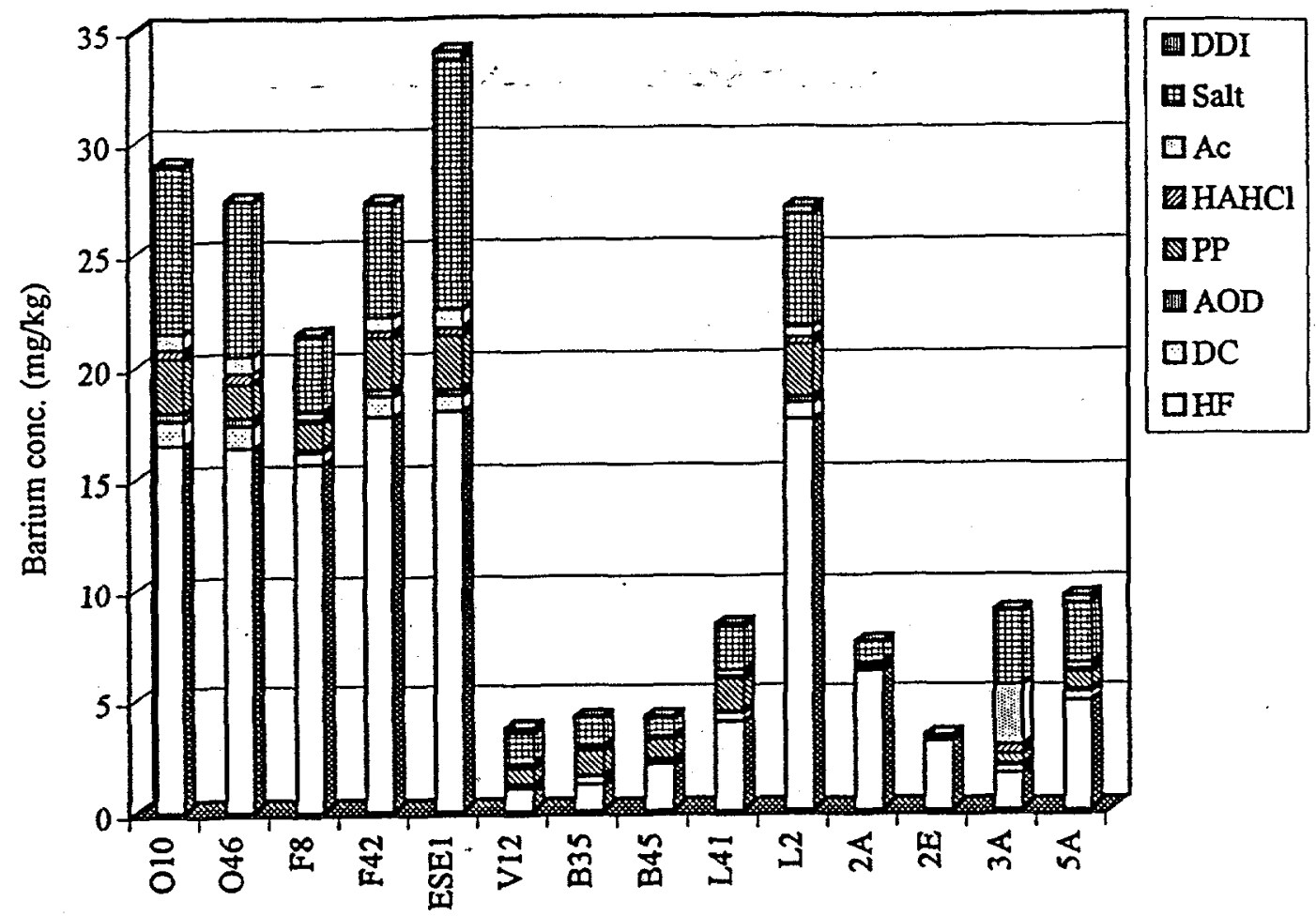

Figure 4.12. Sequential extraction profiles for barium from background and CMP Pit soil samples.

The poor recovery suggests that the sequential extraction procedure acts as a "leaky" system for barium. This is likely due to the similar chemical behavior of barium and calcium (both being group II elements). The calcium nitrate solution employed during the rinse steps would be effective at exchanging with any barium that had reabsorbed onto soil surfaces. The chemical compositions of the rinsates were not measured for this study so it is not known if barium was removed during the rinse steps of the sequential extraction procedure.

The calcium nitrate reagent used in the rinse steps and the Salt and Ac extraction steps has barium impurities and acts as a source of barium during the procedure. The method blanks from the Ac extraction step $\left(0.1 \mathrm{M} \mathrm{Ca}\left(\mathrm{NO}_{3}\right)_{2}\right)$ contained around $1 \mathrm{ppb}$ of barium. Approximately 0.5 to $1 \mathrm{ml}$ of entrained fluid remained in the soils after each extraction or rinse step. Based on these estimates, the maximum amount of barium added to the samples from entrained rinsate $\left(0.0127 \mathrm{M} \mathrm{Ca}\left(\mathrm{NO}_{3}\right)_{2}\right)$ is less than $0.001 \mathrm{mg} / \mathrm{kg}$ essentially insignificant. 
The amount of barium released during the salt extraction step is expected to follow the cation exchange capacity of soils. However, Figure 4.13 shows that the relation between barium removed during the salt extraction step and cation exchange capacity is tenuous at best. This may be due to the low barium concentrations and low cation exchange values relative to the amount of error in the measurements.

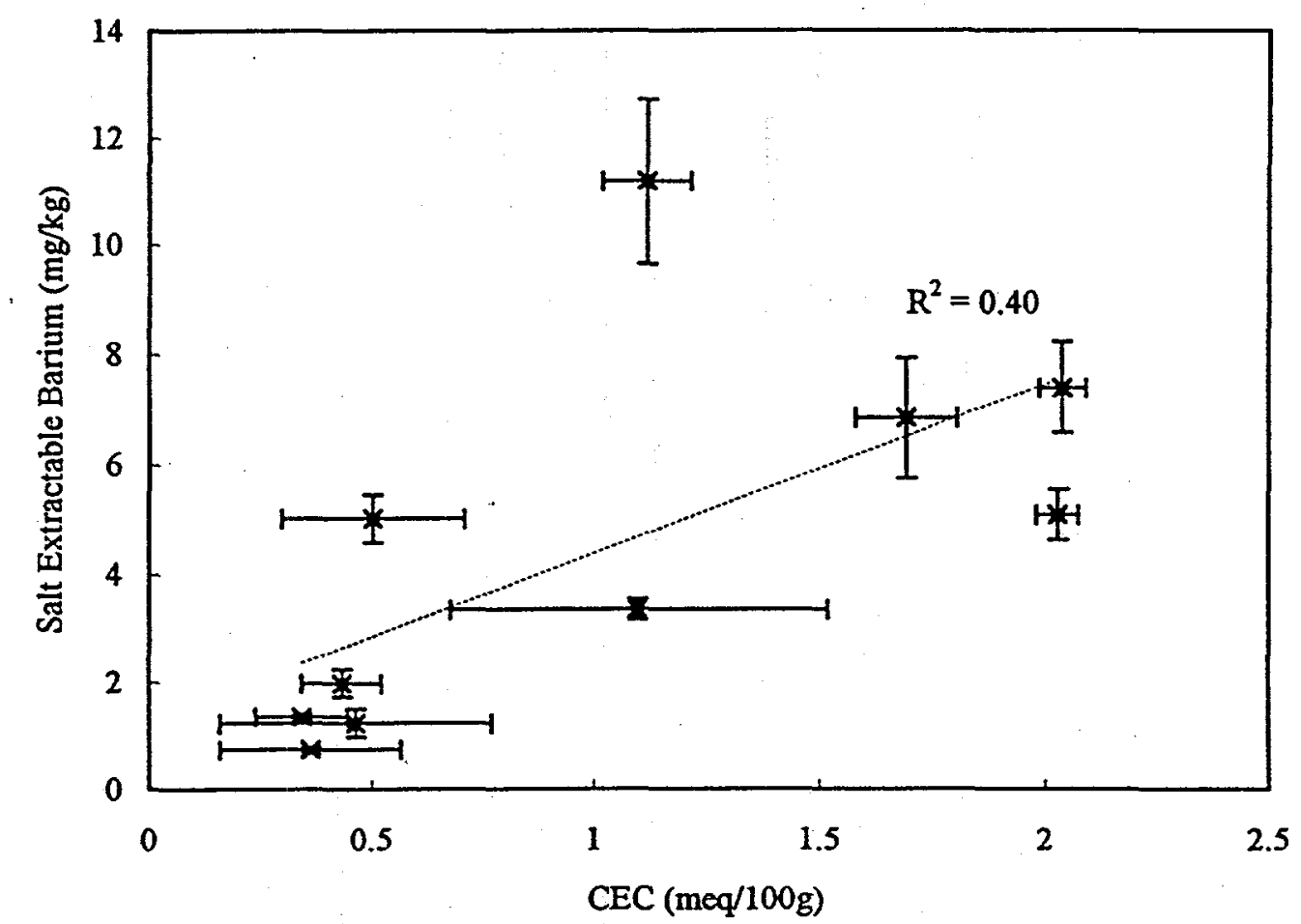

Figure 4.13. Salt extractable barium vs. cation exchange capacity of the background soils.

The barium sequential extraction profiles (up until the DC step) for the CMP pit soil samples is also presented in Figure 4.12. As shown, CMP Pit soil samples $3 \mathrm{~A}$ and $5 \mathrm{~A}$ contain higher amounts of barium in each of the extraction steps than $2 \mathrm{~A}$ and $2 \mathrm{E}$.

\section{Chromium}

The results of the sequential extraction procedure for chromium from the background and CMP pit soils are presented in the appendix as Tables A.17 and A.18 and are summarized in Figure 4.14. Most of the extraction steps have chromium in concentrations below their detection limits. In some cases, such as 
the DDI, and HAHCl extraction steps, this was because there was simply very small amounts of chromium in the sample. The AC and AOD extraction steps, however, contained matrices that made it difficult to measure low chromium concentrations. Both of these steps employed carbon rich reagents (acetic acid from the Ac step and oxalic acid from the AOD step) that resulted in an ${ }^{40} \mathrm{Ar}^{12} \mathrm{C}^{+}$isobaric interference with chromium-52. As a result, the method blanks for these reagents had high effective chromium signals. More importantly, the method blank signals tended to be unsteady, resulting in high minimum detection limits (approximately $1.5 \mathrm{mg} / \mathrm{kg}$ for Ac and $1 \mathrm{mg} / \mathrm{kg}$ for AOD).

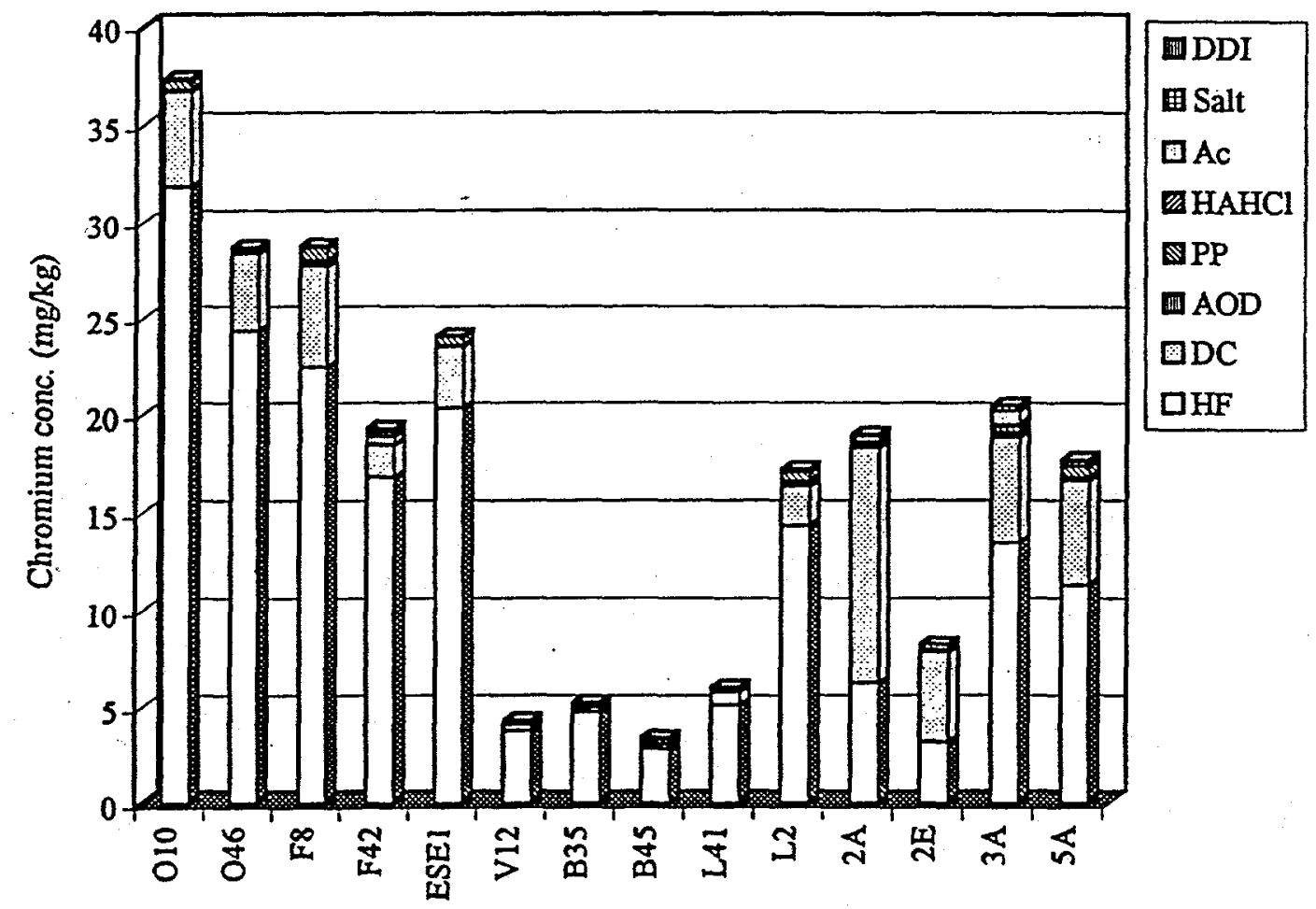

Figure 4.14. Sequential extraction profiles of chromium from SRS background and CMP Pit soil samples. 
Compounding the problem of isobaric interferences, was that the instrument tended to drift and lose calibration for chromium during the course of a run Several of the runs experienced an upward shift in the baseline, as evidenced by the check standard and blank that was analyzed at the end of each run. This may be from carbon deposits gradually accumulating on the surface of the sampling cones and acting a carbon source.

It should also be mentioned that chromium and lead were often culprits in contaminated samples that were encountered in some of the early ICP-MS work (the results have been excluded from this report). The source of contamination was traced to a Teflon-coated, stainless steel autosampler probe that had a smail tear in it. Although this probe was replaced with another intact probe, the possibility still exists that some of the samples in these data may have been contaminated and not detected. For example, one of the method blanks nun with the CMP pit digestions, some of the last samples analyzed for this project, contained a slightly elevated chromium signal. This suggests that contamination problems persisted throughout the course of the project.

The problems with isobaric interferences, instrument drift, and the potential of contamination does not instill a great deal of confidence in the results presented in Figure 4.14. Nevertheless, the information does suggest that most chromium is released from the soil during the two final extraction steps, DC and HF. Also, the total amount of chromium in soil tends to follow soil texture $\left(\mathrm{R}^{2}=0.85\right)$. Those soils with higher clay contents tended to have higher total chromium concentrations. The precision of the chromium results was low particularly with respect to those soil samples with lower clay contents. As a result, mass balances ranged between 30 and 144 percent.

\section{Remaining RCRA metals}

The remaining RCRA metals examined in this study, silver, cadmium, selenium, and arsenic, were not present above detection limits in any of the extracts or could not be reliably measured using an ICP-MS. Silver and cadmium had reasonably low detection limits and stable signals. The arsenic and selenium signals were such that measurement of these elements using an ICP-MS was difficult.

Instrumental detection limits for cadmium and silver were routinely below one part per billion and the soil detection limits depended primarily on the amount of dilution necessary to analyze an extract. Representative detection limits for these two elements are presented in Table 4.7. Quantitative results are 
missing for cadmium in the AOD extracts from the background soils because it was inadvertently left out of the calibration standards. However, none of the AOD extracts had raw signals (counts per second) that were significantly different from the blanks. None of the extraction steps and digestions had detectable amounts of silver. The DC extract of one of the three replicates of CMP pit soil $2 \mathrm{~A}$ contained levels of cadmium just above the detection limit (the signals at the 111 cadmium isotope and the 114 isotope were significantly above the baseline). This was the only confirmed occurrence of cadmium in any of the extracts.

Table 4.7. Typical silver and cadmium detection limits.

\begin{tabular}{|c|c|c|}
\hline \multirow{2}{*}{ Extraction Step } & \multicolumn{2}{|c|}{ Detection Limits (mg/kg) } \\
\cline { 2 - 3 } & $\mathrm{Cd}$ & $\mathrm{Ag}$ \\
\hline DDI & 0.0025 & 0.0020 \\
\hline Sait & 0.10 & 0.18 \\
\hline AC & 0.035 & 0.010 \\
\hline HAHCl & 0.0032 & 0.0013 \\
\hline PP & 0.030 & 0.010 \\
\hline AOD & 0.025 & 0.012 \\
\hline DC & 0.14 & 0.05 \\
\hline HF \& TD & 1.0 & 1.0 \\
\hline
\end{tabular}

Arsenic and selenium were difficult elements to measure using the ICP-MS. The concentrations of both elements were measured with signals that tended to give imprecise results and drift during the course of an ICP-MS session. One of the problems encountered with measuring selenium concentrations using and ICP-MS was simply selecting a peak; all selenium isotopes have an isobaric interference that must be considered. The most abundant selenium isotopes, ${ }^{80} \mathrm{Se}\left(50\right.$ percent), ${ }^{78} \mathrm{Se}\left(23.5\right.$ percent), and ${ }^{76} \mathrm{Se}(9.0$ percent) are coincident with the $\mathrm{Ar}_{2}{ }^{+}$dimers, ${ }^{77} \mathrm{Se}$ has an interference with ${ }^{40} \mathrm{Ar}^{37} \mathrm{Cl}^{+}$, and ${ }^{82} \mathrm{Se}$ (9.0 percent) has an interference with one of the impurities in the gas supply, ${ }^{82} \mathrm{Kr}$. Ultimately, selenium-82 was used to measure selenium concentrations because the baseline peak at mass 82 from kypton was smaller than the argon dimer peaks. Also, unlike chlorine, krypton is not a commonly occurring element in soils. The krypton component of mass 82 can be removed by subtracting the method blank signals from the samples. The selenium signal measured during an ICP-MS session that analyzed the DC extracts from the CMP pit 
soils is presented in Figure 4.15. It illustrates the problems that were frequently encountered with measuring selenium. The check standards (labeled "S2") should have a signal at $12.5 \mathrm{ppb}$. Midway through the run, however, the instrument measures this standard to be approximately $45 \mathrm{ppb}$. The samples identified as "40 Cr", "60 Cr", and " $50 \mathrm{Cr}$ " are method blanks and should have a signal at the baseline. The graph shows signal drift within the five minutes that it takes to acquire three replicate measurements. It should be noted that the instrument was in control for most of the other metals during this session.



Figure 4.15. Selenium signal drift during an ICP-MS nun.

Arsenic, in contrast with selenium, has only one stable isotope $\left({ }^{75} \mathrm{As}\right)$ to choose from and, unfortunately, it is coincident with a commonly occurring isobaric interference, ${ }^{40} \mathrm{Ar}^{35} \mathrm{Cl}^{+}$. Chlorine was explicitly added during the sequential extraction procedure as $\mathrm{NH}_{2} \mathrm{OH}-\mathrm{HCl}$ during the $\mathrm{HAHCl}$ extraction step and $\mathrm{HCl}$ during the total and residual digestion steps. Because chloride is also a ubiquitous component of soil systems, subtracting the method blanks from samples may not correct for potential interferences. An interference equation from EPA Method 6020 (US EPA, 1994) was used to correct for potential arsenic interferences from ${ }^{40} \mathrm{Ar}^{35} \mathrm{Cl}^{+}$. The arsenic signal behaved similarly to the selenium signal in that it tended 
to drift over the course of the nun and replicate measurements of samples exhibited high variability. Those sessions where the selenium and arsenic signals did not drift gave results that were consistently below detection limits. Typical detection limits for arsenic and selenium, when the instrument was in control, are presented in Table 4.8 .

Table 4.8. Typical arsenic and selenium detection limits.

\begin{tabular}{|c|c|c|}
\hline \multirow{2}{*}{ Extraction Step } & \multicolumn{2}{|c|}{ Detection Limits (mg/kg) } \\
\cline { 2 - 3 } & As & Se \\
\hline DDI & 0.0740 & 0.0640 \\
\hline Salt & 1.30 & 4.10 \\
\hline Ac & 0.810 & 0.770 \\
\hline HAHCl & 0.13 & 0.28 \\
\hline PP & 0.480 & 9.900 \\
\hline AOD & 0.69 & 0.34 \\
\hline DC & 2.2 & 14 \\
\hline HF \& TD & 3.5 & 12.0 \\
\hline
\end{tabular}

Other Elements of Interest

In addition to uranium, thorium and the metals regulated explicitly under RCRA, the results of several other metals were examined. This section presents the results for vanadium, cobalt, copper, zinc, nickel, rubidium, cesium, and cerium.

\section{Vanadium}

The results of the sequential extraction procedure for vanadium from the background and the CMP pit soil samples are presented in the appendix as Tables A.19 and A.20 and are summarized in Figure 4.16. The sequential extraction profiles of vanadium from both the background soils and the CMP pit soils show that the bulk of the metal remains bound in the soil until the DC and HF extraction steps. Detectable amounts of vanadium are also present in the $\mathrm{HAHCl}$ and $\mathrm{AOD}$ extraction steps of those soils with relatively high clay contents and the PP extraction step of all samples. Vanadium was not released during the first three extraction steps from any of the background soil samples. The results from later extraction steps and the total digestions show that the amount of vanadium in a soil is influenced by clay content $\left(R^{2}=0.90\right.$ for total vanadium concentrations). The CMP pit soil samples have vanadium sequential extraction profiles 
that are similar to the background soils. The only notable difference is with the extraction profile of sample 3A. In this sample, variadium is present at detectable amounts in the DDI and Ac extraction steps.

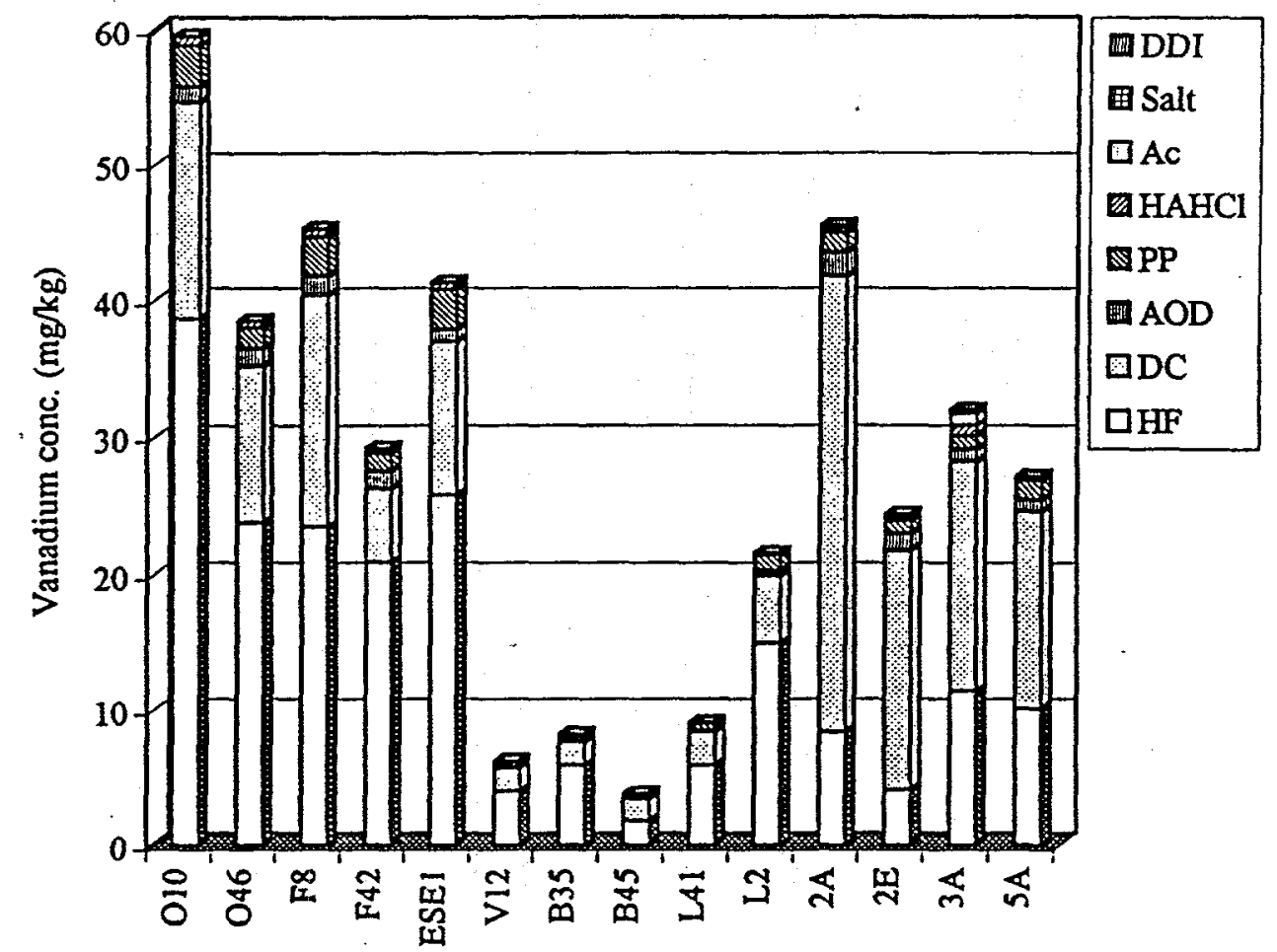

Figure 4.16. Sequential extraction profile for vanadium from SRS background and CMP Pit soil samples.

\section{Cobalt}

The results of the sequential extraction procedure for cobalt are presented in the appendix as Tables A.21 and A.22. As shown, this element is not present above detection limits in most of the extraction steps. Because they were analyzed with minimal amounts of dilution, the samples from the DDI and HAHCl extraction steps were the only ones that regularly contained detectable amounts of cobalt. Concentrations of cobalt released from the soils during these steps never exceeded $1 \mathrm{mg} / \mathrm{kg}$. Detectable amounts of cobalt were also present in many of the total digestion and HF extraction steps from the background soils.

There is only one stable cobalt isotope, ${ }^{59} \mathrm{Co}$. Fortunately, there are few interferences associated with the cobalt- 59 peak, and the instrument routinely produced acceptable calibration curves between 0.0 and 1.0 part per billion. The only extraction steps that presented problems with the measurement of cobalt were 
the Salt and Ac steps because the method blanks from these steps contained high cobalt signals. The cobalt signals in the method blanks may be due to ${ }^{12} \mathrm{Ca}^{16} \mathrm{O}^{1} \mathrm{~F}^{+}$polyatomic ion. Several other calcium oxide and hydroxide peaks are present on the spectra of samples from these extraction steps because of the $\mathrm{Ca}\left(\mathrm{NO}_{3}\right)_{2}$ used in the extraction reagents. With this in mind, it is possible that the low levels of cobalt seen in other extraction steps (such as the $\mathrm{HAHCl}$ step) are the result of calcium carried through the procedure during the rinse steps. There is enough consistency between replicates of soil samples, however, to suggest that the cobalt signal was from soil cobalt.

\section{Copper, Zinc, and Nickel}

Copper and zinc were difficult analytes to measure using an ICP-MS. Sodium, sulfur, calcium, and phosphorus from the different extraction reagents created various polyatomic ions that coincided with copper and zinc isotopes. Additional setbacks were encountered with respect to zinc measurements. The sequential extraction of trace metals from the set of background soils was split into two separate runs. Four soil samples were extracted in late-March 1997, while the remaining six were extracted in mid-April 1997. All the method blanks and samples generated during the late-March experiment contained approximately $100 \mathrm{ppb}$ zinc (likely from the deionized water source). As a consequence of these difficulties, zinc and copper results are not available on these analysis.

It was also difficult to measure the concentrations of nickel using an ICP-MS. Nickel from the sampling cones of the ICP-MS created an elevated baseline signal and made measurement of this element troublesome. A typical calibration curve for nickel and silver is presented in Figure 4.17. The nickel calibration curve crosses the $y$-axis at around 5,000 NACPS. This is in contrast with elements with low baseline signals, such as silver, where the $y$-intercept for the calibration curve approaches the origin. From the perspective of measuring nickel concentrations, the magnitude of the nickel baseline is secondary to the stability of the baseline. However, because the instrument is fundamentally based on counting statistics, signal stability is a function of signal magnitude. Higher signals, such as the nickel baseline signal, tend to have larger standard deviations associated with them. 


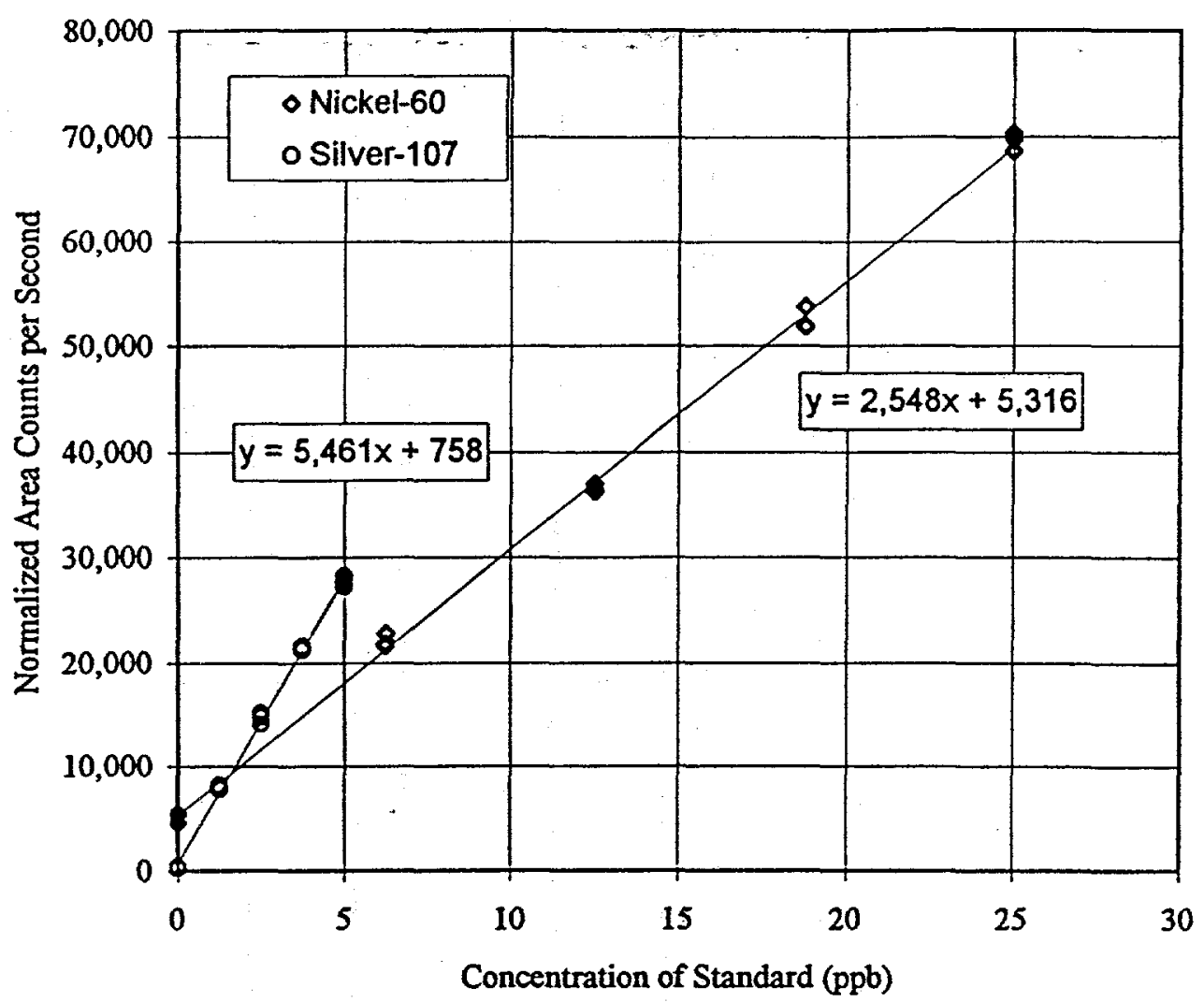

Figure 4.17. ICP-MS calibration curves of nickel and silver.

Nickel measurements were also susceptible to instrument drift as evidenced by the check standards that were analyzed at the end of a run. The ICP-MS was most prone to instrument drift whenever new sampling cones were installed. In the most extreme case, the nickel baseline effectively shifted up around $50 \mathrm{ppb}$ during the course of a nun. While some ICP-MS sessions were stable enough to allow nickel to be measured, most of the results are invalid. One of the sessions that analyzed total digestions of background soils was stable enough for nickel to suggest that this metal is present in some of the soils. However, information is not available to assemble a complete nickel extraction profile for any of the soils.

\section{Rubidium and Cesium}

The sequential extraction of rubidium and cesium from the background and CMP pit soils are presented the appendix as Tables A.23 through A.26 and are summarized in Figure 4.18 for rubidium and Figure 4.19 for cesium. As shown, the bulk of rubidium and cesium in the soils are not released until the 
final extraction step. Detectable quantities of rubidium were released from each step except PP. Detection limits for rubidium in these extracts were relatively higher $(0.2 \mathrm{mg} / \mathrm{kg})$ because this element is an impurity in the sodium PP reagent. Cesium was not detected in any of the DDI, Salt, Ac, or DC extracts from the background soils.

Rubidium is present in the SRS soils at concentrations that range between 10 and $30 \mathrm{mg} / \mathrm{kg}$, while stable cesium is present at lower concentrations- between 0.5 and $5 \mathrm{mg} / \mathrm{kg}$. Total concentrations of these elements in the background soils are influenced by the soil clay content $R^{2}=0.59$ for nubidium and $R^{2}=$ 0.83 for cesium). The precision of the rubidium and cesium results, particularly with respect to the HF extraction step, is poor with relative standard deviations that were as high as 187 percent for rubidium and 78 percent for cesium (both were from the replicates of Blanton \#45). As a result, the mass balances of the sequential extractions ranged between 46 and 107 percent for rubidium and 51 and 171 percent for cesium.

The CMP pit soil samples show the same general trends as the background soils, with the bulk of these elements are retained in the soil until the final extraction step. A notable exception is that rubidium is released from CMP Pit sample 3A during the Salt and Ac extraction steps at concentrations exceeding 1 . $\mathrm{mg} / \mathrm{kg}$ - higher than any of the background soils or other waste site samples. Sample 3A also has higher amounts of cesium released during early extraction steps relative to the other samples. 

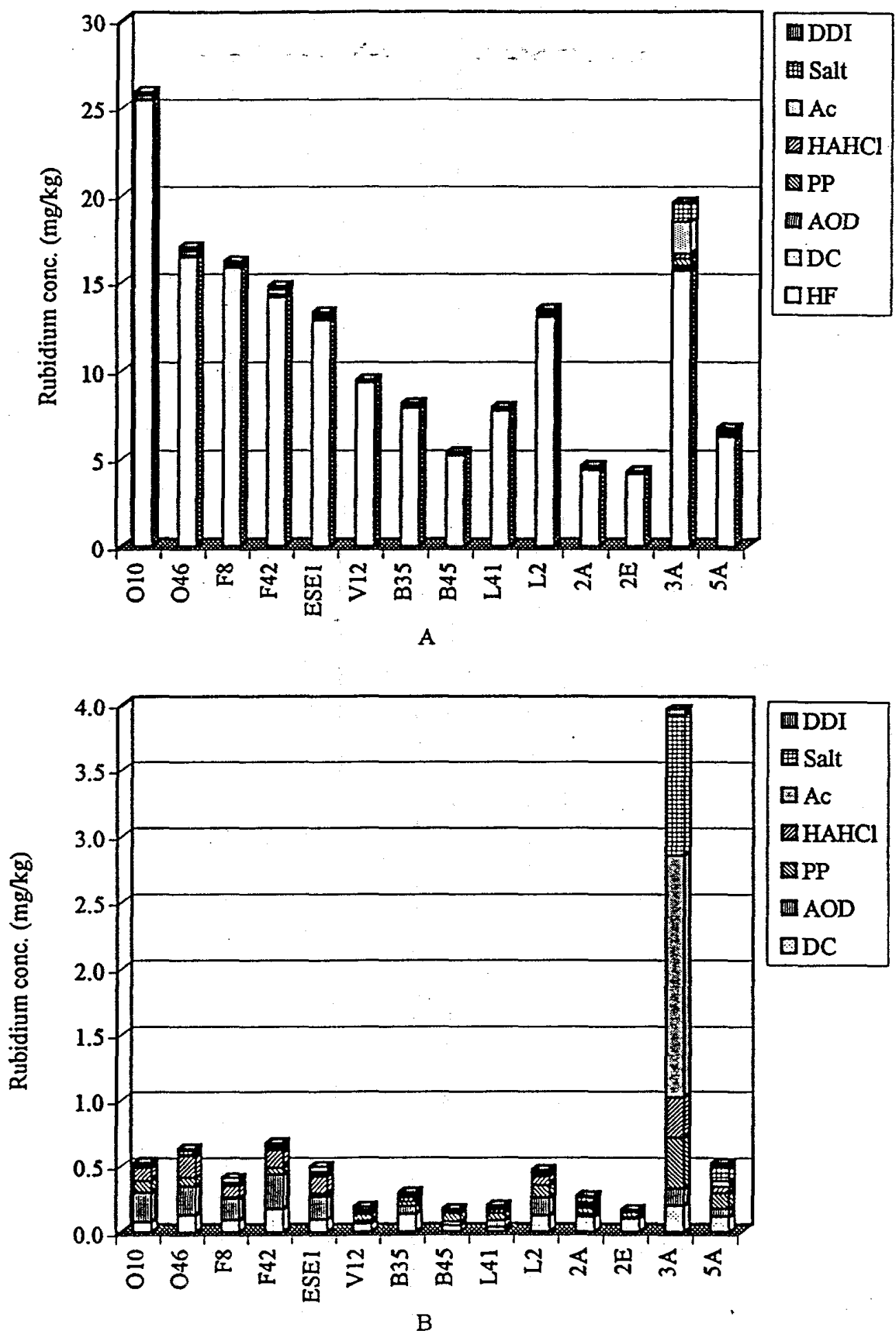

Figure 4.18. Sequential extraction profiles of rubidium from background and CMP pit soil samples. Figure A presents the amount of rubidium released during the entire extraction procedure (steps DDI through HF). Figure $B$ is a detail focussing on the first seven steps (steps DDI through DC). 




A

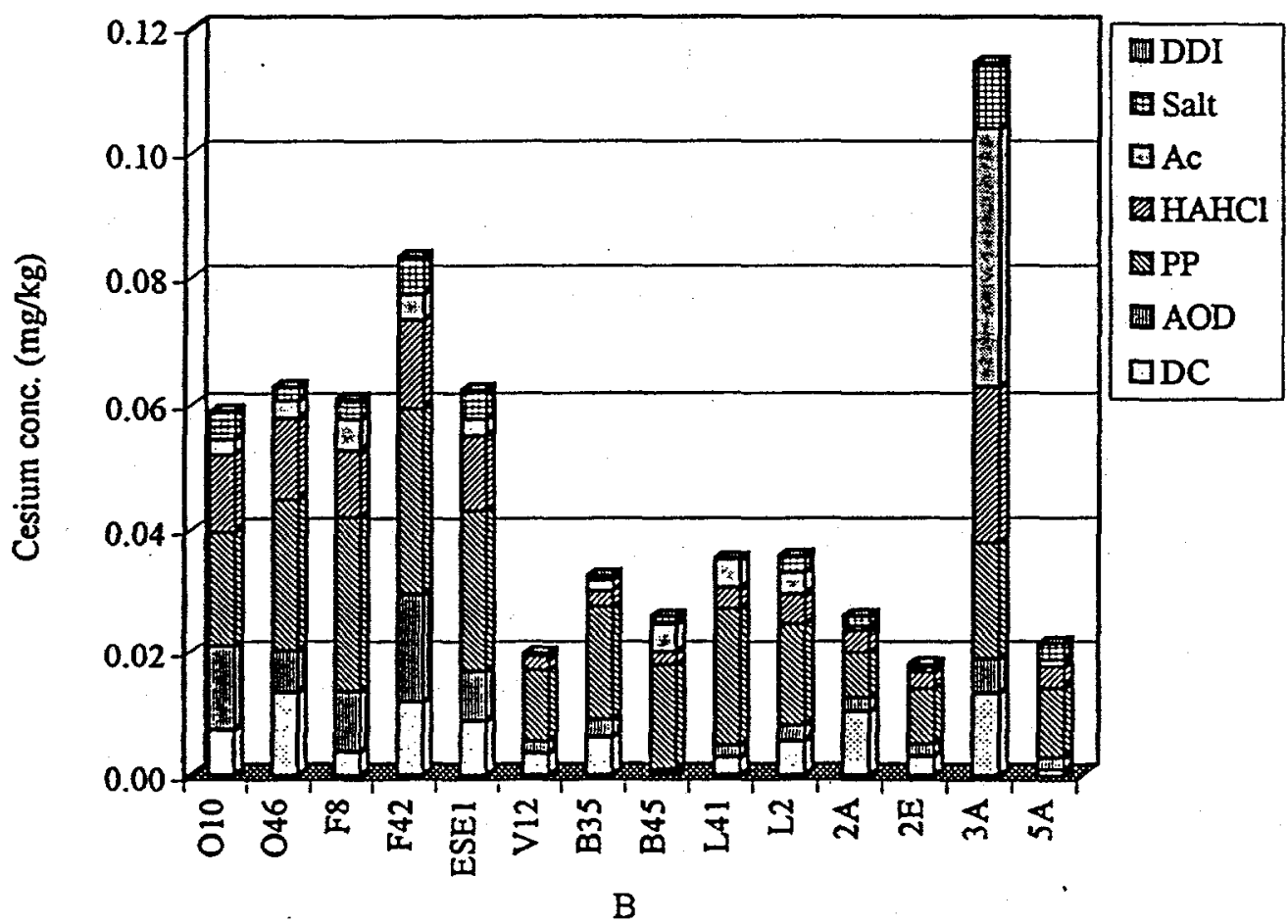

Figure 4.19. Sequential extraction profiles of cesium from background and CMP pit soil samples. Figure A presents the amount of cesium released during the entire extraction procedure (steps DDI through HF). Figure $B$ is a detail focussing on the first seven steps (steps DDI through DC). 
Cerium and Other Lanthanides

Results from the sequential extraction procedure for cerium are presented in the appendix as Tables A.27 and A.28 and are summarized in Figure 4.20. As shown, cerium is present at detectable concentrations in all the soil samples. Total concentrations in the background soils range between 2 and 30 $\mathrm{mg} / \mathrm{kg}$ and are influenced by clay content $\left(\mathrm{R}^{2}=0.75\right)$. In contrast with other trace elements, the results suggest that there is more than one major soil fraction associated with cerium. Much of the cerium is released from the background soils during early extraction steps. It was detected in every extraction step from the background soils but was concentrated in the Salt, Ac, PP and DC steps.

Percent recoveries exceed 100 percent for most of the background soils. The extreme case was Orangeburg \#10 where the amount of cerium from the sequential extraction procedure was twice as high as the amount from the total digestions. A possible explanation for these discrepancies is that cerium is unstable in the presence of fluoride ions. Lanthanides precipitate in the presence of fluoride ions even in 3 $M$ nitric acid (Cotton and Wilkinson, 1972). Cerium results are missing for the samples that were analyzed during the last of the four sessions that analyzed the HF samples because cerium was not stable in the calibration standards.

The amount of cerium released from soils $2 \mathrm{~A}, 2 \mathrm{E}$, and $5 \mathrm{~A}$ during the salt extraction is comparable to the low clay background soils. Although smaller quantities of cerium are released from sample $3 \mathrm{~A}$ during the salt step compared to the other waste site soils, cerium released from the $3 \mathrm{~A}$ during subsequent steps, Ac through $A O D$, is consistently higher.

One advantage of an ICP-MS as an instrument to measure trace metals is that it is capable of scanning a sample for almost all metals without having to explicitly state the analytes of interest beforehand. This advantage was exploited during the analysis of the CMP pit waste sites because lanthanides were detected in the $\mathrm{HAHCl}$ extracts from sample $3 \mathrm{~A}$. Figure 4.21 presents the details, focussing on the mass region for lanthanides, of one of the spectrums acquired from the $\mathrm{HAHCl}$ extracts of sample $3 \mathrm{~A}$. This cluster of peaks was present in the all the spectra acquired from the $\mathrm{HAHCl}$ extracts of sample $3 \mathrm{~A}$ and indicates the presence of all of the stable lanthanide elements (promethium is not a naturally occurring element; isotopes of promethium have a half life of less than 20 years). The concentrations of the elements released from the 

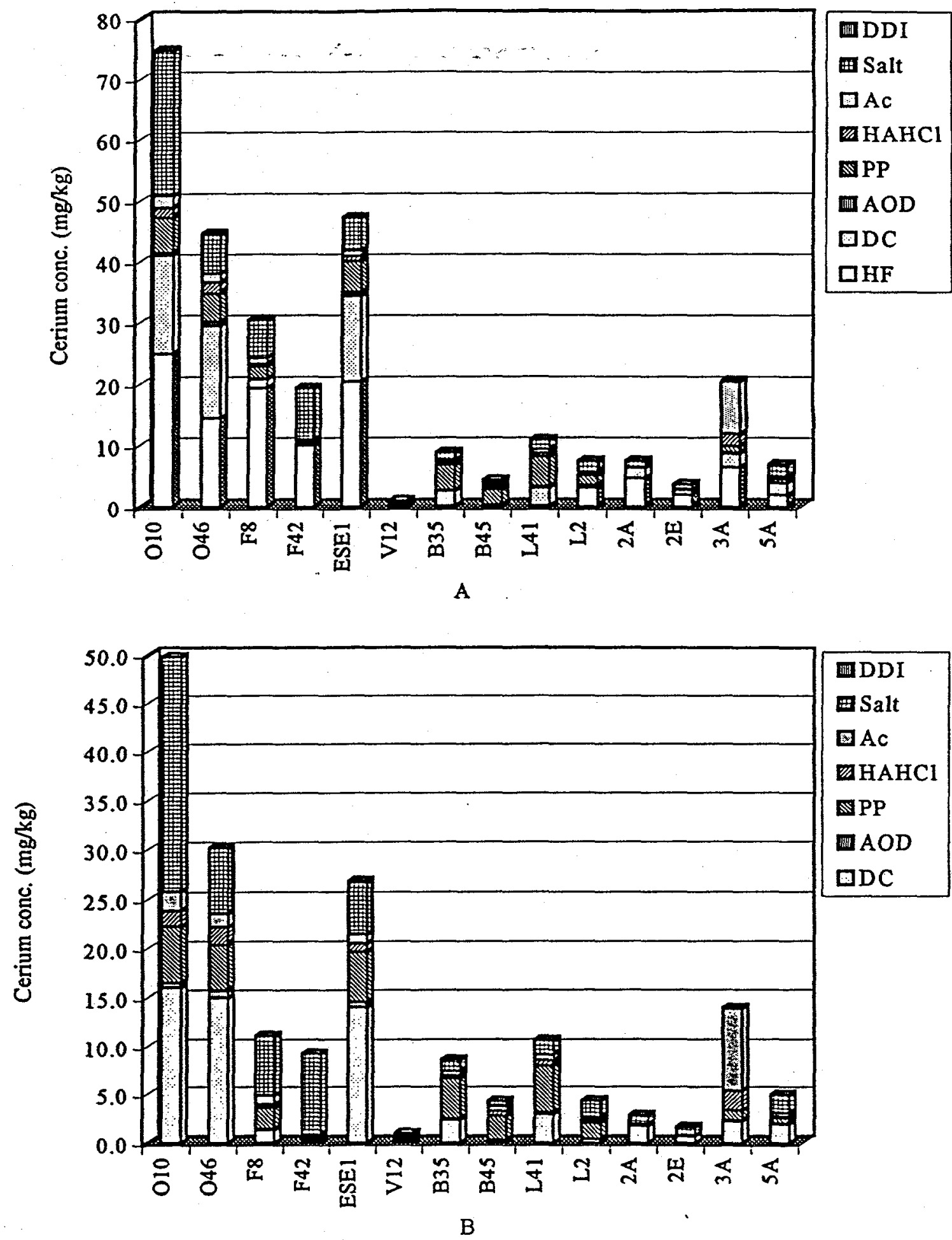

Figure 4.20. Sequential extraction profiles of cerium from background and CMP pit soil samples. Figure A presents the amount of cerium released during the entire extraction procedure (steps DDI through HF). Figure $B$ is a detail focussing on the first seven steps (steps DDI through DC). 
soil were estimated using the semi-quantitative analysis function of the instrument and are presented in Table 4.9. The presence of these elements was not observed in any of the spectra from the background soils or any of the other extraction steps from sample $3 \mathrm{~A}$. It should be noted that, with the exception of cerium and lanthanum, the elements are present at low levels and that the $\mathrm{HAHCl}$ and DDI extracts were the only extracts that were analyzed without any dilution. The low concentrations combined with the dilution factors required for the other extracts may have prevented these elements from being detected. Lanthanides are naturally present in soil in the mineral form of monzanite. However, because the entire lanthanide series was never detected in any of the background samples, it is unlikely that the occurrence of these elements in CMP Pit sample 3A is natural. The ratios of the barium, cesium, and lanthanide peaks are such that the isotopic distributions of the elements reflect their natural abundances. The isotopic distributions of elements in the rubidium and strontium region of the mass spectra were also all consistent with natural abundances. These distributions do not suggest that the lanthanides in sample $3 \mathrm{~A}$ are fission products. 


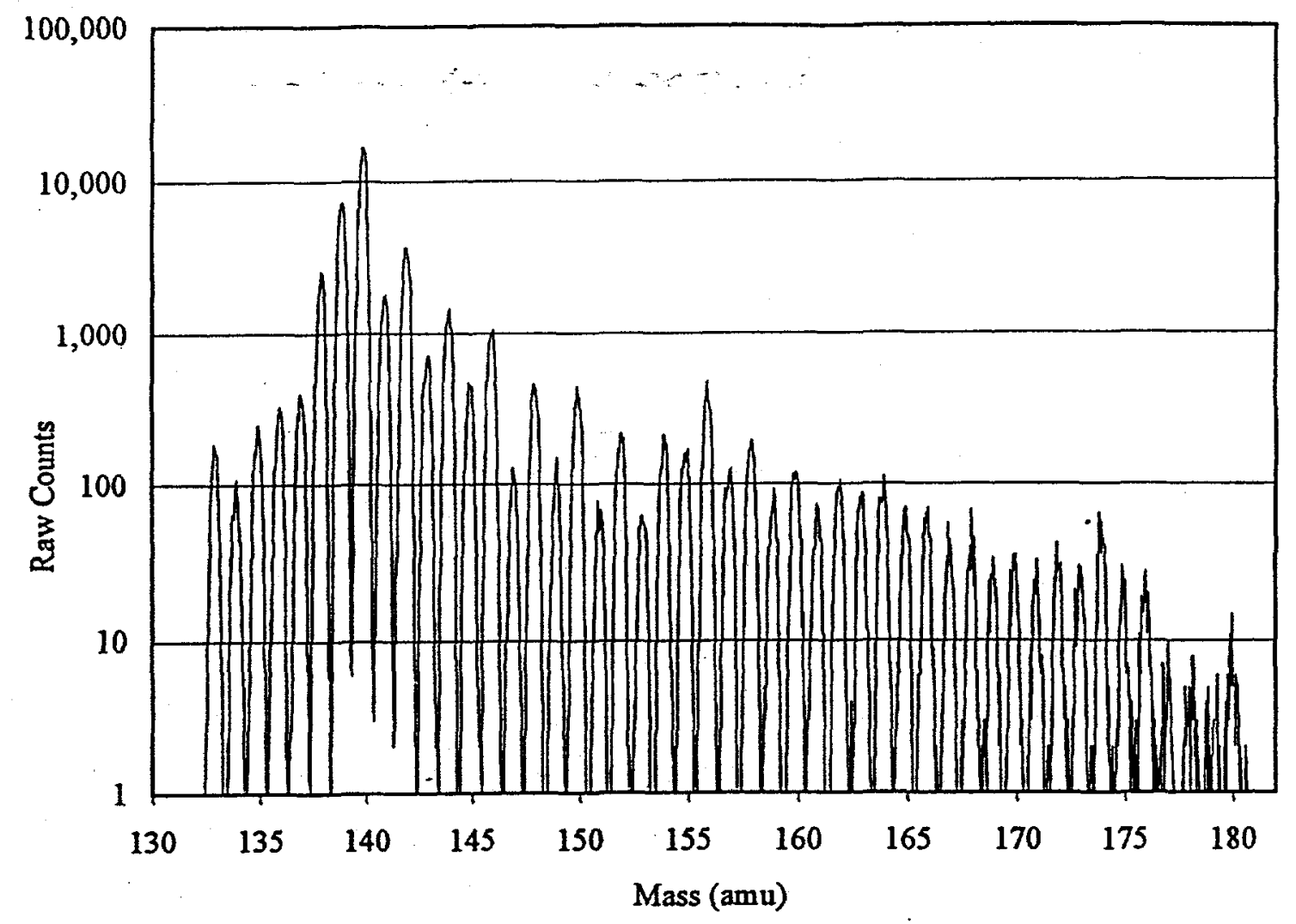

Figure 4.20. Detail of a mass spectrum from an $\mathrm{HAHCl}$ extract of CMP Pit soil sample $3 \mathrm{~A}$.

Table 4.9. Concentration of lanthanides in $\mathrm{HAHCl}$ extracts from CMP Pit sample 3A

\begin{tabular}{|c|c|}
\hline Lanthanide & $\begin{array}{c}\text { Concentration } \\
(\mu \mathrm{g} / \mathrm{kg})\end{array}$ \\
\hline Lanthanum (La) & 689 \\
\hline Cerium (Ce) & 2248 \\
\hline Praseodymium (Pr) & 174 \\
\hline Neodymium (Nd) & 617 \\
\hline Samarium (Sm) & 89 \\
\hline Europium (Eu) & 17 \\
\hline Gadolinium (Gd) & 98 \\
\hline Terbium (Tb) & 10 \\
\hline Dysprosium (Dy) & 52 \\
\hline Holmium (Ho) & 8 \\
\hline Erbium (Er) & 25 \\
\hline Thulium (Tm) & 3 \\
\hline Ytterbium (Yb) & 23 \\
\hline Luteium (Lu) & 4 \\
\hline
\end{tabular}




\section{Discussion of Results}

Availability of Trace Metals in Background Soils

\section{Differences in Trace Metal Availability Among Background Soils}

Based on the review of the ICP-MS results, data for eight trace metals $(\mathrm{U}, \mathrm{Pb}, \mathrm{Cr}, \mathrm{Ba}, \mathrm{V}, \mathrm{Cr}, \mathrm{Cs}, \mathrm{Ce}$, and $\mathrm{Rb}$ ) were used to evaluate differences among the background soils. Consistent results were not observed for other trace metals of interest such as arsenic, selenium, thorium, zinc, nickel, and copper.

One of the major differences between the background soils is soil texture. Because other factors, such as $\mathrm{pH}$ and organic matter, are similar for all the soils, these confounding factors are minimized and the data set from these soils illustrates the important role that the clay fraction plays in the total concentrations and environmental availability of trace metals in SRS soils. The clay contents of the ten background soils were distributed between 1 percent (Vaucluse \#12) and 25 percent (Orangeburg \#46). The ranges of trace element concentrations measured in the background soils and the correlation coefficients with clay content are summarized in Table 4.10. As shown, total concentrations of vanadium, cerium, chromium, lead, cesium, and uranium $\left(\mathrm{R}^{2}>0.73\right)$ are correlated with clay content of the background soils.

Soil texture also seems to influence the environmental availability of at least some trace elements in the background soils. One way to quantify environmental availability from a sequential extraction procedure is to sum together the amount of metal released from extraction steps that are associated with labile fractions of the soil. For the sequential extraction procedure that was used in this project, Johnson (1995) divides available and residual metals between the AOD and DC extraction steps. Metals released from the soil during the first six extraction steps operationally represent the environmentally available pool of trace metals, while the metals release during the final two extraction steps (DC and HF) represent the residual fraction. Presented in Table 4.11 are the concentrations of trace metal released from the first six extraction steps for nine of the elements of interest and the comparisons between available metals and clay content of the soil. The values were calculated by:

- averaging, across replicates of a soil sample, the amount of metals released during each extraction step, and

- summing together the average amount of a metal released from steps DDI through AOD (only positive values). 
Table 4.10. Ranges of total trace metal concentrations measured in background soils.

\begin{tabular}{|l|c|c|}
\hline Element & $\begin{array}{c}\text { Range of } \\
\text { Concentrations } \\
(\mathrm{mg} / \mathrm{kg})\end{array}$ & $\begin{array}{c}\text { Correlation with } \\
\text { Clay Content } \\
\left(\mathrm{R}^{2}\right)\end{array}$ \\
\hline Zirconium & $30-120$ & 0.13 \\
\hline Manganese & $30-80$ & 0.17 \\
\hline Barium & $10-60$ & 0.22 \\
\hline Vanadium & $10-50$ & 0.90 \\
\hline Cerium & $2-40$ & 0.75 \\
\hline Chromium & $10-30$ & 0.73 \\
\hline Rubidium & $10-40$ & 0.59 \\
\hline Strontium & $3-15$ & 0.55 \\
\hline Lead & $3-15$ & 0.84 \\
\hline Cesium & $0.5-5$ & 0.83 \\
\hline Cobalt & $1-5$ & 0.17 \\
\hline Uranium & $0.5-2$ & 0.82 \\
\hline Silver & $<0.5$ & N/A \\
\hline Cadmium & $<1$ & N/A \\
\hline Arsenic & $<10$ & N/A \\
\hline Selenium & $<10$ & N/A \\
\hline
\end{tabular}







The uncertainty surrounding each sum is quantified using standard error propagation techniques (Knoll, 1989) by calculating a standard deviation associated with each extraction step and, based on these standard deviations, the error from adding across extraction steps.

The information in this table suggests that soil texture influences the environmental availability of the uranium, vanadium, cesium, rubidium, and cerium present in background soils. Except for cerium, most of these metals are released from the soil during the HAHCl, PP, and AOD steps of the sequential extraction procedure. The DDI, Salt, and Ac extraction steps that are intended to remove metals from the surface of soil solids had little capacity to extract these naturally occurring trace metals.

Soil texture does not account for the differences in the environmental availability of lead, barium, and chromium between background soils. Chromium was below detection limits in all of the early extraction steps except PP. Lead and barium are released from soils during the salt extraction step and the amount of the metals released during this step is not completely explained by soil texture.

The clay sized component of soil solids plays an important role in the trace metals content of soils because reactive minerals such as kaolinites, sesquioxides, and humic substances are concentrated in this fraction. Smaller particles also have higher specific surface areas to react with aqueous species than larger sized particles.

Presented in Table 4.12 is the environmentally available fraction of trace metals released from the background soils as a percentage of the total concentration. As shown, the amount of naturally occurring trace metals released during the first six steps is generally small when compared to the total metals content of a soil, with the exception being barium, cerium, and lead. Additionally, differences in availability between soil types is not as apparent when evaluated on the basis of fractions of total metal concentrations. 
Table 4.12. Environmentally available trace metals as a fraction of total metals.

\begin{tabular}{|l|c|c|c|c|c|c|c|c|}
\hline & \multicolumn{6}{|c|}{ Environmentally available trace melals as fraction of total melal concentration (percent) } \\
\cline { 2 - 8 } \multicolumn{1}{c|}{ Sample ID } & $\mathrm{U}$ & $\mathrm{Pb}$ & $\mathrm{Cr}$ & $\mathrm{Ba}$ & $\mathrm{V}$ & $\mathrm{Cs}$ & $\mathrm{Rb}$ & $\mathrm{Ce}$ \\
\hline Orangeburg \#46 & $13 \pm 2$ & $7 \pm 2$ & $1 \pm 3$ & $37 \pm 8$ & $9 \pm 1$ & $1.9 \pm 0.4$ & $2.9 \pm 0.5$ & $34 \pm 5$ \\
\hline Orangeburg \#10 & $18 \pm 3$ & $26 \pm 5$ & $2 \pm 2$ & $39 \pm 13$ & $8 \pm 1$ & $1.1 \pm 0.2$ & $1.7 \pm 0.2$ & $45 \pm 7$ \\
\hline Fuquay \#42 & $23 \pm 10$ & $18 \pm 5$ & $4 \pm 4$ & $32 \pm 10$ & $10 \pm 3$ & $2.6 \pm 0.5$ & $3.3 \pm 0.9$ & $46 \pm 19$ \\
\hline ESE \#1 & $15 \pm 2$ & $16 \pm 2$ & $2 \pm 4$ & $45 \pm 8$ & $10 \pm 1$ & $2.2 \pm 0.4$ & $2.8 \pm 0.7$ & $27 \pm 3$ \\
\hline Fuquay \#8 & $16 \pm 2$ & $9 \pm 1$ & $3 \pm 2$ & $25 \pm 2$ & $11 \pm 1$ & $1.7 \pm 0.6$ & $1.9 \pm 0.5$ & $32 \pm 7$ \\
\hline Lakeland \#2 & $12 \pm 6$ & $7 \pm 4$ & $5 \pm 4$ & $32 \pm 21$ & $8 \pm 3$ & $1.6 \pm 0.9$ & $2.3 \pm 1.7$ & $53 \pm 20$ \\
\hline Lakeland \#41 & $11 \pm 4$ & $31 \pm 7$ & $4 \pm 14$ & $49 \pm 8$ & $7 \pm 3$ & $2.5 \pm 0.5$ & $2.1 \pm 0.6$ & $71 \pm 16$ \\
\hline Blanton \#35 & $22 \pm 16$ & $61 \pm 19$ & $3 \pm 11$ & $65 \pm 19$ & $7 \pm 4$ & $3.0 \pm 1.9$ & $2.1 \pm 2.2$ & $71 \pm 6$ \\
\hline Blanton \#45 & $14 \pm 7$ & $72 \pm 23$ & $9 \pm 27$ & $46 \pm 23$ & $11 \pm 8$ & $6.7 \pm 5.0$ & $2.5 \pm 4.7$ & $49 \pm 6$ \\
\hline Vaucluse \#12 & $8 \pm 2$ & $48 \pm 25$ & $4 \pm 5$ & $70 \pm 8$ & $9 \pm 2$ & $3.5 \pm 1.0$ & $1.4 \pm 1.1$ & $79 \pm 16$ \\
\hline
\end{tabular}


To investigate the relationship between environmentally available components of soil trace metals and HFO reactive surfaces, environmentally available trace metals were plotted against iron released during the HAHCl, PP, and AOD extraction steps. Relatively large standard deviations limit the value of the chromium and cesium information (most of the values were below detection limits). Rubidium, lead, barium and cerium are not strongly correlated with iron removed during the three extraction steps, with correlation coefficients $\left(R^{2}\right)$ not exceeding 0.4 (presented as Table 4.13). The remaining two elements, uranium and vanadium, are weakly correlated with iron $R^{2}=0.66$ for vanadium and $R^{2}=0.53$ for uranium).

Table 4.13. Correlation of environmentally available trace metals with different soil components.

\begin{tabular}{|l|c|c|c|}
\hline \multirow{2}{*}{$\begin{array}{c}\text { Trace } \\
\text { Metal }_{1-6}\end{array}$} & \multicolumn{3}{|c|}{ Correlation Coefficient $\left(\mathrm{r}^{2}\right)$} \\
\cline { 2 - 4 } & $\mathrm{Fe}_{46}$ & $\mathrm{Fe}_{\mathrm{Al}} \mathrm{Al}_{4-6}$ & $\mathrm{Al}_{1-6}$ \\
\hline Barium & 0.29 & 0.43 & 0.50 \\
\hline Cerium & 0.38 & 0.60 & 0.65 \\
\hline Lead & 0.07 & 0.12 & 0.14 \\
\hline Uranium & 0.53 & 0.83 & 0.92 \\
\hline Vanadium & 0.66 & 0.83 & 0.77 \\
\hline Chromium & 0.33 & 0.39 & 0.36 \\
\hline Rubidium & 0.19 & 0.45 & 0.67 \\
\hline Cesium & 0.15 & 0.40 & 0.61 \\
\hline
\end{tabular}

Because iron and aluminum are readily substituted for each other in their respective oxides, a similar comparison was made between environmentally available trace metals and iron and aluminum removed from the soil during the $\mathrm{HAHCl}, \mathrm{PP}$, and $\mathrm{AOD}$ extraction steps. On a molar basis, iron represents only between 30 and 40 percent of the iron and aluminum released from the background soils during these steps. Iron released during these steps from Fuquay $\# 42$ only comprises 17 percent of iron and aluminum. As a result, it is unlikely that all of the aluminum is isomorphically substituted into HFO minerals: Rather, discrete aluminum oxide phases such as gibbsite or noncrystalline aluminum oxides may be present in soil. Irrespective, the correlation coefficients, (also presented in Table 4.13) do not improve for barium, cerium, lead, and rubidium when correlated against iron and aluminum released during the $\mathrm{HAHCl}, \mathrm{PP}$, and $\mathrm{AOD}$ 
steps for. The correlation coefficients for vanadium and uranium increase to 0.8 when correlated against iron and aluminum.

Because, on a molar basis, more aluminum than iron is removed during the first six extraction steps, environmentally available trace metals were compared to aluminum released during the first six extraction steps. Aluminum released during these extraction steps was concentrated into three of the extraction steps, Ac, PP, and AOD. These three steps comprise, on average, 90 percent of aluminum removed during the first six steps from the background soils, with all values falling between 80 and 95 percent. The correlation coefficients describing the relationship between environmentally available trace metals and aluminum extracted through the AOD extraction step are also presented in Table 4.13. Environmentally available uranium and aluminum are highly correlated with each other $\left(\mathrm{R}^{2}=0.92\right)$ and the relationship is graphed as Figure 4.22. The sequential extraction profiles of the two elements are similar in that both have components that are associated with the Ac extraction step. The strong correlation between these two metals suggests that environmentally available uranium is controlled by aluminum oxides present in the background soils.



Figure 4.22. Environmentally available uranium from SRS background soils plotted against aluminum extracted during the first six sequential extraction steps. 


\section{Differences in Availability Among Trace Metals}

Sequential extraction results of the different trace metals from the background soils can be roughly grouped into four categories:

- results where the metal is present in the soils at very low, essentially insignificant amounts (silver, cadmium, and cobalt),

- resuits that show significant quantities of trace metals released sometime during the first three extraction steps (lead, barium, and cerium),

- results where the metal remains in the soil until the final two extraction steps (DC and HF) but is present in both fractions (chromium and vanadium), and

- results where most of the metal is released from the soil only during the final (HF) extraction step (rubidium, cesium, and, to some extent, uranium).

Figure 4.23 illustrates the different extraction profiles for lead, barium, cerium, chromium, vanadium, rubidium, cesium, and uranium. The results in this figure are from the sequential extraction of Orangeburg \#10 except for the barium results, which are from Orangeburg \#46. Uranium seems to share characteristics of all of these groups. It is present in the background soils at low concentrations; never exceeding 2-3 $\mathrm{mg} / \mathrm{kg}$ and, although the bulk of the metal is not released until the final extraction step, soils with higher clay contents consistently show uranium released throughout the extraction profile, with the Ac extraction step playing a significant role. 


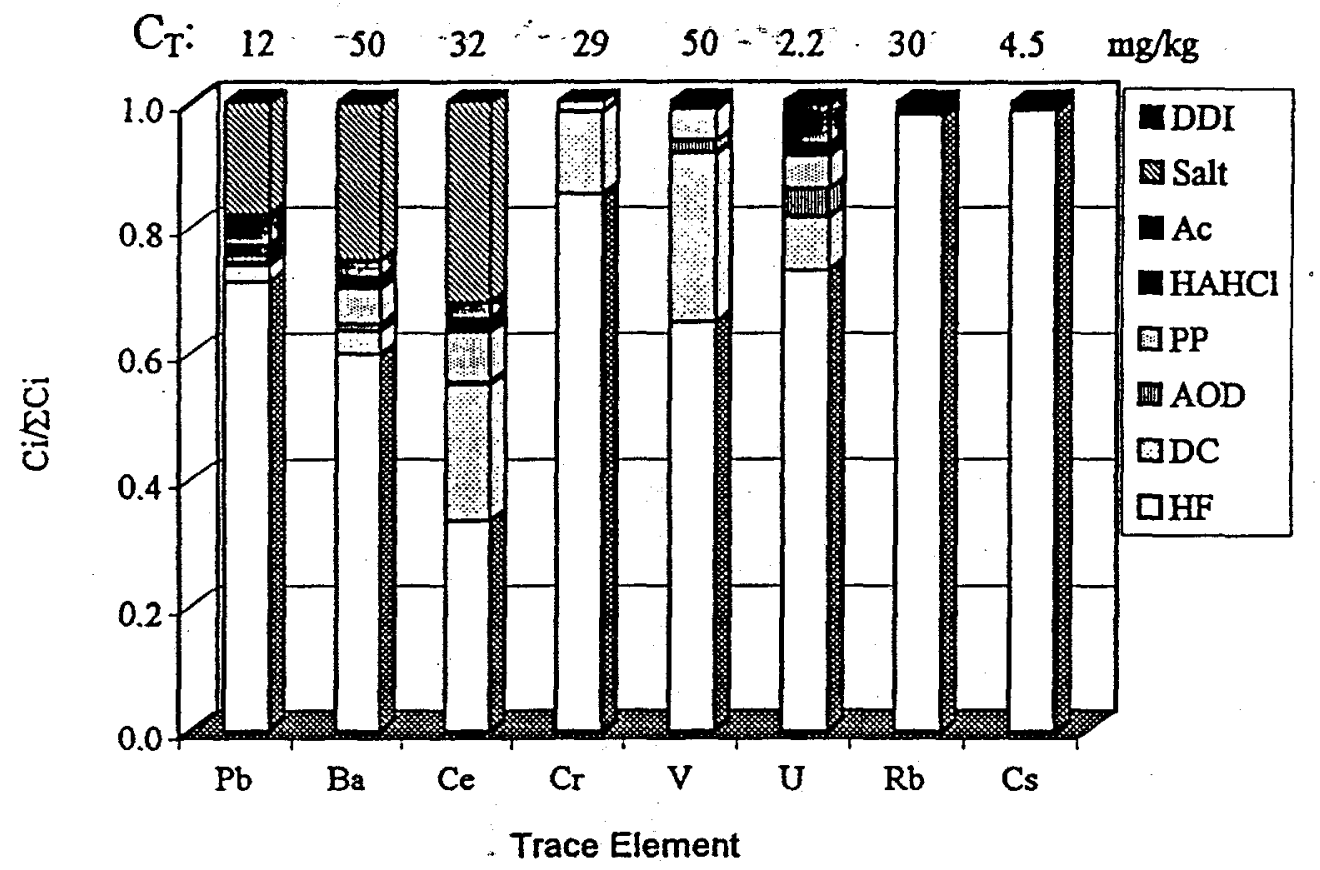

Figure 4.23. Sequential extraction of profiles of different trace elements from SRS background soils. The barium results are from Orangeburg $\# 46$, while the other results are from Orangeburg \#10.

The association between the metals and soils were created in uncontrolled natural environments and it is difficult to draw detailed conclusions that explain why different metals have different sequential extraction profiles. Because lead, barium, and cerium have components that were released during the first three extraction steps, this suggests that these metals are associated with the surface of soil minerals. Barium and cerium are ionic metals and electrostatic interactions between charged surfaces and these ions are likely to play an important role in the sorption process. As previously mentioned, uranium and aluminum are strongly correlated with each other, suggesting that aluminum oxides control the environmentally available component of this naturally occurring radionuclide. The oxyanions, chromate and vanadate $\left(\mathrm{CrO}_{4}^{-2}\right.$ and $\left.\mathrm{VO}_{4}^{-2}\right)$ display strong affinities toward iron oxide minerals. With this in mind, it is not surprising to find that these metals are associated with the DC extraction step. Because they are not released until the final sequential extraction step, soil rubidium and cesium are bound up in residual phases of the soil. Monovalent cations, such as these, are commonly found in the interlayer spaces of 2:1 clay minerals. 
Differences between Waste Site Soils and Background Soils

Figures 4.8 and 4.9 contrast the sequential extraction profiles of uranium from the background soils and the soil samples from the F-Area Seepage Basin. The sequential extraction technique shows differences in the environmental availability of uranium from the F-Area Seepage Basin soils when compared to the background soils. Although complete sequential extraction profiles are not available for the samples, a greater fraction of the soil uranium in the waste site soils is released during early extraction steps when compared to the background soils. Because total uranium concentrations were also higher in the waste site soils when compared to the background soils, differences between these two sets of samples can also be resolved based on total metal concentrations.

At least one of the soil samples collected from the CMP Pits, sample 3A, is contaminated as indicated by the presence of lanthanides in the $\mathrm{HAHCl}$ extracts and the titanium removed during the early extraction steps. The site history reveals that the side slopes at the CMP Pits were used to dispose of fluorescent light bulbs. It is likely that the source of the environmentally available titanium and the lanthanides are from land disposal of these materials. Lanthanides are commonly used in fluorescent light bulbs as phosphors to convert the ultra-violet light emitted from mercury vapors or noble gases to visible light. Strontium-, calcium-, and magnesium-based phosphors are also commonly used in these type of lights (Srivastava and Soules, 1995). They are mixed with paint (likely to contain titanium dioxide) and coat the inside of fluorescent light bulbs (Waymouth, 1992). Because of its low solubility, the titanium that is present in the early extraction steps likely originates from titanium dioxide particles that are less than $0.45 \mu \mathrm{m}$ in diameter and pass through the syringe filters.

The sequential extraction profiles from soil sample $3 \mathrm{~A}$ suggest that this sample may have anthropogenic sources of other metals. A comparison between CMP pit sample $3 \mathrm{~A}$ and the ter background soils is presented in Table 4.14 and it illustrates the utility of a sequential extraction technique for detecting low level contamination in samples with naturally occurring trace metals. This table compares the amount of cerium, cesium, rubidium, and barium released during extraction steps DDI through AOD from CMP pit sample $3 \mathrm{~A}$ with the average amount of these metals released from all the background soils.

Environmentally available cerium in CMP pit sample $3 \mathrm{~A}$ exceeds the average amount of environmentally available cerium in the background soils by $9 \mathrm{mg} / \mathrm{kg}$. More importantly, it is around 5 standard deviations 
above the background mean. Similar results are seen with the amount of environmentally available cesium and rubidium. Environmentally available barium does not seem significantly different from that observed from the background soil. A comparison of this sample based on the total digestion results leads to different conclusions. In these comparisons, the amount of total cerium, cesium, and rubidium present in soil sample $3 \mathrm{~A}$ falls below the average background soil concentrations. 
Table 4.14. Comparison of trace metals released from CMP Pit soil sample $3 \mathrm{~A}$ compared to average background concentrations.

\begin{tabular}{|l|c|c|r|r|r|r|r|r|}
\hline & \multicolumn{4}{|c|}{ Sum of DDI through AOD (mg/kg) } & \multicolumn{3}{c|}{ Total Digestions (mg/kg) } \\
\cline { 2 - 9 } & $\begin{array}{c}\text { CMP Pit } \\
\text { Eample 3A }\end{array}$ & $\begin{array}{c}\text { Average of } \\
\text { Background } \\
\text { Soils }\end{array}$ & $\begin{array}{c}\text { Absolute } \\
\text { Difference }\end{array}$ & $\begin{array}{c}\text { Number of } \\
\text { Standard } \\
\text { deviations }\end{array}$ & $\begin{array}{c}\text { CMP Pit } \\
\text { Sample 3A }\end{array}$ & $\begin{array}{c}\text { Average of } \\
\text { Background } \\
\text { Soils }\end{array}$ & $\begin{array}{c}\text { Absolute } \\
\text { Difference }\end{array}$ & $\begin{array}{c}\text { Standard } \\
\text { deviations }\end{array}$ \\
\hline Cerium & $11.79 \pm 0.72$ & $2.41 \pm 1.85$ & 9.4 & 5.1 & $13.23 \pm 1.31$ & $17.59 \pm 10.59$ & -4.4 & -0.4 \\
\hline Cesium & $0.10 \pm 0.00$ & $0.04 \pm 0.02$ & 0.1 & 3.3 & $0.51 \pm 0.02$ & $2.87 \pm 1.70$ & -2.4 & -1.4 \\
\hline Rubidium & $3.77 \pm 0.76$ & $0.30 \pm 0.15$ & 3.5 & 23.2 & $18.23 \pm 1.25$ & $21.69 \pm 7.90$ & -3.5 & -0.4 \\
\hline Barium & $7.03 \pm 0.25$ & $7.07 \pm 4.49$ & -0.04 & -0.01 & $51.97 \pm 4.69$ & $25.76 \pm 14.89$ & 26.2 & 1.8 \\
\hline Lead & $2.65 \pm 0.71$ & $1.89 \pm 1.40$ & 0.76 & 0.54 & $8.56 \pm 0.29$ & $7.36 \pm 3.82$ & 0.3 \\
\hline
\end{tabular}


Applicability of the Sequential Extraction Procedure

Johnson (1995) identified several opportunities to improve the sequential extraction procedure that was used for this project. The suggestions included simplifying the procedure by eliminating extraction steps and taking measures to improve the recovery and accuracy of the results. Johnson (1995) noted that organic matter and amorphous iron oxides were not significant components of the samples that were examined and suggested eliminating the extraction steps that dissolve those soil components. To improve accuracy, he suggested that refreshing extraction reagents, particularly during the DC extraction, may improve the efficiency of extractions and minimize incomplete dissolution. He also suggested that contaminant recoveries can be improved by saving all the filters and combining them with the soil during subsequent extraction steps to prevent losses of fine soil particles.

There are additional experimental considerations that may result in incremental improvements in the sequential extraction procedure. One of the weaknesses of the procedure that should be considered is the poor precision of the results. Several changes may result in higher levels of precision. The largest source of error in the sequential extraction procedure was generally found in digestions of residual soil material. As was mentioned above, digesting the entire mass of residual material rather than a 200-mg subsample eliminates subsampling errors and may improve precision of the results. An effort should be made to determine the maximum amount of solids that can digested without resulting in excessive gas production or incomplete digestion, and then ensuring that the amount of digested solids approaches, but does not exceed this threshold.

Precision of results also depended on the concentration of the analyte in the solution. Generally, higher concentration metals yielded more precise results. There are several changes that could be incorporated into the technique that have the potential to increase the aqueous concentrations of trace metals extracted from the soil. One change would be to increase the solid:solution ratio during the extraction steps. The ratio currently employed, $750-\mathrm{mg}$ soil to $30 \mathrm{ml}$ of extractant, is on the low range when compared to other sequential extraction procedures in the literature. One consideration, however, is the capacity of the reagent to completely attack the targeted soil phase. Reactants in extraction reagents may be exhausted before the intended soil reaction proceeds to completion or aqueous products may accumulate and inhibit dissolution. Because SRS soils generally do not contain significant amounts of 
easily soluble salts, carbonates, or manganese oxides, and they do not have high cation exchange capacities and base saturations, increasing the solid to solution ratio may be appropriate for the first four extraction steps. Increasing the solid solution ratio may not be appropriate for during later extraction steps, such as the pyrophosphate and dithionate extraction particularly for soils with high concentrations of iron. The solid:solution ratio should be increased by increasing the mass of soil added to the extraction. This minimizes the error associated with the natural heterogeneity of samples.

Another change that may improve concentrations of analytes is to modify extraction reagents so that they complement sample analysis with an ICP-MS. Several of the reagents resulted in isobaric interferences that made it difficult to determine concentrations of transition metals such as copper and zinc. Using magnesium instead of calcium during the Salt and Ac extraction steps and during the intervening rinse steps may eliminate interferences due to calcium oxides. Employing potassium pyrophosphate instead of sodium pyrophosphate during the organic matter extraction step will eliminate interferences due to sodium argon dimers. Using a high-efficiency or desolvating nebulizer, low power plasma, or other modifications to the ICP-MS may increase the tolerance of the instrument to high concentrations of dissolved solids and reduce isobaric interferences due to polyatomic ions with argon, oxygen, and carbon. This may reduce the amount of dilution required for some of the extracts, increase analyte concentrations, and lower detection limits.

One modification that may improve accuracy of the technique is to combine the supernatant from the wash step with the previous extracts and bring it up to a known volume. This eliminates losses in the system due to the wash steps. As mentioned earlier in this report, the sequential extraction technique should also be modified to prevent unstable extracts. This can be accomplished by analyzing the pyrophosphate and dithionate extracts immediately after the samples have been generated, and not mixing calcium salts with the ammonium oxalate reagent. Adding a bicarbonate buffer to the dithionate/citrate extraction reagent, as prescribed by Mehra and Jackson (1960) may minimize precipitate formation.

Fundamental changes, such as eliminating extraction steps, may also improve the utility of the sequential extraction procedure in estimating the environmental availability of trace metals and contaminants from SRS soils. One modification would be to reduce the number of extraction steps. If the purpose of the extraction procedure is to estimate the fraction of trace metals or contaminants that are 
associated with labile soil components rather than investigate trace metal solid phase speciation, then it may not be necessary it divide the total pool of soil bound metals into eight fractions. The minimum number of necessary fractions is two: environmentally available and not environmentally available.

Because, as was pointed out by Tessier et al. (1979), no single-step extraction technique is able to attack all of the soil components of interest at once without dissolving residual materials, multi-step extraction procedures have advantages. However, more is not always better, and there reaches a point of diminished returns by adding extraction steps. Each extraction steps increases the uncertainty of the results, with respect to both precision and accuracy. Also, sequential extraction procedures that employ a large number of steps may not be the most appropriate or convenient technique for large sets of samples. A sequential extraction procedure should be designed with as few steps as possible (Johnson, 1995). Conversely, multi-step sequential extraction techniques can provide information on the major ion chemistry of the soil, particularly with respect to the different iron oxide components, and they have a utility beyond simply estimating an environmentally available pool of soil bound contaminants. Striking a balance between the number of steps and a description of the major ion chemistry requires of consideration of the relevant mineral phases in SRS soils.

Because SRS soils do not have significant amount of soluble salts, and have low cation exchange capacities, eliminating the first two extraction steps of the sequential extraction procedure would not significantly decrease the amount of useful information from the procedure. Using the Ac extraction step (acetic acid with a neutral salt) as the first step would have the effect of combining the first three steps into one. This step would target all metals and radionuclides sorbed onto the surface of soil minerals. Because manganese in the background soils rarely exceed $100 \mathrm{mg} / \mathrm{kg}$ and most subsurface soils at SRS contain low amounts of organic matter, the extraction steps that target discrete manganese oxide minerals and organic matter could also be eliminated from the procedure. Eliminating the pyrophosphate extraction step would also reduce the possibility of non-specific reactions with hydrous ferric oxide. The ammonium oxalate in the dark (AOD) extraction step would target the labile oxides in the soil, manganese oxides and hydrous ferric oxides.

Although this study combined the dithionate extraction and the residual digestion results to estimate the fraction of a trace metal that is not considered environmentally available, the distinction between these 
two extraction steps was useful, particularly for chromium and vanadium. The dithionate extraction, if allowed to proceed to completion, may also provide a useful indication of the amount of iron and aluminum not associated with clay minerals (free iron and aluminum).

Eliminating the deionized water, calcium nitrate, hydroxylamine hydrochloride, and pyrophosphate extraction steps would reduce the number of steps in the sequential extraction procedure from eight to four. The remaining four steps, using acetic acid, ammonium oxalate in the dark, dithionate/citrate/bicarbonate, and a residual digestion may still be as effective as the original technique in estimating the environmental availability of trace metals and contaminants in soils and characterizing the major ion chemistry of SRS soils. 


\section{CHAPTER 5}

\section{CONCLUSIONS}

The upland soils at the Savannah River Site contain detectable amounts of naturally occurring trace metals such as lead, uranium, chromium, barium, and others. However, the RCRA metals silver and cadmium were never detected in any of background soil samples despite the low detection limits available with an ICP-MS. Much of the chromium, uranium, vanadium, rubidium, and cesium present in the soils are in a leach resistant, environmentally unavailable form as demonstrated by the sequential extraction profiles of these metals from the soils. Although much of the soil bound barium, lead, and cerium are associated with the residual fraction of the soils, a fraction of these metals is also present in a more environmentally available form that can be removed from soils with high concentrations of neutral salts.

The amount of clay sized material in a soil influences both the total concentration and the environmentally available portion of naturally occurring soil bound uranium, vanadium, cesium, and nubidium. Soils with relatively higher amounts of clay tend to have more trace metals than soils with lower amounts of clay. This has implications to waste site characterization efforts because soil texture represents a confounding factor that is not generally considered when comparing background and waste site soil samples. Additionally, environmentally available uranium from the background soils was highly correlated with aluminum that was removed during the first six extraction steps.

All the background soils examined in this study were acidic, well drained, sandy soils with low amounts of organic matter. Although these types of soils cover most of the Savannah River Site, other soils with higher amounts of organic carbon and higher moisture contents are present at the site (particularly in strearn valleys and areas of lower elevation). The distribution of trace metals in these soils was not examined and it may not be appropriate to extrapolate the conclusions of this project to these other types of soils.

Anthropogenic sources of metals from two waste sites at SRS, the F-Area Seepage Basins, and the CMP Pits, are in a more environmentally available form than from background sources, and a sequential extraction technique can be used to resolve sources of metals in waste site soils. The distribution of 
cesium, rubidium, and cerium in soil sample $3 \mathrm{~A}$ from the CMP Pits demonstrates that a procedure that fractionates total soil bound metals based on the concept of environimental availability can detect low level contamination. Anthropogenic metals can be detected even when contaminated soils are not significantly different from the background soils on the basis of total metal concentrations. 
CHAPTER 6

\section{ENGINEERING AND SCIENTIFIC SIGNIFICANCE}

There are numerous areas at SRS where the soils contain metals because of site operations. An accurate evaluation of the environmental impact of low level contamination sometimes requires a better characterization of the contamination than is offered by using total soil concentrations of contaminants. Distinguishing between natural and anthropogenic sources of trace metals is helpful during site characterization studies or remedial investigation and feasibility studies (RU/FS) where investigators identify contaminants of concern. Many waste sites around the country are similar to the CMP Pits at SRS. The initial impetus for site investigation and cleanup activities are chlorinated solvents and other synthetic chemicals. However, inadequate characterization of background and waste site metals concentrations often implicate naturally occurring trace metals as contaminants of concern (Streeter et al., 1992). This results in site cleanup efforts that may seem to clean up soil to below-background levels. Techniques, such as sequential extraction procedures, that improve the ability to resolve between anthropogenic and natural sources provide more realistic estimates of contaminants of concern at waste sites.

By focussing on the trace metal contents in SRS background soils, this research identified a confounding factors, soil texture and extractable iron and aluminum, that should be considered when making comparisons between waste site and background soils. Although the sequential extraction technique is limited in its ability to describe the solid phase speciation of trace metals in soils, it was able to identify general differences in the behavior of different trace metals in soil. Some metals, such as lead, cerium, and barium, have components that are in a more environmentally available form, while other metals (chromium, vanadium, nubidium, and cesium) are more difficult to extract and are associated with weather resistant soil minerals such as iron oxides and clay minerals. 
APPENDIX 
Table A.1. Sequential extraction of iron from SRS background soils.

\begin{tabular}{|c|c|c|c|c|c|c|c|c|c|c|c|c|c|}
\hline \multirow{2}{*}{$\begin{array}{c}\text { Background Soil } \\
\text { Sample ID }\end{array}$} & \multirow[b]{2}{*}{ Trial } & \multicolumn{10}{|c|}{ Iron Removed During Extraction Step (mg/kg) } & \multirow{2}{*}{$\begin{array}{c}\text { Average } \\
\text { Total }\end{array}$} & \multirow{2}{*}{$\begin{array}{l}\text { Percent } \\
\text { Recovery }\end{array}$} \\
\hline & & DDI & Salt & Ac & $\mathrm{HAHCl}$ & PP & AOD & $\overline{\mathrm{DC}}$ & HF & Sum & TD & & \\
\hline \multirow{3}{*}{$\begin{array}{c}\text { Orangeburg } \\
\quad 110\end{array}$} & 62 & 0.17 & -17.0 & *9 & 10.7 & 605 & 176 & 8,927 & 4,569 & 14,280 & 14,993 & \multirow{3}{*}{14,663} & \multirow{3}{*}{$104 \%$} \\
\hline & 63 & $* 0.11$ & -8.5 & -40 & 7.3 & 593 & 172 & 6,732 & 8,700 & 16,235 & 14,422 & & \\
\hline & 64 & -0.24 & -31.1 & $* 7$ & 6.3 & 733 & 152 & 6,958 & 7,331 & 15,218 & 14,574 & & \\
\hline \multirow{3}{*}{$\begin{array}{c}\text { Orangeburg } \\
\# 46\end{array}$} & 97 & $\$ 0.09$ & $*-6.5$ & *6 & 10.4 & 163 & 244 & 5,663 & 3,962 & 10,041 & 8,700 & \multirow{3}{*}{9,045} & \multirow{3}{*}{$101 \%$} \\
\hline & 98 & $*-0.24$ & $*-15.5$ & -34 & 10.9 & 159 & 189 & 5,345 & 2,984 & 8,706 & 10,270 & & \\
\hline & 99 & 0.10 & - 1.2 & $\circ$ & 13.0 & 195 & 188 & 5,211 & 3,073 & 8,682 & 8,167 & & \\
\hline \multirow{3}{*}{$\begin{array}{c}\text { Fuquay } \\
\# 8\end{array}$} & 66 & $* 0.14$ & -37.4 & 22 & 9.8 & 568 & 251 & 6,459 & 3,051 & 10,304 & 10,651 & \multirow{3}{*}{10,802} & \multirow{3}{*}{$99 \%$} \\
\hline & 67 & $* 0.06$ & $* 13.5$ & $* 51$ & 10.3 & $\$ 55$ & 270 & 7,277 & 3,151 & 11,327 & 10,063 & & \\
\hline & 68 & -0.13 & -2.5 & $* 13$ & 10.1 & 489 & 236 & 6,486 & 3,254 & 10,484 & 11,693 & & \\
\hline \multirow{3}{*}{$\begin{array}{c}\text { Fuquay } \\
\# 42\end{array}$} & 81 & 0.11 & 62.5 & +3 & 5.5 & 62 & 159 & 1,641 & 2,257 & 4,130 & 5,444 & \multirow{3}{*}{6,270} & \multirow{3}{*}{$71 \%$} \\
\hline & 82 & 0.15 & * 33.8 & -13 & 6.3 & 63 & 158 & 1,699 & 1,870 & 3,843 & 6,317 & & \\
\hline & 83 & $* 0.08$ & $*-5.9$ & 40 & 8.8 & 42 & 160 & 1,592 & 3,506 & 5,343 & 7,049 & & \\
\hline \multirow{3}{*}{$\begin{array}{c}\text { ESE } \\
\# 1\end{array}$} & 77 & $* 0.03$ & -44.4 & 6 & 6.4 & 420 & 89 & 4,634 & 3,437 & 8,548 & 9,260 & \multirow{3}{*}{9,170} & \multirow{3}{*}{$100 \%$} \\
\hline & 78 & $*-0.30$ & -8.0 & $* 7$ & 5.9 & 573 & 81 & 4,292 & 4,350 & 9,300 & 9,656 & & \\
\hline & 79 & $* 0.06$ & $* 7.7$ & 28 & 9.8 & 440 & 87 & 4,097 & 4,900 & 9,569 & 8,594 & & \\
\hline \multirow{3}{*}{$\begin{array}{c}\text { Vaucluse } \\
\# 12\end{array}$} & 74 & $*-0.21$ & 6.0 & 66 & 5.6 & 202 & 36 & 587 & 1,337 & 2,179 & 2,295 & \multirow{3}{*}{2,043} & \multirow{3}{*}{$107 \%$} \\
\hline & 75 & 0.13 & --15.6 & $\bullet 2$ & 9.1 & 195 & 36 & 552 & 1,173 & 1,951 & 1,965 & & \\
\hline & 76 & $* 2.51$ & $*-8.7$ & $* 4$ & 5.3 & 212 & 38 & 580 & 1,571 & 2,404 & 1,870 & & \\
\hline \multirow{3}{*}{$\begin{array}{c}\text { Blanton } \\
\# 35\end{array}$} & 89 & -0.15 & $*-14.7$ & $* 53$ & 8.8 & 165 & 27 & 687 & 1,897 & 2,823 & 2,786 & \multirow{3}{*}{2,484} & \multirow{3}{*}{$89 \%$} \\
\hline & 90 & $* 0.13$ & -1.7 & $* 9$ & 10.9 & 181 & 28 & 651 & 890 & 1,767 & 2,385 & & \\
\hline & 91 & $* 0.42$ & $*-27.3$ & $*-1$ & 8.4 & 200 & 27 & 632 & 1,178 & 2,017 & 2,279 & & \\
\hline & 93 & 0.15 & $*-19.3$ & 10 & 11.1 & 197 & 27 & 455 & 1,038 & 1,718 & 1,580 & & \\
\hline $\begin{array}{l}\text { Blanton } \\
\text { \#45 }\end{array}$ & 94 & $* 0.04$ & $*-12.7$ & $* 31$ & 8.5 & 167 & 24 & 487 & 811 & 1,516 & 1,841 & 1,805 & $90 \%$ \\
\hline & 95 & $* 0.47$ & $*-1.0$ & * 42 & 7.5 & 196 & 24 & 560 & 825 & 1,654 & 1,994 & & \\
\hline & 85 & $*-0.02$ & -35.6 & $* 18$ & 10.9 & 197 & 39 & 794 & 925 & 1,948 & 2,817 & & \\
\hline \#41 & 86 & $* 1.05$ & -26.2 & $* 33$ & 10.0 & 279 & 36 & 804 & 1,043 & 2,180 & 2,544 & 2,631 & $77 \%$ \\
\hline & 87 & -0.26 & $*-7.5$ & $* 5$ & 12.8 & 228 & 37 & 853 & 858 & 1,985 & 2,533 & & \\
\hline & 70 & -0.30 & $* 35.7$ & 44 & 14.7 & 482 & 92 & 1,979 & 2,240 & 4,847 & 4,611 & & \\
\hline \#2 & 71 & $* 0.37$ & $* 29.4$ & $* 3$ & 16.3 & 442 & 94 & 1,782 & 1,274 & 3,642 & 4,545 & 4,171 & $110 \%$ \\
\hline & 72 & $* 0.05$ & $\cdot-12.5$ & $\begin{array}{r}* \\
*\end{array}$ & 17.5 & 495 & 101 & 2,016 & 2,617 & 5,284 & 3,358 & & \\
\hline
\end{tabular}

Note: An asterisk symbol by a result indicates that the value was below the detection limit. Results for the DDI, Salt, Ac and HAHCl extraction steps are from ICP-MS analysis of the samples. The rest of the values are from ICP-ES analysis of the samples. 
Table A.2. Sequential extraction of iron from CMP pit soils.

\begin{tabular}{|c|c|c|c|c|c|c|c|c|c|c|c|c|c|}
\hline $\begin{array}{c}\text { CMP Pit } \\
\text { Sample ID }\end{array}$ & Trial & \multicolumn{10}{|c|}{ Iron Removed During Extraction Step (mg/kg) } & Average & $\begin{array}{c}\text { Percent } \\
\text { Recovery }\end{array}$ \\
\hline \multirow{3}{*}{$2 \mathrm{~A}$} & 37 & $* 0.36$ & $* 13.9$ & $* 12.2$ & 4.7 & 19.4 & 148 & 13,921 & 1,931 & 16,050 & 18,070 & & \\
& 38 & $* 0.20$ & $* 14.2$ & $* 10.6$ & 6.2 & 20.8 & 134 & 15,111 & 2,400 & 17,696 & 20,995 & 19,727 & $82 \%$ \\
& 39 & $* 0.17$ & $* 3.6$ & $* 5.9$ & 5.3 & 16.2 & 162 & 12,438 & 2,105 & 14,736 & 20,115 & & \\
\hline \multirow{3}{*}{$2 \mathrm{E}$} & 41 & $* 0.14$ & $* 11.6$ & $* 5.7$ & 1.5 & 6.0 & 69 & 7,315 & 1,397 & 8,806 & 11,537 & & \\
& 42 & $* 0.21$ & $* 26.9$ & $* 5.7$ & 1.5 & $* 5.0$ & 80 & 7,039 & 1,180 & 8,339 & 10,149 & 10,871 & $78 \%$ \\
& 43 & $* 0.18$ & $*-6.2$ & $* 7.6$ & 1.5 & 6.8 & 72 & 6,877 & 1,278 & 8,243 & 10,926 & & \\
\hline \multirow{3}{*}{$3 \mathrm{~A}$} & 44 & 39.81 & $* 5.0$ & 168.0 & 395.2 & 118.0 & 193 & 5,790 & 3,092 & 9,800 & 11,443 & & \\
& 45 & 32.92 & $* 13.8$ & 171.0 & 373.6 & 132.3 & 182 & 6,397 & 3,902 & 11,205 & 11,353 & 11,716 & $89 \%$ \\
& 46 & 19.76 & $* 0.0$ & 164.4 & 389.1 & 123.0 & 186 & 5,750 & 3,525 & 10,157 & 12,353 & & \\
\hline \multirow{3}{*}{$5 \mathrm{~A}$} & 57 & $*-0.08$ & $* 11.1$ & $* 6.1$ & 14.0 & 381.1 & 171 & 6,492 & 2,934 & 10,010 & 11,599 & & \\
& 58 & $*-0.17$ & $* 11.3$ & $* 2.4$ & 13.6 & 388.2 & 163 & 5,594 & 2,697 & 8,869 & 11,762 & 10,976 & $83 \%$ \\
& 59 & $*-0.04$ & $* 10.5$ & $* 5.1$ & 14.7 & 389.8 & 157 & 5,877 & 2,027 & 8,481 & 9,567 & & \\
\hline
\end{tabular}

Note: An asterisk symbol by a result indicates that the value was below the detection limit. Results for the DDI, Salt, and Ac extraction steps are from ICP-MS analysis of the samples. The rest of the values are from ICP-ES analysis of the samples. Negative values were treated as zero when concentrations from all extraction steps are summed. 
Table A.3. Sequential extraction of aluminum from SRS background soils.

\begin{tabular}{|c|c|c|c|c|c|c|c|c|c|c|c|c|c|}
\hline \multirow{2}{*}{$\begin{array}{l}\text { Background Soil } \\
\text { Sample ID }\end{array}$} & \multirow[b]{2}{*}{ Trial } & \multicolumn{10}{|c|}{ Aluminum Removed During Extraction Step ( $\mathrm{mg} / \mathrm{kg}$ ) } & \multirow{2}{*}{$\begin{array}{c}\text { Average } \\
\text { Total }\end{array}$} & \multirow{2}{*}{$\begin{array}{l}\text { Percent } \\
\text { Recovery }\end{array}$} \\
\hline & & DDI & Salt & $A c$ & HAHCl & $\mathrm{PP}$ & $\mathrm{AOD}$ & DC & $\mathrm{HF}$ & Sum & TD & & \\
\hline \multirow{3}{*}{$\begin{array}{c}\text { Orangeburg } \\
\# 10\end{array}$} & 62 & 0.06 & 77.1 & 355 & 38.1 & 257 & 509 & 2,056 & 35,233 & 38,525 & 47,604 & \multirow{3}{*}{47,123} & \multirow{3}{*}{$93 \%$} \\
\hline & 63. & 0.09 & 70.8 & 275 & 33.1 & 251 & 499 & 1,486 & 47,138 & 49.753 & 46,711 & & \\
\hline & 64 & 0.04 & 56.3 & 329 & 38.0 & 283 & 445 & 1,552 & 40,117 & 42,820 & 47,056 & & \\
\hline \multirow{3}{*}{$\begin{array}{l}\text { Orangeburg } \\
\text { \#46 }\end{array}$} & 97 & $* 0.01$ & 14.4 & 282 & 29.2 & 132 & 362 & 878 & 31,798 & 33,495 & 27,458 & \multirow{3}{*}{28,193} & \multirow{3}{*}{$105 \%$} \\
\hline & 98 & $* 0.00$ & 11.9 & 176 & 29.0 & 130 & 294 & 853 & 24,764 & 26,258 & 30,883 & & \\
\hline & 99 & $* 0.01$ & 19.3 & 264 & 47.9 & 148 & 285 & 842 & 27,594 & 29,200 & 26,240 & & \\
\hline \multirow{3}{*}{$\begin{array}{l}\text { Fuquay } \\
\# 8\end{array}$} & 66 & 0.12 & 33.8 & 186 & 42.1 & 213 & 359 & 1,229 & 27,000 & 29,063 & 28,049 & \multirow{3}{*}{27,705} & \multirow{3}{*}{$115 \%$} \\
\hline & 67 & $* 0.04$ & 33.3 & 184 & 27.4 & 220 & 381 & 1,256 & 32,288 & 34,390 & 26,823 & & \\
\hline & 68 & 0.04 & 31.3 & 204 & 24.6 & 196 & 338 & 1,248 & 29,898 & 31,940 & 28,244 & & \\
\hline \multirow{3}{*}{$\begin{array}{c}\text { Fuquay } \\
\# 42\end{array}$} & 81 & 0.06 & 116.7 & 318 & 28.3 & 167 & 350 & 362 & 21,614 & 22,957 & 30,729 & \multirow{3}{*}{30,655} & \multirow{3}{*}{$82 \%$} \\
\hline & 82 & 0.07 & 110.9 & 252 & 28.3 & 173 & 333 & 438 & 19,097 & 20,433 & 29,893 & & \\
\hline & 83 & 0.12 & 102.5 & 215 & 41.7 & 125 & 322 & 368 & 30,494 & 31,667 & 31,342 & & \\
\hline \multirow{3}{*}{$\begin{array}{c}\text { ESE } \\
\# 1\end{array}$} & 77 & 0.07 & 17.3 & 224 & 25.8 & 180 & 263 & 920 & 25,442 & $27,07 !$ & 25,317 & \multirow{3}{*}{25,269} & \multirow{3}{*}{$104 \%$} \\
\hline & 78 & $* 0.02$ & 18.1 & 223 & 26.9 & 220 & 238 & 921 & 26,684 & 28,331 & 26,275 & & \\
\hline & 79 & 0.01 & 24.2 & 162 & 26.9 & 193 & 240 & 841 & 22,134 & 23,621 & 24,215 & & \\
\hline \multirow{3}{*}{$\begin{array}{c}\text { Vaucluse } \\
\# 12\end{array}$} & 74 & 0.01 & 5.1 & 76 & 10.9 & 119 & 72 & 107 & 3,125 & 3,515 & 3,887 & \multirow{3}{*}{3,401} & \multirow{3}{*}{$88 \%$} \\
\hline & 75 & $* 0.00$ & 5.4 & 78 & 12.9 & 124 & 63 & 106 & 2,448 & 2,839 & 3,142 & & \\
\hline & 76 & 0.03 & 5.2 & 78 & 11.0 & 125 & 67 & 113 & 2,250 & 2,650 & 3,174 & & \\
\hline \multirow{3}{*}{$\begin{array}{c}\text { Blanton } \\
\text { \#35 }\end{array}$} & 89 & 0.80 & 14.3 & 90 & 15.8 & 124 & 81 & 185 & 2,027 & 2,538 & 5,409 & \multirow{3}{*}{5,156} & \multirow{3}{*}{$68 \%$} \\
\hline & 90 & 0.90 & 13.6 & 94 & 15.8 & 140 & 82 & 192 & 2,615 & 3,153 & 4,881 & & \\
\hline & 91 & 1.03 & 16.4 & 107 & 17.9 & 160 & 80 & 159 & 4,237 & 4,778 & 5,180 & & \\
\hline & 93 & 2.02 & 14.0 & 116 & 21.7 & 169 & 75 & 152 & 3,890 & 4,440 & 5,038 & & \\
\hline H45 & 94 & 2.23 & 11.3 & 77 & 14.3 & 148 & 67 & 153 & 2,502 & 2,975 & 5,017 & 5,065 & $65 \%$ \\
\hline & 95 & 1.37 & 14.1 & 82 & 15.3 & 164 & 67 & 171 & 1,973 & 2,488 & 5,140 & & \\
\hline & 85 & 0.34 & 17.1 & 106 & 23.6 & 146 & 115 & 205 & 4,985 & 5,598 & 7,249 & & \\
\hline$\$ 41$ & 86 & 0.44 & 20.0 & 113 & 23.1 & 220 & 108 & 224 & 4,113 & 4,821 & 7,231 & 7,364 & $66 \%$ \\
\hline & 87 & 0.29 & 20.3 & 146 & 20.3 & 164 & 109 & 231 & 3,362 & 4,053 & 7,614 & & \\
\hline & 70 & 0.05 & 44.4 & 163 & 28.5 & 223 & 206 & 384 & 14,651 & 15,701 & 13,018 & & \\
\hline 72 & 71 & 0.04 & 35.9 & 193 & 37.5 & 203 & 206 & 342 & 6,085 & 7,102 & 12,694 & 11,575 & $116 \%$ \\
\hline & 72 & 0.08 & 39.1 & 151 & 37.4 & 212 & 222 & 377 & 16,271 & 17,310 & 9,014 & & \\
\hline
\end{tabular}

Note: An asterisk symbol by a result indicates that the value was below the detection limit. Results for the DDI, Salt, Ac and $\mathrm{HAHCl}$ extraction steps are from ICP-MS analysis of the samples. The rest of the values are from ICP-ES analysis of the samples. 
Table A.4. Sequential extraction of aluminum from CMP pit soils.

\begin{tabular}{|c|c|r|r|r|r|r|r|r|r|r|r|r|r|r|}
\hline CMP Pit & & \multicolumn{10}{|c|}{ Aluminum Removed During Extraction Step (mg/kg) } & Average & Percent \\
Sample ID & Trial & DDI & Salt & Ac & HAHCl & PP & AOD & DC & HF & Sum & TD & Total & Recovery \\
\hline \multirow{3}{*}{$2 \mathrm{~A}$} & 37 & 0.48 & 98 & 139 & 13 & 62 & 162 & 1,369 & 38,168 & 40,013 & 65,732 & & \\
& 38 & 0.17 & 104 & 138 & 15 & 65 & 157 & 1,537 & 50,944 & 52,961 & 72,520 & 70,265 & $58 \%$ \\
& 39 & $* 0.07$ & 102 & 127 & 20 & 56 & 178 & 1,061 & 28,488 & 30,033 & 72,541 & & \\
\hline & 41 & $*-0.03$ & 113 & 99 & 16 & 38 & 122 & 608 & 32,076 & 33,071 & 64,182 & & \\
$2 \mathrm{E}$ & 42 & $*-0.01$ & 111 & 100 & 14 & 28 & 135 & 533 & 28,674 & 29,595 & 59,326 & 60,292 & $50 \%$ \\
& 43 & $*-0.01$ & 101 & 106 & 15 & 34 & 126 & 573 & 27,072 & 28,026 & 57,367 & & \\
\hline & 44 & 41.28 & $* 1$ & 312 & 255 & 54 & 180 & 629 & 31,063 & 32,534 & 40,427 & & \\
3A & 45 & 31.73 & $* 1$ & 326 & 246 & 70 & 233 & 653 & 34,392 & 35,950 & 39,706 & 40,079 & $86 \%$ \\
& 46 & 24.04 & $* 1$ & 313 & 259 & 57 & 179 & 585 & 33,900 & 35,317 & 40,103 & & \\
\hline \multirow{3}{*}{ SA } & 57 & 0.50 & 121 & 164 & 31 & 191 & 205 & 757 & 28,675 & 30,145 & 30,029 & & \\
& 58 & 0.42 & 111 & 142 & 31 & 191 & 185 & 702 & 18,406 & 19,769 & 31,802 & 29,915 & $75 \%$ \\
& 59 & 0.42 & 118 & 151 & 31 & 192 & 198 & 751 & 15,584 & 17,026 & 27,915 & & \\
\hline
\end{tabular}

Note: An asterisk symbol by a result indicates that the value was below the detection limit. Results for the DDI, Salt, and Ac extraction steps are from an ICP-MS analysis of the samples. The rest of the values are from an ICP-ES analysis of the samples. 
Table A.5. Sequential extraction of titanium from SRS background soils.

\begin{tabular}{|c|c|c|c|c|c|c|c|c|c|c|c|c|c|}
\hline \multirow{2}{*}{$\begin{array}{c}\text { Background Soil } \\
\text { Sample ID }\end{array}$} & \multirow[b]{2}{*}{ Trial } & \multicolumn{10}{|c|}{ Titanium Removed During Extraction Step (mg/kg) } & \multirow{2}{*}{$\begin{array}{c}\text { Average } \\
\text { Total }\end{array}$} & \multirow{2}{*}{$\begin{array}{l}\text { Percent } \\
\text { Recovery }\end{array}$} \\
\hline & & DDI & Salt & Ac & HAHCl & $\overline{\mathrm{PP}}$ & AOD & $\overline{D C}$ & HF & Sum & TD & & \\
\hline \multirow{3}{*}{$\begin{array}{c}\text { Orangeburg } \\
\# 10\end{array}$} & 62 & $<1$ & 2 & $<l$ & $<1$ & 7.9 & 2.2 & 87 & 3,470 & 3,568 & 3,341 & \multirow{3}{*}{3,631} & \multirow{3}{*}{$110 \%$} \\
\hline & 63 & $<1$ & $<$ & $<1$ & $<1$ & 7.4 & 2.2 & 62 & 4,390 & 4,461 & 3,684 & & \\
\hline & 64 & $<1$ & 2 & $<1$ & $\leq 1$ & 9.5 & 1.8 & 63 & 3,856 & 3,931 & 3,867 & & \\
\hline \multirow{3}{*}{$\begin{array}{c}\text { Orangeburg } \\
\sharp 46\end{array}$} & 97 & $<1$ & 2 & $<1$ & $<1$ & 3.2 & 3.3 & 65 & 3,478 & 3,549 & 3,098 & \multirow{3}{*}{3,333} & \multirow{3}{*}{$97 \%$} \\
\hline & 98 & $<1$ & $<$ & $<1$ & $<1$ & 3.1 & 2.6 & 64 & 3,212 & 3,282 & 4,044 & & \\
\hline & 99 & $<1$ & 2 & $<1$ & $<1$ & 3.6 & 2.6 & 65 & 2,802 & 2,873 & 2,857 & & \\
\hline \multirow{3}{*}{$\begin{array}{c}\text { Fuquay } \\
\# 8\end{array}$} & 66 & $<1$ & 2 & $<1$ & $<1$ & 7.4 & 2.1 & 58 & 3,551 & 3,619 & 3,146 & \multirow{3}{*}{2,948} & \multirow{3}{*}{$116 \%$} \\
\hline & 67 & $<1$ & 2 & $<1$. & $<1$ & 7.4 & 2.1 & 59 & 3,322 & 3,391 & 2,799 & & \\
\hline & 68 & $<1$ & $<$ & $<1$ & $<1$ & 6.6 & 1.9 & 56 & 3,178 & 3,242 & 2,901 & & \\
\hline \multirow{3}{*}{$\begin{array}{c}\text { Fuquay } \\
\# 42\end{array}$} & 81 & $<1$ & 2 & $<1$ & $<1$ & 4.2 & 1.3 & 6 & 1,818 & 1,830 & 2,946 & \multirow{3}{*}{2,898} & \multirow{3}{*}{$68 \%$} \\
\hline & 82 & $<1$ & $<$ & $<1$ & $<1$ & 4.3 & 1.3. & 7. & 1,271 & 1,283 & 3,041 & & \\
\hline & 83 & $<1$ & $<$ & $<1$ & $\leq 1$ & 2.1 & 1.2 & 6 & 2,803 & 2,812 & 2,708 & & \\
\hline \multirow{3}{*}{$\begin{array}{c}\text { ESE } \\
\# 1\end{array}$} & 77 & $<1$ & $<$ & $<1$ & $<1$ & 5.2 & 1.2 & 37 & 2,197 & 2,240 & 2,676 & \multirow{3}{*}{2,767} & \multirow{3}{*}{$89 \%$} \\
\hline & 78 & $<1$ & $<$ & $<1$ & $<1$ & 6.8 & 1.1 & 35 & 2,955 & 2,998 & 3,060 & & \\
\hline & 79 & $<1$ & $<$ & $<1$ & $<1$ & 5.6 & 1.2 & 34 & 2,071 & 2,112 & 2,566 & & \\
\hline \multirow{3}{*}{$\begin{array}{c}\text { Vaucluse } \\
\# 12\end{array}$} & 74 & $<1$ & 2 & $<1$ & $<1$ & 3.6 & 0.8 & 11 & 2,017 & 2,032 & 2,480 & \multirow{3}{*}{2,288} & \multirow{3}{*}{$97 \%$} \\
\hline & 75 & $<1$ & $<$ & $<1$ & $<1$ & 3.7 & 0.8 & 11 & 1,906 & 1,922 & 2,166 & & \\
\hline & 76 & $\leq 1$ & $\leq$ & $<1$ & $<1$ & 3.9 & 0.8 & 11 & 2,688 & 2,703 & 2,218 & & \\
\hline \multirow{3}{*}{$\begin{array}{c}\text { Blanton } \\
\# 35\end{array}$} & 89 & $<1$ & $<$ & $<1$ & $<1$ & 2.9 & 0.6 & 11 & 2,903 & 2,917 & 3,314 & \multirow{3}{*}{3,124} & \multirow{3}{*}{$66 \%$} \\
\hline & 90 & $<1$ & $<$ & $<1$ & $<1$ & 3.3 & 0.7 & 11 & 1,434 & 1,449 & 3,136 & & \\
\hline & 91 & $<1$ & $\leq$ & $<1$ & $<1$ & 3.6 & 0.5 & 11 & 1,772 & 1,788 & 2,923 & & \\
\hline & 93 & $<1$ & 2 & $<1$ & $<1$ & 2.5 & 0.5 & 7 & 1,278 & 1,288 & 1,748 & & \\
\hline $\begin{array}{l}\text { \#45 } \\
\text { Danting }\end{array}$ & 94 & $<1$ & $<$ & $<1$ & $<1$ & 2.1 & 0.5 & 7 & 1,264 & 1,274 & 1,722 & 1,858 & $72 \%$ \\
\hline & 95 & $\leq 1$ & 2 & $<1$ & $\leq 1$ & 2.5 & 0.4 & 7 & 1,457 & 1,467 & 2,103 & & \\
\hline & 85 & $<1$ & $<$ & $<1$ & $<1$ & 2.8 & 0.8 & 13 & 1,287 & 1,304 & 2,634 & & \\
\hline$\# 41$ & 86 & $<1$ & $<$ & $<1$ & $<1$ & 4.4 & 0.6 & 12 & 1,550 & 1,567 & 2,509 & 2,601 & $53 \%$ \\
\hline & 87 & $<1$ & $<$ & $<1$ & $<1$ & 3.4 & 0.5 & 13 & 1,231 & 1,248 & 2,660 & & \\
\hline & 70 & $<1$ & 2 & $<1$ & $<1$ & 7.7 & 1.4 & 27 & 2,692 & 2,729 & 3,333 & & \\
\hline$\# 2$ & 71 & $<1$ & $<$ & $<1$ & $<1$ & 7.0 & 1.6 & 25 & 2,044 & 2,078 & 2,831 & 2,845 & $93 \%$ \\
\hline & 72 & $<1$ & 2 & $<1$ & $<1$ & 7.6 & 1.6 & 27 & 3,134 & 3,170 & 2,370 & & \\
\hline
\end{tabular}

Note: Results for the DDI, Salt, Ac and HAHCl extraction steps are from an ICP-MS analysis of the samples. The rest of the values are from an ICP-ES analysis of the samples. 
Table A.6. Sequential extraction of titanium from CMP pit soils.

\begin{tabular}{|c|c|c|c|c|c|c|c|c|c|c|c|c|c|c|}
\hline CMP Pit & & \multicolumn{10}{|c|}{ Titanium Removed During Extraction Step (mg/kg) } & Average & Percent \\
Sample ID & Trial & DDI & Salt & AC & HAHCl & PP & AOD & DC & HF & Sum & TD & Total & Recovery \\
\hline \multirow{3}{*}{$2 \mathrm{~A}$} & 37 & $* 0.00$ & $*-0.20$ & $* 0.02$ & $* 0.05$ & $* 0.34$ & 1.3 & 65 & 1,616 & 1,682 & 1,738 & & \\
& 38 & $* 0.00$ & $*-0.01$ & $* 0.02$ & $* 0.08$ & $* 0.51$ & 1.4 & 69 & 1,933 & 2,003 & 3,118 & 2,267 & $79 \%$ \\
& 39 & $* 0.01$ & $*-0.52$ & $* 0.06$ & $* 0.06$ & $* 0.55$ & 1.5 & 53 & 1,607 & 1,662 & 1,945 & & \\
\hline \multirow{3}{*}{$2 \mathrm{E}$} & 41 & $* 0.00$ & $*-0.20$ & $* 0.00$ & $*-0.02$ & $* 0.13$ & 0.7 & 33 & 1,036 & 1,070 & 1,517 & & \\
& 42 & $*-0.01$ & $* 0.02$ & $* 0.04$ & $*-0.02$ & $* 0.21$ & 0.9 & 33 & 716 & 749 & 1,197 & 1,219 & $72 \%$ \\
& 43 & $*-0.01$ & $*-0.05$ & $* 0.03$ & $*-0.03$ & $* 0.44$ & 0.7 & 30 & 779 & 811 & 942 & & \\
\hline \multirow{3}{*}{$3 \mathrm{~A}$} & 44 & 3.73 & $*-0.03$ & 0.25 & 28.41 & 22.31 & 11.6 & 33 & 1,554 & 1,653 & 1,818 & & \\
& 45 & 2.40 & $*-0.39$ & 0.27 & 26.56 & 22.85 & 10.4 & 33 & 2,328 & 2,424 & 1,959 & 1,965 & $104 \%$ \\
& 46 & 0.97 & 1.90 & 0.19 & 27.13 & 22.69 & 10.6 & 33 & 1,933 & 2,030 & 2,119 & & \\
\hline \multirow{3}{*}{$5 \mathrm{~A}$} & 57 & $* 0.00$ & $*-0.28$ & $* 0.02$ & $* 0.09$ & 4.23 & 2.0 & 30 & 2,532 & 2,568 & 2,615 & & \\
& 58 & $* 0.00$ & $*-0.06$ & 0.12 & $* 0.08$ & 4.91 & 2.0 & 43 & 2,585 & 2,634 & 3,616 & 2,878 & $81 \%$ \\
& 59 & $* 0.00$ & 1.85 & $* 0.01$ & $* 0.08$ & 4.66 & 1.9 & 34 & 1,732 & 1,775 & 2,403 & & \\
\hline
\end{tabular}

Note: An asterisk symbol by a result indicates that the value was below the detection limit. Results for the DDI, Salt, and Ac extraction steps are from an ICP-MS analysis of the samples. The rest of the values are from ICP-ES analysis of the samples. 
Table A.7. Sequential extraction of manganese from SRS background soils.

\begin{tabular}{|c|c|c|c|c|c|c|c|c|c|c|c|c|c|}
\hline \multirow{2}{*}{$\begin{array}{c}\text { Background } \\
\text { Soil Sample DD }\end{array}$} & \multirow[b]{2}{*}{ Trial } & \multicolumn{10}{|c|}{ Manganese Removed During Extraction Step (mg/kg) } & \multirow{2}{*}{$\begin{array}{c}\text { Average } \\
\text { Total }\end{array}$} & \multirow{2}{*}{$\begin{array}{l}\text { Percent } \\
\text { Recovery }\end{array}$} \\
\hline & & DDI & Salt & $\overline{\mathrm{Ac}}$ & HAHCl & $\overline{\mathrm{PP}}$ & $\widehat{\mathrm{AOD}}$ & $\overline{D C}$ & $\mathrm{HF}$ & Sum & TD & & \\
\hline \multirow{3}{*}{$\begin{array}{c}\text { Orangeburg } \\
\# 10\end{array}$} & 62 & 0.02 & $=-0.03$ & 0.11 & 0.17 & 0.28 & 0.11 & 4.63 & 57.39 & 63 & 33.78 & \multirow{3}{*}{40.49} & \multirow{3}{*}{$125 \%$} \\
\hline & 63 & 0.02 & $\cdot 0.10$ & 0.20 & 0.13 & 0.36 & 0.14 & 4.16 & 37.76 & 43 & 43.98 & & \\
\hline & 64 & $* 0.01$ & $\cdot 0.51$ & 0.12 & +0.08 & 0.34 & 0.12 & 4.09 & 41.24 & 47 & 43.71 & & \\
\hline \multirow{3}{*}{$\begin{array}{c}\text { Orangeburg } \\
\quad \# 46\end{array}$} & 97 & 0.15 & 1.38 & 1.22 & 6.38 & 0.82 & 0.83 & 12.9 & 45.38 & 69 & 63.45 & \multirow{3}{*}{67.44} & \multirow{3}{*}{$121 \%$} \\
\hline & 98 & 0.13 & 1.59 & 1.35 & 8.32 & 0.70 & 0.81 & 12.5 & 52.04 & 78 & 85.64 & & \\
\hline & 99 & 0.13 & 2.15 & 1.30 & 6.32 & 0.74 & 0.95 & 11.8 & 74.42 & 98 & 53.22 & & \\
\hline \multirow{3}{*}{$\begin{array}{c}\text { Fuquay } \\
\# 8\end{array}$} & 66 & 0.06 & -0.12 & 0.18 & 0.38 & 0.20 & 0.21 & 3.24 & 44.45 & 49 & 38.19 & \multirow{3}{*}{39.06} & \multirow{3}{*}{$116 \%$} \\
\hline & 67 & 0.06 & 0.51 & 0.40 & 0.52 & 0.34 & 0.18 & 2.96 & 43.32 & 48 & 33.75 & & \\
\hline & 68 & 0.05 & 0.27 & 0.16 & 0.37 & 0.24 & 0.13 & 2.55 & 35.21 & 39 & 45.25 & & \\
\hline \multirow{3}{*}{$\begin{array}{c}\text { Fuquay } \\
\# 42\end{array}$} & 81 & 0.02 & 0.21 & 0.07 & 0.13 & 0.09 & 0.05 & 0.43 & 108.32 & 109 & 33.99 & \multirow{3}{*}{34.81} & \multirow{3}{*}{$283 \%$} \\
\hline & 82 & 0.02 & 0.70 & $* 0.05$ & 0.09 & 0.13 & $* 0.04$ & 0.47 & 104.09 & 106 & 42.76 & & \\
\hline & 83 & 0.02 & $* 0.21$ & 0.14 & 0.17 & 0.07 & $* 0.03$ & 0.66 & 79.31 & 81 & 27.69 & & \\
\hline \multirow{3}{*}{$\begin{array}{c}\text { ESE } \\
\# 1\end{array}$} & 77 & 0.25 & 1.99 & 1.62 & 6.65 & 0.96 & 1.03 & 3.91 & 70.99 & 87 & 55.51 & \multirow{3}{*}{55.74} & \multirow{3}{*}{$148 \%$} \\
\hline & 78 & 0.25 & 2.05 & 1.41 & 6.20 & 1.16 & 1.22 & 3.82 & 62.02 & 78 & 61.17 & & \\
\hline & 79 & 0.26 & 2.64 & 1.69 & 6.29 & 1.01 & missin & 4.25 & 58.60 & - & 50.53 & & \\
\hline \multirow{3}{*}{$\begin{array}{c}\text { Vaucluse } \\
\# 12\end{array}$} & 74 & 0.14 & 0.34 & 0.42 & 1.32 & 0.48 & 0.20 & 1.84 & 58.22 & 63 & 75.20 & \multirow{3}{*}{73.15} & \multirow{3}{*}{$90 \%$} \\
\hline & 75 & 0.16 & $* 0.12$ & 0.47 & 1.35 & 0.47 & 0.18 & 1.81 & 64.71 & 69 & 64.60 & & \\
\hline & 76 & 0.22 & $* 0.22$ & 0.42 & 1.28 & 0.44 & 0.21 & 1.72 & missin & 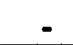 & 79.66 & & \\
\hline \multirow{3}{*}{$\begin{array}{c}\text { Blanton } \\
\text { \#35 }\end{array}$} & 89 & 0.45 & $* 0.72$ & 1.54 & 6.59 & 3.04 & 1.44 & 1.76 & 13.84 & 29 & 79.32 & \multirow{3}{*}{70.07} & \multirow{3}{*}{$69 \%$} \\
\hline & 90 & 0.43 & $* 0.71$ & 1.29 & 7.10 & 2.90 & 1.38 & 1.91 & 44.82 & 61 & 66.17 & & \\
\hline & 91 & 0.43 & $0.79^{\circ}$ & 1.66 & 7.31 & 3.22 & 1.22 & 1.97 & 38.94 & 56 & 64.72 & & \\
\hline & 93 & 0.28 & $* 0.01$ & 0.63 & 1.08 & 0.64 & 0.18 & 0.80 & 7.59 & 11 & 25.73 & & \\
\hline Blanton & 94 & 0.25 & 0.25 & 0.63 & 1.02 & 0.62 & 0.17 & 1.70 & 22.50 & 27 & 32.38 & 30.19 & $54 \%$ \\
\hline & 95 & 0.28 & 0.29 & 0.73 & 1.02 & 0.69 & 0.23 & 1.03 & $5: 97$ & 10 & 32.46 & & \\
\hline & 85 & 0.42 & 0.37 & 1.67 & 15.02 & 4.24 & 2.23 & 2.52 & 39.75 & 66 & 81.72 & & \\
\hline Lakelar & 86 & 0.57 & 0.54 & 1.77 & 14.75 & 4.87 & 1.99 & 2.35 & 40.55 & 67 & 74.72 & 79.91 & $80 \%$ \\
\hline & 87 & 0.47 & 0.77 & 1.83 & 18.64 & 4.31 & 2.04 & 2.47 & 28.73 & 59 & 83.29 & & \\
\hline & 70 & 0.50 & 1.78 & $1: 66$ & 13.43 & 1.61 & 1.06 & 4.93 & 47.71 & 73 & 69.98 & & \\
\hline kels & 71 & 0.54 & $* 1.31$ & 1.67 & 9.31 & 1.52 & 1.42 & 3.91 & 36.00 & 56 & 75.97 & 66.96 & $111 \%$ \\
\hline & 72 & 0.42 & $* 1.13$ & 1.90 & 10.21 & 1.63 & 1.03 & 4.22 & 73.52 & 94 & 54.94 & & \\
\hline
\end{tabular}

Note: An asterisk symbol by a result indicates that the value was below the detection limit. 
Table A.8. Sequential extraction of manganese from CMP pit soils.

\begin{tabular}{|c|c|c|c|c|c|c|c|c|c|c|c|c|c|}
\hline \multirow{2}{*}{$\begin{array}{l}\text { CMP Pit } \\
\text { Sample ID }\end{array}$} & \multirow[b]{2}{*}{ Trial } & \multicolumn{10}{|c|}{ Manganese Removed During Extraction Step (mg/kg) } & \multirow{2}{*}{$\begin{array}{c}\text { Average } \\
\text { Total }\end{array}$} & \multirow{2}{*}{$\begin{array}{c}\text { Percent } \\
\text { Recovery }\end{array}$} \\
\hline & & $\overline{\mathrm{DDI}}$ & Salt & Ac & $\mathrm{HAHCl}$ & $\mathrm{PP}$ & AOD & $\overline{D C}$ & $\mathrm{HF}$ & Sum & $T D$ & & \\
\hline \multirow{3}{*}{$2 \mathrm{~A}$} & 37 & 0.11 & 0.61 & 0.09 & 0.05 & 0.03 & 0.07 & 24.7 & 19.5 & 45.1 & 56.1 & \multirow{3}{*}{62.0} & \multirow{3}{*}{$\mathbf{7 7 \%}$} \\
\hline & 38 & 0.11 & 0.60 & 0.08 & 0.08 & 0.02 & 0.06 & 26.2 & 19.5 & 46.7 & 84.3 & & \\
\hline & 39 & 0.10 & 0.49 & 0.05 & 0.06 & 0.05 & 0.06 & 22.5 & 27.5 & 50.7 & 45.6 & & \\
\hline \multirow{3}{*}{$2 \mathrm{E}$} & 41 & 0.01 & $* 0.09$ & $* 0.00$ & $* 0.00$ & $* 0.03$ & $* 0.03$ & 25.6 & 10.6 & 36.4 & 53.9 & \multirow{3}{*}{40.9} & \multirow{3}{*}{$84 \%$} \\
\hline & 42 & 0.01 & $* 0.11$ & $* 0.00$ & $* 0.00$ & $*-0.02$ & $* 0.03$ & 24.2 & 9.6 & 34.0 & 38.7 & & \\
\hline & 43 & 0.01 & $*-0.02$ & $* 0.01$ & $* 0.00$ & $* 0.00$ & $* 0.02$ & 25.1 & 7.4 & 32.5 & 30.1 & & \\
\hline \multirow{3}{*}{$3 \mathrm{~A}$} & 44 & 0.04 & $* 0.05$ & 8.02 & 9.76 & 0.80 & 1.08 & 9.9 & 38.6 & 68.3 & 83.3 & \multirow{3}{*}{84.0} & \multirow{3}{*}{$102 \%$} \\
\hline & 45 & 0.03 & $* 0.03$ & 8.46 & 9.45 & 0.97 & 1.17 & 9.9 & 64.4 & 94.5 & 86.1 & & \\
\hline & 46 & 0.03 & $*-0.73$ & 8.03 & 10.60 & 1.02 & 1.17 & 10.7 & 62.3 & 93.8 & 82.6 & & \\
\hline \multirow{3}{*}{$S A$} & 57 & 1.00 & 0.97 & 0.84 & 1.06 & 0.61 & 0.80 & 17.0 & 55.9 & 78.2 & 76.5 & \multirow{3}{*}{84.7} & \multirow{3}{*}{$93 \%$} \\
\hline & 58 & 0.88 & 0.91 & 0.81 & 1.13 & 0.60 & 0.72 & 11.7 & 80.0 & 96.8 & 104.3 & & \\
\hline & 59 & 0.94 & 0.38 & 1.03 & 1.45 & 0.66 & 0.83 & 12.4 & 42.9 & 60.6 & 73.2 & & \\
\hline
\end{tabular}

Note: An asterisk symbol by a result indicates that the value was below the detection limit. Negative values are treated as zero when concentrations across all extraction steps are summed. 
Table A.9. Sequential extraction of uranium from SRS background soils.

\begin{tabular}{|c|c|c|c|c|c|c|c|c|c|c|c|c|c|}
\hline \multirow{2}{*}{$\begin{array}{l}\text { Background } \\
\text { Soil Sample ID }\end{array}$} & \multirow[b]{2}{*}{ Trial } & \multicolumn{10}{|c|}{ Uranium-238 Removed During Extraction Step (mg/kg) } & \multirow{2}{*}{$\begin{array}{c}\text { Average } \\
\text { Total }\end{array}$} & \multirow{2}{*}{$\begin{array}{l}\text { Percent } \\
\text { Recovery }\end{array}$} \\
\hline & & DDI & Salt & $\overline{A C}$ & HAHCl & $\mathrm{PP}$ & AOD & DC & HF & Sum & TD & & \\
\hline \multirow{3}{*}{$\begin{array}{c}\text { Orangeburg } \\
\# 10\end{array}$} & 62 & $* 0.000$ & $*-0.011$ & 0.140 & 0.034 & 0.119 & 0.094 & 0.224 & 1.52 & 2.13 & 2.10 & \multirow{3}{*}{2.20} & \multirow{3}{*}{$96 \%$} \\
\hline & 63 & $* 0.000$ & $*-0.002$ & 0.120 & 0.035 & 0.092 & 0.116 & 0.129 & 1.82 & 2.31 & 2.33 & & \\
\hline & 64 & $* 0.000$ & $* 0.032$ & 0.144 & 0.050 & 0.113 & 0.089 & 0.184 & 1,31 & 1.92 & 2.19 & & \\
\hline \multirow{3}{*}{$\begin{array}{c}\text { Orangeburg } \\
\quad \# 46\end{array}$} & 97 & $* 0.000$ & $* 0.001$ & $* 0.039$ & 0.018 & 0.032 & 0.086 & 0.137 & 1.09 & 1.41 & 1.95 & \multirow{3}{*}{1.96} & \multirow{3}{*}{$80 \%$} \\
\hline & 98 & $* 0.000$ & $*-0.017$ & 0.051 & 0.016 & 0.032 & 0.099 & 0.149 & 1.32 & 1.65 & 2.27 & & \\
\hline & 99 & $* 0.000$ & $*-0.027$ & 0.053 & 0.023 & 0.040 & 0.102 & 0.114 & 1.31 & 1.62 & 1.65 & & \\
\hline \multirow{3}{*}{$\begin{array}{c}\text { Fuquay } \\
\# 8\end{array}$} & 66 & $* 0.000$ & $*-0.018$ & 0.094 & 0.032 & 0.078 & 0.080 & 0.158 & 1.33 & 1.75 & 1.79 & \multirow{3}{*}{1.68} & \multirow{3}{*}{$102 \%$} \\
\hline & 67 & $* 0.000$ & $* 0.032$ & 0.087 & 0.020 & 0.076 & 0.071 & 0.144 & 1.15 & 1.58 & 1.68 & & \\
\hline & 68 & $* 0.000$ & $* 0.018$ & 0.092 & 0.020 & 0.072 & 0.082 & 0.183 & 1.35 & 1.82 & 1.57 & & \\
\hline \multirow{3}{*}{$\begin{array}{c}\text { Fuquay } \\
\# 42\end{array}$} & .81 & 0.000 & $* 0.009$ & 0.114 & 0.019 & 0.050 & 0.082 & 0.092 & 0.45 & 0.82 & 1.69 & \multirow{3}{*}{1.39} & \multirow{3}{*}{$81 \%$} \\
\hline & 82 & $* 0.000$ & $* 0.022$ & 0.103 & 0.016 & 0.057 & 0.085 & $* 0.074$ & 0.58 & 0.94 & 1.25 & & \\
\hline & 83 & $* 0.000$ & $*-0.015$ & 0.115 & 0.024 & 0.041 & 0.070 & 0.093 & 1.32 & 1.65 & 1.24 & & \\
\hline \multirow{3}{*}{$\begin{array}{c}\text { ESE } \\
\# 1\end{array}$} & 77 & $* 0.000$ & $*-0.016$ & 0.069 & 0.019 & 0.052 & 0.050 & 0.120 & 1.13 & 1.42 & 1.57 & \multirow{3}{*}{1.53} & \multirow{3}{*}{$94 \%$} \\
\hline & 78 & $* 0.000$ & $* 0.015$ & 0.081 & 0.021 & 0.065 & 0.051 & 0.128 & 1.10 & 1.46 & 1.69 & & \\
\hline & 79 & $* 0.000$ & $*-0.009$ & 0.075 & 0.022 & 0.057 & missing & 0,090 & 0.96 & - & 1.33 & & \\
\hline \multirow{3}{*}{$\begin{array}{c}\text { Vaucluse } \\
\# 12\end{array}$} & 74 & $* 0.000$ & $* 0.003$ & 0.005 & 0.004 & $* 0.010$ & 0.019 & $* 0.018$ & 0.34 & 0.40 & 0.51 & \multirow{3}{*}{0.58} & \multirow{3}{*}{$74 \%$} \\
\hline & 75 & $* 0.000$ & $*-0.001$ & $* 0.010$ & 0.004 & $* 0.015$ & 0.012 & $*-0.011$ & 0.43 & 0.45 & 0.64 & & \\
\hline & 76 & $\begin{array}{r}* 0.000 \\
\end{array}$ & $* 0,001$ & $* 0,005$ & $* 0.002$ & $* 0,011$ & 0.010 & $* 0,025$ & missing & $=$ & 0.58 & & \\
\hline \multirow{3}{*}{$\begin{array}{c}\text { Blanton } \\
\# 35\end{array}$} & 89 & $* 0.000$ & $*-0.001$ & $* 0.017$ & 0.004 & $* 0.029$ & $* 0.007$ & $* 0.004$ & $* 0.01$ & 0.07 & 0.86 & \multirow{3}{*}{0.80} & \multirow{3}{*}{$37 \%$} \\
\hline & 90 & $* 0.000$ & $* 0.038$ & $* 0.015$ & 0.004 & $* 0.010$ & 0.010 & $* 0.014$ & 0.28 & 0.37 & 0.70 & & \\
\hline & 91 & $* 0.000$ & $* 0.001$ & $* 0,005$ & 0,007 & $* 0.026$ & 0.016 & $* 0.019$ & 0.36 & 0,44 & 0.84 & & \\
\hline & 93 & $* 0.000$ & $*-0.024$ & 0.024 & 0.007 & $* 0.009$ & $* 0.005$ & $* 0.002$ & $* 0.14$ & 0.16 & 0.56 & & \\
\hline \#15 & 94 & $* 0.000$ & $*-0.017$ & $* 0.007$ & 0.003 & $* 0,011$ & ${ }^{*}-0.002$ & $* 0.006$ & $* 0.25$ & 0.26 & 0.74 & 0.61 & $32 \%$ \\
\hline & 95 & $* 0.000$ & $*-0.019$ & $* 0.015$ & 0.005 & $* 0.005$ & $* 0.004$ & $* 0.023$ & $* 0.13$ & 0.17 & 0.54 & & \\
\hline & 85 & $* 0.000$ & $* 0.009$ & $* 0.023$ & 0.008 & $* 0.019$ & 0.010 & $* 0.017$ & 0.28 & 0.36 & 0.94 & & \\
\hline$\# 41$ & 86 & $* 0.000$ & $*-0.008$ & $* 0.016$ & 0.009 & $* 0.024$ & 0.012 & $* 0.010$ & 0.52 & 0.59 & 1.04 & 1.04 & $50 \%$ \\
\hline & 87 & $* 0.000$ & $*-0,010$ & $* 0.024$ & 0.008 & $* 0.012$ & 0.015 & $* 0.026$ & 0.54 & 0.62 & 1.15 & & \\
\hline IKela & 70 & $* 0.000$ & $* 0.025$ & $* 0.030$ & 0.012 & 0.024 & 0.019 & $* 0.068$ & 0.95 & 1.13 & 1.21 & & \\
\hline \#2 & 71 & $* 0.000$ & $* 0.050$ & $* 0.024$ & 0.017 & 0.038 & 0.037 & $* 0.054$ & 0.37 & 0.59 & 1.31 & 1.15 & $93 \%$ \\
\hline & 72 & $* 0,000$ & $* 0,006$ & $* 0,035$ & 0,017 & 0.029 & 0.024 & $* 0.035$ & 1,35 & 1.49 & 0.94 & & \\
\hline
\end{tabular}

Note: An asterisk symbol by a result indicates that the value was below the detection limit. 


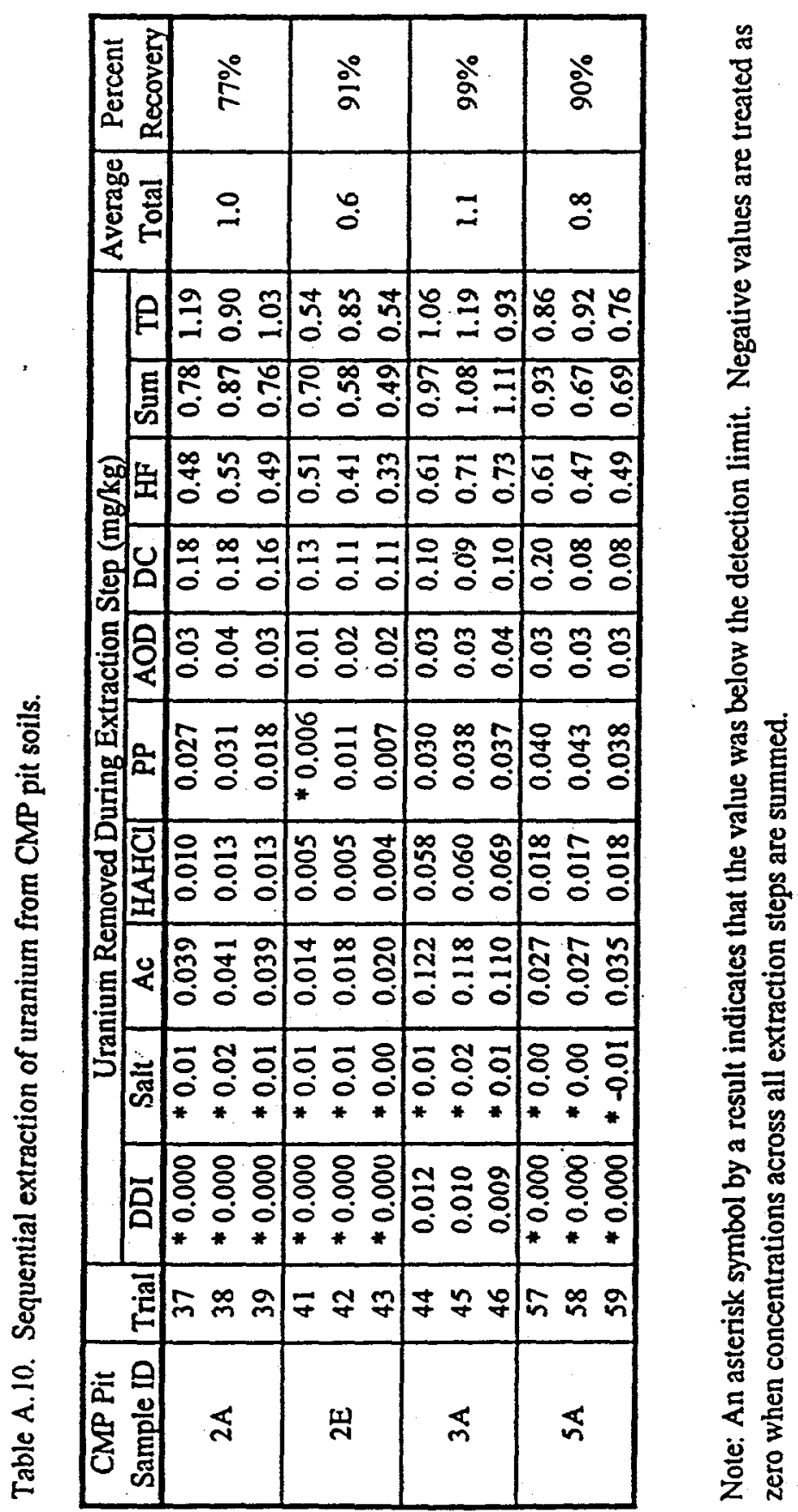


Table A.11. Sequential extraction of thorium from SRS background soils.

\begin{tabular}{|c|c|c|c|c|c|c|c|c|c|c|c|c|c|}
\hline \multirow{2}{*}{$\begin{array}{l}\text { Background Soil } \\
\text { Sample ID }\end{array}$} & \multirow[b]{2}{*}{ Trial } & \multicolumn{10}{|c|}{ Thorium Removed During Extraction Step ( $\mathrm{mg} / \mathrm{kg})$} & \multirow{2}{*}{$\begin{array}{c}\text { Average } \\
\text { Total }\end{array}$} & \multirow{2}{*}{$\begin{array}{l}\text { Percent } \\
\text { Recovery }\end{array}$} \\
\hline & & DDI & Salt & Ac & $\mathrm{HAHCl}$ & $\mathrm{PP}$ & $A O D$ & $\mathrm{DC}$ & $\mathrm{HF}$ & Sum & TD & & \\
\hline \multirow{3}{*}{$\begin{array}{c}\text { Orangeburg } \\
\quad \# 10\end{array}$} & 62 & 0.000 & -0.026 & 0.033 & 0.001 & 0.65 & 0.77 & 0.38 & 1.34 & 3.1 & 0.08 & \multirow{3}{*}{0.06} & \multirow{3}{*}{$6047 \%$} \\
\hline & 63 & 0.000 & -0.005 & 0.038 & 0.001 & 0.55 & 0.31 & 2.03 & missing & 2.9 & $* 0.06$ & & \\
\hline & 64 & 0.000 & $* 0.033$ & 0.024 & $* 0.001$ & 0.70 & 0.37 & 3.07 & 1.41 & 5.6 & $* 0.06$ & & \\
\hline \multirow{3}{*}{$\begin{array}{c}\text { Orangeburg } \\
\quad \# 46\end{array}$} & 97 & 0.000 & 0.030 & 0.028 & 0.000 & 0.28 & 0.96 & 1.21 & $* 0.02$ & 2.5 & $* 0.02$ & \multirow{3}{*}{0.01} & \multirow{3}{*}{$15854 \%$} \\
\hline & 98 & $* 0.000$ & 0.006 & 0.015 & 0.000 & 0.19 & 0.45 & 1.26 & missing & 1.9 & $* 0.00$ & & \\
\hline & 99 & $* 0.000$ & +0.014 & 0.021 & $* 0.001$ & 0.24 & 0.48 & 1.24 & 0.25 & 2.2 & 0.02 & & \\
\hline \multirow{3}{*}{$\begin{array}{c}\text { Fuquay } \\
\# 8\end{array}$} & 66 & $* 0.000$ & $*-0.010$ & 0.041 & $* 0.001$ & 0.66 & 0.25 & 1.90 & 0.91 & 3.8 & 0.46 & \multirow{3}{*}{0.38} & \multirow{3}{*}{$699 \%$} \\
\hline & 67 & $* 0.000$ & * 0.029 & 0.048 & $* 0.000$ & 0.65 & 0.31 & 1.46 & 0.30 & 2.8 & $* 0.05$ & & \\
\hline & 68 & 0.000 & $\div 0.014$ & 0.044 & $* 0.000$ & 0.63 & $* 0.20$ & 0.31 & 0.29 & 1.5 & 0.63 & & \\
\hline \multirow{3}{*}{$\begin{array}{c}\text { Fuquay } \\
\# 42\end{array}$} & 81 & 0.000 & 0.017 & 0.105 & .0 .000 & 0.79 & 0.76 & 1.07 & 0.29 & 3.0 & 0.03 & \multirow{3}{*}{0.57} & \multirow{3}{*}{$564 \%$} \\
\hline & 82 & $* 0.000$ & 0.031 & 0.109 & $* 0.001$ & 1.01 & 0.98 & 0.59 & 0.17 & 2.9 & 0.96 & & \\
\hline & 83 & $* 0.000$ & $*-0.007$ & 0.100 & $* 0.002$ & 0.62 & 0.77 & 1.49 & 0.74 & 3.7 & 0.72 & & \\
\hline \multirow{3}{*}{$\begin{array}{l}\text { ESE } \\
\# 1\end{array}$} & 77 & $* 0.000$ & 0.011 & 0.017 & $*-0.001$ & 0.55 & 0.44 & 0.98 & 0.46 & 2.5 & 0.47 & \multirow{3}{*}{0.28} & \multirow{3}{*}{$864 \%$} \\
\hline & 78 & $* 0.000$ & 0.015 & 0.015 & $* 0.000$ & 0.59 & 0.46 & 1.21 & 0.52 & 2.8 & 0.08 & & \\
\hline & 79 & $* 0.001$ & $*-0.030$ & 0.023 & $\begin{array}{r}* 0.000 \\
\end{array}$ & 0.63 & missin & 0.93 & 0.32 & 1.9 & missing & & \\
\hline \multirow{3}{*}{$\begin{array}{c}\text { Vaucluse } \\
\# 12\end{array}$} & 74 & $* 0.000$ & 0.004 & $* 0.011$ & $\cdot 0.001$ & 0.12 & $* 0.00$ & 0.30 & $* 0.01$ & $\overline{0.4}$ & 0.00 & \multirow{3}{*}{0.04} & \multirow{3}{*}{$887 \%$} \\
\hline & 75 & $* 0.001$ & 0.012 & $* 0.013$ & $* 0.000$ & 0.12 & $* 0.02$ & 0.33 & missing & 0.5 & $* 0.04$ & & \\
\hline & 76 & $* 0.000$ & $*-0.017$ & $* 0.013$ & $*-0.001$ & 0.09 & $* 0.07$ & $* 0.03$ & missing & 0.2 & 0.08 & & \\
\hline \multirow{3}{*}{$\begin{array}{c}\text { Blanton } \\
\# 35\end{array}$} & 89 & 0.000 & $* 0.019$ & 0.012 & 0.000 & 0.55 & 0.39 & 0.12 & missing & 1.0 & 0.32 & \multirow{3}{*}{0.32} & \multirow{3}{*}{$246 \%$} \\
\hline & 90 & $* 0.000$ & -0.005 & 0.010 & $* 0.000$ & 0.24 & $* 0.23$ & $* 0.26$ & $* 0.03$ & 0.7 & missing & & \\
\hline & 91 & $* 0.000$ & -0.001 & 0.013 & 0.000 & 0.33 & 0.06 & $\div 0.14$ & -0.01 & 0.5 & missing & & \\
\hline & 93 & $* 0.000$ & -0.004 & 0.004 & $* 0.001$ & 0.26 & $* 0.02$ & 0.01 & missing & 0.3 & 0.02 & & \\
\hline $\begin{array}{c}\text { Dianion } \\
\text { \#45 }\end{array}$ & 94 & $* 0.000$ & $\div-0.003$ & 0.009 & $* 0.000$ & 0.19 & $* 0.02$ & missin & missing & 0.2 & $* 0.04$ & 0.05 & $722 \%$ \\
\hline & 95 & $=0.000$ & $* 0.009$ & 0.011 & $* 0.003$ & 0.30 & $* 0.08$ & -0.10 & missing & 0.5 & $* 0.08$ & & \\
\hline & 85 & $* 0.000$ & $*-0.014$ & 0.014 & $* 0.000$ & 0.37 & 0.45 & 0.18 & $* 0.00$ & 1.0 & 0.00 & & \\
\hline \#4! & 86 & $* 0.000$ & $*-0.018$ & $* 0.014$ & $* 0.001$ & 0.42 & 0.13 & 0.60 & missing & 1.1 & missing & 0.01 & $11710 \%$ \\
\hline & 87 & $* 0.000$ & 0.020 & $* 0.006$ & $*-0.001$ & 0.31 & 0.61 & 0.38 & 0.00 & 1.3 & 0.02 & & \\
\hline & 70 & 0.000 & 0.025 & 0.010 & 0.001 & 0.34 & $\$ 0.04$ & 0.54 & 0.02 & 1.0 & missing & & \\
\hline \#2 & 71 & $* 0.000$ & 0.013 & $* 0.003$ & $* 0.001$ & 0.60 & missin & 0.16 & -0.01 & 0.8 & 0.01 & 0.01 & $6898 \%$ \\
\hline & 72 & $* 0.000$ & $* 0.006$ & $* 0.012$ & $* 0.001$ & 0.32 & $* 0.08$ & $* 0.07$ & $* 0.12$ & 0.6 & missing & & \\
\hline
\end{tabular}

Note: An asterisk symbol by a result indicates that the value was below the detection limit. Poor calibration curves and poor agreement between calibration standards and check standards make the results for the PP, DC, HF and TD steps of limited quantitative value. 
Table A.12. Sequential extraction of thorium from CMP pit soils.

\begin{tabular}{|c|c|c|c|c|c|c|c|c|c|c|c|c|c|}
\hline \multirow{2}{*}{$\begin{array}{l}\text { CMP Pit } \\
\text { Sample ID }\end{array}$} & \multirow[b]{2}{*}{ Trial } & \multicolumn{10}{|c|}{ Thorium Removed During Extraction Step (mg/kg) } & \multirow{2}{*}{$\begin{array}{c}\text { Average } \\
\text { Total }\end{array}$} & \multirow{2}{*}{$\begin{array}{c}\text { Percent } \\
\text { Recovery }\end{array}$} \\
\hline & & $\overline{\mathrm{DDI}}$ & Salt & Ac & HAHCl & $\mathrm{PP}$ & $\mathrm{AOD}$ & $\overline{\mathrm{DC}}$ & $\mathrm{HF}$ & Sum & $\mathrm{TD}$ & & \\
\hline \multirow{3}{*}{$2 \mathrm{~A}$} & 37 & $* 0.001$ & $*-0.002$ & 0.042 & 0.003 & 0.41 & 0.56 & 3.8 & 0.32 & 5.14 & 9.6 & \multirow{3}{*}{8.0} & \multirow{3}{*}{$64 \%$} \\
\hline & 38 & $* 0.000$ & $*-0.005$ & 0.035 & 0.003 & 0.40 & 0.57 & 4.1 & 0.61 & 5.71 & 7.1 & & \\
\hline & 39 & $* 0.000$ & $*-0.002$ & 0.038 & 0.003 & 0.36 & 0.57 & 3.0 & 0.41 & 4.36 & 7.2 & & \\
\hline \multirow{3}{*}{$2 \mathrm{E}$} & 41 & $* 0.000$ & $*-0.006$ & 0.080 & $* 0.002$ & 0.05 & 0.25 & 2.0 & $* 0.05$ & 2.41 & 3.4 & \multirow{3}{*}{3.5} & \multirow{3}{*}{$71 \%$} \\
\hline & 42 & $* 0.000$ & $* 0.001$ & 0.075 & $* 0.001$ & 0.08 & 0.28 & 1.8 & $* 0.10$ & 2.37 & 3.3 & & \\
\hline & 43 & $* 0.000$ & $*-0.002$ & 0.072 & $* 0.002$ & 0.05 & 0.25 & 2.1 & $* 0.17$ & 2.61 & 3.7 & & \\
\hline \multirow{3}{*}{$3 \mathrm{~A}$} & 44 & 0.022 & $*-0.006$ & 0.048 & 0.035 & 1.19 & 0.91 & 1.6 & 0.49 & 4.28 & * 1.7 & \multirow{3}{*}{1.6} & \multirow{3}{*}{$313 \%$} \\
\hline & 45 & 0.019 & $*-0.007$ & 0.056 & 0.089 & 2.15 & 1.38 & 1.9 & 0.53 & 6.16 & $* 2.2$ & & \\
\hline & 46 & 0.014 & $*-0.027$ & 0.040 & 0.045 & 1.28 & 0.91 & 1.8 & 0.47 & 4.52 & $* 0.9$ & & \\
\hline \multirow{3}{*}{$5 \mathrm{~A}$} & 57 & $* 0.000$ & $* 0.003$ & 0.011 & 0.003 & 0.55 & 0.32 & 1.9 & 1.17 & 3.94 & 2.6 & \multirow{3}{*}{2.5} & \multirow{3}{*}{$115 \%$} \\
\hline & 58 & $* 0.000$ & $* 0.000$ & 0.010 & 0.002 & 0.50 & 0.29 & 1.3 & 0.05 & 2.15 & 2.6 & & \\
\hline & 59 & $* 0.000$ & $*-0.017$ & 0.009 & 0.003 & 0.55 & 0.31 & 1.4 & 0.09 & 2.36 & * 2.2 & & \\
\hline
\end{tabular}

Note: An asterisk symbol by a result indicates that the value was below the detection limit. Poor calibration curves and poor agreement between calibration standards and check standards make the results for the PP, DC, HF, and TD extration steps of limited quantitative value. Negative values are treated as zero when concentrations across all extraction steps are summed. 
Table A.13. Sequential extraction of lead from SRS background soils.

\begin{tabular}{|c|c|c|c|c|c|c|c|c|c|c|c|c|c|}
\hline \multirow{2}{*}{$\begin{array}{l}\text { Background } \\
\text { Soil Sample ID }\end{array}$} & \multirow[b]{2}{*}{ Trial } & \multicolumn{10}{|c|}{ Lead Removed During Extraction Step (mg $/ \mathrm{kg}$ ) } & \multirow{2}{*}{$\begin{array}{c}\text { Average } \\
\text { Total }\end{array}$} & \multirow{2}{*}{$\begin{array}{l}\text { Percent } \\
\text { Recovery }\end{array}$} \\
\hline & & $\overline{\mathrm{DDI}}$ & Salt & Ac & HAHCl & $\overline{\mathrm{PP}}$ & AOD & $\overline{D C}$ & $\mathrm{HF}$ & Sum & $\overline{T D}$ & & \\
\hline \multirow{3}{*}{$\begin{array}{c}\text { Orangeburg } \\
\quad \# 10\end{array}$} & 62 & 0.002 & 3.63 & 0.98 & 0.34 & 0.13 & 0.14 & 0.67 & 10.94 & 16.84 & 12.34 & \multirow{3}{*}{12.64} & \multirow{3}{*}{$157 \%$} \\
\hline & 63 & 0.002 & 3.86 & 0.99 & 0.36 & 0.18 & 0.14 & 0.39 & 18.41 & 24.33 & 12.88 & & \\
\hline & 64 & 0.029 & 3.17 & 0.96 & 0.36 & 0.16 & 0.15 & 0.48 & 13.04 & 18.34 & 12.70 & & \\
\hline \multirow{3}{*}{$\begin{array}{c}\text { Orangeburg } \\
\$ 46\end{array}$} & 97 & 0.000 & 0.22 & 0.43 & 0.30 & 0.03 & 0.08 & 0.51 & 9.03 & 10.59 & 8.93 & \multirow{3}{*}{9.39} & \multirow{3}{*}{$121 \%$} \\
\hline & 98 & 0.001 & $* 0.02$ & 0.32 & 0.27 & $* 0.02$ & 0.04 & 0.42 & 11.19 & 12.27 & 10.55 & & \\
\hline & 99 & $\cdot 0.000$ & $=-0.06$ & 0.37 & 0.29 & 0.03 & 0.09 & 0.50 & 9.94 & 11.16 & 8.69 & & \\
\hline \multirow{3}{*}{$\begin{array}{c}\text { Fuquay } \\
\# 8\end{array}$} & 66 & 0.000 & 0.58 & 0.47 & 0.15 & 0.07 & $\overline{0.07}$ & 0.25 & 13.50 & 15.09 & 12.09 & \multirow{3}{*}{11.85} & \multirow{3}{*}{$134 \%$} \\
\hline & 67 & 0.003 & 0.80 & 0.47 & 0.13 & 0.08 & 0.08 & 0.19 & 14.75 & 16.50 & 11.55 & & \\
\hline & 68 & 0.005 & 0.60 & 0.36 & 0.11 & 0.06 & 0.05 & 0.25 & $14: 49$ & 15.94 & 11.90 & & \\
\hline \multirow{3}{*}{$\begin{array}{c}\text { Fuquay } \\
\# 42\end{array}$} & 81 & 0.000 & 1.15 & 0.31 & 0.15 & 0.08 & 0.12 & 0.45 & 7.12 & 9.37 & 11.76 & \multirow{3}{*}{10.47} & \multirow{3}{*}{$94 \%$} \\
\hline & 82 & 0.000 & 1.24 & 0.29 & 0.14 & 0.08 & 0.09 & 0.24 & 5.84 & 7.92 & 10.10 & & \\
\hline & 83 & 0.000 & 0.98 & 0.26 & 0.18 & 0.06 & 0.08 & 0.17 & 10.62 & 12.35 & 9.55 & & \\
\hline \multirow{3}{*}{$\begin{array}{c}\text { ESE } \\
\# 1\end{array}$} & 77 & 0.000 & 0.79 & 0.45 & 0.26 & 0.07 & 0.08 & 0.29 & 8.63 & 10.56 & 9.70 & & \multirow{3}{*}{$119 \%$} \\
\hline & 78 & 0.001 & 0.85 & 0.53 & 0.28 & 0.08 & 0.08 & 0.36 & 9.87 & 12.06 & 9.44 & & \\
\hline & 79 & 0.001 & $* 0.78$ & 0.45 & 0.25 & 0.08 & missing & 0.37 & 7.61 & - & 9.43 & & \\
\hline \multirow{3}{*}{$\begin{array}{c}\text { Vaucluse } \\
\# 12\end{array}$} & 74 & 0.003 & 1.68 & 0.34 & 0.07 & 0.02 & 0.01 & 0.06 & 1.73 & 3.91 & 2.94 & \multirow{3}{*}{2.65} & \multirow{3}{*}{$145 \%$} \\
\hline & 75 & 0.004 & 1.61 & 0.33 & 0.07 & 0.04 & $* 0.01$ & $* 0.04$ & 1.70 & 3.81 & 2.68 & & \\
\hline & 76 & 0.003 & 0.33 & 0.33 & 0.07 & $* 0.02$ & $* 0.02$ & $\begin{array}{c}* 0.06 \\
\end{array}$ & missing & - & 2.34 & & \\
\hline \multirow{3}{*}{$\begin{array}{c}\text { Blanton } \\
\# 35\end{array}$} & 89 & 0.003 & 0.88 & 0.54 & 0.16 & 0.06 & 0.00 & 0.06 & $=0.16$ & 1.86 & 3.84 & \multirow{3}{*}{4.89} & \multirow{3}{*}{$58 \%$} \\
\hline & 90 & 0.002 & 1.06 & 0.57 & 0.17 & 0.08 & $* 0.05$ & $* 0.09$ & 0.99 & 3.01 & 4.00 & & \\
\hline & 91 & 0.001 & 0.88 & 0.50 & 0.17 & 0.06 & 0.04 & 0.17 & 1.88 & 3.70 & 6.83 & & \\
\hline & 93 & 0.005 & 2.92 & 0.53 & 0.11 & 0.05 & 0.02 & 0.10 & 0.51 & 4.23 & 3.44 & & \\
\hline$\# 45$ & 94 & 0.005 & 2.43 & 0.44 & 0.11 & 0.08 & 0.01 & 0.14 & 2.89 & 6.10 & 3.30 & 3.35 & $141 \%$ \\
\hline & 95 & 0.004 & 2.79 & 0.48 & 0.12 & 0.05 & $* 0.02$ & 0.15 & 0.22 & 3.84 & 3.32 & & \\
\hline & 85 & 0.001 & 0.25 & 0.29 & 0.19 & 0.06 & 0.03 & 0.16 & 1.40 & 2.37 & 3.12 & & \\
\hline$\# 41$ & 86 & 0.001 & 0.24 & 0.26 & 0.18 & 0.08 & 0.03 & 0.10 & 2.42 & 3.30 & 3.22 & 3.13 & $89 \%$ \\
\hline & 87 & $* 0.000$ & 0.39 & 0.31 & 0.19 & $* 0.07$ & 0.02 & 0.12 & 1.58 & 2.69 & 3.05 & & \\
\hline & 70 & 0.000 & 0.03 & 0.22 & 0.06 & 0.08 & $* 0.00$ & 0.09 & 7.16 & 7.64 & 6.29 & & \\
\hline$\# 2$ & 71 & 0.000 & $* 0.06$ & 0.13 & 0.07 & 0.08 & $* 0.03$ & 0.07 & 2.17 & 2.61 & 5. & 5.65 & $119 \%$ \\
\hline & 72 & 0.000 & $* 0.21$ & 0.26 & 0.07 & 0.12 & $* 0.01$ & $* 0.06$ & 9.26 & 9.99 & 5.22 & & \\
\hline
\end{tabular}

Note: An asterisk symbol by a result indicates that the value was below the detection limit. 
Table A.14. Sequential extraction of lead from CMP pit soils.

\begin{tabular}{|c|c|c|c|c|c|c|c|c|c|c|c|c|c|}
\hline CMP Pit & & \multicolumn{10}{|c|}{ Lead Removed During Extraction Step (mg/kg) } & Average & Percent \\
Sample ID & Trial & DDI & Salt & Ac & HAHC & PP & AOD & DC & HF & Sum & TD & Recovery \\
\hline \multirow{3}{*}{$2 \mathrm{~A}$} & 37 & $* 0.001$ & $* 0.12$ & 0.20 & 0.07 & $* 0.00$ & 0.05 & 1.11 & 5.18 & 6.7 & 13.49 & & \\
& 38 & $* 0.001$ & $* 0.09$ & 0.22 & 0.08 & $*-0.01$ & 0.05 & 1.12 & 7.11 & 8.7 & 11.71 & 11.82 & $60 \%$ \\
& 39 & 0.003 & $* 0.08$ & 0.18 & 0.09 & $* 0.00$ & 0.05 & 0.95 & 4.63 & 6.0 & 10.26 & & \\
\hline \multirow{3}{*}{$2 \mathrm{E}$} & 41 & $* 0.000$ & 0.16 & 0.16 & 0.06 & $* 0.01$ & $* 0.02$ & 1.67 & 3.37 & 5.5 & 9.13 & & \\
& 42 & $* 0.000$ & 0.30 & 0.19 & 0.06 & $*-0.02$ & 0.03 & 1.43 & 2.94 & 5.0 & 7.92 & 8.14 & $65 \%$ \\
& 43 & 0.034 & 0.17 & 0.14 & 0.05 & $* 0.00$ & 0.02 & 1.60 & 3.50 & 5.5 & 7.35 & & \\
\hline \multirow{3}{*}{$3 \mathrm{~A}$} & 44 & 0.047 & -0.04 & 2.51 & 0.55 & $* 0.03$ & 0.08 & 0.96 & 5.90 & 10.1 & 8.23 & & \\
& 45 & 0.020 & $* 0.02$ & 1.17 & 0.40 & $* 0.06$ & 0.11 & 0.97 & 5.95 & 8.7 & 8.71 & 8.56 & $116 \%$ \\
& 46 & 0.016 & 0.02 & 2.19 & 0.64 & $* 0.05$ & 0.06 & 1.02 & 6.91 & 10.9 & 8.75 & & \\
\hline \multirow{3}{*}{$5 \mathrm{~A}$} & 57 & 0.002 & 0.42 & 0.73 & 0.54 & 0.72 & 0.49 & 1.38 & 6.16 & 10.4 & 7.23 & & \\
& 58 & $* 0.002$ & 0.34 & 0.54 & 0.25 & 0.11 & 0.11 & 0.53 & 3.90 & 5.8 & 7.48 & 7.13 & $99 \%$ \\
& 59 & $* 0.001$ & 0.39 & 0.56 & 0.27 & $* 0.05$ & 0.08 & 0.58 & 3.09 & 5.0 & 6.68 & & \\
\hline
\end{tabular}

Note: An asterisk symbol by a result indicates that the value was below the detection limit. Negative values are treated as zero when concentrations across all extraction steps are summed. 
Table A.15. Sequential extraction of barium from SRS background soils.

\begin{tabular}{|c|c|c|c|c|c|c|c|c|c|c|c|c|c|}
\hline \multirow{2}{*}{$\begin{array}{c}\text { Background } \\
\text { Soil Sample ID } \\
\end{array}$} & \multirow[b]{2}{*}{ Trial } & \multicolumn{10}{|c|}{ Barium Removed During Extraction Step (mg/kg) } & \multirow{2}{*}{$\begin{array}{c}\text { Average } \\
\text { Total }\end{array}$} & \multirow{2}{*}{$\begin{array}{l}\text { Percent } \\
\text { Recovery }\end{array}$} \\
\hline & & $\overline{\mathrm{DDI}}$ & Salt & Ac & $\mathrm{HAHCl}$ & $\mathrm{PP}$ & AOD & DC & HF & Sum & TD & & \\
\hline \multirow{3}{*}{$\begin{array}{c}\text { Orangeburg } \\
\quad \# 10\end{array}$} & 62 & 0.16 & 8.1 & 0.69 & 0.38 & 2.37 & 0.39 & 1.16 & 23.6 & 36.8 & 19.4 & \multirow{3}{*}{17.7} & \multirow{3}{*}{$163 \%$} \\
\hline & 63 & 0.15 & 7.6 & 0.70 & 0.38 & 2.43 & 0.40 & 0.98 & 5.9 & 18.5 & 15.4 & & \\
\hline & 64 & 0.15 & 6.5 & 0.72 & 0.39 & 2.39 & 0.40 & 0.97 & 20.1 & 31.6 & 18.5 & & \\
\hline \multirow{3}{*}{$\begin{array}{c}\text { Orangeburg } \\
\$ 46\end{array}$} & 97 & 0.08 & 6.9 & 0.79 & 0.53 & 1.60 & 0.34 & 1.01 & 11.5 & 22.8 & 49.8 & \multirow{3}{*}{49.7} & \multirow{3}{*}{$55 \%$} \\
\hline & 98 & 0.06 & 5.7 & 0.73 & 0.49 & 1.48 & 0.31 & 0.94 & 15.9 & 25.6 & 53.2 & & \\
\hline & 99 & 0.06 & 7.9 & 0.71 & 0.51 & 1.42 & 0.35 & 1.01 & 21.7 & 33.7 & 46.1 & & \\
\hline \multirow{3}{*}{$\begin{array}{c}\text { Fuquay } \\
\# 8\end{array}$} & 66 & 0.12 & 3.6 & 0.30 & 0.17 & 1.16 & 0.21 & 0.65 & 15.6 & 21.8 & 41.7 & \multirow{3}{*}{37.0} & \multirow{3}{*}{$58 \%$} \\
\hline & 67 & 0.13 & 3.2 & 0.31 & 0.17 & 1.15 & 0.24 & 0.46 & 17.3 & 23.0 & 33.8 & & \\
\hline & 68 & 0.10 & 3.3 & 0.28 & 0.16 & 1.10 & 0.17 & 0.46 & 13.9 & 19.5 & 35.5 & & \\
\hline \multirow{3}{*}{$\begin{array}{c}\text { Fuquay } \\
\# 42\end{array}$} & 81 & 0.06 & 5.4 & 0.58 & 0.34 & 2.33 & 0.38 & 1.00 & 25.2 & 35.3 & 62.8 & \multirow{3}{*}{57.3} & \multirow{3}{*}{$48 \%$} \\
\hline & 82 & 0.06 & 5.3 & 0.58 & 0.31 & 2.26 & 0.31 & 0.82 & 18.7 & 28.4 & 61.2 & & \\
\hline & 83 & 0.06 & 4.6 & 0.63 & 0.33 & 2.23 & 0.28 & 0.92 & 9.1 & 18.1 & 48.0 & & \\
\hline \multirow{3}{*}{$\begin{array}{c}\text { ESE } \\
\# 1\end{array}$} & 77 & 0.35 & 9.9 & 0.75 & 0.37 & 2.29 & 0.28 & 0.60 & 13.4 & 27.9 & 56.0 & \multirow{3}{*}{55.1} & \multirow{3}{*}{$56 \%$} \\
\hline & 78 & 0.40 & 10.8 & 0.83 & 0.37 & 2.42 & 0.32 & 0.85 & 18.0 & 34.0 & 55.4 & & \\
\hline & 79 & 0.36 & 12.9 & 0.82 & 0.38 & 2.41 & missing & 0.65 & 22.3 & - & 53.9 & & \\
\hline \multirow{3}{*}{$\begin{array}{l}\text { Vaucluse } \\
\# 12\end{array}$} & 74 & 0.18 & 1.4 & 0.14 & 0.10 & 0.65 & 0.07 & 0.19 & 1.2 & 3.9 & 13.3 & \multirow{3}{*}{14.1} & \multirow{3}{*}{$25 \%$} \\
\hline & 75 & 0.20 & 1.3 & 0.14 & 0.10 & 0.67 & 0.06 & $* 0.05$ & 0.7 & 3.2 & 13.0 & & \\
\hline & 76 & 0.29 & 1.4 & 0.12 & 0.10 & 0.70 & 0.06 & 0.19 & missing & - & 15.9 & & \\
\hline \multirow{3}{*}{$\begin{array}{c}\text { Blanton } \\
\# 35\end{array}$} & 89 & 0.05 & 1.2 & 0.16 & 0.08 & 1.01 & 0.05 & 0.20 & 0.0 & 2.7 & 24.5 & \multirow{3}{*}{25.1} & \multirow{3}{*}{$16 \%$} \\
\hline & 90 & 0.05 & 1.0 & 0.15 & 0.08 & 1.11 & 0.08 & 0.30 & 1.3 & 4.1 & 23.9 & & \\
\hline & 91 & 0.04 & 1.5 & 0.15 & 0.09 & 1.13 & 0.09 & 0.42 & 2.2 & 5.6 & 26.9 & & \\
\hline & 93 & 0.08 & 0.8 & 0.10 & 0.06 & 0.81 & 0.04 & 0.20 & 1.8 & 3.9 & 16.6 & & \\
\hline Blo & 94 & 0.08 & 0.7 & 0.12 & 0.06 & 0.87 & 0.03 & $* 0.26$ & 4.2 & 6.3 & 20.3 & 18.4 & $22 \%$ \\
\hline & 95 & 0.08 & 0.8 & 0.12 & 0.07 & 0.84 & 0.03 & $\because 0.16$ & $* 0.0$ & 2.1 & 18.4 & & \\
\hline & 85 & 0.12 & 1.8 & 0.22 & 0.15 & 1.40 & 0.12 & 0.33 & 2.5 & 6.6 & 27.6 & & \\
\hline \#41 & 86 & 0.16 & 1.8 & 0.22 & 0.14 & 1.47 & 0.11 & 0.35 & 4.6 & 8.8 & 27.4 & 27.9 & $30 \%$ \\
\hline & 87 & 0.15 & 2.3 & 0.21 & 0.14 & 1.57 & 0.09 & 0.42 & 4.7 & 9.5 & 28.7 & & \\
\hline & 70 & 0.41 & 5.5 & 0.44 & 0.33 & 2.40 & 0.25 & 0.81 & 11.7 & 21.8 & 53.9 & & \\
\hline akelands & 71 & 0.38 & 4.6 & 0.41 & 0.32 & 2.18 & 0.38 & 0.72 & 3.9 & 12.9 & 52.8 & 50.8 & $53 \%$ \\
\hline & 72 & 0.29 & 4.9 & 0.47 & 0.35 & 2.33 & 0.26 & 0.61 & 36.9 & 46.2 & 45.8 & & \\
\hline
\end{tabular}

Note: An asterisk symbol by a result indicates that the value was below the detection limit. 
Table A.16. Sequential extraction of barium from CMP pit soils.

\begin{tabular}{|c|c|c|c|c|c|c|c|c|c|c|c|c|c|c|}
\hline CMP Pit & & \multicolumn{10}{|c|}{ Barium Removed During Extraction Step (mg/kg) } & Average & Percent \\
Sample ID & Trial & DDI & Salt & Ac & HAHCl & PP & AOD & DC & HF & Sum & TD & Recovery \\
\hline \multirow{2}{*}{$2 \mathrm{~A}$} & 37 & 0.031 & 0.91 & 0.08 & $* 0.05$ & 0.11 & 0.05 & $* 0.11$ & 4.6 & 6.0 & 27.3 & & \\
& 38 & 0.031 & 1.03 & 0.07 & $* 0.06$ & 0.11 & 0.05 & $* 0.15$ & 7.5 & 9.0 & 21.3 & 23.3 & $32 \%$ \\
& 39 & 0.040 & 0.79 & 0.08 & $* 0.07$ & 0.09 & 0.05 & $* 0.12$ & 6.4 & 7.6 & 21.2 & & \\
\hline \multirow{3}{*}{$2 \mathrm{E}$} & 41 & 0.001 & $* 0.13$ & 0.04 & $* 0.03$ & $* 0.00$ & $* 0.01$ & $*-0.06$ & 2.4 & 2.6 & 17.9 & & \\
& 42 & 0.001 & 0.15 & 0.05 & $* 0.03$ & $* 0.00$ & $* 0.02$ & $* 0.03$ & 3.8 & 4.1 & 16.1 & 16.3 & $20 \%$ \\
& 43 & 0.002 & 0.22 & 0.03 & $* 0.04$ & $* 0.00$ & $* 0.02$ & $* 0.02$ & 2.9 & 3.2 & 15.1 & & \\
\hline \multirow{3}{*}{$3 \mathrm{~A}$} & 44 & 0.080 & 3.12 & 2.69 & 0.37 & 0.38 & 0.10 & $* 0.28$ & 1.8 & 8.9 & 47.0 & & \\
& 45 & 0.070 & 3.29 & 2.61 & 0.39 & 0.43 & 0.13 & 0.30 & 1.5 & 8.7 & 52.6 & 52.0 & $17 \%$ \\
& 46 & 0.058 & 3.57 & 2.76 & 0.50 & 0.43 & 0.10 & 0.31 & 1.4 & 9.1 & 56.3 & & \\
\hline \multirow{3}{*}{ 5A } & 57 & 0.353 & 2.74 & 0.25 & 0.18 & 0.85 & 0.18 & 0.42 & 5.5 & 10.5 & 26.8 & & \\
& 58 & 0.302 & 2.29 & 0.24 & 0.17 & 0.70 & 0.18 & 0.29 & 4.0 & 8.2 & 31.1 & 28.8 & $33 \%$ \\
& 59 & 0.311 & 3.12 & 0.24 & 0.18 & 0.74 & 0.12 & 0.40 & 4.8 & 10.0 & 28.7 & & \\
\hline
\end{tabular}

Note: An asterisk symbol by a result indicates that the value was below the detection limit. Negative values are treated as zero when concentrations across all extraction steps are summed. 
Table A.17. Sequential extraction of chromium from SRS background soils.

\begin{tabular}{|c|c|c|c|c|c|c|c|c|c|c|c|c|c|}
\hline \multirow{2}{*}{$\begin{array}{c}\text { Background Soi } \\
\text { Sample ID }\end{array}$} & \multirow[b]{2}{*}{ Trial } & \multicolumn{10}{|c|}{ Chromium Removed During Extraction Step (mg $/ \mathrm{kg}$ ) } & \multirow{2}{*}{$\begin{array}{c}\text { Average } \\
\text { Total }\end{array}$} & \multirow{2}{*}{$\begin{array}{l}\text { Percent } \\
\text { Recovery }\end{array}$} \\
\hline & & DDI & Salt & Ac & HAHC & PP & AOD & $\overline{D C}$ & HFF & Sum & TD & & \\
\hline \multirow{3}{*}{$\begin{array}{c}\text { Orangeburg } \\
\# 10\end{array}$} & 62 & 0.00 & $*-0.15$ & 0.24 & $\$ 0.00$ & 0.38 & $* 0.08$ & 4.95 & 33.49 & 39.14 & 27.85 & \multirow{3}{*}{28.85} & \multirow{3}{*}{$130 \%$} \\
\hline & 63 & $* 0.00$ & $*-0.02$ & $*-1.30$ & $* 0.01$ & 0.68 & $* 0.02$ & 4.52 & 33.50 & 38.72 & 29.24 & & \\
\hline & 64 & $\bullet 0.00$ & $* .0 .02$ & $* 0.07$ & *. & 0.48 & $* 0.06$ & 5.13 & 28.51 & 34.25 & 29.45 & & \\
\hline \multirow{3}{*}{$\begin{array}{c}\text { Orangeburg } \\
\qquad 46\end{array}$} & 97 & 0.01 & 0.06 & -0.49 & *. & 0.20 & -0.01 & 4.00 & 16.66 & 20.93 & 21.51 & \multirow{3}{*}{22.70} & \multirow{3}{*}{$126 \%$} \\
\hline & 98 & $\bullet 0.00$ & $*-0.16$ & --1.87 & $\bullet 0.00$ & 0.14 & $* 0.17$ & 4.11 & 22.81 & 27.24 & 26.67 & & \\
\hline & 99 & $* 0.00$ & $*-0.02$ & $*-0.96$ & 0.09 & 0.18 & $* 0.12$ & 4.00 & 33.48 & 37.87 & 19.93 & & \\
\hline \multirow{3}{*}{$\begin{array}{l}\text { Fuquay } \\
\# 8\end{array}$} & 66 & 0.00 & $*-0.14$ & $* 0.00$ & 0.06 & 0.79 & $* 0.35$ & 5.51 & 20.31 & 27.02 & 24.63 & \multirow{3}{*}{23.11} & \multirow{3}{*}{$124 \%$} \\
\hline & 67 & $* 0.00$ & 0.07 & -0.81 & *. & 0.69 & $* 0.22$ & 5.05 & 22.52 & 28.55 & 22.23 & & \\
\hline & 68 & $* 0.00$ & $* 0.03$ & -0.01 & $* 0.01$ & 0.56 & $* 0.30$ & 5.21 & 24.55 & 30.67 & 22.46 & & \\
\hline \multirow{3}{*}{$\begin{array}{l}\text { Fuquay } \\
\# 42\end{array}$} & 81 & 0.01 & -0.04 & -0.23 & 0.00 & 0.26 & 0.50 & 1.59 & 12.30 & 14.67 & 24.14 & \multirow{3}{*}{20.12} & \multirow{3}{*}{$96 \%$} \\
\hline & 82 & 0.01 & $* 0.03$ & $* 0.14$ & $* 0.01$ & 0.29 & 0.49 & 1.29 & 11.79 & 14.05 & 24.63 & & \\
\hline & 83. & $* 0.00$ & +-0.03 & $*-1.23$ & 0.11 & 0.22 & 0.43 & 2.02 & 26.39 & 29.17 & 11.60 & & \\
\hline \multirow{3}{*}{$\begin{array}{c}\text { ESE } \\
\# 1\end{array}$} & 77 & $* 0.00$ & $*-0.13$ & -0.09 & *. & 0.39 & $* 0.02$ & 3.00 & 19.05 & 22.46 & 20.21 & \multirow{3}{*}{20.15} & \multirow{3}{*}{$119 \%$} \\
\hline & 78 & 0.01 & $*-0.16$ & 0.15 & *. & 0.45 & -0.05 & 3.11 & 19.96 & 23.69 & 22.35 & & \\
\hline & 79 & $* 0.00$ & 0.00 & $\because .1 .54$ & *. & 0.71 & missing & 3.36 & 21.99 & 26.06 & 17.89 & & \\
\hline \multirow{3}{*}{$\begin{array}{c}\text { Vaucluse } \\
\# 12\end{array}$} & 74 & 0.01 & 0.07 & -0.18 & 0.00 & 0.18 & 0.07 & 0.44 & 4.08 & 4.84 & 14.60 & \multirow{3}{*}{14.21} & \multirow{3}{*}{$30 \%$} \\
\hline & 75 & 0.00 & -0.05 & $*-0.55$ & *. & 0.17 & $*-0.02$ & 0.15 & 3.47 & 3.78 & 9.72 & & \\
\hline & 76 & 0.03 & $*-0.16$ & $*-0.35$ & $* 0.00$ & 0.15 & -0.01 & 0.36 & missing & . & 18.31 & & \\
\hline \multirow{3}{*}{$\begin{array}{c}\text { Blanton } \\
\# 35\end{array}$} & 89 & 0.01 & -0.17 & $=0.97$ & *- & 0.17 & -0.15 & $*-0.04$ & 1.09 & 1.27 & 15.58 & \multirow{3}{*}{11.81} & \multirow{3}{*}{$44 \%$} \\
\hline & 90 & $* 0.00$ & 0.09 & $* 0.11$ & *. & 0.16 & 0.05 & 0.55 & 7.04 & 8.00 & 9.47 & & \\
\hline & 91. & $* 0.00$ & $* 0.00$ & -0.53 & *. & 0.16 & $* 0.10$ & $* 0.18$ & 5.98 & 6.42 & 10.39 & & \\
\hline & 93 & $* 0.00$ & $* 0.04$ & 0.14 & 0.01 & 0.27 & -0.14 & 0.31 & * 1.64 & 2.42 & 8.18 & & \\
\hline$\# 45$ & 94 & 0.01 & ${ }^{*} 0.01$ & $* 1.47$ & *. & 0.26 & -0.14 & ${ }^{*}-0.15$ & 4.66 & 4.94 & 9.98 & 8.76 & $39 \%$ \\
\hline & 95 & 0.00 & 0.04 & $*-1.25$ & *. & 0.23 & 0.07 & 0.44 & 2.09 & 2.86 & 8.11 & & \\
\hline & 85 & 0.00 & -0.11 & $7-1.86$ & 0.00 & 0.17 & $=0.05$ & 0.70 & 6.71 & 7.59 & 8.93 & & \\
\hline $\begin{array}{l}\text { Latelana } \\
\text { Hal }\end{array}$ & 86 & 0.01 & $*-0.15$ & $*-1.55$ & 0.01 & 0.27 & $*-0.11$ & 0.51 & 5.10 & 5.89 & 10.59 & 10.19 & $59 \%$ \\
\hline & 87 & 0.01 & 0.05 & $=-0.29$ & 0.01 & 0.17 & $*-0.11$ & 0.83 & 3.51 & 4.58 & 11.05 & & \\
\hline & 70 & $* 0.00$ & 0.00 & 0.04 & $*$ & 0.37 & $* 0.00$ & 2.45 & 14.74 & 17.61 & 15.03 & & \\
\hline$\# 2$ & 71 & $* 0.00$ & 0.07 & -0.37 & 0.12 & 0.71 & $* 0.56$ & 1.94 & 8.14 & 11.53 & 12.17 & 13.10 & $131 \%$ \\
\hline & 72 & 0.00 & $* 0.12$ & $*-0,96$ & 0.07 & 0.40 & $* 0.13$ & 1.57 & 20.17 & 22.46 & 12.10 & & \\
\hline
\end{tabular}

Note: An asterisk symbol by a result indicates that the value was below the detection limit. Negative values are treated as zero when concentrations across all extraction steps are summed. 
Table A.18. Sequential extraction of chromium from CMP pit soils.

\begin{tabular}{|c|c|c|c|c|c|c|c|c|c|c|c|c|c|}
\hline \multirow{2}{*}{$\begin{array}{l}\text { CMP Pit } \\
\text { Sample ID }\end{array}$} & \multirow[b]{2}{*}{ Trial } & \multicolumn{10}{|c|}{ Chromium Removed During Extraction Step (mg/kg) } & \multirow{2}{*}{$\begin{array}{c}\text { Average } \\
\text { Total }\end{array}$} & \multirow{2}{*}{$\begin{array}{l}\text { Percent } \\
\text { Recovery }\end{array}$} \\
\hline & & $\overline{\mathrm{DDI}}$ & Salt & $\overline{A C}$ & HAHC & $\mathrm{PP}$ & AOD & $D C$ & $\mathrm{HF}$ & Sum & $\overline{\mathrm{TD}}$ & & \\
\hline \multirow{3}{*}{$2 \mathrm{~A}$} & 37 & 0.009 & *0.37 & $* 0.25$ & * & *0.07 & 0.10 & 12.05 & 7.53 & 20.38 & 26.79 & \multirow{3}{*}{23.75} & \multirow{3}{*}{$80 \%$} \\
\hline & 38 & $* 0.003$ & $* 0.33$ & $* 0.19$ & * & $* 0.14$ & 0.12 & 12.89 & 6.66 & 20.34 & 21.80 & & \\
\hline & 39 & $* 0.001$ & $* 0.31$ & $*-0.24$ & * & $* 0.02$ & 0.14 & 11.19 & 4.54 & 16.21 & 22.66 & & \\
\hline \multirow{3}{*}{$2 \mathrm{E}$} & 41 & $* 0.000$ & $* 0.45$ & -0.11 & * & $*-0.02$ & 0.00 & 4.83 & 2.53 & 7.81 & 11.75 & \multirow{3}{*}{11.52} & \multirow{3}{*}{$72 \%$} \\
\hline & 42 & $* 0.001$ & $* 0.44$ & $*-0.03$ & * & $* 0.01$ & 0.05 & 4.46 & 2.19 & 7.16 & 11.77 & & \\
\hline & 43 & 0.007 & $*-0.14$ & $* 0.14$ & * & $* 0.09$ & 0.04 & 4.74 & 4.77 & 9.79 & 11.04 & & \\
\hline \multirow{3}{*}{$3 \mathrm{~A}$} & 44 & 0.069 & *0.37 & $* 0.51$ & 0.099 & 0.22 & 0.28 & 4.68 & 23.83 & 30.06 & 13.87 & \multirow{3}{*}{14.21} & \multirow{3}{*}{$144 \%$} \\
\hline & 45 & 0.047 & $* 0.40$ & $* 0.81$ & 0.099 & 0.38 & 0.22 & 6.36 & 7.78 & 16,11 & 14.41 & & \\
\hline & 46 & 0.030 & $*-0.14$ & $* 0.70$ & 0.094 & 0.36 & 0.27 & 5.03 & 8.84 & 15.32 & 14.35 & & \\
\hline \multirow{3}{*}{$5 \mathrm{~A}$} & 57 & $* 0.001$ & $* 0.37$ & $* 0.02$ & 0.022 & 0.95 & 0.17 & 6.75 & 8.25 & 16.54 & 26.72 & \multirow{3}{*}{22.54} & \multirow{3}{*}{$79 \%$} \\
\hline & 58 & $* 0.002$ & $* 0.38$ & $*-0.56$ & * & 0.43 & $* 0.12$ & 3.91 & 6.27 & 11.12 & 23.45 & & \\
\hline & 59 & $* 0.001$ & $* 0.22$ & $*-0.13$ & * & 0.39 & 0.16 & 5.31 & 19.39 & 25.49 & 17.43 & & \\
\hline
\end{tabular}

Note: An asterisk symbol by a result indicates that the value was below the detection limit. Negative values are treated as zero when concentrations across all extraction steps are summed. 
Table A.19. Sequential extraction of vanadium from SRS background soils.

\begin{tabular}{|c|c|c|c|c|c|c|c|c|c|c|c|c|c|}
\hline \multirow{2}{*}{$\begin{array}{c}\text { Background } \\
\text { Soil Sample ID }\end{array}$} & \multirow[b]{2}{*}{ Trial } & \multicolumn{10}{|c|}{ Vanadium Removed During Extraction Step (mg $/ \mathrm{kg}$ ) } & \multirow{2}{*}{$\begin{array}{c}\text { Average } \\
\text { Total }\end{array}$} & \multirow{2}{*}{$\begin{array}{l}\text { Percent } \\
\text { Recovery }\end{array}$} \\
\hline & & $\overline{\mathrm{DDI}}$ & Salt & Ac & HAHCl & $\overline{P P}$ & AOD & $\overline{D C}$ & $\mathrm{HF}$ & Sum & TD & & \\
\hline \multirow{3}{*}{$\begin{array}{c}\text { Orangeburg } \\
\quad \# 10\end{array}$} & $\overline{62}$ & 0.000 & 0.01 & $\$ 0.11$ & 0.70 & 2.60 & 1.26 & 17.65 & 38.71 & 61.04 & 49.70 & \multirow{3}{*}{50.88} & \multirow{3}{*}{$117 \%$} \\
\hline & 63 & -0.001 & $* 0.01$ & -0.34 & 0.66 & 3.41 & 1.21 & 14.97 & 43.53 & 63.79 & 51.09 & & \\
\hline & 64 & $*-0.002$ & $*-0.04$ & 0.05 & 0.64 & 2.93 & 1.31 & 15,18 & 33.66 & 53.77 & 51.84 & & \\
\hline \multirow{3}{*}{$\begin{array}{c}\text { Orangeburg } \\
\# 46\end{array}$} & 97 & 0.004 & -0.01 & -0.07 & 0.55 & 1.62 & 1.42 & 12.11 & 21.14 & 36.83 & 30.59 & \multirow{3}{*}{31.74} & \multirow{3}{*}{$121 \%$} \\
\hline & 98 & $* 0.001$ & -0.01 & $*-0.45$ & 0.49 & 1.35 & 1.30 & 10.55 & 20.55 & 34.23 & 34.93 & & \\
\hline & 99 & $* 0.002$ & $=0.05$ & -0.20 & 0.50 & 1.49 & 1.23 & 11.47 & 29.65 & 44.39 & 29.68 & & \\
\hline \multirow{3}{*}{$\begin{array}{c}\text { Fuquay } \\
\# 8\end{array}$} & 66 & -0.001 & -0.01 & 0.05 & 0.51 & 2.74 & 1.43 & 17.43 & 23.39 & 45.54 & 38.86 & \multirow{3}{*}{40.43} & \multirow{3}{*}{$112 \%$} \\
\hline & 67 & -0.002 & $* 0.02$ & -0.32 & 0.55 & 2.83 & 1.34 & 17.11 & 22.88 & 44.73 & 35.66 & & \\
\hline & 68 & -0.003 & 0.01 & $* 0.03$ & 0.59 & 2.95 & 1.53 & 16.03 & 24.22 & 45.34 & 46.76 & & \\
\hline \multirow{3}{*}{$\begin{array}{c}\text { Fuquay } \\
\# 42\end{array}$} & 81 & 0.004 & -0.04 & 0.04 & 0.31 & 1.35 & 1.34 & 5.31 & 17.46 & 25.82 & 32.04 & \multirow{3}{*}{34.18} & \multirow{3}{*}{$85 \%$} \\
\hline & 82 & $* 0.003$ & -0.06 & $\bullet 0.12$ & 0.30 & 1.27 & 1.24 & 5.07 & 14.54 & 22.53 & 35.15 & & \\
\hline & 83 & $* 0.001$ & 0.01 & $*-0.26$ & 0.28 & 1.17 & 1.27 & 5.69 & 30.62 & 39.05 & 35.34 & & \\
\hline \multirow{3}{*}{$\begin{array}{c}\text { ESE } \\
\# 1\end{array}$} & 77 & -0.001 & -0.05 & 0.05 & 0.48 & 2.86 & 0.82 & 11.38 & 24.15 & 39.75 & 35.09 & \multirow{3}{*}{34.47} & \multirow{3}{*}{$114 \%$} \\
\hline & 78 & $* 0.001$ & $*-0.03$ & $\bullet 0.08$ & 0.49 & 3.10 & 0.92 & 11.48 & 23.04 & 39.11 & 34.86 & & \\
\hline & 79 & 0.000 & $* 0.04$ & $*-0.33$ & 0.46 & 2.80 & missing & 10.56 & 30.27 & $=$ & 33.46 & & \\
\hline \multirow{3}{*}{$\begin{array}{c}\text { Vaucluse } \\
\sharp 12\end{array}$} & 74 & -0.001 & 0.02 & 0.01 & 0.03 & 0.39 & 0.13 & 1.83 & 4.08 & 6.48 & 8.26 & \multirow{3}{*}{8.20} & \multirow{3}{*}{$77 \%$} \\
\hline & 75 & -0.001 & -0.02 & -0.10 & $* 0.02$ & 0.43 & $* 0.11$ & 1.72 & 3.86 & 6.13 & 7.87 & & \\
\hline & 76 & $* 0.007$ & $*-0.11$ & -0.07 & 0.03 & 0.44 & $* 0.08$ & 1.46 & missing & $\therefore$ & 8.47 & & \\
\hline \multirow{3}{*}{$\begin{array}{c}\text { Blanton } \\
\sharp 35\end{array}$} & 89 & 0.001 & -0.03 & -0.35 & 0.08 & 0.38 & 0.06 & 1.30 & 1.69 & 3.52 & 11.86 & \multirow{3}{*}{11.41} & \multirow{3}{*}{$72 \%$} \\
\hline & 90 & -0.001 & $*-0.01$ & 0.05 & 0.02 & 0.38 & $* 0.12$ & 1.78 & 8.18 & 10.53 & 11.43 & & \\
\hline & 91 & $* 0.000$ & $* 0.05$ & -0.13 & $* 0.09$ & 0.44 & $* 0.10$ & 2.03 & 7.74 & 10.45 & 10.96 & & \\
\hline & 93 & -0.002 & +0.03 & $* 0.07$ & 0.03 & 0.37 & -0.02 & 1.62 & 1.28 & 3.40 & 8.12 & & \\
\hline Blanton & 94 & $* 0.001$ & $*-0.01$ & $*-0.41$ & $* 0.01$ & 0.38 & $* 0.02$ & 1.56 & 3.36 & 5.33 & 8.50 & 8.20 & $46 \%$ \\
\hline & 95 & $* 0.000$ & $=-0.05$ & -0.34 & $* 0.00$ & 0.40 & $* 0.08$ & 1.45 & 0.74 & 2.68 & 7.97 & & \\
\hline T & 85 & 0.000 & -0.01 & .0 .50 & 0.05 & 0.39 & 0.11 & 2.30 & 6.21 & 9.05 & 11.77 & & \\
\hline Lat & 86 & $* 0.002$ & $*-0.04$ & +0.39 & $* 0.03$ & 0.64 & $* 0.08$ & 2.55 & 5.74 & 9.04 & 12.84 & 12.34 & $73 \%$ \\
\hline & 87 & $* 0.000$ & $* 0.01$ & $*-0.05$ & 0.02 & 0.61 & $* 0.09$ & 2.61 & 5.70 & 9.04 & 12.41 & & \\
\hline & 70 & 0.001 & $*-0.06$ & 0.04 & $* 0.13$ & 1.17 & $* 0.29$ & 5.89 & 14.85 & 22,37 & 19.54 & & \\
\hline \#2 & 71 & $* 0.001$ & $*-0.04$ & -0.04 & $* 0.13$ & 1.11 & 0.48 & 4.55 & 6.35 & 12.62 & 16.36 & 17.25 & $125 \%$ \\
\hline & 72 & $* 0.000$ & $* 0.01$ & -0.32 & $* 0.14$ & 1.18 & $* 0.38$ & 4.38 & 23.59 & 29.69 & 15.85 & & \\
\hline
\end{tabular}

Note: An asterisk symbol by a result indicates that the value was below the detection limit. 
Table A.20. Sequential extraction of vanadium from CMP pit soils.

\begin{tabular}{|c|c|c|c|c|c|c|c|c|c|c|c|c|c|}
\hline CMP Pit & & \multicolumn{8}{|c|}{ Vanadium Removed During Extraction Step (mg/kg) } & Average & Percent \\
Sample ID & Trial & DDI & Salt & AC & HAHCI & PP & AOD & DC & HF & Sum & TD & Total & Recovery \\
\hline \multirow{3}{*}{$2 \mathrm{~A}$} & 37 & $* 0.00$ & $* 0.13$ & $* 0.13$ & 0.33 & 1.43 & 1.76 & 33.96 & 8.13 & 45.88 & 58.06 & & \\
& 38 & $* 0.00$ & $* 0.09$ & $* 0.13$ & 0.37 & 1.47 & 1.81 & 35.98 & 9.73 & 49.58 & 55.48 & 55.1 & $82 \%$ \\
& 39 & $* 0.00$ & $* 0.08$ & $*-0.03$ & 0.33 & 1.34 & 1.86 & 30.08 & 7.22 & 40.91 & 51.77 & & \\
\hline \multirow{3}{*}{$2 \mathrm{E}$} & 41 & $* 0.00$ & $* 0.15$ & $* 0.02$ & 0.31 & 0.91 & 1.25 & 17.94 & 4.77 & 25.37 & 28.19 & & \\
& 42 & $* 0.00$ & $* 0.15$ & $* 0.04$ & 0.29 & 0.98 & 1.24 & 17.46 & 3.51 & 23.68 & 25.72 & 27.0 & $90 \%$ \\
& 43 & $* 0.00$ & $*-0.08$ & $* 0.09$ & 0.29 & 0.89 & 1.25 & 17.58 & 3.99 & 24.09 & 27.12 & & \\
\hline \multirow{3}{*}{$3 \mathrm{~A}$} & 44 & 0.23 & $* 0.15$ & 0.81 & 0.78 & 0.80 & 0.83 & 16.22 & 10.66 & 30.46 & 31.19 & & \\
& 45 & 0.19 & $* 0.09$ & 0.87 & 0.77 & 1.10 & 0.91 & 17.22 & 13.00 & 34.15 & 30.85 & 31.3 & $102 \%$ \\
& 46 & 0.14 & $* 0.02$ & 0.88 & 0.78 & 1.07 & 0.91 & 17.02 & 10.44 & 31.26 & 31.97 & & \\
\hline \multirow{2}{*}{ SA } & 57 & $* 0.00$ & $* 0.07$ & $* 0.08$ & $* 0.05$ & 1.44 & 1.00 & 15.40 & 11.90 & 29.94 & 33.16 & & \\
& 58 & $* 0.00$ & $* 0.13$ & $*-0.07$ & 0.10 & 1.43 & 0.86 & 13.41 & 11.03 & 26.96 & 32.48 & 31.1 & $87 \%$ \\
& 59 & $* 0.00$ & $* 0.09$ & $* 0.02$ & $* 0.07$ & 1.39 & 0.88 & 14.44 & 7.45 & 24.35 & 27.67 & & \\
\hline
\end{tabular}

Note: An asterisk symbol by a result indicates that the value was below the detection limit. Negative values are treated as zero when concentrations across all extraction steps are summed. 
Table A.21. Sequential extraction of cobalt from SRS background soils.

\begin{tabular}{|c|c|c|c|c|c|c|c|c|c|c|c|c|c|}
\hline \multirow{2}{*}{$\begin{array}{l}\text { Background } \\
\text { Soil Sample }\end{array}$} & \multirow[b]{2}{*}{ Trial } & \multicolumn{10}{|c|}{ Cobalt Removed During Extraction Step (mg/kg) } & \multirow{2}{*}{$\begin{array}{c}\text { Average } \\
\text { Total }\end{array}$} & \multirow{2}{*}{$\begin{array}{l}\text { Percent } \\
\text { Recovery }\end{array}$} \\
\hline & & DDI & Salt & $\overline{A c}$ & $\mathrm{HAHCl}$ & $\mathrm{PP}$ & $\mathrm{AOD}$ & $\overline{D C}$ & HF & Sum & $\mathrm{TD}$ & & \\
\hline \multirow{3}{*}{$\begin{array}{c}\text { Orangeburg } \\
\# 10\end{array}$} & 62 & 0.002 & $* 0.11$ & 0.04 & 0.007 & $* 0.03$ & 0.06 & *0.17 & 4.32 & 4.74 & 2.46 & \multirow{3}{*}{2.55} & \multirow{3}{*}{$165 \%$} \\
\hline & 63 & 0.002 & -0.13 & $\star-0.29$ & 0.007 & $* 0.04$ & 0.04 & $* 0.06$ & 4.73 & 4.88 & 2.62 & & \\
\hline & 64 & -0.001 & -0.25 & -0.01 & 0.005 & 0.01 & 0.04 & 0.09 & 2.83 & 2.99 & 2.56 & & \\
\hline \multirow{3}{*}{$\begin{array}{c}\text { Orangeburg } \\
\quad \$ 46\end{array}$} & 97 & 0.008 & 0.31 & 0.06 & 0.523 & 0.01 & 0.04 & $* 0.24$ & 2.10 & 3.30 & 2.50 & \multirow{3}{*}{2.75} & \multirow{3}{*}{$145 \%$} \\
\hline & 98 & 0.007 & -0.36 & -0.23 & 0.577 & 0.02 & $* 0.04$ & $* 0.13$ & 2.91 & 3.67 & 2.99 & & \\
\hline & 99 & 0.006 & $\begin{array}{c}0.59 \\
\end{array}$ & $* 0.06$ & 0.506 & $\begin{array}{c}0.02 \\
\end{array}$ & $* 0.04$ & 0.20 & 3.53 & 4.95 & 2.75 & & \\
\hline \multirow{3}{*}{$\begin{array}{c}\text { Fuquay } \\
\# 8\end{array}$} & 66 & 0.003 & 0.07 & -0.01 & 0.013 & 0.03 & $* 0.03$ & $* 0.04$ & 2.16 & 2.34 & 2.11 & \multirow{3}{*}{1.84} & \multirow{3}{*}{$128 \%$} \\
\hline & 67 & $* 0.003$ & -0.02 & $*-0.29$ & 0.011 & $* 0.03$ & $* 0.02$ & $* 0.03$ & 2.38 & 2.48 & 1.57 & & \\
\hline & 68. & 0.001 & $* 0.00$ & 0.05 & 0.010 & $* 0.01$ & $* 0.03$ & $* 0.11$ & 2.02 & 2.23 & missing & & \\
\hline \multirow{3}{*}{$\begin{array}{l}\text { Fuquay } \\
\$ 42\end{array}$} & 81 & 0.001 & -0.19 & $*-0.04$ & $* 0.003$ & $* 0.01$ & $* 0.03$ & 0.06 & 1.81 & 1.92 & 2.34 & \multirow{3}{*}{2.34} & \multirow{3}{*}{$114 \%$} \\
\hline & 82 & $* 0.001$ & 0.02 & 0.05 & $* 0.004$ & 0.02 & $* 0.03$ & $* 0.10$ & 1.99 & 2.21 & missing & & \\
\hline & 83 & 0.001 & -0.45 & $\begin{array}{r}-0.29 \\
\end{array}$ & $* 0.006$ & 0.02 & $* 0.02$ & $* 0.01$ & 3.85 & 3.91 & missing & & \\
\hline \multirow{3}{*}{$\begin{array}{c}\text { ESE } \\
\# 1\end{array}$} & 77 & 0.002 & -0.23 & 0.00 & 0.077 & $* 0.00$ & 0.01 & $* 0.16$ & 2.58 & 2.83 & 2.39 & \multirow{3}{*}{2.54} & \multirow{3}{*}{$118 \%$} \\
\hline & 78 & $* 0.000$ & $*-0.42$ & 0.01 & 0.073 & $* 0.01$ & $* 0.01$ & $* 0.05$ & 3.00 & 3.15 & 2.30 & & \\
\hline & 79 & $* 0.003$ & $* 0.30$ & $*-0.29$ & 0.073 & -0.03 & missing & 0.02 & 3.87 & - & 2.93 & & \\
\hline \multirow{3}{*}{$\begin{array}{c}\text { Vaucluse } \\
\# 12\end{array}$} & 74 & 0.010 & -0.06 & 0.02 & 0.071 & $* 0.03$ & $* 0.03$ & $* 0.02$ & 2.46 & 2.64 & 3.60 & \multirow{3}{*}{3.60} & \multirow{3}{*}{$84 \%$} \\
\hline & 75 & 0.011 & $\begin{array}{c}* 0.24 \\
\end{array}$ & -0.03 & 0.070 & $* 0.02$ & $* 0.01$ & $* 0.03$ & 3.29 & 3.43 & missing & & \\
\hline & 76 & 0.018 & -0.40 & 0.00 & 0.075 & $* 0.02$ & $* 0.02$ & $* 0.08$ & missing & - & missing & & \\
\hline \multirow{3}{*}{$\begin{array}{c}\text { Blanton } \\
\# 35\end{array}$} & 89 & 0.008 & 0.05 & $*-0.26$ & 0.238 & 0.05 & 0.05 & $* 0.10$ & $* 0.16$ & 0.65 & missing & \multirow{3}{*}{1.67} & \multirow{3}{*}{$82 \%$} \\
\hline & 90 & 0.009 & $* 0.03$ & 0.03 & 0.243 & 0.05 & 0.06 & $* 0.07$ & 1.91 & 2.40 & 1.70 & & \\
\hline & 91 & 0.008 & $*-0.02$ & $*-0.01$ & 0.280 & 0.04 & 0.05 & $* 0.09$ & 0.56 & 1.03 & 1.63 & & \\
\hline & 93 & 0.003 & 0.05 & 0.03 & 0.032 & $* 0.02$ & $* 0.01$ & 0.04 & 0.25 & 0.43 & 0.65 & & \\
\hline $\begin{array}{l}\# 45 \\
\text { Biminon }\end{array}$ & 94 & 0.003 & $*-0.26$ & $=-0.30$ & 0.022 & $* 0.02$ & $* 0.01$ & $*-0.05$ & 1.36 & 1.42 & 0.96 & 0.74 & $86 \%$ \\
\hline & 95 & 0.006 & $*-0.23$ & $\begin{array}{l}*-0.29 \\
\end{array}$ & 0.021 & $* 0.01$ & $* 0.02$ & $*-0.02$ & $*-0.04$ & 0.06 & 0.62 & & \\
\hline & 85 & 0.005 & -0.11 & -0.25 & 0.437 & 0.05 & 0.05 & $* 0.04$ & 1.20 & 1.80 & 2.34 & & \\
\hline $\begin{array}{l}\text { Lakelana } \\
\text { \#41 }\end{array}$ & 86 & 0.010 & $*-0.19$ & -0.27 & 0.434 & 0.08 & 0.05 & $*-0.01$ & 1.58 & 2.15 & 3.09 & 2.58 & $76 \%$ \\
\hline & 87 & 0.005 & 0.55 & $* 0.01$ & 0.476 & 0.05 & 0.06 & $* 0.01$ & 0.82 & 1.98 & 2.31 & & \\
\hline Lakeland & 70 & 0.014 & 0.51 & 0.06 & 0.432 & $* 0.04$ & 0.05 & $* 0.10$ & 2.02 & 3.23 & 3.39 & & \\
\hline \#2 & 71 & 0.014 & $* 0.35$ & $* 0.05$ & 0.373 & $* 0.01$ & 0.08 & $* 0.11$ & 1.17 & 2.16 & 2.25 & 2.86 & $113 \%$ \\
\hline & 72 & 0.010 & $\begin{array}{r}0.17 \\
\end{array}$ & -0.22 & 0.374 & $* 0.04$ & 0.06 & $* 0.14$ & 3.49 & 4.28 & 2.94 & & \\
\hline
\end{tabular}

Note: An asterisk symbol by a result indicates that the value was below the detection limit. 
Table A.22. Sequential extraction of cobalt from CMP pit soils.

\begin{tabular}{|c|c|c|c|c|c|c|c|c|c|c|c|c|c|}
\hline CMP Pit & & \multicolumn{10}{|c|}{ Cobalt Removed During Extraction Step (mg/kg) } & Average & Percent \\
Sample ID & Trial & DDI & Salt & AC & HAHC & PP & AOD & DC & HF & Sum & TD & Total & Recovery \\
\hline \multirow{2}{*}{$2 \mathrm{~A}$} & 37 & 0.002 & $* 0.086$ & $* 0.032$ & 0.003 & $*-0.001$ & $* 0.004$ & $* 0.092$ & $* 0.032$ & 0.25 & $* 1.34$ & & \\
& 38 & 0.002 & $* 0.109$ & $* 0.035$ & 0.003 & $* 0.001$ & $* 0.006$ & $* 0.048$ & $* 0.002$ & 0.21 & $* 0.70$ & 1.15 & $54 \%$ \\
& 39 & 0.002 & $* 0.608$ & $*-0.046$ & 0.003 & $* 0.001$ & $* 0.005$ & $* 0.081$ & $* 0.697$ & 1.40 & $* 1.40$ & & \\
\hline & 41 & $* 0.001$ & $* 0.243$ & $* 0.002$ & 0.002 & $* 0.001$ & $* 0.000$ & $* 0.089$ & $* 0.314$ & 0.65 & $* 1.13$ & & \\
$2 \mathrm{E}$ & 42 & $* 0.001$ & $* 0.200$ & $*-0.010$ & 0.002 & $*-0.001$ & $* 0.003$ & $* 0.066$ & $*-0.594$ & 0.27 & $* 1.84$ & 1.04 & $32 \%$ \\
& 43 & $* 0.001$ & $*-0.240$ & $* 0.030$ & 0.002 & $* 0.001$ & $*-0.001$ & $* 0.058$ & $*-0.049$ & 0.09 & $* 0.16$ & & \\
\hline \multirow{3}{*}{$3 \mathrm{~A}$} & 44 & 0.003 & $* 0.147$ & $* 0.153$ & 0.124 & $* 0.011$ & 0.034 & $* 0.076$ & $*-0.164$ & 0.55 & $* 1.60$ & & \\
& 45 & 0.003 & $* 0.110$ & 0.212 & 0.120 & $* 0.014$ & 0.030 & $* 0.083$ & $* 1.030$ & 1.60 & $* 1.69$ & 1.23 & $96 \%$ \\
& 46 & 0.002 & $* 0.090$ & 0.196 & 0.119 & $* 0.009$ & 0.038 & $* 0.068$ & $* 0.883$ & 1.41 & $* 0.41$ & & \\
\hline \multirow{2}{*}{$5 \mathrm{~A}$} & 57 & 0.030 & $* 0.094$ & $* 0.023$ & 0.043 & $* 0.015$ & 0.032 & $*-0.030$ & $*-0.292$ & 0.24 & $* 0.75$ & & \\
& 58 & 0.026 & $* 0.304$ & $*-0.023$ & 0.046 & $* 0.009$ & 0.034 & $* 0.108$ & $* 0.802$ & 1.33 & $* 1.64$ & 1.10 & $66 \%$ \\
& 59 & 0.027 & $* 0.338$ & $* 0.022$ & 0.061 & $* 0.014$ & 0.039 & $* 0.098$ & $*-0.544$ & 0.60 & $* 0.90$ & & \\
\hline
\end{tabular}

Note: An asterisk symbol by a result indicates that the value was below the detection limit. Negative values are treated as zero when concentrations across all extraction steps are summed. 
Table A.23. Sequential extraction of rubidium from SRS background soils.

\begin{tabular}{|c|c|c|c|c|c|c|c|c|c|c|c|c|c|}
\hline \multirow{2}{*}{\begin{tabular}{|c|} 
Background Soil \\
Sample D
\end{tabular}} & \multirow[b]{2}{*}{ Trial } & \multicolumn{10}{|c|}{ Rubidium Removed During Extraction Step (mg/kg) } & \multirow{2}{*}{$\begin{array}{c}\text { Average } \\
\text { Total } \\
\end{array}$} & \multirow{2}{*}{$\begin{array}{l}\text { Percent } \\
\text { Recovery }\end{array}$} \\
\hline & & DDl & Salt & Ac & $\mathrm{HAHCl}$ & $\mathrm{PP}$ & AOD & $\overline{D C}$ & $\mathrm{HF}$ & Sum & $\mathrm{TD}$ & & \\
\hline \multirow{3}{*}{$\begin{array}{c}\text { Orangeburg } \\
\# 10\end{array}$} & 62 & 0.019 & 0.009 & 0.009 & 0.10 & 0.07 & 0.22 & 0.08 & 26.79 & 27.31 & 29.89 & \multirow{3}{*}{30.65} & \multirow{3}{*}{$85 \%$} \\
\hline & 63 & 0.023 & 0.012 & 0.008 & 0.10 & $* 0.05$ & 0.22 & 0.09 & 25.76 & 26.26 & 31.38 & & \\
\hline & 64 & 0.013 & 0.019 & 0.009 & 0.10 & $\div 0.12$ & 0.23 & $* 0.06$ & 23.58 & 24.14 & 30.68 & & \\
\hline \multirow{3}{*}{$\begin{array}{c}\text { Orangeburg } \\
\sharp 46\end{array}$} & 97 & 0.016 & 0.026 & 0.016 & 0.17 & 0.05 & 0.25 & 0.08 & 13.32 & 13.93 & 20.96 & \multirow{3}{*}{21.78} & \multirow{3}{*}{$78 \%$} \\
\hline & 98 & 0.012 & 0.027 & 0.016 & 0.15 & $* 0.10$ & 0.20 & 0.10 & 17.40 & 18.01 & 22.05 & & \\
\hline & 99 & 0.014 & 0.024 & 0.017 & 0.16 & $\bullet 0.05$ & 0.20 & 0.20 & 18.55 & 19.21 & 22.33 & & \\
\hline \multirow{3}{*}{$\begin{array}{c}\text { Fuquay } \\
\# 8\end{array}$} & 66 & 0.040 & 0.019 & 0.010 & 0.08 & $*-0.10$ & 0.17 & 0.09 & 18.10 & 18.51 & 25.49 & \multirow{3}{*}{26.23} & \multirow{3}{*}{$62 \%$} \\
\hline & 67 & 0.034 & 0.016 & 0.008 & 0.09 & $*-0.05$ & 0.16 & 0.09 & 13.56 & 13.96 & 20.35 & & \\
\hline & 68 & 0.027 & 0.018 & 0.010 & 0.08 & $\begin{array}{r}0.03 \\
\end{array}$ & 0.16 & 0.08 & 15.72 & 16.13 & 32.87 & & \\
\hline \multirow{3}{*}{$\begin{array}{c}\text { Fuquay } \\
\# 42\end{array}$} & 81 & 0.017 & 0.023 & 0.014 & 0.13 & 0.03 & 0.27 & 0.35 & 9.96 & 10.80 & 26.37 & \multirow{3}{*}{30.41} & \multirow{3}{*}{$49 \%$} \\
\hline & 82 & 0.015 & 0.021 & 0.014 & 0.13 & 0.02 & 0.25 & 0.08 & 15.13 & 15.67 & 42.87 & & \\
\hline & 83 & 0.015 & 0.019 & 0.012 & 0.13 & 0.11 & 0.26 & 0.08 & 17.26 & 17.88 & 22.01 & & \\
\hline \multirow{3}{*}{$\begin{array}{c}\text { ESE } \\
\# 1\end{array}$} & 77 & 0.039 & 0.024 & 0.016 & 0.13 & $* 0.04$ & 0.16 & 0.09 & 11.90 & 12.40 & 23.04 & \multirow{3}{*}{24.57} & \multirow{3}{*}{$51 \%$} \\
\hline & 78 & 0.035 & 0.020 & 0.014 & 0.13 & 0.04 & 0.19 & 0.10 & 12.03 & 12.57 & 24.38 & & \\
\hline & 79 & 0.038 & 0.025 & 0.014 & 0.12 & -0.11 & missing & 0.08 & 14.47 & - & 26.29 & & \\
\hline \multirow{3}{*}{$\begin{array}{c}\text { Vaucluse } \\
\# 12\end{array}$} & 74 & 0.020 & 0.011 & 0.004 & 0.02 & 0.03 & $* 0.02$ & $*-0.09$ & 4.28 & 4.39 & 13.53 & \multirow{3}{*}{17.53} & \multirow{3}{*}{$54 \%$} \\
\hline & 75 & 0.023 & $* 0.011$ & $* 0.005$ & 0.02 & 0.02 & 0.02 & ${ }^{*} 0.02$ & 14.29 & 14.41 & 18.06 & & \\
\hline & 76 & 0.037 & 0.008 & 0.005 & 0.02 & $\begin{array}{r}* 0.08 \\
\end{array}$ & $* 0.03$ & 0.15 & missing & $=$ & 21.00 & & \\
\hline \multirow{3}{*}{$\begin{array}{c}\text { Blanton } \\
\# 35\end{array}$} & 89 & 0.025 & 0.010 & 0.007 & 0.03 & $* 0.03$ & 0.06 & 0.04 & $*-0.55$ & 0.19 & 21.47 & \multirow{3}{*}{17.64} & \multirow{3}{*}{$46 \%$} \\
\hline & 90 & 0.022 & 0.012 & 0.006 & 0.03 & 0.04 & 0.06 & $* 0.06$ & 16.19 & 16.43 & 15.31 & & \\
\hline & 91 & 0.021 & $* 0.011$ & 0.008 & 0.03 & 0.04 & 0.05 & 0.29 & 7.34 & 7.79 & 16.16 & & \\
\hline & 93 & 0.014 & 0.006 & 0.003 & 0.01 & 0.03 & $* 0.03$ & 0.13 & $* 0.16$ & 0.39 & 14.67 & & \\
\hline$\# 45$ & 94 & 0.015 & 0.007 & 0.002 & 0.01 & $* 0.13$ & $* 0.03$ & $*-0.02$ & 15.37 & 15.56 & 9.05 & 11.25 & $48 \%$ \\
\hline & 95 & 0.011 & $* 0.009$ & 0.003 & 0.01 & $* 0.03$ & $* 0.03$ & $* 0.00$ & $*-0.93$ & 0.10 & 10.03 & & \\
\hline & 85 & 0.018 & 0.011 & 0.006 & 0.03 & 0.04 & 0.06 & 0.03 & 8.27 & 8.45 & 12.99 & & \\
\hline $\begin{array}{l}\text { Lakeland } \\
* \Delta 1\end{array}$ & 86 & 0.020 & 0.008 & $* 0.005$ & 0.02 & $* 0.04$ & 0.05 & 0.06 & 9.41 & 9.62 & 20.47 & 15.12 & $52 \%$ \\
\hline & 87 & 0.017 & $* 0.010$ & 0.007 & 0.03 & $* 0.08$ & 0.06 & -0.02 & 5.44 & 5.64 & 11.91 & & \\
\hline & 70 & 0.027 & 0.016 & 0.010 & 0.07 & $* 0.11$ & 0.14 & 0.11 & 14.65 & 15.13 & 24.85 & & \\
\hline$\# 2$ & 71 & 0.029 & 0.016 & 0.009 & 0.07 & $=-0.13$ & 0.15 & 0.18 & 5.29 & 5.74 & 13.82 & 21.02 & $64 \%$ \\
\hline & 72 & 0.023 & 0.017 & 0.009 & 0.07 & $* 0.17$ & 0.12 & 0.07 & 19.05 & 19.52 & 24.37 & & \\
\hline
\end{tabular}

Note: An asterisk symbol by a result indicates that the value was below the detection limit. 
Table A.24. Sequential extraction of nubidium from CMP pit soils.

\begin{tabular}{|c|c|c|c|c|c|c|c|c|c|c|c|c|c|}
\hline \multirow{2}{*}{$\begin{array}{c}\text { CMP Pit } \\
\text { Sample ID }\end{array}$} & \multirow[b]{2}{*}{ Trial } & \multicolumn{10}{|c|}{ Rubidium Removed During Extraction Step (mg/kg) } & \multirow{2}{*}{$\begin{array}{c}\text { Average } \\
\text { Total }\end{array}$} & \multirow{2}{*}{$\begin{array}{l}\text { Percent } \\
\text { Recovery }\end{array}$} \\
\hline & & $\overline{\mathrm{DDI}}$ & Salt & Ac & HAHC & $\overrightarrow{\mathrm{PP}}$ & AOD & DC & $\mathrm{HF}$ & Sum & TD & & \\
\hline \multirow{3}{*}{$2 \mathrm{~A}$} & 37 & 0.016 & $* 0.040$ & 0.02 & 0.02 & $* 0.05$ & 0.02 & $* 0.2$ & 4.4 & 4.7 & 7.2 & \multirow{3}{*}{7.2} & \multirow{3}{*}{$64 \%$} \\
\hline & 38 & 0.017 & $* 0.047$ & 0.02 & 0.02 & $* 0.03$ & 0.03 & $* 0.1$ & 4.7 & 5.0 & 7.2 & & \\
\hline & 39 & 0.016 & $* 0.027$ & 0.02 & 0.02 & $* 0.04$ & 0.03 & $* 0.0$ & 4.0 & 4.2 & 7.2 & & \\
\hline \multirow{3}{*}{$2 \mathrm{E}$} & 41 & 0.003 & +-0.006 & $* 0.005$ & 0.01 & $* 0.03$ & $* 0.01$ & $* 0.0$ & 3.7 & 3.8 & 4.7 & \multirow{3}{*}{5.6} & \multirow{3}{*}{$77 \%$} \\
\hline & 42 & 0.003 & $* 0.002$ & $* 0.005$ & 0.01 & $* 0.05$ & $* 0.01$ & $* 0.2$ & 4.2 & 4.4 & 5.3 & & \\
\hline & 43 & 0.002 & $* 0.016$ & $* 0.005$ & 0.01 & $* 0.03$ & 0.02 & $* 0.1$ & 4.5 & 4.7 & 6.7 & & \\
\hline \multirow{3}{*}{$3 A$} & 44 & 0.048 & 1.077 & 1.78 & 0.28 & 0.33 & 0.12 & $* 0.2$ & 13.3 & 17.2 & 18.3 & \multirow{3}{*}{18.2} & \multirow{3}{*}{$107 \%$} \\
\hline & 45 & 0.047 & 1.073 & 1.83 & 0.31 & 0.39 & 0.13 & $* 0.1$ & 15.9 & 19.8 & 19.5 & & \\
\hline & 46 & 0.042 & 1.045 & 1.90 & 0.34 & 0.41 & 0.14 & $* 0.3$ & 17.6 & 21.7 & 17.0 & & \\
\hline \multirow{3}{*}{$5 A$} & 57 & 0.029 & 0.062 & 0.04 & 0.05 & 0.12 & $\overline{0.06}$ & $* 0.2$ & 7.1 & 7.7 & 8.5 & \multirow{3}{*}{8.4} & \multirow{3}{*}{$80 \%$} \\
\hline & 58 & 0.026 & 0.061 & 0.03 & 0.05 & 0.11 & 0.06 & $*-0.1$ & 7.2 & 7.5 & 9.4 & & \\
\hline & 59 & 0.027 & 0.210 & 0.04 & 0.05 & 0.11 & 0.06 & $* 0.1$ & 4.4 & 5.0 & 7.3 & & \\
\hline
\end{tabular}

Note: An asterisk symbol by a result indicates that the value was below the detection limit. Negative values are treated as zero when concentrations across all extraction steps are summed. 
Table A.25. Sequential extraction of cesium from SRS background soils.

\begin{tabular}{|c|c|c|c|c|c|c|c|c|c|c|c|c|c|}
\hline \multirow{2}{*}{$\begin{array}{l}\text { Background } \\
\text { Soil Sample ID }\end{array}$} & \multirow[b]{2}{*}{ Trial } & \multicolumn{10}{|c|}{ Cesium Removed During Extraction Step (mg/kg) } & \multirow{2}{*}{$\begin{array}{c}\text { Average } \\
\text { Total }\end{array}$} & \multirow{2}{*}{$\begin{array}{l}\text { Percent } \\
\text { Recovery }\end{array}$} \\
\hline & & DDI & Salt & Ac & HAHCI & PP & $A O D$ & DC & $\overline{\mathrm{HF}}$ & Sum & TD & & \\
\hline \multirow{3}{*}{$\begin{array}{l}\text { Orangeburg } \\
\quad \# 10\end{array}$} & 62 & $* 0.00$ & $* 0.00$ & $* 0.00$ & 0.013 & 0.017 & 0.014 & $* 0.02$ & 4.62 & 4.68 & 4.50 & \multirow{3}{*}{4.49} & \multirow{3}{*}{$102 \%$} \\
\hline & 63 & $* 0.00$ & $* 0.00$ & $* 0.01$ & 0.013 & 0.022 & 0.014 & $* 0.00$ & 4.35 & 4.40 & 4.56 & & \\
\hline & 64 & $* 0.00$ & $* 0.01$ & $* 0.00$ & 0.012 & 0.018 & 0.013 & $* 0.00$ & 4.58 & 4.64 & 4.39 & & \\
\hline \multirow{3}{*}{$\begin{array}{l}\text { Orangeburg } \\
\text { \#46 }\end{array}$} & 97 & $* 0.00$ & $* 0.00$ & $* 0.00$ & 0.014 & 0.026 & 0.006 & $* 0.01$ & 2.56 & 2.62 & 3.69 & \multirow{3}{*}{3.83} & \multirow{3}{*}{$67 \%$} \\
\hline & 98 & $* 0.00$ & $* 0.00$ & $* 0.01$ & 0.013 & 0.023 & 0.010 & $* 0.02$ & 2.19 & 2.26 & 4.26 & & \\
\hline & 99 & $* 0.00$ & $* 0.00$ & $* 0.00$ & 0.013 & 0.024 & 0.004 & $* 0.01$ & 2.74 & 2.79 & 3.54 & & \\
\hline \multirow{3}{*}{$\begin{array}{c}\text { Fuquay } \\
\# 8\end{array}$} & 66 & $* 0.00$ & $* 0.00$ & $* 0.00$ & 0.010 & 0.027 & 0.011 & $* 0.00$ & 4.57 & 4.62 & 4.01 & \multirow{3}{*}{3.86} & \multirow{3}{*}{$88 \%$} \\
\hline & 67 & $* 0.00$ & $* 0.00$ & $* 0.01$ & 0.011 & 0.032 & 0.009 & $* 0.00$ & 2.34 & 2.40 & 3.95 & & \\
\hline & 68 & $* 0.00$ & $* 0.00$ & $* 0.00$ & 0.011 & 0.026 & 0.009 & $* 0.01$ & 3.11 & 3.17 & 3.63 & & \\
\hline \multirow{3}{*}{$\begin{array}{l}\text { Fuquay } \\
\# 42\end{array}$} & 81 & $* 0.00$ & $* 0.00$ & $* 0.00$ & 0.015 & 0.030 & 0.019 & $* 0.02$ & 2.26 & 2.34 & 4.91 & \multirow{3}{*}{5.33} & \multirow{3}{*}{$51 \%$} \\
\hline & 82 & $* 0.00$ & $* 0.01$ & $* 0.00$ & 0.014 & 0.030 & 0.017 & $* 0.01$ & 2.52 & 2.61 & 6.70 & & \\
\hline & 83 & $* 0.00$ & $* 0.00$ & $* 0.01$ & 0.013 & 0.029 & 0.017 & $* 0.01$ & 3.18 & 3.26 & 4.37 & & \\
\hline \multirow{3}{*}{$\begin{array}{c}\text { ESE } \\
\# 1\end{array}$} & 77 & $* 0.00$ & $* 0.01$ & $* 0.00$ & 0.013 & 0.029 & 0.009 & $* 0.01$ & 1.93 & 2.00 & 3.67 & \multirow{3}{*}{3.68} & \multirow{3}{*}{$64 \%$} \\
\hline & 78 & $* 0.00$ & $* 0.01$ & $* 0.00$ & 0.011 & 0.024 & 0.008 & $* 0.01$ & 2.29 & 2.35 & 4.01 & & \\
\hline & 79 & $* 0,00$ & $* 0.00$ & $* 0.01$ & 0.012 & 0.025 & missing & $* 0.01$ & 2.66 & 2.71 & 3.37 & & \\
\hline \multirow{3}{*}{$\begin{array}{c}\text { Vaucluse } \\
\# 12\end{array}$} & 74 & $* 0.00$ & $* 0.00$ & $\$ 0.00$ & 0.003 & 0.011 & $* 0.002$ & $* 0.00$ & 0.51 & 0.53 & 0.51 & \multirow{3}{*}{0.49} & \multirow{3}{*}{$62 \%$} \\
\hline & 75 & $* 0.00$ & $* 0.00$ & $* 0.00$ & 0.002 & 0.010 & $* 0.003$ & $*-0.01$ & 0.36 & 0.37 & 0.40 & & \\
\hline & 76 & $* 0.00$ & $* 0.00$ & $* 0.00$ & 0.002 & 0.013 & $* 0.002$ & $* 0.01$ & missing & 0.02 & 0.56 & & \\
\hline \multirow{3}{*}{$\begin{array}{c}\text { Blanton } \\
\# 35\end{array}$} & 89 & $* 0.00$ & $* 0.00$ & $* 0.01$ & 0.002 & 0.019 & $* 0.002$ & $* 0.01$ & 0.21 & 0.24 & 1.54 & \multirow{3}{*}{1.44} & \multirow{3}{*}{$58 \%$} \\
\hline & 90 & $* 0.00$ & $* 0.00$ & $* 0.00$ & 0.003 & 0,018 & $* 0.004$ & $* 0.00$ & 1.07 & 1.10 & 1.25 & & \\
\hline & 91 & $* 0.00$ & $* 0.00$ & $* 0.00$ & 0,002 & 0.018 & $* 0.002$ & $* 0.01$ & 1.15 & 1.18 & 1.54 & & \\
\hline & 93 & $* 0.00$ & $* 0.00$ & $* 0.00$ & 0.002 & 0.018 & $* 0.000$ & $* 0.00$ & 0.24 & 0.26 & 0.88 & & \\
\hline$\# 15$ & 94 & $* 0.00$ & $* 0.00$ & $* 0.01$ & 0.002 & 0.016 & $* 0.001$ & $* 0.00$ & 0.64 & 0.67 & 1.06 & 1.00 & $36 \%$ \\
\hline & 95 & $* 0.00$ & $* 0.00$ & $* 0.01$ & 0.002 & 0.017 & $* 0.000$ & $* 0.00$ & 0.14 & 0.16 & 1.06 & & \\
\hline Lakeland & 85 & $* 0.00$ & $* 0.00$ & $* 0,01$ & 0.003 & 0.024 & $* 0.002$ & $* 0.00$ & 1.31 & 1.35 & 1.80 & & \\
\hline HA1 & 86 & $* 0.00$ & $*-0.01$ & $* 0.00$ & 0.004 & 0.022 & $* 0.002$ & $*-0.01$ & 1.41 & 1.43 & 1.66 & 1.73 & $75 \%$ \\
\hline & 87 & $* 0.00$ & $*-0,01$ & $* 0.00$ & 0.003 & 0.021 & $* 0.002$ & $* 0.01$ & 1.09 & 1.12 & 1.72 & & \\
\hline Lakelan & 70 & $* 0.00$ & $* 0.00$ & $* 0.00$ & 0.005 & 0.016 & $*-0.001$ & $* 0.01$ & 2.33 & 2.36 & 1.52 & & \\
\hline$\# 2$ & 71 & 0.00 & $* 0.00$ & $* 0.00$ & 0.005 & 0.017 & $* 0.005$ & $* 0.01$ & 0.66 & 0.69 & 1.64 & 1.51 & $120 \%$ \\
\hline & & & 0.00 & $* 0,01$ & 0.0 & 00 & 0.0 & 0,00 & 2,35 & 2,39 & .38 & & \\
\hline
\end{tabular}

Note: An asterisk symbol by a result indicates that the value was below the detection limit. 
Table A.26. Sequential extraction of cesium from CMP pit soils.

\begin{tabular}{|c|c|c|c|c|c|c|c|c|c|c|c|c|c|}
\hline \multirow{2}{*}{$\begin{array}{l}\text { CMP Pit } \\
\text { Sample ID }\end{array}$} & \multirow[b]{2}{*}{ Trial } & \multicolumn{10}{|c|}{ Cesium Removed During Extraction Step ( $\mathrm{mg} / \mathrm{kg})$} & \multirow{2}{*}{$\begin{array}{c}\text { Average } \\
\text { Total }\end{array}$} & \multirow{2}{*}{$\begin{array}{l}\text { Percent } \\
\text { Recovery }\end{array}$} \\
\hline & & $\overline{\mathrm{DDI}}$ & Salt & Ac & HAHC & $\mathrm{PP}$ & $A O D$ & DC & $\mathrm{HF}$ & Sum & $\mathrm{TD}$ & & \\
\hline \multirow{3}{*}{$2 \mathrm{~A}$} & 37 & * 0.000 & 0.004 & * 0.001 & 0.003 & 0.008 & $* 0.002$ & $* 0.015$ & 0.464 & 0.50 & 0.52 & \multirow{3}{*}{0.46} & \multirow{3}{*}{$90 \%$} \\
\hline & 38 & $* 0.000$ & $*-0.001$ & $* 0.001$ & 0.004 & 0.008 & $* 0.003$ & $* 0.010$ & 0.437 & 0.46 & 0.39 & & \\
\hline & 39 & $* 0.000$ & $*-0.002$ & $* 0.001$ & 0.004 & 0.007 & $* 0.002$ & $* 0.005$ & 0.272 & 0.29 & 0.48 & & \\
\hline \multirow{3}{*}{$2 \mathrm{E}$} & 41 & 0.000 & $*-0.001$ & $* 0.001$ & 0.003 & $* 0.008$ & $* 0.001$ & $* 0.002$ & 0.311 & 0.32 & 0.32 & \multirow{3}{*}{0.30} & \multirow{3}{*}{$79 \%$} \\
\hline & 42 & $* 0.000$ & $*-0.001$ & * 0.000 & 0.003 & $* 0.010$ & $* 0.001$ & $* 0.006$ & 0.163 & 0.18 & 0.33 & & \\
\hline & 43 & $* 0.000$ & $* 0.002$ & $* 0.001$ & 0.003 & $* 0.009$ & $* 0.004$ & $* 0.001$ & 0.186 & 0.21 & 0.26 & & \\
\hline \multirow{3}{*}{$3 \mathrm{~A}$} & 44 & 0.000 & $* 0.010$ & 0.041 & 0.025 & 0.019 & 0.005 & $* 0.015$ & 0.756 & 0.87 & 0.49 & \multirow{3}{*}{0.51} & \multirow{3}{*}{$171 \%$} \\
\hline & 45 & 0.000 & $* 0.011$ & 0.041 & 0.024 & 0.019 & 0.005 & $* 0.015$ & 0.699 & 0.81 & 0.49 & & \\
\hline & 46 & 0.000 & $* 0.009$ & 0.041 & 0.026 & 0.019 & 0.007 & $* 0.010$ & 0.793 & 0.91 & 0.53 & & \\
\hline \multirow{3}{*}{ 5A } & 57 & $* 0.000$ & $* 0.005$ & $* 0.001$ & 0.004 & 0.013 & $* 0.002$ & $*-0.005$ & 0.842 & 0.87 & 0.76 & \multirow{3}{*}{0.76} & \multirow{3}{*}{$84 \%$} \\
\hline & 58 & $* 0.000$ & $* 0.001$ & $* 0.001$ & 0.003 & 0.012 & $* 0.003$ & $*-0.002$ & 0.526 & 0.55 & 0.84 & & \\
\hline & 59 & $* 0.000$ & $* 0.002$ & $* 0.002$ & 0.003 & 0.009 & $* 0.002$ & $* 0.003$ & 0.495 & 0.52 & 0.69 & & \\
\hline
\end{tabular}

Note: An asterisk symbol by a result indicates that the value was below the detection limit. Negative values are treated as zero when concentrations across all extraction steps are summed. 
Table A.27. Sequential extraction of cerium from SRS background soils.

\begin{tabular}{|c|c|c|c|c|c|c|c|c|c|c|c|c|c|}
\hline \multirow{2}{*}{$\begin{array}{l}\text { Background Soil } \\
\text { Sample D }\end{array}$} & \multirow[b]{2}{*}{ Trial } & \multicolumn{10}{|c|}{ Cerium Removed During Extraction Step ( $\mathrm{m} / \mathrm{kg}$ ) } & \multirow{2}{*}{$\begin{array}{c}\text { Average } \\
\text { Total }\end{array}$} & \multirow{2}{*}{$\begin{array}{l}\text { Percent } \\
\text { Recovery }\end{array}$} \\
\hline & & DDI & Salt & Ac & HAHC & PP & AOD & DC & $\mathrm{HF}$ & Sum & $\mathrm{TD}$ & & \\
\hline \multirow{3}{*}{$\begin{array}{l}\text { Orangeburg } \\
\# 10\end{array}$} & 62 & 0.000 & 26.7 & 2.03 & 1.64 & 5.5 & 0.46 & 22.75 & 23.4 & 82.5 & 29.4 & \multirow{3}{*}{32.3} & \multirow{3}{*}{$206 \%$} \\
\hline & 63 & 0.000 & 24.9 & 1.87 & 1.57 & 6.0 & 0.43 & 7.29 & missing & 42.0 & 33.6 & & \\
\hline & 64 & $* 0.000$ & 20.2 & 2.00 & 1.55 & 6.0 & 0.44 & 18.03 & 26.6 & 74.8 & 33.8 & & \\
\hline \multirow{3}{*}{$\begin{array}{c}\text { Orangeburg } \\
\# 46\end{array}$} & 97 & 0.000 & 6.3 & 1.40 & 1.93 & 5.3 & 0.77 & 18.45 & 14.0 & 48.1 & 33.1 & \multirow{3}{*}{35.5} & \multirow{3}{*}{$112 \%$} \\
\hline & 98 & 0.000 & 5.4 & 1.34 & 1.84 & 4.5 & 0.61 & 16.74 & missing & 30.4 & 40.1 & & \\
\hline & 99 & $* 0.000$ & 8.1 & 1.41 & 1.72 & 4.2 & 0.78 & 9.78 & 14.9 & 40.9 & 33.1 & & \\
\hline \multirow{3}{*}{$\begin{array}{c}\text { Fuquay } \\
\# 8\end{array}$} & 66 & 0.000 & 6.4 & 0.99 & 0.45 & 2.3 & 0.08 & 1.51 & 26.7 & 38.4 & 27.1 & \multirow{3}{*}{23.1} & \multirow{3}{*}{$132 \%$} \\
\hline & 67 & $* 0.000$ & 6.0 & 0.91 & 0.44 & 2.2 & 0.10 & 1.55 & 14.8 & 26.0 & 20.1 & & \\
\hline & 68 & $* 0.000$ & 6.0 & 0.88 & 0.40 & 2.0 & 0.10 & 0.95 & 16.7 & 26.9 & 22.1 & & \\
\hline \multirow{3}{*}{$\begin{array}{c}\text { Fuquay } \\
\# 42\end{array}$} & 81 & $* 0.000$ & 9.0 & 0.27 & 0.03 & 0.2 & 0.05 & 0.46 & 9.1 & 19.1 & 15.7 & \multirow{3}{*}{17.3} & \multirow{3}{*}{$112 \%$} \\
\hline & 82 & $* 0.000$ & 8.4 & 0.26 & 0.03 & 0.2 & 0.04 & 0.32 & 2.9 & 12.1 & 21.4 & & \\
\hline & 83 & $\bullet 0.000$ & 7.9 & 0.29 & 0.03 & 0.2 & 0.03 & 0.22 & 18.2 & 26.8 & 14.7 & & \\
\hline \multirow{3}{*}{$\begin{array}{c}\text { ESE } \\
\# 1\end{array}$} & 77 & 0.000 & 4.6 & 0.78 & 0.89 & 4.5 & 0.55 & 14.84 & 19.4 & 45.6 & 30.7 & \multirow{3}{*}{28.2} & \multirow{3}{*}{$167 \%$} \\
\hline & 78 & 0.000 & 5.1 & 0.97 & 0.89 & 5.3 & 0.69 & 16.91 & 23.7 & 53.6 & 28.9 & & \\
\hline & 79 & $* 0.000$ & 6.3 & 0.93 & 0.96 & 5.1 & missing & 10.29 & 18.2 & 41.9 & 24.9 & & \\
\hline \multirow{3}{*}{$\begin{array}{c}\text { Vaucluse } \\
\# 12\end{array}$} & 74 & 0.000 & 0.2 & 0.09 & 0.17 & 0.4 & 0.02 & 0.10 & 0.0 & 1.0 & 2.0 & \multirow{3}{*}{2.1} & \multirow{3}{*}{$47 \%$} \\
\hline & 75 & 0.000 & 0.2 & 0.11 & 0.16 & 0.3 & 0.03 & 0.11 & missing & 0.9 & 2.5 & & \\
\hline & 76 & 0.000 & 0.2 & 0.10 & 0.17 & 0.3 & 0.02 & 0.10 & missing & 0.9 & 1.7 & & \\
\hline \multirow{3}{*}{$\begin{array}{c}\text { Blanton } \\
\text { \#35 }\end{array}$} & 89 & 0.007 & 1.2 & 0.42 & 0.36 & 3.9 & 0.07 & 2.09 & missing & 8.0 & 6.9 & \multirow{3}{*}{6.2} & \multirow{3}{*}{$141 \%$} \\
\hline & 90 & 0.006 & 1.0 & 0.43 & 0.37 & 4.3 & 0.13 & 2.25 & $* 0.0$ & 8.5 & 6.0 & & \\
\hline & 91 & 0.009 & 1.3 & 0.50 & 0.36 & 4.5 & 0.11 & 2.67 & 0.4 & 9.8 & 5.8 & & \\
\hline & 93 & 0.009 & 0.6 & 0.58 & 0.55 & 2.4 & 0.03 & 0.19 & missing & 4.3 & 4.0 & & \\
\hline Blanton & 94 & 0.009 & 0.5 & 0.44 & 0.44 & 2.5 & 0.02 & 0.45 & missing & 4.4 & 3.4 & 4.0 & $109 \%$ \\
\hline & 95 & 0.008 & 0.5 & 0.49 & 0.45 & 2.5 & 0.02 & 0.35 & missing & 4.3 & 4.5 & & \\
\hline & 85 & 0.002 & 1.4 & 0.57 & 0.66 & 3.3 & 0.18 & 3.44 & 0.3 & 9.9 & 10.2 & & \\
\hline Lakeland & 86 & 0.003 & 1.5 & 0.61 & 0.65 & 5.6 & 0.18 & 2.61 & missing & 11.1 & 8.8 & 9.8 & $110 \%$ \\
\hline & 87 & 0.002 & 1.6 & 0.51 & 0.65 & 5.7 & 0.14 & 2.73 & $* 0.1$ & 11.4 & 10.4 & & \\
\hline & 70 & 0.000 & 1.9 & 0.32 & 0.30 & 1.7 & 0.03 & 0.61 & 3.2 & 8.2 & 8.0 & & \\
\hline \#2 & 71 & 0.000 & 1.5 & 0.27 & 0.30 & 1.5 & 0.06 & 0.23 & 0.2 & 4.1 & 8.9 & 8.1 & $92 \%$ \\
\hline & 72 & $* 0.000$ & 1.6 & 0.35 & 0.31 & 1.7 & 0.03 & 0.30 & 5.8 & 10.1 & 7.4 & & \\
\hline
\end{tabular}

Note: An asterisk symbol by a result indicates that the value was below the detection limit. 
Table A.28. Sequential extraction of cerium from CMP pit soils.

\begin{tabular}{|c|c|c|c|c|c|c|c|c|c|c|c|c|c|}
\hline CMP Pit & & \multicolumn{10}{|c|}{ Cerium Removed During Extraction Step (mg/kg) } & Average & Percent \\
Sample ID & Trial & DDI & Salt & Ac & HAHC & PP & AOD & DC & HF & Sum & TD & Recovery \\
\hline \multirow{3}{*}{$2 \mathrm{~A}$} & 37 & $* 0.00$ & 0.98 & 0.10 & 0.01 & 0.04 & 0.00 & 2.36 & 4.18 & 7.7 & 17.4 & & \\
& 38 & $* 0.00$ & 1.01 & 0.11 & 0.01 & 0.04 & 0.01 & 2.43 & 5.55 & 9.2 & 14.2 & 15.3 & $49 \%$ \\
& 39 & $* 0.00$ & 0.79 & 0.08 & 0.01 & 0.02 & 0.00 & 0.48 & 4.22 & 5.6 & 14.1 & & \\
\hline & 41 & $* 0.00$ & 0.81 & 0.02 & 0.01 & $* 0.01$ & $* 0.00$ & 1.15 & 2.00 & 4.0 & 6.3 & & \\
$2 \mathrm{E}$ & 42 & $* 0.00$ & 0.83 & 0.02 & 0.01 & $* 0.01$ & $* 0.00$ & 0.35 & 1.96 & 3.2 & 6.9 & 6.3 & $58 \%$ \\
& 43 & $* 0.00$ & 0.92 & 0.02 & 0.01 & $* 0.01$ & $* 0.00$ & 0.72 & 2.05 & 3.7 & 5.6 & & \\
\hline \multirow{3}{*}{$3 \mathrm{~A}$} & 44 & 0.06 & 0.02 & 8.11 & 1.60 & 0.70 & 0.10 & 1.38 & 5.15 & 17.1 & 13.1 & & \\
& 45 & 0.06 & 0.02 & 8.97 & 2.41 & 1.50 & 0.21 & 3.20 & 9.24 & 25.6 & 14.6 & 13.2 & $155 \%$ \\
& 46 & 0.04 & 0.02 & 8.52 & 1.99 & 0.97 & 0.06 & 2.07 & 5.18 & 18.8 & 12.0 & & \\
\hline & 57 & $* 0.00$ & 1.86 & 0.36 & 0.13 & 0.60 & 0.02 & 2.07 & 3.17 & 8.2 & 10.2 & & \\
5A & 58 & $* 0.00$ & 1.67 & 0.35 & 0.13 & 0.65 & 0.02 & 1.63 & 1.46 & 5.9 & 12.8 & 10.9 & $63 \%$ \\
& 59 & $* 0.00$ & 2.11 & 0.39 & 0.12 & 0.65 & 0.01 & 2.11 & 1.24 & 6.6 & 9.8 & & \\
\hline
\end{tabular}

Note: An asterisk symbol by a result indicates that the value was below the detection limit. 
Table A.29. Nominal detection limits (mg/kg-soil) for extracts from soils.

\begin{tabular}{|c|c|c|c|c|c|c|c|c|c|}
\hline \multirow[b]{2}{*}{ Metal } & \multicolumn{9}{|c|}{ Extraction Step } \\
\hline & DDI & Salt & AC & $\mathrm{HAHCl}$ & $\mathrm{PP}$ & $\mathrm{AOD}$ & $\overline{D C}$ & HF & $\mathrm{TD}$ \\
\hline Iron & 1 & 100 & 20 & 5 & 2 & $1 \%$ & 1725 & 350 & 100 \\
\hline Aluminum & 0.05 & 3 & 0.75 & 0.3 & 5 & $1 \%$ & 10 & 1100 & 100 \\
\hline Titanium & 1 & 2 & 1 & 1 & 0.5 & 0.23 & 5 & 50 & 10 \\
\hline Manganese & 0.005 & 0.75 & 0.05 & 0.1 & 0.1 & 0.1 & 0.5 & 1 & 10 \\
\hline Uranium & 0.001 & 0.1 & 0.05 & 0.05 & 0.025 & 0.01 & 0.1 & 0.1 & 0.1 \\
\hline Barium & 0.01 & 0.3 & 0.04 & 0.005 & 0.05 & 0.025 & 0.25 & 0.2 & 0.2 \\
\hline Chromium & 0.02 & 0.5 & 0.1 & 0.075 & 0.2 & 0.75 & 1 & 1 & 10 \\
\hline Lead & 0.001 & 0.5 & 0.075 & 0.025 & 0.05 & 0.05 & 0.2 & 0.3 & 0.5 \\
\hline Rubidium & 0.005 & 0.01 & 0.05 & 0.025 & 0.05 & 0.025 & 0.075 & 1 & 0.75 \\
\hline Cesium & 0.001 & 0.025 & 0.015 & 0.001 & 0.01 & 0.01 & 0.05 & 0.1 & 0.05 \\
\hline Vanadium & 0.01 & 0.25 & 1 & 0.15 & 0.15 & 0.25 & 0.5 & 2.5 & 1.5 \\
\hline Cerium & 0.001 & 0.025 & 0.01 & 0.001 & 0.05 & 0.01 & 0.05 & 0.15 & 0.1 \\
\hline
\end{tabular}

Note: The shaded portion of the table represents detection limits that were from ICP-ES analysis of extracts. All other values are from ICP-MS analysis. Individual detection limits were calculated for each ICP-MS session. The values in this table are nominal, reflecting approximate detection limits observed during the project. 
Table A.30. Average amount of metal extracted from SRS background soils during sequential extraction procedure.

\begin{tabular}{|c|c|c|c|c|c|c|c|c|c|}
\hline \multirow[b]{2}{*}{ Metal } & \multicolumn{9}{|c|}{ Extraction Step } \\
\hline & $\mathrm{DDI}$ & Salt & Ac & $\mathrm{HAHCl}$ & $\mathrm{pP}$ & AOD & $D C$ & $\mathrm{HF}$ & TD \\
\hline \multicolumn{10}{|c|}{ Major Components } \\
\hline Iron & $<1$ & $<100$ & $<20$ & $10 \pm 3$ & $317 \pm 193$ & $109 \pm 80$ & $3,014 \pm 2,668$ & $2,669 \pm 1,913$ & $6,308 \pm 4,306$ \\
\hline Aluminum & $0.35 \pm 0.60$ & $34 \pm 31$ & $177 \pm 83$ & $26 \pm 10$ & $178 \pm 45$ & $228 \pm 141$ & $612 \pm 528$ & $17,194 \pm 13,784$ & $19,151 \pm 14,220$ \\
\hline Titanium & $<1$ & $<$ & $<1$ & $\leq 1$ & $4.9 \pm 2.1$ & $1.3 \pm 0.8$ & $30 \pm 25$ & $2,434 \pm 905$ & $2,829 \pm 550$ \\
\hline Manganese & $0.23 \pm 0.18$ & $0.79 \pm 0.75$ & $0.94 \pm 0.67$ & $5.1 \pm 5.3$ & $1.27 \pm 1.38$ & $0.72 \pm 0.68$ & $3.6 \pm 3.3$ & $50 \pm 24$ & $56 \pm 19$ \\
\hline \multicolumn{10}{|c|}{ Trace Components } \\
\hline Uranium & $<0.001$ & $<0.1$ & $0.054 \pm 0.045$ & $<0.05$ & $0.042 \pm 0.031$ & $0.047 \pm 0.038$ & $<0.1$ & $0.82 \pm 0.51$ & $1.3 \pm 0.6$ \\
\hline Barium & $0.16 \pm 0.12$ & $4.4 \pm 3.3$ & $0.42 \pm 0.26$ & $0.25 \pm 0.15$ & $1.61 \pm 0.66$ & $0.21 \pm 0.13$ & $0.59 \pm 0.33$ & $11 \pm 10$ & $35 \pm 16$ \\
\hline Chromium & $<0.02$ & $<0.5$ & $<0.1$ & $<0.075$ & $0.34 \pm 0.20$ & $<0.75$ & $2.2 \pm 1.9$ & $15 \pm 11$ & $17 \pm 7$ \\
\hline Lead & $0.003 \pm 0.005$ & $1.1 \pm 1.1$ & $0.44 \pm 0.21$ & $0.179 \pm 0.092$ & $0.072 \pm 0.036$ & $0.055 \pm 0.044$ & $0.23 \pm 0.17$ & $6.9 \pm 5.3$ & $7.4 \pm 3.7$ \\
\hline Vanadium & $<0.01$ & $<0.25$ & $<1$ & $0.28 \pm 0.25$ & $1.4 \pm 1.1$ & $0.68 \pm 0.59$ & $7.3 \pm 5.8$ & $17 \pm 12$ & $25 \pm 15$ \\
\hline Rubidium & $0.023 \pm 0.009$ & $0.016 \pm 0.006$ & $<0.05$ & $0.075 \pm 0.051$ & $0.053 \pm 0.067$ & $0.13 \pm 0.09$ & $0.094 \pm 0.086$ & $13 \pm 7$ & $22 \pm 8$ \\
\hline Cesium & $<0.001$ & $<0.025$ & $<0.015$ & $0.008 \pm 0.005$ & $0.021 \pm 0.006$ & $<0.01$ & $<0.05$ & $2.0 \pm 1.4$ & $2.7 \pm 1.7$ \\
\hline Cerium & $0.0019 \pm 0.0033$ & $5.6 \pm 6.9$ & $0.74 \pm 0.56$ & $0.68 \pm 0.58$ & $3.1 \pm 2.0$ & $0.21 \pm 0.25$ & $5.3 \pm 7.0$ & $11 \pm 10$ & $17 \pm 12$ \\
\hline
\end{tabular}




\section{REFERENCES}

Ammonette, J. E., G. R. Holdren, K. M. Krupa, C. W. Lindenmeier. Assessing the Environmental Availability of Uranium in Soils and Sediments. U.S. Nuclear Regulatory Commission report NUREG/CR-6232. 1994.

Belzile N., P. Pierre, A. Tessier. Testing Reabsorption of Trace Metals during Partial Chemical Extractions of Bottom Sediments. Environmental Science and Technology. Vol. 23, no.8, pp. 10151020. August 1989.

Birkeland, P. W. Soils and Geomorphology. Oxford University Press, New York. 1984.

Brady, N. C. The Nature and Properties of Soils, $8^{\text {th }}$ Edition. MacMillan Publishing, New York. 1974.

Chao, T. T. Selective Dissolution of Manganese Oxides from Soil and Sediments with Acidified Hydroxylamine Hydrochloride. Soil Science Society of America Proceedings. Vol. 36 pp. 764-768. 1972.

Chao, T. T. Use of Partial Dissolution Techniques in Geochemical Exploration. Journal of Geochemical Exploration. Vol. 20, pp. 101-135. 1984.

Chao, T.T., L. Zhou. Extraction Techniques for Selective Dissolution of Amorphous Iron Oxides from Soils and Sediments. Soil Science Society of America Journal. Vol. 47 pp. 225-232. 1983.

Chester R, M J. Hughes. A Chemical Technique for the Separation of Ferro-Manganese Minerals, Carbonate Minerals and Adsorbed Trace Elements from Pelagic Sediments. Chemical Geology. Vol. 2, pp. 249-262. 1967.

Clevenger, T. E. Use of Sequential Extraction To Evaluate the Heavy Metals in Mining Wastes. Water, Air, and Soil Pollution. Vol. 50, pp. 241-254. 1990.

Cotton, F. A., G. Wilkinson. Advanced Inorganic Chemistry: A Comprehensive Text. John Wiley and Sons, New York. 1972.

Dzombak, D. A., Morel, F. M. M. Surface Complexation Modeling: Hydrous Ferric Oxide. John Wiley and Sons, New York. 1990.

Fisons. PlasmaQuad System Manual. Fisons Instruments, Inc. 1992.

Gee, G. W., J. W. Bauder. in Methods of Soil Analysis: Part I - Physical and Mineralogical Methods, $2^{\text {nd }}$ Edition. A.L. Page; R.H. Miller, D.R. Keeney, eds. American Society of Agronomy, Madison. pp. 383-409. 1986.

Gibson, M. J., J. G. Farmer. Multi-step Sequential Chemical Extraction of Heavy Metals from Urban Soils. Environmental Pollution (Series B). Vol. 11, pp. 117-135. 1986.

Gombert, D. Treatability Testing to Evaluate What Can Work. Nuclear Technology. Vol. 108. Oct 1994.

Hayes, M. H., F. L. Himes. in Interaction of Soil Minerals with Natural Organic and Microbes. Soil Science Society of America Special Publication \#17, Madison. p 103. 1986. 
Jackson, M. L., C. H. Lim, L. W. Zelazny. in Methods of Soil Analysis: Part 1-Physical and Mineralogical Methods, $2^{\text {nd }}$ Edition. A.L. Page; R.H. Miller, D.R. Keeney, eds. American Society of Agronomy, Mađisōn. pp. 101-150. 1986.

Johnson, L. Development of Stability Constants for the Sorption of Uranium to Gibbsite - A Surface Complexation Approach. M.S. Thesis. Clemson University. 1995.

Johnson, W. Sorption Models of Uranium, Cesium, and Cadmium on Upper Atlantic Coastal Plain Soils. Ph.D. Dissertation. Georgia Institute of Technology. 1995.

Kirchmer, C. L. in Detection in Analytical Chemistry-Importance, Theory, and Practice. L. A. Currie, ed. American Chemical Society, Washington D.C. 1988.

Kersten, M., U. Förstner. in Trace Element Speciation. Batley, ed. CRC Press, Baca Raton. 1989.

Kheboian, C., C. Bauer. Accuracy of Selective Extraction Procedures for Metal Speciation in Model Aquatic Sediments. Analytical Chemistry. Vol. 59, pp. 1417-1423. 1987.

Knoll, G. F. Radiation Detection and Measurement, $2^{\text {nd }} e d$. John Wiley and Sons, New York. 1989.

Kunze, G. W., J. B. Dixon. in Methods of Soil Analysis, Part 1. Physical and Mineralogical Methods $2^{\text {nd }}$ edition. A.L. Page; R.H. Miller, D.R. Keeney, eds. American Society of Agronomy, Madison. pp 9199. 1986.

LaGrega, D., P. L. Buckingham, J. Evans. Hazardous Waste Management. McGraw-Hill, Inc, New York. 1994.

Lahann, R. W. The Effect of Trace Metal Extraction Procedures on Clay Minerals. Joumal of Environmental Science and Health. A11, 639-662. 1976.

Langmuir, D. Aqueous Environmental Geochemistry. Prentice-Hall, New York. 1997.

Looney, B. B., C. A. Eddy, M. Ramdeen, J. Pickett, V. Rogers, M. T. Scott, P. A. Shirley. Geochemical and Physical Properties of Soils and Shallow Sediments at the Savannah River Site (U). WSRC (Westinghouse Savannah River Company). WSRC-RP-90-1031. August 1990.

Lindsay, W. L. Chemical Equilibria in Soils. Wiley-Interscience, New York. 1979.

Malo, B. A. Partial Extraction of Metals from Aquatic Sediments. Environmental Science and Technology. Vol. 11 pp. 277-282. 1977.

Martin, J. M., P. Nirel, A. J. Thomas. Sequential Extraction Techniques: Promises and Problems. Marine Chemistry. Vol. 22 pp. 313-341. 1987.

McKeague, J. A An Evaluation of $0.1 \mathrm{M}$ Pyrophosphate and Pyrophosphate/Dithionate in Comparison with Oxalate as Extractants of the Accumulation Products in Podsols an Some Other Soils. Canadian Journal of Soil Science. Vol. 45, pp. 95-99. 1967.

Mehra, O. P., M. L. Jackson Iron Oxide Removal from Soil and Clays by a Dithionate-Citrate System Buffered with Sodium Bicarbonate. Seventh National Conference on Clays and Clay Minerals. Vol. 7 pp 317-327. 1960.

Miller, W., D. Martens, L. Zelazny. Effect of Sequence in Extraction of Trace Metals from Soils. Journal of the Soil Science Society of America. 50:598-601. 1986. 
Munsell Color Company. Munsell Soil Color Charts. Munsell Color Co., Baltimore. 1975.

Nirel, P. M. V., F. M. M. Morel, Technical Note: PitfaHs of Sequential Extractions. Water Research. Vol. 24, No. 8, pp. 1055-1056. 1990.

Oughton, D., B. Salbu, G. Riise, H. Lien, G. Østby, A. Noren. Radionuclide Mobility and Biocvailability in Nonwegian and Soviet Soils. Analyst. Vol. 117, pp. 481-486 March, 1992.

Rapin, F., A. Tessier, P. Campbell, R. Carignan. Potential Artifacts of Metal Partitioning in Sediments be a Sequential Extraction Procedure. Environmental Science and Technology. Vol. 20, No. 8. 1986.

Rhoades, J. D. in Methods of Soil Analysis: Part 2 - Chemical and Microbiological Properties, $2^{\text {nd }}$ Edition. A.L. Page; R.H. Miller, D.R. Keeney, eds. American Society of Agronomy, Madison. p 149. 1982.

Schulze, D.G. in Minerals in Soil Environments, 2nd ed. J.B Dixon and S.B. Weed, eds. Soil Science Society of America, Madison. 1989.

Schwertmann, U., R. M. Taylor. in Minerals in Soil Environments, 2nd ed. J.B Dixon and S.B. Weed, eds. Soil Science Society of America, Madison. 1989.

Shimadzu Corporation. Solid Sample Module SSM-5000 for TOC-5000/5050 Total Organic Carbon Analyzer: Instruction Manual. P/N 638-93094. 1993.

Shuman, L. M. Separating Soil Iron-and Manganese Oxide Fraction for Microelement Analysis. Soil Science Society of America Journal. Vol. 46 p. 1099. 1982.

Sposito, G. The Chemistry of Soils. Oxford University Press, New York. 1989.

Srivastava, A. M., T. F. Soules. Luminescent Materials (Phosphors). in Kirk-Othmer Encyclopedia of Chemical Technology, Vol. 15. J. Kroschwitz, M Howe-Grant, eds. John Wiley and Sons, New York. p584. 1995.

SSSA. Internet Glossary of Soil Science Terms, available at http://www.soils.org/sssagloss/. Soil Science Society of America. July 1997.

Stich, R. Integration of Soils and Landforms in the Refinement of a Landscape Ecosystem Classification Model: Upper Loam Hill Region, Hilly Coastal Province, South Carolina. M.S. Thesis. Clemson University. 1994.

Streeter, R. A., B. Molholt, C. Jampo. in Superfund Risk Assessment in Soil Contamination Studies, K. B. Hoddinott, ed. American Society for Testing and Materials, Philadelphia. 1992.

Stumm, W., J. J. Morgan. Aquatic Chemistry: Chemical Equilibria and Rates in Natural Waters, $3^{\text {rd }}$ Edition. John Wiley \& Sons, New York. 1996.

Tessier, A., P. G. C. Campbell, M Bisson. Sequential Extraction Procedure for the Speciation of Trace Metals. Analytical Chemistry. Vol. 51, No. 7. June 1979.

Tessier, A., F. Rapin, R. Carigan. Trace Metals in Oxic Lake Sediments: Possible Adsorption onto Iron Oxyhyrdoxides. Geochim Cosmochim Acta. Vol. 49, pp. 183-194. 1985.

Tessier, A., P. G. C. Campbell. Comment on "Pitfalls of Sequential Extractions". Water Research. Vol. 25 , no. 1 , pp. 115-117. 1991. 
U.S. Department of Agriculture, Soil Conservation Service. Soil Survey of the Savannah River Plant Area, Parts of Aiken, Barnwell, and Allendale Counties, South Carolina. June 1990.

U.S. Department of Energy, Office of Environmental Management. Linking Legacies: Connecting the Cold War Nuclear Weapons Production Processes to Their Environmental Consequences. DOE/EM0319. January 1997.

U.S. Environmental Protection Agency, Office of Solid Waste and Emergency Response. Method 9045; Soil pH. in Test Methods for Evaluating Solid Waste, Volume IC: Laboratory Manual; Physical/Chemical Methods, $3^{\text {nd }}$ Edition. SW-846. November 1986.

U.S. Environmental Protection Agency, Office of Solid Waste and Emergency Response. Method 6020; Inductively Coupled Mass Spectrometry. in Test Methods for Evaluating Solid Waste, Volume IC: Laboratory Manual; PhysicalChemical Methods, $3^{\text {rd }}$ Edition. SW-846. September 1994.

VG Elemental. PlasmaQuad System Manual Version 2b. 1988.

Waymouth, J. F. Light Sources. in Encyclopedia of Physical Science and Technology, $2^{\text {nd }}$ ed. R. A. Meyers, ed. Academic Press, San Diego. 1992.

WSRC (Westinghouse Savannah River Company). Corrective Measures Study/Feasibility Study Report for the Chemical, Metal, and Pesticide (CMP) Pits at the Savannah River Site; Draft. WSRC-RP-96124, Rev. 0. October 1996a.

WSRC. CMP Pits - Arsenic in Soil Remediation Study (U). WSRC-RP-96-301, Rev. 0. $1996 \mathrm{~b}$.

WSRC. CMP Pits -Arsenic in Soil Remediation Study; Soil Characterization Report (U). WSRC-RP-96492, Rev. 0. 1996c.

Xiao-Quan, S., C. Bin. Evaluation of Sequential Extraction for Speciation of Trace Metals in Model Soil Containing Natural Minerals and Humic Acid. Analytical Chemistry. Vol. 65, pp. 802-807. 1993. 


$\begin{array}{lc}\text { BALADI, SADIKA M. (Dika) } & 730-2 \mathrm{~B} \\ \text { BRETT, DENA D. } & 730-2 \mathrm{~B} \\ \text { DYER, SUSAN A. } & 730-2 \mathrm{~B} \\ \text { FRAZIER, WILLIE L. } & 730-2 \mathrm{~B} \\ \text { HART, E. BLAKE } & 730-2 \mathrm{~B} \\ \text { HASELOW, LAURA A. } & 730-2 \mathrm{~B} \\ \text { MARTINSON, DOUGLAS J. } & 730-2 \mathrm{~B} \\ \text { NIX, DAVID W. (DAVE) } & 730-2 \mathrm{~B} \\ \text { RABIN, MONIQUE S. } & 730-2 \mathrm{~B} \\ \text { ELIZABETH TOPP (3) } & 730-2 \mathrm{~B} \\ \text { BRUCE SCHAPPELL } & 730-2 \mathrm{~B} \\ \text { MARTHA THOMPSON } & 730-2 \mathrm{~B} \\ \text { STEVE HEVEL } & 730-2 \mathrm{~B} \\ \text { TOM BUTCHER } & 773-43 \mathrm{~A} \\ \text { JIM COOK } & 773-43 \mathrm{~A} \\ \text { DAN KAPLAN } & 773 \mathrm{~A}- \\ \text { JEFF ROSS } & 730-2 \mathrm{~B} \\ \text { MILES DENHAM } & 773-42 \mathrm{~A} \\ \text { JOHN GLADDEN } & 773-42 \mathrm{~A} \\ \text { CATHY LEWIS } & 730-2 \mathrm{~B} \\ \text { STI } & 703-43 \mathrm{~A} \\ \text { WM\&ED } & 773-43 \mathrm{~A} \\ \text { L. PAPOUCHADO (w/o Attachments) } 773-\mathrm{A} \\ \text { W. E. STEVENS (w/o Attachments) } 773-\mathrm{A} \\ \text { W. L. TAMOSAITIS (w/o Attachments) } 773-\mathrm{A} \\ \text { DAVE DUNN } & 773-42 \mathrm{~A} \\ \text { MICHAEL BOERSTE } & 773-43 \mathrm{~A} \\ & \end{array}$

